JOÃO LUIZ VEIGA MANGUINO

\title{
MÉTODOS HEURÍSTICOS APLICADOS AO PROBLEMA DE ROTEAMENTO DE VEÍCULOS COM FROTA MISTA, JANELAS DE TEMPO E CUSTOS ESCALONADOS POR FAIXAS DE DISTÂNCIA
}




\section{JOÃO LUIZ VEIGA MANGUINO}

\section{MÉTODOS HEURÍSTICOS APLICADOS AO PROBLEMA DE ROTEAMENTO DE VEÍCULOS COM FROTA MISTA, JANELAS DE TEMPO E CUSTOS ESCALONADOS POR FAIXAS DE DISTÂNCIA}

Versão Corrigida

Tese apresentada à Escola Politécnica da Universidade de São Paulo para obtenção do Título de Doutor em Ciências. 
Autorizo a reprodução e divulgação total ou parcial deste trabalho, por qualquer meio convencional ou eletrônico, para fins de estudo e pesquisa, desde que citada a fonte.

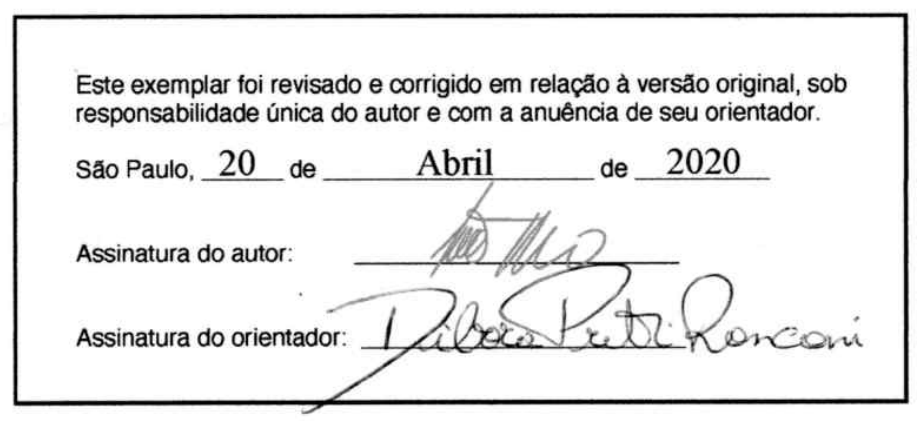

Catalogação-na-publicação

Manguino, João

MÉTODOS HEURÍSTICOS APLICADOS AO PROBLEMA DE

ROTEAMENTO DE VEÍCULOS COM FROTA MISTA, JANELAS DE TEMPO

E CUSTOS ESCALONADOS POR FAIXAS DE DISTÂNCIA / J. Manguino -versão corr. -- São Paulo, 2020.

$151 \mathrm{p}$.

Tese (Doutorado) - Escola Politécnica da Universidade de São Paulo. Departamento de Engenharia de Produção.

1.Roteamento de Veículos 2.Programação Linear Inteira Mista 3.Heurística 4.Meta-heurística 5.Busca Local I.Universidade de São Paulo. Escola Politécnica. Departamento de Engenharia de Produção II.t. 


\section{JOÃO LUIZ VEIGA MANGUINO}

\section{MÉTODOS HEURÍSTICOS APLICADOS AO PROBLEMA DE ROTEAMENTO DE VEÍCULOS COM FROTA MISTA, JANELAS DE TEMPO E CUSTOS ESCALONADOS POR FAIXAS DE DISTÂNCIA \\ Versão Corrigida}

Tese apresentada à Escola Politécnica da Universidade de São Paulo para obtenção do Título de Doutor em Ciências.

Área de Concentração:

Engenharia de Produção

Orientador:

Débora Pretti Ronconi 


\section{AGRADECIMENTOS}

Primeiramente quero agradecer a toda a equipe do Departamento de Engenharia de Produção da Poli. Professores e funcionários, inclusive da Xerox do Osni que sempre me auxiliaram nessa jornada desde minha graduação, mestrado e agora no doutorado.

Um agradecimento muito especial a minha orientadora e amiga, professora Débora. Que jornada juntos!

Agradeço também a minha família, minha esposa e meu filho que foram tão compreensivos nessa jornada e me apoiaram até nas horas mais difíceis.

Um agradecimento grande aos meus colegas de GOL, que como um grupo sempre se apoiou e formou tantas amizades. Agradeço também ao professor Laporte que me recebeu tão bem na Universidade de Montreal e todos os brilhantes e amigos colegas de CIRRELT.

Muito obrigado a todos! 


\section{RESUMO}

Este trabalho aborda o problema de roteamento de veículos com frota mista, janelas de tempo e custos escalonados o FSMVRPTWSC (the Fleet Size and Mix Vehicle Routing Problem with Time Windows and Step Costs). Esse problema adiciona ao problema de roteamento de veículos custos fixos por faixas de distância percorridas por veículo, de acordo com o seu tipo. Essa forma de aferição de custo é possível quando a entrega é feita por um parceiro logístico e é uma prática que simplifica o cálculo e verificação da cobrança frete a pagar pela empresa contratante e contratada. Ao endereçar esse problema, este trabalho o caracteriza cuidadosamente e propõe diferentes abordagens para sua solução. Um modelo de programação linear inteira mista é apresentado; seguido por duas heurísticas construtivas, com base em inserções sequenciais, três movimentos de busca em vizinhança, duas meta-heurísticas, o VNS (Variable Neighbourhood Search) e GRASP (Greedy Randomized Adaptive Search Procedure), e um método híbrido que combina os dois. Os métodos são avaliados em instâncias geradas com base em referências na literatura, além de outras de dimensões menores, a fim de se obter resultados ótimos globais, e instâncias reais a partir de um estudo de caso. Apesar do ineditismo do problema na literatura, as comparações feitas com os resultados obtidos pelos diferentes métodos e instâncias mostram que as escolhas feitas no trabalho se justificam.

Palavras-Chave - Roteamento de Veículos, Modelo Matemático, Programação Linear Inteira Mista, Heurística, Meta-heurística, Busca Local, VNS, GRASP, Híbrido. 


\section{ABSTRACT}

This work addresses the FSMVRPTWSC, the Fleet Size and Mix Vehicle Routing Problem with Time Windows and Step Costs. This problem is a proposition of adding attributes to the vehicle routing problem that seeks to bring fixed costs per distance traveled by each type of vehicle. This form of cost attirbution is possible when the delivery is performed by a logistics partner and is a practice that simplifies the calculation and verification of the freight costs to be payed by the company that hires the service. In addressing this problem, this work carefully characterizes and proposes a mathematical model, two constructive heuristical method, three neighborhood search movements, two metaheuristics, the VNS (Variable Neighborhood Search) and GRASP (Greedy Randomized Adaptive Search Procedure) and a hybrid method combining both meta-heuristics. The methods are evaluated in instances generated based on references in the literature, in addition to smaller dimensions, in order to obtain optimal global results, and real instances with from a case study. Despite the novelty of the problem in the literature, comparisons made with the results obtained in the different methods and instances show that the choices made in the work are justified.

Keywords - Vehicle Routing Problem, Mathematical Model, Heuristics, Meta-heuristics, Local Search, VNS, GRASP, Hybrid. 


\section{SUMÁRIO}

1 Introdução 1

2 Caracterização do Problema 4

$2.1 \quad$ Definição . . . . . . . . . . . . . . . . . . . . . . . . . . . 4

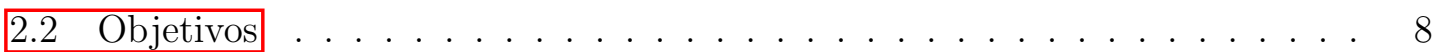

\begin{tabular}{lll}
\hline 3 & Revisão Bibliográfica & 10
\end{tabular}

3.1 Problema de Roteamento de Veículos . . . . . . . . . . . . . . . . . . . 10

3.1 .1 VRP Clássico . . . . . . . . . . . . . . . . . . . . . . . . . . 10

3.1.2 Problema de determinação do tamanho e composição da frota e roteamento de veículos . . . . . . . . . . . . . . . . . . . . . . . . . 12

$3.1 .3 \quad$ Problema de roteamento de veículos com janelas de tempo . . . . . 13

3.1.4 Problema de determinação do tamanho e composição da frota e roteamento de veículos com janelas de tempo . . . . . . . . . . . . 14

3.2 Uso de Parceiros Logísticos $\ldots \ldots \ldots \ldots$

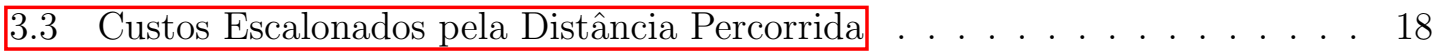

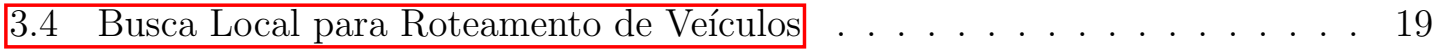

3.5 Meta-Heurísticas em Problemas de Roteamento de Veículos . . . . . . . . . . 24

$\begin{array}{lll}4 & \text { Geração de instâncias } & 27\end{array}$

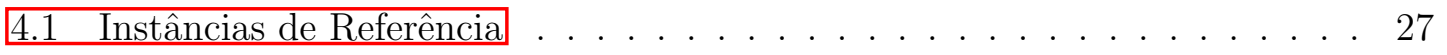

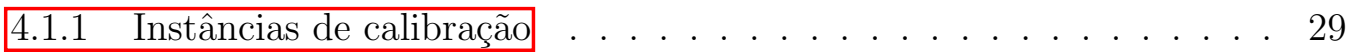

4.2 Instâncias de Dimensões Menores $\ldots \ldots \ldots$. . . . . . . . . . . . . . . . . . . . . 29

4.3 Instâncias Inspiradas em Dados Reais . . . . . . . . . . . . . . . . . . . 31

5 Formulação Matemática 34 
5.1 Elementos da Formulação $\ldots \ldots \ldots$. . . . . . . . . . . . . . . 34

5.1 .1 Clientes $\ldots \ldots \ldots \ldots \ldots \ldots \ldots \ldots$

5.1 .2 Frota de Veículos . . . . . . . . . . . . . . . . . . . 35

$5.1 .3 \quad$ Janela de Tempo $\ldots \ldots \ldots \ldots \ldots$

5.1 .4 Faixas de Custo . . . . . . . . . . . . . . . . . . . 35

5.2 Modelo de Programação Linear Inteira Mista . . . . . . . . . . . . . . . 36

5.3 Melhorias no Modelo . . . . . . . . . . . . . . . . . . . . . . . . . 42

5.3 .1 Simplificação das Restrições de Janelas de Tempo . . . . . . . . . . 42

5.3 .2 Introdução de Variáveis de Distância Percorrida por Faixa . . . . . 43

5.4 Experimentos Numéricos $\ldots \ldots \ldots \ldots \ldots$

6 Heurísticas Construtivas 46

$6.1 \quad$ Características Gerais . . . . . . . . . . . . . . . . . . . . 46

6.2 Heurísticas Propostas $\ldots \ldots \ldots \ldots \ldots \ldots$

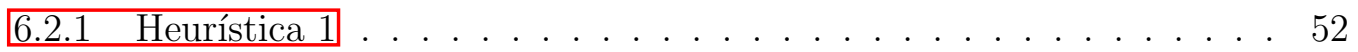

6.2 .2 Heurística $2 \ldots \ldots \ldots \ldots \ldots \ldots \ldots \ldots \ldots$

6.3 Experimentos Numéricos $\ldots \ldots \ldots \ldots \ldots$

$6.3 .1 \quad$ Calibração de Índices . . . . . . . . . . . . . . . . . . . . . . . . 59

6.3 .2 Resultados Obtidos . . . . . . . . . . . . . . . . . . . 61

6.3 .2 .1 Instâncias de Referência . . . . . . . . . . . . . . . . . . 61

6.3.2.2 Instâncias de Dimensões Menores . . . . . . . . . . . . . . 63

6.3 .2 .3 Instâncias inspiradas em Dados Reais. . . . . . . . . . . 65

$\begin{array}{lll}7 & \text { Buscas Locais } & 66\end{array}$

7.1 Escolha de Movimentos. . . . . . . . . . . . . . . . . . . . . 67

7.2 Implementação dos Movimentos de Busca em Vizinhança . . . . . . . . . 70

7.2 .1 Relocate . . . . . . . . . . . . . . . . . . . . . 70

$7.2 .2 \quad$ CROSS $\ldots \ldots \ldots \ldots \ldots \ldots \ldots \ldots \ldots \ldots \ldots$ 


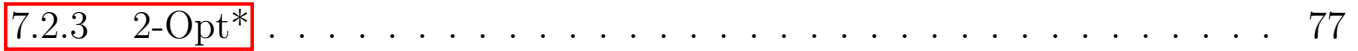

7.3 Experimentos Numéricos $\ldots \ldots \ldots$. . . . . . . . . . . . . . . . 80

7.3.1 RELOCATE . . . . . . . . . . . . . . . . . . 80

$7.3 .2 \quad$ Cross $\ldots \ldots \ldots \ldots \ldots \ldots$. . . . . . . . . . . . . . . . . . 82

$7.3 .3 \quad$ Comparação entre Buscas Locais $\ldots . . . . . . . .83$

$\begin{array}{lll}8 & \text { Meta-Heurísticas } & 86\end{array}$

$8.1 \quad$ Busca em vizinhança variável $(\mathrm{VNS}) \ldots \ldots$. . . . . . . . . . . 87

$8.1 .1 \quad$ Aplicações bem-sucedidas $\ldots \ldots \ldots$. . . . . . . . . . . . 88

8.1 .2 Procedimento básico . . . . . . . . . . . . . . . . . . . . . . 90

8.1 .3 VNS Aplicado ao FSMVRPTWSC . . . . . . . . . . . . . . . . . . 92

$8.1 .4 \quad$ Experimentos Numéricos . . . . . . . . . . . . . . . . . 93

8.1.4.1 Processo de Calibração de Parâmetros . . . . . . . . . . . 94

8.1.4.2 Instâncias de Referência . . . . . . . . . . . . . . . . . . . 97

$8.1 .4 .3 \quad$ Instâncias de Dimensões Menores . . . . . . . . . . . . . . 99

8.1.4.4 Instâncias Inspiradas em Dados Reais . . . . . . . . . . . 99

8.2 GRASP . . . . . . . . . . . . . . . . . . . . . . . . 100

$8.2 .1 \quad$ Características do Procedimento . . . . . . . . . . . . . . . . . . 100

8.2.2 GRASP Aplicado ao FSMVRPTWSC . . . . . . . . . . . . . 103

8.2.2.1 Instâncias de Dimensões Menores . . . . . . . . . . . . . . 105

8.2.2.2 $\quad$ Processo de Calibração de Parâmetros do GRASP. . . . . . 106

8.2 .2 .3 Instâncias de Referência . . . . . . . . . . . . . . . . . . . 108

8.2.2.4 Instâncias de Dimensões Menores . . . . . . . . . . . . . . 110

8.2.2.5 Instâncias Inspiradas em Dados Reais . . . . . . . . . . . 110

8.3 Método Híbrido . . . . . . . . . . . . . . . . . . . . . . . . . . . . . . 111

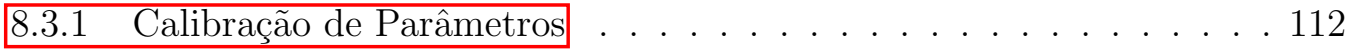

$8.3 .2 \quad$ Experimentos Numéricos . . . . . . . . . . . . . . . . . . 114 
\begin{tabular}{llr}
\hline 9 Conclusões & 118
\end{tabular}

\begin{tabular}{ll}
\hline Referências & 120
\end{tabular}

\begin{tabular}{ll}
\hline Apêndice A - Instâncias & 124
\end{tabular}

A.1 Instâncias de Referência . . . . . . . . . . . . . . . . . . . . . . . . . 124

A.2 Instância de Dimensões Menores . . . . . . . . . . . . . . . . . . . . . . . . 128

A.3 Instâncias Inspiradas em Dados Reais . . . . . . . . . . . . . . . . . . . . . 135

\begin{tabular}{|ll}
\hline Apêndice B - Resultados & 140
\end{tabular}

B.1 Instâncias de Referência . . . . . . . . . . . . . . . . . . . . . . . 140

B.2 Instâncias de Dimensões Menores . . . . . . . . . . . . . . . . . . . . . . 145 


\section{INTRODUÇÃO}

O tema de roteamento de veículos tem grande importância na literatura e vem sendo amplamente estudado por sua relevância para a indústria e aplicação em diversas atividades. O estudo deste problema se iniciou como uma adaptação do problema do caixeiro viajante (TSP - Travelling Salesman Problem), onde o vendedor que deve fazer uma única rota otimizada foi substituído por veículos idênticos com limitação de capacidade e, portanto, cada um executa uma rota atendendo diferentes grupos de clientes. Com a evolução do tema na literatura e com o objetivo de aproximar-se mais da realidade vivida pela indústria e transportadoras, o problema foi enriquecido com uma grande variedade restrições, características de clientes, frota, rota, depósito, características de demandas, e objetivos.

Desta forma, existem diversas variantes do problema de roteamento de veículos ( VRP - Vehicle Routing Problem) com diversas metodologias de soluções aplicadas. Em uma pesquisa do tipo survey, Vidal et al. (2013a) investigam 15 diferentes problemas de roteamento de veículos com diferentes combinações de atributos e os métodos heurísticos utilizados para solucionar cada problema. Os diferentes tipos de problemas de roteamento de veículo são agrupados sob o nome de Problemas de Roteamento de Veículos com Múltiplos Atributos (MAVRP - Multi Attribute Vehicle Routing Problem). Os problemas são combinações de atributos como janelas de tempo, que podem ser rígidas ou flexíveis, demanda pré-conhecida ou estocástica, frota heterogênea com ou sem limitação na quantidade de veículos, rotas que podem fazer entregas e coletas simultaneamente, múltiplos depósitos de origem, entregas parciais, múltiplos períodos de atendimento, múltiplas rotas para o mesmo veículo, rota sem retorno ao depósito.

Hoff et al. (2010) apresentam um extenso levantamento bibliográfico sobre as diferentes abordagens para o roteamento de veículos com dimensionamento de frota e as diferentes metodologias utilizadas para solução, terminando com uma análise crítica da produção científica. Apesar de citar positivamente essa adição de restrições e características reais ao problema, foi feita a crítica de a literatura ainda estar aquém da aderência necessária 
às situações reais.

No problema abordado nesta tese, é explorada a situação na qual um fornecedor prepara seu próprio roteiro de entregas, avaliando capacidade de veículos e custos de frete, mas não é dono da frota que faz o atendimento aos clientes. A frota, neste caso, é terceirizada a um parceiro logístico que possui ampla disponibilidade de veículos para executar entregas solicitadas pelo fornecedor.

Essa tendência de terceirização de frotas é confirmada por Lieb e Bentz (2005), cuja pesquisa indicou que em 2004, 80\% das indústrias dos EUA utilizavam esta modalidade de transporte. Lieb e Lieb (2015) indicam que em 2013, as empresas que ofereciam o serviço de transportes já somavam receitas em torno de 700 bilhões de dólares anualmente. Desta maneira é possível delegar ao terceiro custos relacionados à aquisição e manutenção de uma frota de veículos, depreciação, salários e encargos de motoristas e ajudantes, entre outros componentes de custo de uma frota. Além disso, usufrui da vantagem da disponibilidade e flexibilidade de uma empresa especializada em fornecimento de frota e equipe treinada e preparada para entregas, com um custo cobrado de acordo com tabelas e contratos de serviços pré-estabelecidos e simples de se aferir.

Uma das formas possíveis de cobrança, e que é objeto deste trabalho, é a cobrança feita a partir de uma combinação entre o tipo de veículo utilizado e a faixa de distância percorrida, com valores fixos a cada combinação. Essa combinação é facilmente expressa em uma tabela e sua aferição é simples e direta, evitando a necessidade de fazer conta para verificação do custo, bastando apenas conhecer qual faixa de distância foi percorrida e qual veículo foi utilizado.

O problema, portanto, é o Problema de Roteamento de Veículos com Janelas de Tempo, Frota Mista e o Custo Escalonado em valores fixos por faixas de distância percorrida (FSMVRPTWSC - Fleet Size and Mix Vehicle Routing Problem with Time Windows and Step Costs function). Trata-se do mesmo problema abordado em Manguino (2013), dissertação de mestrado deste mesmo autor, e apresentado em Manguino e Ronconi (2012) e em Ronconi e Manguino (2016).

Desde então o tema mostrou ganhar relevância, principalmente com a ascensão do e-business que conta com entregas diretas a clientes com cargas pequenas, porém com maior frequência, e grande sazonalidade. O uso de uma frota ampla e diversificada faz com que o capital investido na frota para atender as demandas de pico seja ineficiente se comparado à contratação de um ou mais parceiros para execução do transporte.

A forma de cálculo de custos é diferente do método tradicional encontrado na litera- 
tura, cujo custo é proporcional à distância percorrida pelos veículos, somado aos custos fixos de cada tipo de veículo. Isso faz com que sejam necessárias diversas adaptações sobre o que já está estabelecido na literatura.

Ao abordar este problema, esta tese apresenta uma formulação de programação linear inteira mista (PLIM), que trata de uma evolução sobre a já apresentada em Manguino (2013), e investiga métodos heurísticos para solucioná-la. Como problemas de roteamento de veículos são classificados como NP-Hard, a busca por uma solução ótima é inviável em um tempo razoável, assim o modelo PLIM é apresentado e aplicado apenas em pequenas instâncias, enquanto para instâncias maiores são propostos métodos heurísticos.

Este trabalho apresenta duas heurísticas construtivas de inserção sequencial, como originalmente proposto por Solomon (1987), que também são melhorias sobre os métodos apresentados em Manguino (2013). Em seguida, buscas locais e meta-heurísticas, inclusive uma híbrida, são apresentadas para gerar soluções de melhor qualidade. Todos os métodos de solução propostos são avaliados em instâncias geradas especificamente para este problema, sendo um grupo de instâncias com 100 clientes, baseadas em problemas que são referência na literatura, outro grupo de dimensões menores gerados para obter soluções ótimas e, outro grupo a partir de um caso real.

O trabalho está dividido da seguinte forma: no Capítulo 2 o FSMVRPTWSC é definido, com apresentação dos seus principais atributos e maior detalhamento na forma de cálculo de custos, que é o aspecto que o diferencia dos problemas já estudados na literatura. Ainda no Capítulo 2, os objetivos deste trabalho são detalhados. Em seguida, no Capítulo 3 é apresentada uma revisão bibliográfica com a evolução do tema de roteamento de veículos até chegar ao problema apresentado e ao uso de parceiros logísticos na literatura, bem como dos métodos de solução. No Capítulo 4, as instâncias que são utilizadas em todo este trabalho para avaliações dos métodos e formulações propostos são apresentadas. No Capítulo 5 o modelo matemático para o problema é apresentado. No Capítulo6 são descritas as heurísticas propostas para solucionar o problema, no Capítulo 7 são apresentadas as buscas locais e, finalmente, no Capítulo 8 as meta-heurísticas são apresentadas. O Capítulo 9 apresentam-se as conclusões e próximos passos. 


\section{CARACTERIZAÇÃO DO PROBLEMA}

Nesse capítulo é caracterizado o FSMVRPTWSC, o problema abordado nessa tese. Primeiro ele é definido, assim como seus principais atributos. Em seguida, o objetivo deste estudo é exposto, para então ser feita uma revisão bibliográfica acerca do tema.

\subsection{Definição}

O problema a ser estudado é o de roteamento de veículos (VRP) com uma série de características que o torna mais próximo à realidade de empresas que prestam serviços de coleta ou entregas utilizando a frota de um operador logístico, em diversos pontos de uma região.

O processo de roteamento dentro da rotina da empresa ocorre conforme a periodicidade. Por exemplo e em linhas gerais, um caso de processo diário. Ao fim de cada dia é feito um corte na carteira de pedidos de clientes com data de entrega até o dia seguinte e para os quais existe estoque disponível para atendimento. Com esse grupo de pedidos em mãos, a empresa desenha o roteamento das entregas e informa à transportadora quais veículos (quantos e de que tipo) serão necessários e as rotas que cada um fará no dia seguinte. No momento combinado, a transportadora disponibilizará os veículos prontos para serem carregados e realizarem as entregas conforme as rotas descritas pela empresa contratante. Esse processo se repete diariamente ou conforme a frequência programada por cada empresa contratante e seu transportador contratado.

As características do problema, portanto, são:

- Clientes espalhados no espaço com posição e demanda pré-determinada para o desenho das rotas:

Para cada clientes $i$ existe uma demanda $q_{i}$;

Entre clientes $i$ e $j$ é conhecida a distância $d_{i j}$ e o tempo de trânsito $t_{i, j}$. 
- Depósito de onde todos os veículos devem iniciar e encerrar suas rotas. Também é referido como armazém ou centro de distribuição.

- Janelas de tempo nos clientes e no depósito: A chegada do veículo para realizar o serviço deve respeitar os horários de atendimento dos clientes e, no caso do armazém, os veículos devem partir e regressar dentro de sua janela de tempo.

Essa característica torna relevante a direção em que a rota é executada e não apenas quais clientes cada rota atende;

Para cada cliente $i$ as janelas são caracterizadas pelo seu momento de início $e_{i}$ e fim $l_{i}$;

O depósito, assim como os clientes, tem sua janela de tempo identificada por $e_{0}$ e $l_{0}$.

- Frota heterogênea de veículos: Existem diferentes tipos de veículos, com diferentes capacidades e custos que podem realizar as coletas (ex. Figura 1). Neste problema, quanto maior o veículo, mais caro o seu uso. A transportadora tem uma quantidade grande de cada tipo de veículo, uma vez que ela atende diversas empresas e tem uma previsão de necessidade dos clientes, o que torna, para fins de planejamento de roteamento, a quantidade de veículos de cada tipo ilimitada.

Os tipos de veículos são identificados por $k$, sendo $k=1$ o veículo de menor capacidade e $k=K$ o de maior capacidade;

A capacidade de cada veículo será identificada por $a_{k}$;

- Faixas de distância: Conforme pré-acordado com o prestador de serviços logísticos, existem faixas de distância estabelecidas previamente para cálculo do custo de frete (ex. Figura 1).

As faixas de distância são identificadas por $f$, sendo $f=0$ associada a uma distância 0 , quando o veículo não é utilizado, $f=1$ a primeira faixa de distância e $f=F$ a última faixa de distância da tabela de fretes;

Cada faixa $f$ se inicia na distância identificada por $W_{f}$ e vai até o início da faixa seguinte. Com exceção da ultima faixa que não tem uma distância máxima definida.

- Custos escalonados de transportes: Custo cobrado pelo prestador de serviços logísticos, determinado com valor fixo de acordo com a faixa de distância percorrida 


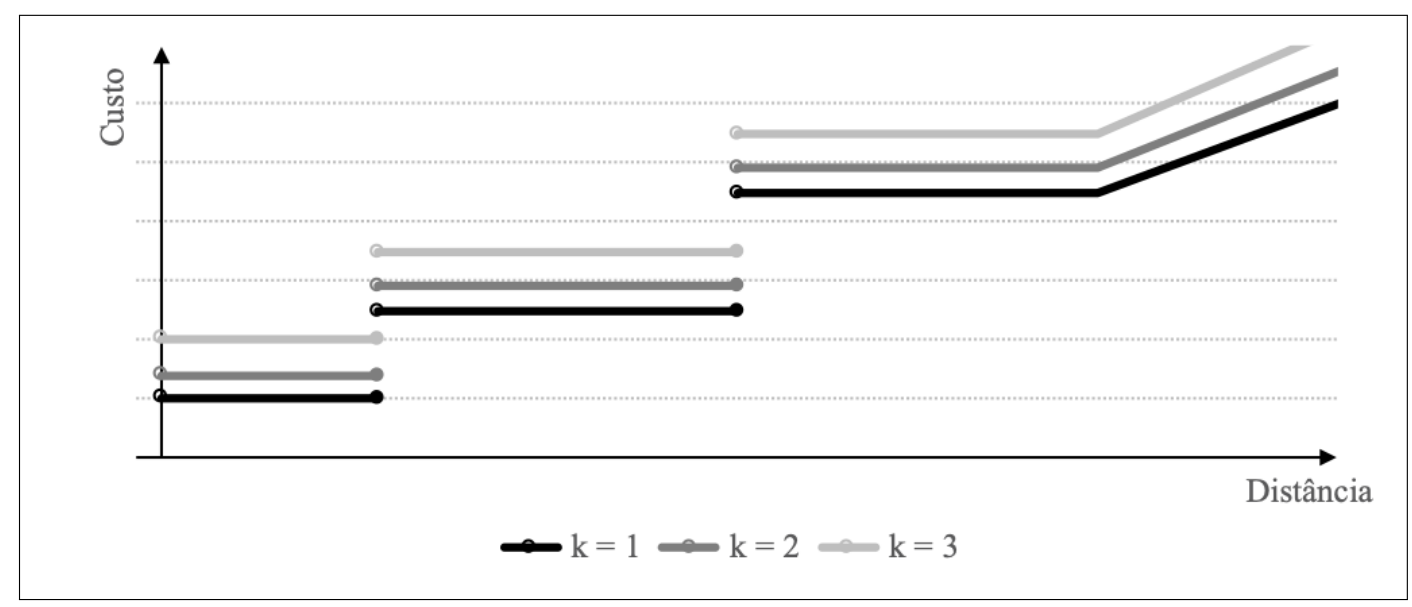

Figura 1: Exemplo de custos escalonados com três tipos de veículos ( $K=3$ e quatro faixas de distância $F=4$.

e do tipo de cada veículo. A partir da última faixa o custo é calculado linear pela distância (ex. Figura 1).

Para cada faixa de distância $f$ e tipo de veículo $k$ é associado um custo fixo $C_{k f}$

A exceção é a última faixa, $f=F$ que o custo é variável, para uma distância $d$ calculado por $C_{k F-1}+\left(d-W_{F}\right) C_{k F}$.

Essas características apresentadas são algumas das mais comuns presentes em empresas que preparam seu próprio roteamento de veículos e contratam a frota de um terceiro. Assim, existem diversas opções de veículos a serem contratados e o pagamento de frete para a empresa que fornece os veículos não se dá de forma linear, mas por custos fixos, conforme a faixa de distância percorrida pelos veículos, previamente tabelada por esse fornecedor.

A utilização de frota de veículos de um terceiro é uma estratégia muito utilizada na indústria desde os anos 1980. As empresas que oferecem o serviço são conhecidas como "prestadores de serviços logísticos" (PSL), ou simplesmente "operadores logísticos". Em uma pesquisa realizada em 2004 com as 500 maiores indústrias de manufatura dos EUA, Lieb e Lieb (2015) constataram que, das 60 empresas que responderam ao questionário, $80 \%$ delas terceirizavam os serviços de logística. A pesquisa foi feita anualmente por 14 anos e mostrou crescimento sustentável com o passar das edições. Em 1991, a pesquisa indicou que apenas 38\% da indústria usava terceiros em sua distribuição; a partir de 1997 essa fração subira para 2/3 da indústria e, a partir de 2003, o número já havia alcançado 80\%. Lieb e Lieb (2015) mostram que, em 2013, o mercado de PSL evoluiu numa 
importante opção de terceirização para gerentes de logísticas no mundo. No estudo, foi apresentado que esse mercado gera em torno de 700 bilhões de dólares em receitas e provê um amplo leque de serviços para gestores buscando não só reduzir custos operacionais, mas, em muitos casos, reduzir seu custo de capital usando os recursos de um parceiro.

Existem diferentes tipos de acordo possíveis com operadores logísticos. Ghiani, Laporte e Musmanno (2004) descrevem uma série de possíveis critérios para este relacionamento, variando desde o aluguel da frota de um terceiro, até o pagamento de taxas de acordo com a faixa de peso transportado e local de destino.

As formas de cobrança de frete podem ser feitas de diversas formas e serem definidas para cada cliente e empresa de transporte. Para facilitar a compreensão, listamos alguns casos. Existe o "frete destino", no qual o custo de transporte é fixo e dado por destino de forma abrangente, agrupando todos os destinos como macrorregiões, como estado e capital e interior, ou regiões relevantes como "Grande São Paulo", "Grande Campinas", entre outros destinos. Existe outra uma forma de cobrança feita por faixas de distância diretamente do depósito, independente da rota que foi feita, considerando apenas a distância em linha reta entre cada cliente e o depósito. Ainda existe uma forma que, para cada rota, o valor a ser pago é calculado pela distância do cliente da rota mais distante do depósito, independente do trajeto feito, ou localização dos outros clientes da rota. O caso abordado nesse trabalho é a cobrança de frete com valores fixos por faixas de distância conforme a distância total de cada rota e está detalhado a seguir.

O problema abordado neste trabalho pode ser classificado, segundo a nomenclatura da literatura, como FSMVRPTW (Fleet Size and Mix Vehicle Routing Problem with Time Windows), conforme definido por Liu e Shen (1999), com a adição da restrição de custos escalonados. Assim, é adicionado à sigla o termo em inglês para custos escalonados, "step cost functions", e o problema é referido como FSMVRPTWSC (Fleet Size and Mix Vehicle Routing Problem with Time Windows and Step Cost function).

Liu e Shen (1999) afirmaram que o FSMVRPTW é NP-Hard, deste modo, por redução polinomial, o FSMVRPTWSC pode ser definido também como NP-Hard, ou seja, é pouco provável que exista um algoritmo de complexidade polinomial que forneça uma solução ótima.

O FSMVRPTWSC tem caráter inovador, pois na revisão da literatura não foi encontrado nenhum estudo que trate dos custos de transporte escalonados, somente em trabalhos do mesmo autor desta tese (Manguino e Ronconi (2012), Manguino (2013) e Ronconi e Manguino (2016)). Esta metodologia de aferição de custos leva a diversas al- 


\begin{tabular}{c|c}
\hline Distância percorrida $(d)$ & Custo de Frete \\
\hline Maior que 0 a $D 1$ & $C 1$ \\
Maior que $D 1$ até $D 2$ & $C 2$ \\
Maior que $D 2$ até $D 3$ & $C 3$ \\
Maior que $D 3$ & $C 3+(d-D 3) \times C 4$ \\
\hline
\end{tabular}

Tabela 1: Exemplo de tabela de custos escalonados de frete

terações em aspectos tradicionais da lógica de resolução do problema, uma vez que deixa de existir a divisão do custo em dois tipos: fixo e variável. O primeiro se refere ao tipo de veículo escolhido para cada rota, enquanto o segundo à distância percorrida. Já nos custos escalonados, a aferição do custo consiste na somatória dos custos atribuídos à faixa de distância percorrida por cada veículo, de acordo com o seu tipo.

Em um método de aferição do custo de frete linear, o custo $P^{v}(d)$ para um dado veículo $v$ que percorre uma distância $d$, pode ser obtido a partir da seguinte expressão:

$$
P^{v}(d)=C F_{v}+C V_{v} \times d
$$

onde $d$ é a distância percorrida pelo veículo $v, C F_{v}$ é o custo fixo deste veículo e $C V_{v}$ é o custo variável do veículo por unidade de distância percorrida.

Já no caso de custos escalonados, o valor é obtido a partir de uma informação em tabela. No exemplo da Tabela 1, para um dado tipo de veículo, onde $D 1, D 2$ e $D 3$ são valores limítrofes de distância, $C 1, C 2$ e $C 3$ são valores fixos de custo, onde $C 1<C 2<$ $C 3$, e $C 4$ é o fator de custo para cada unidade de distância maior que D3.

Portanto, na metodologia tradicional, de custos lineares, a cada pequena variação na distância percorrida por um veículo existe uma variação proporcional em seu custo. No custo escalonado, dependendo da faixa de distância, isto não ocorre. Se a faixa de distância for de 50 a $100 \mathrm{~km}$, um veículo que percorreu $55 \mathrm{~km}$ custará exatamente o mesmo que um que percorreu $90 \mathrm{~km}$. A diferença entre esses dois tipos de cálculo de frete pode ser visualizada na Figura 2

\section{$2.2 \quad$ Objetivos}

O objetivo deste trabalho é propor métodos para solucionar o problema de roteamento de veículos com frota mista, janelas de tempo e custos escalonados por faixas de distância (FSMVRPTWSC - sigla em inglês para Fleet Size and Mix Vehicle Routing Problem with Time Windows and Step Cost function). Nesta abordagem é proposta uma formulação de 


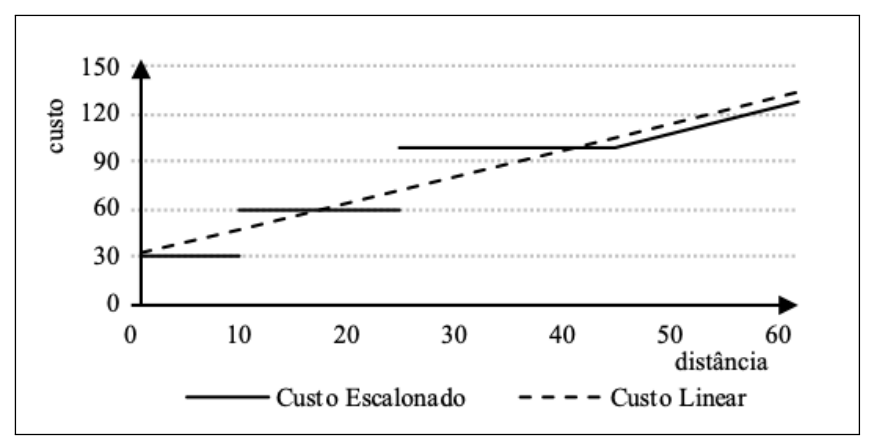

Figura 2: Comparação gráfica entre custos escalonados e custos lineares.

programação linear inteira mista, métodos heurísticos, médotos de busca local e métodos meta-heurísticos. 


\section{REVISÃO BIBLIOGRÁFICA}

Na literatura, o tema de roteamento de veículos é amplamente estudado (Laporte $(2009)$ ) e de grande relevância por estar relacionado à logística, transportes e toda a cadeia de suprimentos, com aplicações na indústria, bancos, governos, exércitos, etc. Portanto, é relevante para diversas áreas e possui muitas aplicações práticas.

Da mesma forma, o uso de heurísticas e meta-heurísticas para a solução de problemas deste tipo é prática comumente encontrada, uma vez que sua complexidade faz com que não possa ser encontrada a solução exata em tempo de execução viável. Diferentes métodos vêm podem ser encontrados na literatura para resolver os problemas de roteamento de veículos, nas mais diversas formas.

Nesse capítulo, é apresentada uma revisão das variações do problema de roteamento de veículos na Seção 3.1. o uso de parceiros logísticos na Seção 3.2, o uso de custos escalonados por distância 3.3, o uso de técnicas de buscas locais para o VRP na Seção 3.4 e de meta-heurísticas na Seção 3.5 .

\subsection{Problema de Roteamento de Veículos}

Conforme mencionado na introdução, o problema de roteamento de veículos tem sido amplamente estudado e diversas variantes foram geradas na literatura para estudo, como mostra Laporte (2009). A seguir, apresentamos a abordagem da literatura às variações do problema com características que compõe o problema abordado neste trabalho.

\subsubsection{VRP Clássico}

O problema de roteamento de veículos clássico, VRP (Vehicle Routing Problem) trata de encontrar um conjunto de rotas, a partir de um armazém central, utilizando veículos idênticos, para atender com o menor custo possível um conjunto de pontos de demanda, que representam os clientes, suprindo totalmente a demanda. As restrições principais são: 
- Restrição de capacidade dos veículos;

- Cada rota deve se iniciar e terminar no depósito;

- Todos os clientes devem ser atendidos.

A primeira abordagem foi feita por Dantzig e Ramser (1959) para um problema real de distribuição de combustível de um terminal para postos de combustíveis. Nesse artigo é proposto um modelo de programação linear inteira, com base no utilizado para o TSP com adições de restrições de capacidade de transporte.

A experiência com heurísticas para solucionar o problema de roteamento clássico tem como marco a heurística das economias (Savings Heuristics), proposta por Clarke e Wright (1964). Essa heurística ainda é bastante utilizada por ser flexível o suficiente para permitir adaptações e inclusão de restrições para solução de problemas mais complexos. A heurística das economias gera roteiros que respeitam as restrições citadas anteriormente. Ela inicia no cenário em que cada veículo sai do armazém para atender um único cliente e retorna. A partir deste ponto, passa a buscar economias unindo rotas e diminuindo a distância e tempo percorridos. Existem dois tipos de procedimentos para fazer isso: o paralelo e o sequencial. No primeiro, busca-se a maior economia possível considerando todas as rotas existentes no problema. Assim, em cada iteração, são unidas em par as rotas que juntas não extrapolem a capacidade do veículo e que gerem a maior economia. No segundo, uma rota é estendida até seu limite, para depois se analisar outra rota.

O desenvolvimento de métodos de solução para o VRP é amplamente abordado por Laporte (2009) que faz uma revisão do desenvolvimento do tema nos 50 anos após a primeira proposição, de Dantzig e Ramser (1959), abordando formulações para solução exata, métodos heurísticos e meta-heurísticos.

Existe uma seção, no trabalho de Laporte (2009), específica para os algoritmos exatos. São descritas formulações de Branch-and-Bound, Dynamic Programming, Vehicle Flow Formulation, entre outras. No mesmo tema de soluções exatas, o trabalho de Baldacci, Mingozzi e Roberti (2012) é dedicado a explorar essas formas de solução para o VRP e para o VRPTW (Roteamento de Veículos com Janelas de Tempo, que será abortdado na Seção 3.1.3. 


\subsubsection{Problema de determinação do tamanho e composição da frota e roteamento de veículos}

A partir do clássico VRP, foi agregada uma característica que o aproximasse de um caso real, dimensionando uma frota heterogênea. Assim, os veículos utilizados no roteamento não são mais idênticos, mas de diferentes tipos. Cada tipo de veículo possui uma capacidade de transporte e custos de aquisição e manutenção próprios, além de custos variáveis (por unidade de carga transportada ou distância percorrida) de acordo com seu tipo. Desta maneira, além de determinar a melhor rota para atender todos os pontos de demanda, devem se determinar quais tipos de veículos e a quantidade de cada um deles que percorrerá as rotas atendendo aos pontos de demanda.

Neste caso, o objetivo do problema pode ser tanto minimizar o custo total do roteamento, somando-se custos fixos de aquisição e manutenção dos veículos, e variáveis, proporcional à distância percorrida por cada um, como também pode se encontrar o número mínimo de veículos que execute o roteamento.

Golden et al. (1984) foram os primeiros a estudar este problema, nomeando-o "problema de roteamento de veículos com determinação do tamanho e composição da frota" ou, na sigla em inglês, FSMVRP (Fleet Size and Mix Vehicle Routing Problem). No trabalho, é apresentada uma nova formulação matemática para o problema que adapta a formulação do VRP adicionando à função objetivo o custo fixo dos veículos e, nas restrições, adiciona restrições de capacidade para os tipos de veículo. Tudo é conectado por uma variável binária para os arcos entre clientes para cada tipo de veículo.

Como o problema é $N P$-Hard, os autores apresentam sete heurísticas são apresentadas para este problema, baseadas na heurística das economias de Clarke e Wright (1964) para o VRP, levando em conta a capacidade ociosa do veículo em diferentes níveis de "otimismo" para o aproveitamento deste espaço ocioso no decorrer da solução. Como não existiam problemas-teste anteriormente formulados para o FSMVRP, Golden et al. (1984) geraram 20 problemas para comparar as heurísticas desenvolvidas, ainda usados nas avaliações de novos métodos propostos.

Após essa primeira abordagem por Golden et al. (1984), diversos outros autores publicaram estudos sobre o tema de FSMVRP. Hoff et al. (2010) apresentam uma extensa pesquisa sobre estudos realizados a respeito deste problema e citam diversos autores que contribuíram ao tema.

A busca por soluções exatas para esse problema não é tão frequente como para o VRP 
e VRPTW. Hoff et al. (2010) apresenta uma revisão dos métodos exatos utilizados, apresentando inclusive uma formulação base para discussão. Em um artigo recente, Pessoa, Sadykov e Uchoa (2018) apresentam um método exato de Branch-and-Cut.

\subsubsection{Problema de roteamento de veículos com janelas de tempo}

No VRPTW (sigla em inglês para Vehicle Routing Problem with Time Windows) adiciona-se ao roteamento de veículos clássico o limite de horário de atendimento nos pontos de demanda (clientes), trazendo o problema mais próximo à realidade. Na prática, empresas têm horário de início e fim de operação e jornadas de trabalho a respeitar, além das restrições de horário em que portos operam ou para circulação de certos tipos de veículos em cidades e vias.

No VRPTW, o atendimento sempre deve ser feito respeitando um horário inicial e final em cada ponto de demanda. Também existe restrição de horário no próprio armazém de onde partem os veículos. Apesar de parecer uma simples adição de restrições de tempo, isso gera complexidades, pois nessas condições existem fatores de decisão a ponderar, o sentido da viagem do veículo na rota se torna relevante e fatores antes não considerados, como tempo de atendimento no cliente, velocidade de veículos e outros fatores relacionados direta ou indiretamente ao tempo, se tornam relevantes.

O artigo publicado por Solomon (1987) propõe as primeiras heurísticas para solução deste problema. São quatro heurísticas construtivas:

- SAV: Uma adaptação da heurística das economias para as janelas de tempo.

- Vizinho mais próximo: Heurística construtiva sequencial na qual a cada iteração, o cliente mais próximo ao último adicionado à rota do veículo é visitado, até se chegar ao limite da janela de tempo ou da capacidade do veículo.

- Inserção Sequencial: Também uma heurística construtiva sequencial. Uma rota é iniciada ou pelo cliente mais distante ou por aquele cuja janela de tempo está mais próxima de se encerrar. A cada iteração, para os clientes que respeitem as restrições de janelas de tempo e capacidade dos veículos, são calculados os critérios $c_{1}$ (que determina o custo da posição na rota onde a adição do cliente gera menor custo adicional) e $c_{2}$ (que determina a economia gerada por se deixar de fazer uma viagem de ida e volta do armazém a este cliente) para determinar qual ponto deve ser adicionado à rota. São propostos três heurísticas desse tipo (I1, I2 e I3) que se diferem na forma como $c_{1}$ e $c_{2}$ são calculados: I1: Leva em conta variações de 


\begin{tabular}{l|c|c|c}
\hline & $\begin{array}{l}\text { R: Clientes dis- } \\
\text { tribuídos }\end{array}$ & $\begin{array}{l}\text { C: Clientes agru- } \\
\text { pados }\end{array}$ & $\begin{array}{l}\text { RC: Clientes } \\
\text { semi-agrupados }\end{array}$ \\
\hline $\begin{array}{l}\text { 1: Janelas de } \\
\text { tempo apertadas }\end{array}$ & $\mathrm{R} 1$ & $\mathrm{C} 1$ & $\mathrm{RC} 1$ \\
$\begin{array}{l}\text { 2: Janelas de } \\
\text { tempo largas }\end{array}$ & $\mathrm{R} 2$ & $\mathrm{C} 2$ & $\mathrm{RC} 2$ \\
\hline
\end{tabular}

Tabela 2: Características dos grupos de instâncias de Solomon (1987) para o VRPTW.

distância e tempo; I2: Leva em conta o custo e tempo total da rota antes e depois de adicionar o cliente; I3: Leva em conta a urgência de atendimento dos clientes na avaliação dos parâmetros.

- Varredura: Adaptação da heurística da varredura proposta por Gillett e Miller (1974) para o VRPTW. Este método é divido em duas fases. Primeiro se agrupa os clientes conforme um método de varredura e, em seguida, executa-se um roteamento de um veículo para cada grupo de clientes. Para garantir respeito às restrições, ajustam-se as rotas e agrupamentos de acordo com limites de janelas de tempos e capacidade de veículos. O procedimento deve ser feito algumas vezes, cada vez partindo de um ângulo inicial de varredura diferente.

Apresentando o melhor desempenho, o método das inserções sequenciais foi amplamente usado posteriormente na literatura, para diferentes problemas.

Além dos métodos propostos, Solomon (1987) gerou seis grupos de instâncias de referência para o problema, que variam tanto na distribuição geográfica dos clientes - entre aleatoriamente agrupados no espaço e pré-agrupados - como na janela de tempo disponível para que se realizem as entregas ou coletas - entre largas e mais apertadas. Os tipos são: R1, C1, RC1, R2, C2 e RC2. As características de cada grupo são apresentadas na Tabela 2. Essas instâncias se tornaram referência para avaliação de métodos por toda a literatura e adaptado para diversos outros atributos de roteamento de veículos.

\subsubsection{Problema de determinação do tamanho e composição da frota e roteamento de veículos com janelas de tempo}

Como sugere a sigla FSMVRPTW, este problema surge a partir da união das características e restrições do FSMVRP com o VRPTW. O objetivo, portanto, é minimizar simultaneamente os custos fixos e variáveis do roteamento de uma frota heterogênea de veículos, respeitando as janelas de tempo nos clientes e do armazém central. 
A primeira abordagem para o problema foi feita por Liu e Shen (1999) que o descrevem como um problema de determinação do tamanho e composição da frota e roteamento de veículos com janelas de tempo, FSMVRPTW (sigla em inglês para Fleet Size and Mix Vehicle Routing Problema with Time Windows). Neste problema devem ser determinados os tipos e a quantidade de veículos para executar um roteamento e atender clientes, mas que não cheguem após um horário máximo em cada cliente e aguardem caso cheguem muito cedo. O problema se aproxima à realidade vivida por empresas e transportadoras, que têm diversos tipos de veículos para atender a um grupo de clientes e também devem atender horário de trabalho em cada cliente, assim como legislações de restrição de horário em portos ou trânsito em regiões urbanas.

Liu e Shen (1999) abordam o problema com uma proposta heurística baseando-se principalmente nos métodos desenvolvidos por Golden et al. (1984), com modificações que os adaptem para a restrição de janelas de tempo. Estas heurísticas foram avaliadas nas instâncias criadas por Solomon (1987) para o VRPTW com adaptações para que suas instâncias recebessem frota heterogênea. Assim, Liu e Shen (1999) geraram 168 instâncias que se tornaram referência para problemas de FSMVRPTW e suas variações que foram propostas na literatura.

Dullaert et al. (2002) aprofundaram os estudos no tema e implementaram três novas heurísticas, baseadas na Heurística de Inserção Sequencial de Solomon (1987) para o VRPTW e os conceitos de economia com oportunidades de Golden et al. (1984). Os três métodos têm sistemática semelhante, somente mudando na avaliação de parte dos custos que incluem a oportunidade, assim como já foi apresentado nos métodos de Solomon (1987).

O trabalho de Dell'Amico et al. (2007) propõe uma nova formulação e uma heurística construtiva para fornecer uma solução inicial a uma meta-heurística para o FSMVRPTW, denominada ParellelRegret_TW. Esta é iniciada com uma solução parcial, a partir da qual, as rotas são expandidas paralelamente. Para cada cliente não roteado é verificado se sua inserção é viável, de acordo com a capacidade dos veículos e janelas de tempo, e é calculada uma pontuação (score). Para o cálculo dessa pontuação é gerada uma penalidade do cliente não roteado, esta penalidade é calculada com base no aumento da distância total da rota, aumento no custo fixo, caso seja necessário trocar o veículo por outro com capacidade maior, e o aumento de tempo gasto na rota. O cálculo da pontuação, assim, é feito com base na diferença entre a menor e a segunda menor penalidade de adição do cliente nas rotas existentes, a distância do cliente até o armazém e o quanto sua janela de tempo está apertada. 
A partir desse critério de pontuação, o método leva em conta os parâmetros usuais do FSMVRPTW, como janela de tempos, custo fixo da frota e distância percorrida, mas no critério de decisão de qual cliente adicionar à rota é dimensionado não só o custo desta adição, mas o arrependimento que se sentiria ao deixar esse cliente para ser inserido em outra rota. Por isso o nome de Parallel Regret (arrependimento paralelo, em tradução livre).

São encontrados outros desenvolvimentos posteriores para o FSMVRPTW, principalmente com o uso de meta-heurísticas, que estão abordadas na Seção 3.5 .

\subsection{Uso de Parceiros Logísticos}

Como mencionado na Introdução, o problema abordado neste trabalho é aplicável à situação em que uma empresa decide fazer a sua distribuição com o apoio de um parceiro logístico, terceirizando essa etapa da cadeia logística, porém ainda deseja controlar as rotas e entregas que são feitas. Portanto, no caso deste trabalho especificamente, a frota de veículos pertence ao parceiro, mas quem decide as rotas das entregas é a empresa que contrata o parceiro e o pagamento dessas entregas é feita com base em uma tabela de fretes com custo pré-determinado para faixas de distância de viagem e tipos de veículos que são utilizados.

O tema de terceirização de entregas não é novo na literatura. Ele foi abordado em Ball et al. (1983), em um estudo realizado para uma indústria química para a distribuição de produtos usando parcialmente a frota própria da indústria e outra parte sendo delegada a um parceiro logístico. Neste caso, são geradas rotas para as entregas feitas com a frota própria e apenas se entrega as demais entregas para o parceiro logístico, sem se preocupar em como este irá executar suas entregas. O problema foi classificado como VRPPC, ou seja, problema de roteamento de veículos com frota própria e transportadoras comuns (Vehicle Routing Problem with Private fleet and Common carriers). Nesse problema, a abordagem é separar primeiramente quais clientes são atendidos por um terceiro, e quais devem ser atendidos pela frota própria (no caso do problema de Ball et al (1983), frota alugada). Depois disso, realiza-se o método de VRP de sua preferência para os clientes que foram designados para a frota própria.

Marasco (2008) apresenta uma revisão ampla da evolução da literatura no tema de parceiros logísticos terceiros (TPL ou 3PL, dependendo do autor). O trabalho mostra uma ampla pesquisa de como o tema é abordado de 1989 a 2006 em 152 artigos de 33 
revistas de grande impacto. O tema é tratado como o estudo do relacionamento entre empresas que possuem os produtos a serem transportados (shippers) e as empresas que realizam o transporte dentro de um contexto de Supply Chain. Marasco (2008) deixa claro que o uso de parceiros logísticos é crescente e o quanto se tem estudado na literatura para melhorar a coordenação e administração desses parceiros junto à empresa contratante A abordagem é feita com uma visão de administração e estratégia de implementar e gerir o uso de parceiros logísticos, enfatizando a pesquisa em artigo que abordam o contexto em que há a decisão de uma empresa de contratar um 3PL, como podem ser elaborados os contratos, formas de controle, impacto na cultura organizacional e impactos sentidos na empresa como impacto desta contratação. Portanto, essa pesquisa não foi ao aspecto tático e operacional, como a execução das entregas de fato ou detalhar formas de cobrança de fretes.

Foram encontrados na literatura estudos que abordam o aspecto tático e operacional do trabalho de parceiros logísticos. Em Başligil et al. (2011), busca-se reduzir os custos da perspectiva do operador logístico. Neste caso, as entregas são feitas diretamente de uma origem a um destino, com entregas diretas e não agrupando clientes em rotas. As origens podem ser de um ponto inicial, como um armazém que pertence ao operador logístico ou a planta da empresa, para o cliente da empresa que o contratou ou um armazém intermediário. Esse tipo de problema não é uma variação do VRP, pois não são feitas rotas cujo custo deve ser minimizado, trata-se de um Problema de Coleta e Entrega (Pick up and Delivery Problem - PDP), o qual não será abordado neste trabalho. O PDP é uma forma frequente de uso de parceiros logísticos em que a indústria que produz os materiais terceiriza uma parte maior da sua cadeia de suprimentos, delegando ao parceiro todo o processo de armazenagem e distribuição de seus produtos que são vendidos.

O tema de distribuição utilizando o suporte de parceiros logísticos se mantém atual. Recentemente foi abordado em Gahm, Brabänder e Tuma (2017) com uma combinação do problema de VRPPC adicionando mais opções de frete que aproximam ainda mais da realidade de empresas que devem tomar decisões sobre suas entregas e tem parceiros logísticos e frota própria para escolher. Neste artigo, o problema possui quatro opções de transporte para a empresa, que são: (i) utilizar a sua própria frota; (ii) alugar veículos para utilizar como frota própria, porém com um custo fixo maior; (iii) contratar uma transportadora que fará entregas exclusivas no estilo origem-destino (FTL, Full Truck Load); (iv) contratar transportadoras que fazem entregas de cargas inferiores a da lotação de seus veículos (LTL - Less than Truck Load) sendo que, para esse caso, existe a possibilidade de obter descontos proporcionais à lotação do veículo do parceiro. Os autores 
definem esse problema como o VRPPCdR e apresentam uma formulação de programação linear inteira mista para o problema e uma meta-heurística do tipo Busca em Vizinhança Variada (VNS) com bons resultados.

Desta forma, é possível perceber que o tema de uso de parceiros logísticos para entregas é amplamente discutido e estudado na literatura, com diversas abordagens do tema, em aspectos operacionais, administrativos e com visões de diversos horizontes. O problema estudado neste trabalho segue esta mesma tendência ao agregar novas características ao problema.

\subsection{Custos Escalonados pela Distância Percorrida}

Na literatura, vários formas de avaliação de custo de frete e transporte são abordados. Em Ghiani, Laporte e Musmanno (2004), são listados diferentes formas de cálculo custo de frete, levando em conta se a empresa é dona de sua frota de veículos, se esta aluga a frota ou usa um operador logístico. Entre os custeios apresentados, existem inclusive custos de frete escalonados de acordo com o peso transportado.

Além da busca na literatura, foi realizada uma pesquisa por e-mail ou telefone com operadores logísticos, empresas especializadas em realizar roteamentos e uma empresa de comercialização de software para verificação de custos de frete. Todos confirmaram a ampla utilização de custeio de frete por faixas escalonadas de distância, ligadas ao tipo de veículo. Não existe um nome padronizado no mercado para esse tipo de cobrança, mas o mais recorrentemente encontrado foi "frete distância". Os dados fornecidos das empresas são confidencias e os nomes das empresas não podem ser divulgados conforme solicitação.

Na literatura não foi encontrada uma abordagem direta ao FSMVRPTWSC. É possível verificar a resolução de um caso específico de custos escalonados em uma situação real de uma empresa da construção civil que coleta material para suas obras nos fornecedores em Bassi (2009). Neste caso foi proposta uma solução para o problema de roteamento de uma frota heterogênea de veículos com janelas de tempo e entregas parciais (HFVRPTWSD) com custos escalonados. A pesquisa adaptou a heurística de Dullaert et al. (2002) ao cálculo de frete escalonado. Apesar da amostra pequena e o escopo limitado, seus resultados foram superiores aos aplicados na empresa e mostraram oportunidade de estudo dessa modalidade de custo escalonado. 


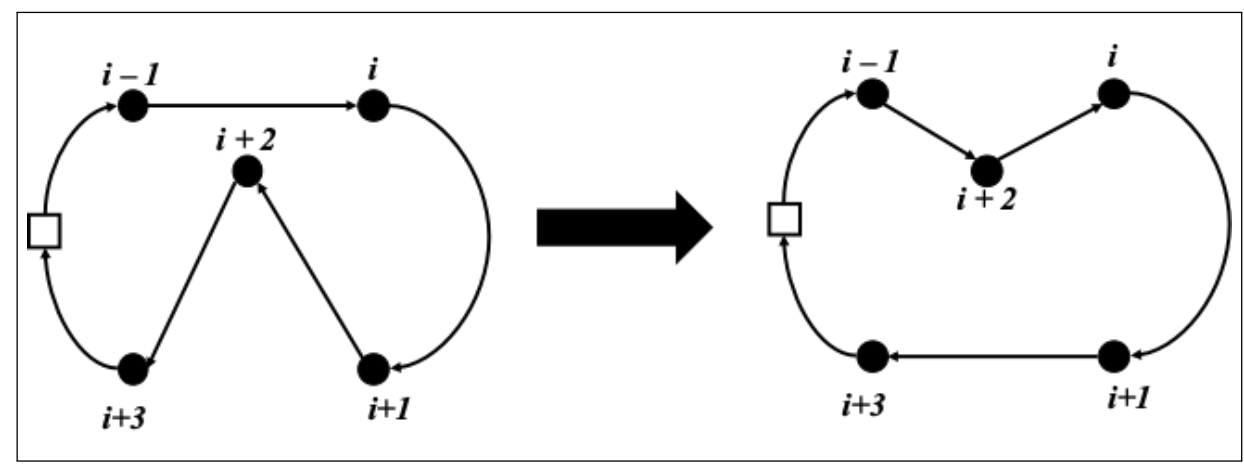

Figura 3: Movimento tipo RELOCATE em que o cliente i+2 é reposicionado na rota, deixando de ser atendido entre $\mathrm{i}+1$ e $\mathrm{i}+3$ para ser atendido entre $\mathrm{i}-1$ e $\mathrm{i}$.

\subsection{Busca Local para Roteamento de Veículos}

Na literatura são apresentados diversos movimentos para explorar soluções e gerar vizinhanças para uma busca local. Os trabalhos de Vidal et al. (2013a) e de Bräysy e Gendreau (2005a) abordam e detalham diversos tipos de movimentos de busca em vizinhança dentre os quais os mais relevantes serão descritos nessa seção.

Em geral, os movimentos de busca em vizinhança podem ser agrupados em dois tipos, os que geram novas soluções a partir de trocas dentro da mesma rota trocando clientes de posição na rota (intra-rota), e os que geram novas soluções trocando clientes entre rotas (inter-rotas). Os movimentos estão explicados a seguir e acompanham figuras baseadas nas apresentadas em Bräysy e Gendreau (2005a).

\section{Movimentos intrarrotas}

Os movimentos intrarrotas, em grande parte, se originaram nas práticas já conhecidas para o TSP (problema do caixeiro viajante), com alteração de arcos das rotas.

Os movimentos podem ser do tipo RELOCATE, em que um cliente é realocado dentro da própria rota, conforme ilustra a Figura 3. A execução do movimento RELOCATE tem duas fases, primeiro o cliente é removido da rota e, em seguida, inserido em uma nova posição.

É possível também executar o movimento SWAP, ou seja, troca de posição entre clientes, como ilustra a Figura 4 .

Lin (1965) apresenta o conceito de otimalidade $k$, cuja notação é dada por $k$-opt. Segundo o autor, em problemas de TSP com $n$ cidades a serem visitadas, uma rota é $k$ - opt quando for impossível obter uma nova rota com custo menor que ela trocando de 


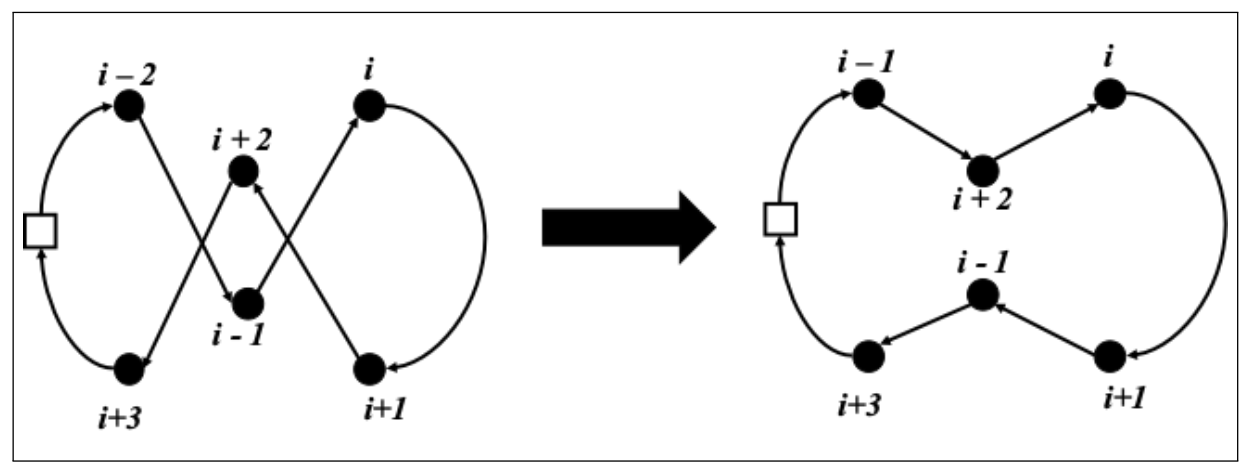

Figura 4: Movimento tipo SWAP em que os clientes i - 1 e i+2 tem suas posições trocadas na rota.

posição $k$ arcos entre si. Sendo assim, Lin (1965) propõe alguns teoremas, dentre os quais são pertinentes para esse trabalho os seguintes:

- Toda rota é 1 -opt $(k=1)$;

- Uma rota é o ótimo global do problema se, e tão somente se, ela for $n$-opt $(k=n)$;

- Assumindo $C_{k}$ como o conjunto de todas as soluções possíveis de se obter de uma rota trocando $k$ arcos, pode se afirmar que $C_{1} \supset C_{2} \supset \cdots \supset C_{n}$, ou seja, se uma solução é $k$ - opt então ela também é $k^{\prime}-o p t$ para $k^{\prime}<k$;

A partir destes conceitos, Lin (1965) apresenta buscas locais intrarrotas do tipo 2-opt, em que arcos das rotas são trocados aos pares, e 3-opt. A complexidade das trocas $k$-opt para rotas de tamanho $n$ são da ordem de $\mathrm{O}\left(n^{k}\right)$, portanto cada aumento de $k$ representa um aumento significativo do custo computacional. Por esta razão, não é frequente encontrar na literatura proposições de $k$ maiores que 4 . Vale observar que eventuais trocas podem gerar inversões de direção em outros arcos da mesma rota. A Figura 5 apresenta graficamente uma troca do tipo 2-opt.

Além das trocas $k$-opt, existe também a troca $O r$-opt, em que as trocas são feitas em trechos da rota, ou seja, um ou mais arcos são mantidos inalterados, mas as extremidades do grupo se altera. Essa troca não gera troca de nenhuma direção da rota. A Figura 6 exemplifica a troca Or-Opt. É notável que a troca Or-Opt, também é um tipo especial de 3-Opt, uma vez que três arcos da rota são alterados, mas com a diferença de que não existe nenhuma troca de sentido na rota. 


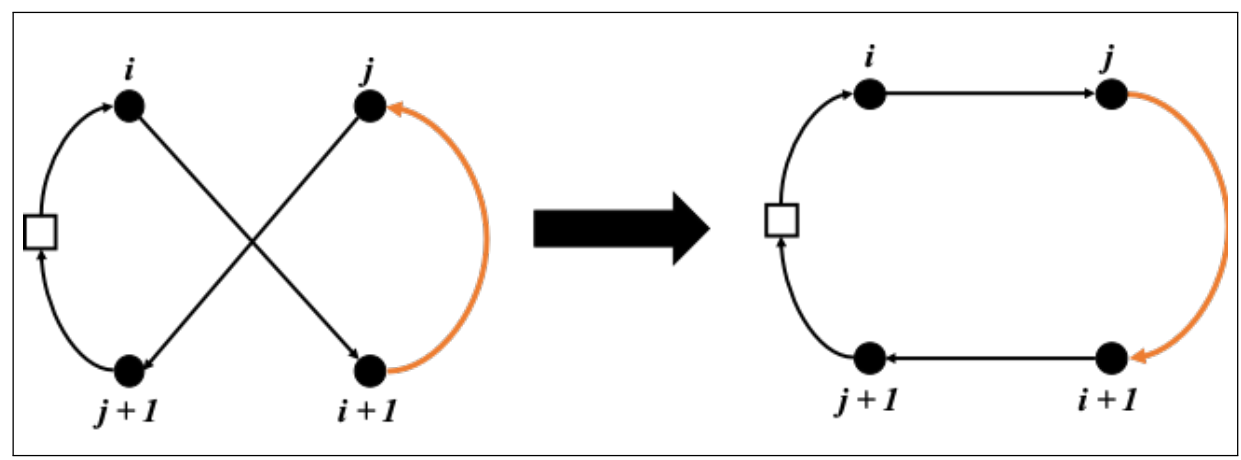

Figura 5: Troca do tipo 2-opt: o arco $(\mathrm{i}, \mathrm{i}+1)$ e o $\operatorname{arco}(\mathrm{j}, \mathrm{j}+1)$ são substituídos pelos arcos $(i, j)$ e $(i+1, j+1)$. Note que o arco $(i+1, j)$ tem sentido invertido para $(j, i+1)$.

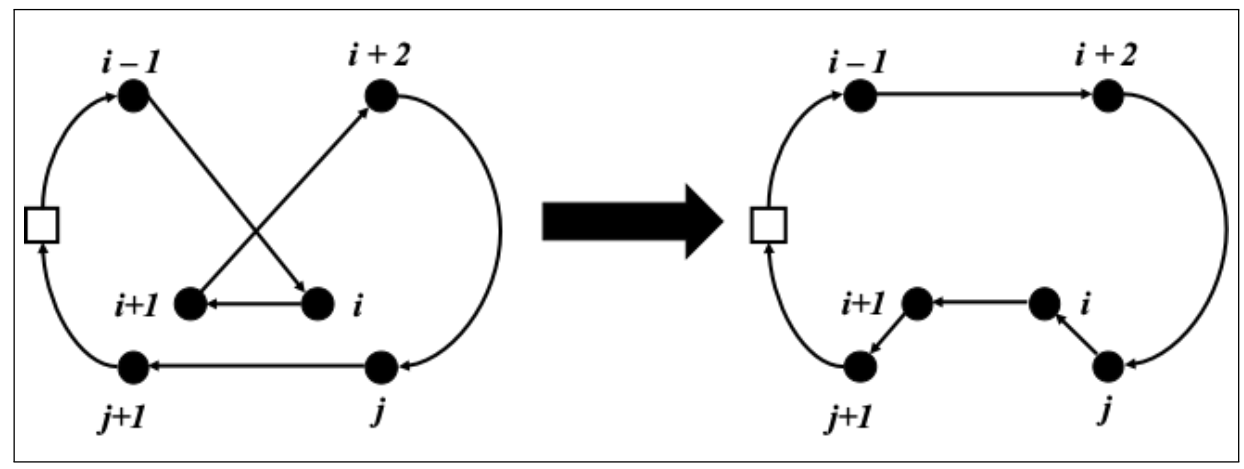

Figura 6: Movimento do tipo Or-opt em que um arco $(\mathrm{i}, \mathrm{i}+1)$ é realocado na rota a partir da troca dos $\operatorname{arcos}(\mathrm{i}-1, \mathrm{i})$ e $(\mathrm{j}, \mathrm{j}+1) \operatorname{pelos}(\mathrm{j}, \mathrm{i})$ e $(\mathrm{i}+1, \mathrm{j}+1)$ e, consequentemente troca o arco $(j, j+1)$ pelo $(i-1, i+2)$. Note que, nessa troca não há nenhuma troca de direção na rota.

\section{Movimentos inter-rotas}

Além de trocas internas às rotas, também são encontrados movimentos de troca entre diferentes rotas no mesmo problema.

O movimento 2-opt*, proposto por Potvin e Rousseau (1995), se assemelha à troca 2-opt, em que dois arcos são trocados na mesma rota, porém a troca é feita entre duas rotas diferentes, sem alteração no sentido dos demais arcos. Desta forma, o movimento faz com que aconteça uma troca na rota a partir do ponto onde houve a troca entre rotas, ou seja, todos os clientes que eram atendidos após o arco trocado passam a ser atendido pela outra rota. Assim, existe uma troca de fim de rotas, em que o fim de uma rota passa para a outra. Por exemplo, numa troca entre duas rota com clientes (A, B, C, D) e outra $(1,2,3,4)$ entre os $\operatorname{arcos}(\mathrm{B}, \mathrm{C})$ e $(2,3)$ e as rotas ficam $(\mathrm{A}, \mathrm{B}, 3,4)$ e $(1,2, \mathrm{C}$, D). Observe que, diferente do movimento 2-opt, não existe nenhuma troca de sentido dos 


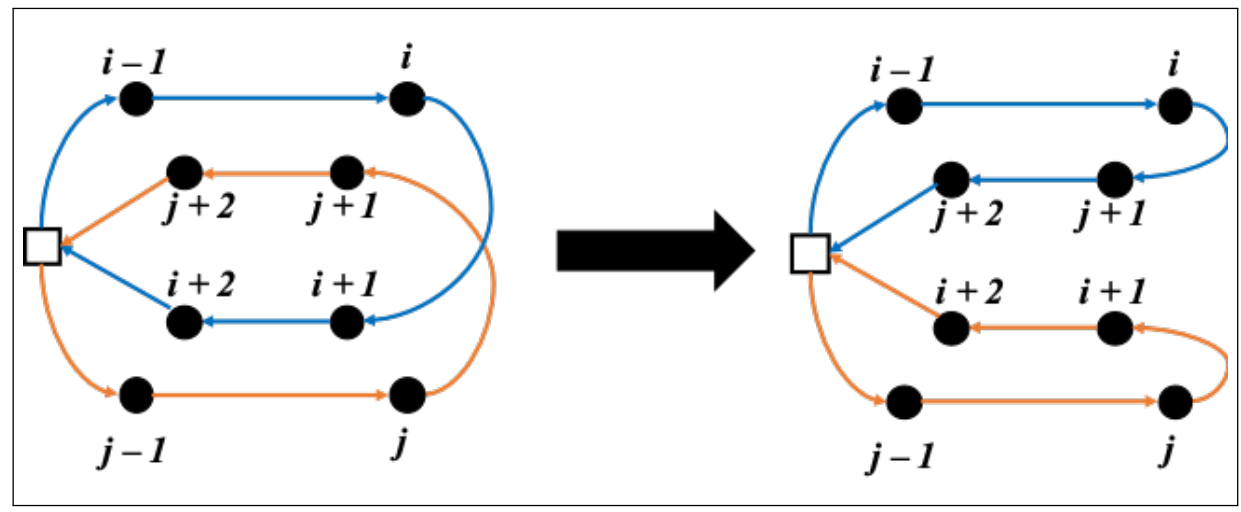

Figura 7: Movimento do tipo 2-opt* em que um arco $(\mathrm{i}, \mathrm{i}+1)$ é trocado pelo $(\mathrm{i}, \mathrm{j}+1)$ e o $\operatorname{arco}(j, j+1)$ é trocado pelo $(j, i+1)$. Desta forma todos os clientes que estão após i e $\mathrm{j}$ trocam de rota. Note que nenhum arco muda de sentido.

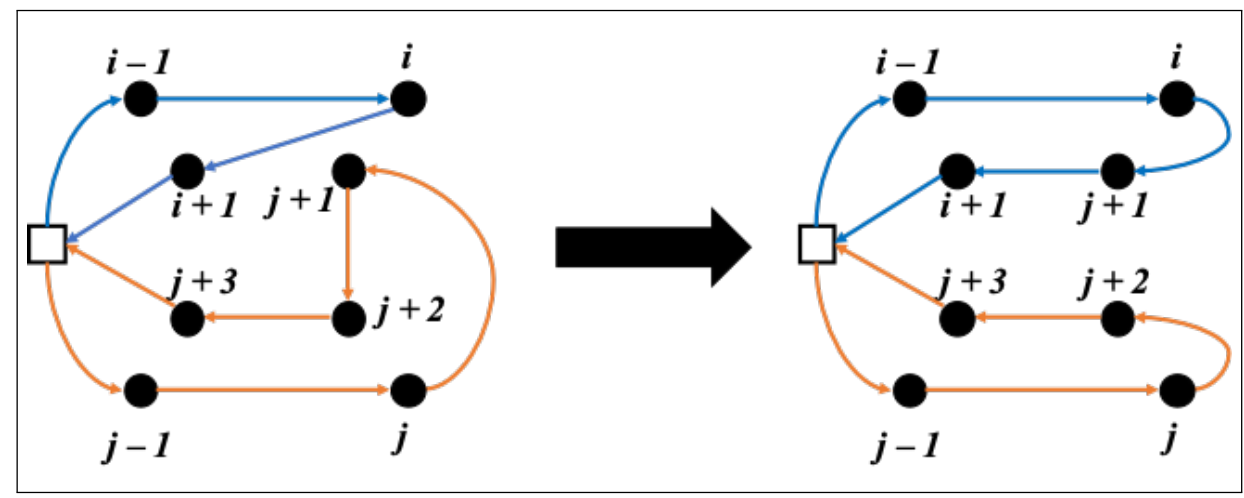

Figura 8: Movimento do tipo RELOCATE em que o cliente $\mathrm{j}+1$ é trocado de rota.

arcos na 2-opt*. A Figura 7 ilustra essa troca.

O movimento do tipo RELOCATE pode ser utilizado também para problemas interrotas. Assim como no caso do RELOCATE intrarrota, o movimento consiste na troca de um cliente de posição, nesse caso, porém, a troca é de uma rota para outra. Esse caso é o que ilustra a Figura 8 .

Uma outra opção de movimento é o EXCHANGE, em que o cliente de uma rota é trocado com o cliente de outra rota, conforme representado na Figura 9.

Similar ao movimento Or-opt, em que um trecho da rota é realocado dentro da mesma rota, o CROSS faz movimento similar inter-rotas, em que um trecho de uma rota é trocado por um trecho de outra rota, sem gerar mudanças de sentido nos arcos existentes, como apresentado na Figura 10.

Além desses movimentos também existem movimentos com maior complexidade de trocas que podem ser combinações de diferentes movimentos citados anteriormente ou 


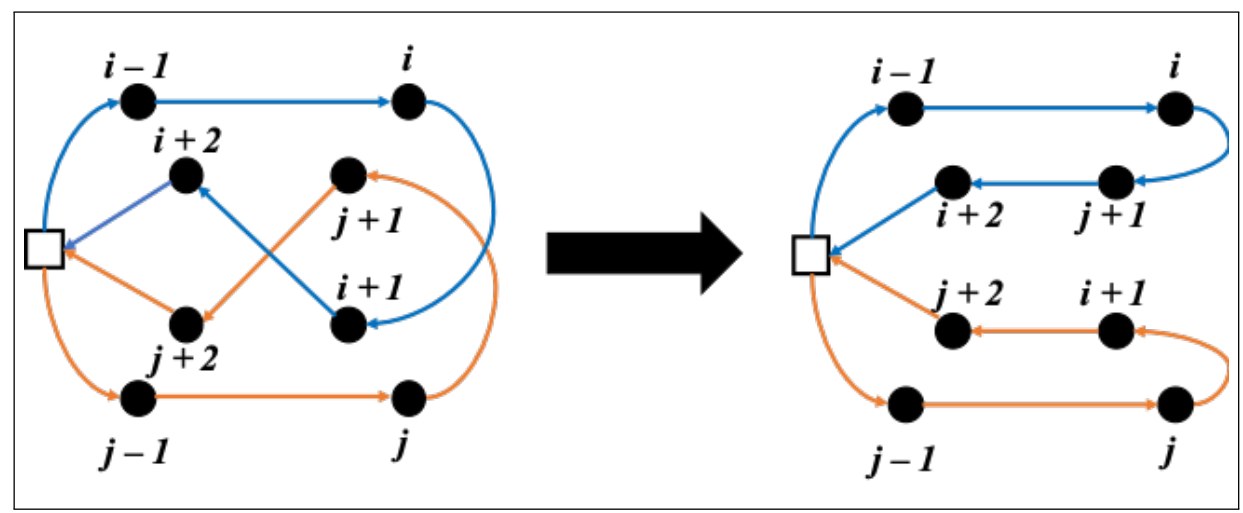

Figura 9: Movimento do tipo EXCHANGE em que o cliente $\mathrm{j}+1$ é trocado de rota pelo cliente $\mathrm{i}+1$. Desta forma o trecho $(\mathrm{i}, \mathrm{i}+1, \mathrm{i}+2)$ passa a ser $(\mathrm{i}, \mathrm{j}+1, \mathrm{i}+2)$ e o trecho $(\mathrm{j}$, $\mathrm{j}+1, \mathrm{j}+2)$ passa a ser $(\mathrm{j}, \mathrm{i}+1, \mathrm{j}+2)$. Nenhum outro cliente muda de rota e nenhum arco muda de sentido.

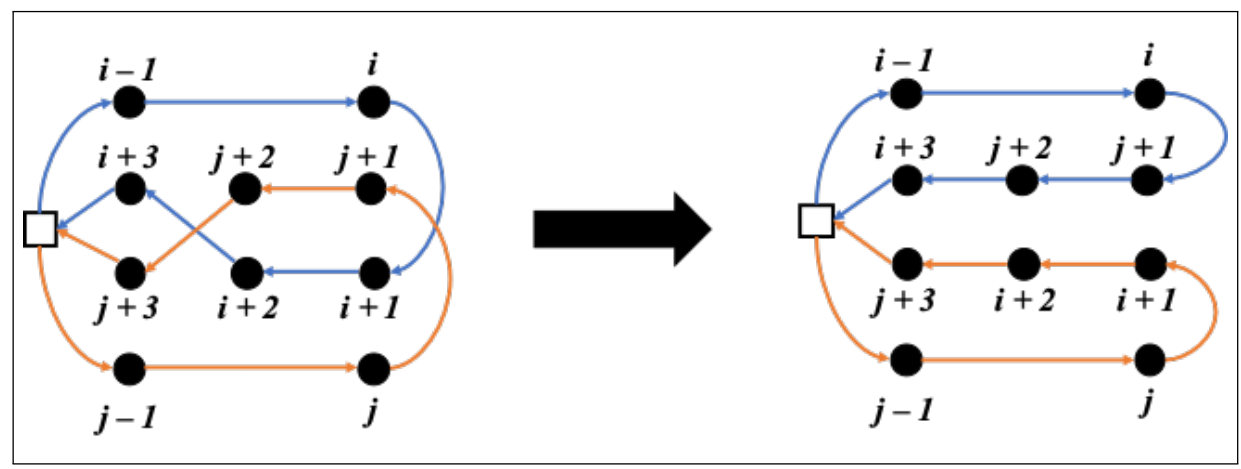

Figura 10: Movimento do tipo CROSS: O trecho $(\mathrm{j}+1, \mathrm{j}+2)$ são trocados com o trecho $(\mathrm{i}+1, \mathrm{i}+2)$ 
incluem uma reorganização de arcos após uma troca. O movimento GENI, por exemplo, após uma troca do tipo RELOCATE, gera uma reorganização da rota para clientes próximos aos clientes cujos arcos foram trocados. que trocam diversos clientes de uma só vez. Similarmente, existe a troca CYCLIC TRANSFER, na qual diversos clientes sofrem o movimento RELOCATE inter-rotas simultaneamente seguindo um sentido (horário ou anti-horário) para a rota mais próxima.

\subsection{Meta-Heurísticas em Problemas de Roteamento de Veículos}

O Roteamento de Veículos foi um dos primeiros problemas a ser resolvido com métodos meta-heurísticos para sua solução. Laporte (2009) aponta uma grande diversidade de métodos já aplicados ao VRP nos seus 50 anos de estudo. Vidal et al. (2013a) também destacam a evolução de métodos meta-heurísticoas e de busca local na literatura para MAVRP (VRP com multi atributos).

Os principais métodos podem ser agrupados entre o uso de métodos de busca em vizinhança, que realizam busca de melhores soluções a partir de buscas em vizinhanças em sequência e possuem estratégias para fugir de mínimos locais; métodos multi-start que são executados repetidamente com diferentes parâmetros a cada execução; métodos de busca populacional, que geram uma grande quantidade de soluções e as combinam

para buscar novos mínimos locais; métodos híbridos, que combinam mais de um método na mesma estratégia de solução; e métodos paralelos e cooperativos, que buscam realizar diferentes abordagens para o mesmo problema paralelamente e trocando informação entre os métodos para gerar novos mínimos locais, geralmente dependendo de multiplos processadores para tal.

Exemplos de meta-heurísticas baseados em busca local incluem Busca Tabu (Tabu Search), Simulated Annealing, Busca em Vizinhança Variável (Variable Neighbourhood Search), ILS (Iterated Local Search) entre outros. Métodos multi-start incluem o GRASP, Greedy Randomized Adaptive Search Procedure. Exemplos de métodos de busca populacional incluem os Algoritmos Genéticos e Algorítmos Evolucionários.

Com o objetivo de buscar métodos que podem ser aplicados para solução do problema abordado neste trabalho, o FSMVRPTWSC, foram estudados trabalhos que abordaram o tema de roteamento de veículos. Na busca, foi dada prioridade a trabalhos que abordam o FSMVRPTW, que é um dos problemas mais próximos do investigado neste trabalho 
e outros problemas com janelas de tempo, uma vez que elas são restrições de grande relevância na solução do problema por gerar infactibilidades.

Dentre meta-heurísticas com busca em vizinhança, diversos métodos foram aplicados no FSMVRPTW e similares. Bräysy e Gendreau (2005a) propõem uma meta-heurística híbrida que combina Threshold Acceptance (TA) com Busca Local Guiada, ambos métodos de busca em vizinhança. Paraskevopoulos et al. (2008) abordam o HFVRPTW, similar ao FSMVRPTW, porém com frota limitada, com uma combinação do VNS com a Busca Tabu. Repoussis e Tarantilis (2010) propõem o uso de Programação de Memória Adaptável (AMP - Adaptive Memory Programming), um processo multi início que gera diversas soluções que utiliza de memória para acelerar a busca local com o apoio de Busca Tabu.

O uso da meta-heurística GRASP na literatura tem destaque e é exposto por Feo e Resende (1995) e Festa e Resende (2009). Estes autores ressaltam que, por sua fácil implementação, o método tem pouca necessidade de parâmetros e boa capacidade de geração de bons resultados, o que explica o amplo uso do GRASP na literatura, inclusive como parte de métodos híbridos. Um exemplo é Palomo-Martínez et al. (2017) que propõem a combinação de GRASP com VNS para resolver o problema de orientação, uma espécie de jogo em que a partir de uma série de pontos distribuídos no mapa em que cada ponto possui uma pontuação, deve ser maximizar a pontuação total respeitando-se uma distância máxima a ser percorrida.

Existem diversos trabalhos que abordam problemas de roteamento usando métodos de busca populacional. Tem grande frequência a sua implementação na forma de métodos híbridos, ao utilizar um método de melhoria em trajetória ou multi-start durante a geração de novas soluções em cada rodada.

Vidal et al. (2014) busca propor um método populacional que tenha bom desempenho para qualquer tipo de MAVRP (problemas de roteamento de veículo com multi-atributos, na sigla em ingês). O trabalho explora os diversos tipos de problema explorados na literatura e os métodos usados para tal e propõe um método que tenha bom desempenho para todos os problemas expostos. O método proposto, UHGS (Unified Hybrid Genetic Search) possui bom desempenho em comparação aos métodos mais bem sucedidos para cada tipo de problema testado em suas instâncias de referência. O método empata ou supera 1045 das 1099 melhores soluções conhecidas destas instâncias à época da publicação do artigo, confirmando ser uma estratégia robusta.

Koç et al. (2015) abordam o HFVRPTW, problema de roteamento de veículos com 
frota heterogênea e janelas de tempo, utilizando um algoritmo de busca populacional híbrido (HEA). Neste método durante a geração de novos indivíduos para a população, existe uma fase de educação que, de fato, significa a execução de busca local para a solução obtida a partir do crossover de outras duas soluções do tipo Destruir e Reparar, muito similar ao RELOCATE. Neste trabalho é feita uma comparação de desempenho entre o método proposto e outros métodos para solução do HFMVRPTW. Nessa comparação o HEA apresenta o melhor desempenho dentre os métodos comparados, seguido pelo UHGS de Vidal et al. (2014).

Koç et al. (2016) propõe o método HESA que combina busca em trajetória com busca populacional para resolver o FSMLRPTW. Esse problema tem como objetivo determinar a localização de um ou mais depósitos que minimize o custo do roteamento decorrente da posição escolhida. O HESA tem a etapa de busca populacional ao gerar um conjunto de soluções e as combinar (crossover), selecionando as melhores e gerando novas soluções no conjunto iterativamente. A etapa de busca local se dá após a combinação de soluções, em que a cada nova solução se aplica um metódo meta-heurístico de busca local denominado L-HALNS que combina operadores de RELOCATE.

Arnold e Sörensen (2019) argumentam a importância de, ao se escolher e aplicar métodos heurísticos a um problema, é importante conhecer e explorar as características do problema. Portanto, este trabalho, que apresenta e explora o problema e suas características usa o conhecimento para a escolha dos métodos de meta-heurística que serão gerados.

É possível ver, portanto, que existe um amplo campo para estudo de métodos metaheurístivos para o FSMVRPTWSC, como foi explorado no Capítulo 8 . 


\section{GERAÇÃO DE INSTÂNCIAS}

Para avaliar o desempenho dos métodos propostos neste trabalho, testes computacionais foram realizados. Entretanto, como na literatura não foram encontradas instâncias de referência para o FSMVRPTWSC, foi necessário gerar instâncias com diferentes características.

Na Seção 4.1, as instâncias de referência para o FSMVRPTW propostas por Liu e Shen (1999), num total de 168 instâncias com 100 clientes cada, são adaptadas para os custos escalonados. Em seguida, com o objetivo de comparar o desempenho dos métodos com resultados ótimos, instâncias de dimensões menores foram geradas na Seção 4.2 . Finalmente, para avaliar a qualidade dos métodos para a situação real de empresas, na Seção 4.3 instâncias com base em um estudo de caso foram geradas.

Os detalhes de todas as instâncias utilizadas neste trabalho estão no Apêndice A.

\subsection{Instâncias de Referência}

As instâncias de referência foram geradas a partir da adaptação das 168 instâncias propostas por Liu e Shen (1999) para o FSMVRPTW, com a criação de faixas de distância com atribuição de custo fixo a elas. As instâncias do FSMVRPTW são uma adaptação das 56 instâncias propostas por Solomon 1987) para o problema de VRPTW, a partir da inserção de diferentes tipos de veículos para o problema em três tipos de custos fixos, altos, médios e baixos.

Solomon (1987) gerou 56 instâncias com 100 clientes para o VRPTW, enquanto Liu e Shen (1999) adicionaram a essas instâncias três grupos de custos fixos e capacidades para adaptá-las para o FSMVRPTW, formando um total de 168 instâncias. As instâncias têm 100 clientes cada uma e podem ser agrupadas em classes seguindo os seguintes critérios:

- Distribuição Espacial: Existem três formas de agrupar os clientes e o armazém no espaço: 
R: Clientes distribuídos aleatoriamente no espaço;

C: Clientes agrupados em pequenos grupos no espaço;

RC: Parte dos clientes agrupados em pequenos grupos e outra parte distribuídos aleatoriamente.

- Janelas de Tempo: Cada cliente, bem como o armazém, tem sua janela de tempo. Existem duas formas de janela de tempo consideradas no problema:

1: Janelas apertadas, ou seja, os clientes estão disponíveis por pouco tempo para o atendimento, que faz com que sejam geradas mais rotas e cada uma atenda menos clientes;

2: Janelas folgadas, ou seja, os clientes estão disponíveis por mais tempo para o atendimento, que faz com que sejam geradas menos rotas com mais clientes podem ser atendidos na mesma rota.

\section{- Custos de Veículos:}

a: Os veículos tem custos iniciais maiores, o que faz com que a solução tenha uma tendência a usar o mínimo possível de veículos e aproveitar ao máximo cada rota gerada;

b: Custos inicias médios de veículos;

c: Custos de veículos menores, o que torna a criação de mais rotas, menos custosa.

Nas instâncias para o FSMVRPTWSC são mantidas todas essas características, com a adaptação sendo feita somente na estrutura de custo. Para manter os custos fixos gerados por Liu e Shen (1999), esses valores são usados para o custo da primeira faixa de distância de cada veículo $\left(C_{k 1}\right)$, a partir daí são definidas as faixas de distância e seus respectivos custos fixos $\left(C_{k f}, 1<f<F\right)$.

O número de faixas de distância (F) para cada tipo de problema foi definido de acordo com o tempo total de planejamento. Para as instâncias com o horizonte menor (R1, C1 e $\mathrm{RC} 1$ ), foram definidas 4 faixas de distância, enquanto para instâncias com horizonte maior (R2, C2 e RC2), 5 faixas. Essa distribuição se deu pois, quando o horizonte de roteamento se torna maior, a distância percorrida pelos veículos se torna proporcionalmente maior e, assim, as faixas se tornariam muito longas e o salto de custo de uma para outra seria grande demais, tornando pouco benéfico a adição de clientes a cada rota e aumentar a distância de forma a mudar de faixa. 
Cada faixa de custo fixo teve seu valor calculado com base na distância em que ela se inicia e multiplicado por um fator de custo. Ou seja, cada faixa, $1<f<F$ tem custo calculado por $C_{k f}=C_{k f-1}+\theta\left(W_{f}-W_{f-1}\right)$, onde $\theta$ é um fator de custo para conversão de distância em custo. A última faixa, $f=F$, recebe o valor de custo por distância percorrida.

Com apenas essa adaptação nos custos das instâncias, foram geradas as 168 instâncias de referência para o FSMVRPTWSC mantendo o máximo de rastreabilidade com as instâncias já conhecidas do FSMVRPTW e o VRPTW. As instâncias de referência estão expostas no Anexo B.

\subsubsection{Instâncias de calibração}

Para permitir realizarmos calibrações dos diferentes parâmetros dos métodos que serão propostos nesse trabalho, um pequeno grupo de instâncias retirado das instâncias de referência foi escolhido. São três instâncias de cada combinação de atributos: as três distribuições espaciais ( $\mathrm{R}, \mathrm{C}$ e RC), duas janela de tempos (1 e 2) e três custos de veículos (a, b e c), resultando em 54 instâncias para calibração.

\subsection{Instâncias de Dimensões Menores}

Por se tratar de um problema NP-Hard, não é possível resolver e obter a solução ótima para instâncias com 100 clientes como os de referência gerados conforme a Seção 4.1 Por esta razão, para avaliar o desempenho da formulação proposta, as instâncias foram adaptadas para terem dimensões menores, mantendo as características definidas anteriormente.

Para a avaliação em diferentes tamanhos de problema, foram gerados problemas para cada uma das características acima com números diferentes de clientes a serem atendidos: 10, 15, 20 e 25 clientes, chegando a um total de 72 instâncias. Como, durante as avaliações, nenhuma das 18 instâncias de 30 clientes obteve a solução ótima e,como o objetivo da geração de instâncias de dimensões menores é a comparação dos resultados obtidos pelos diversos métodos com o resultado ótimo, não houve a geração de instâncias com mais clientes.

Durante a adaptação das instâncias para as Instâncias de Dimensões Menores, houve cuidado de manter as características originais de cada problema. Isto foi feito selecionando clientes com todas as suas características originais de Solomon (1987), como posição, 
janelas de tempo e demanda, sempre com o cuidado de manter as três configurações originais. Na Figura 11 pode ser visto como as instâncias com distribuição espacial do tipo $\mathrm{R}, \mathrm{C}$ e $\mathrm{RC}$ foram reduzidas de forma a manter suas características.

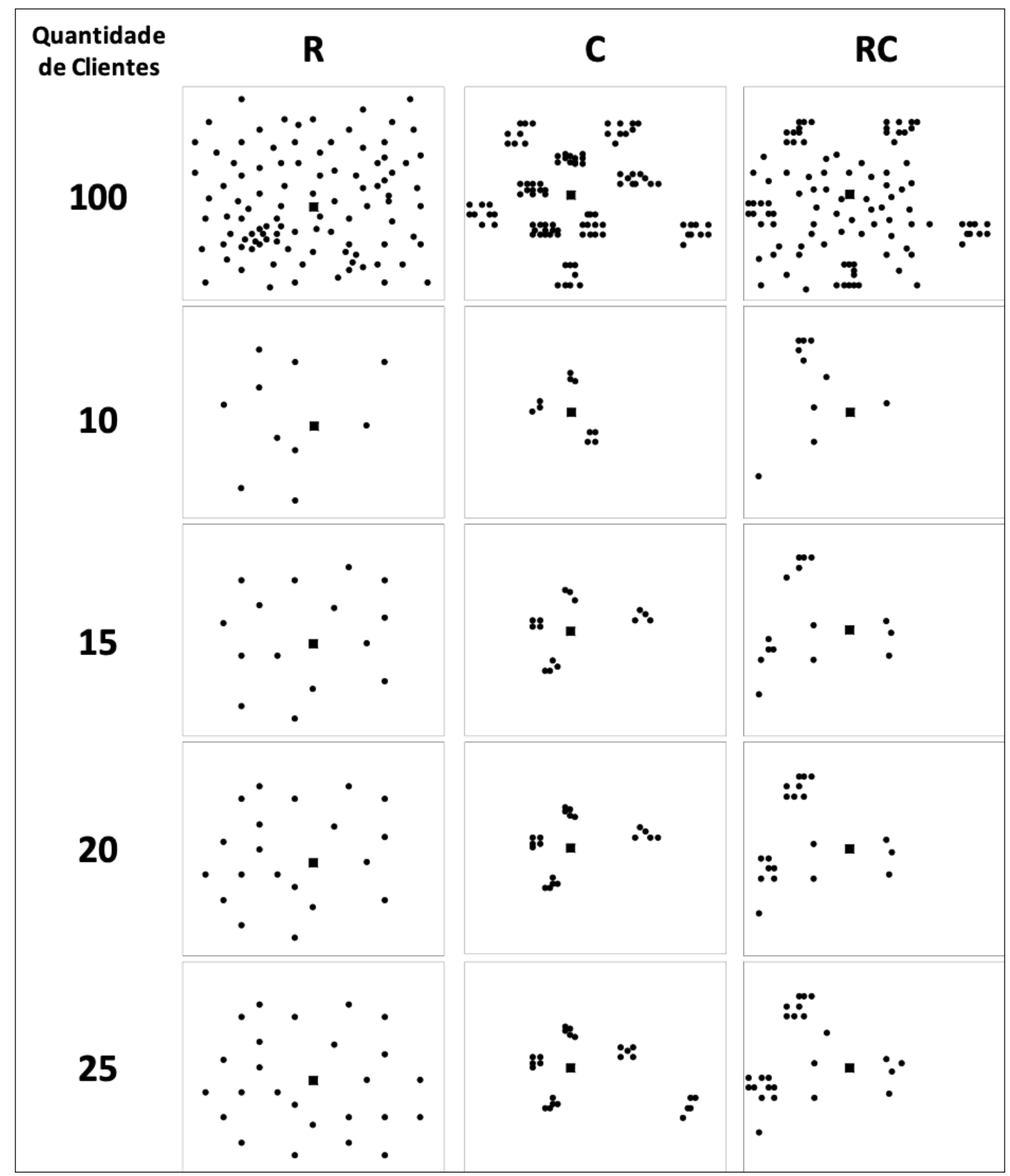

Figura 11: Apresentação gráfica da distribuição física dos clientes e o armazém nos três tipos de problema para as diferentes quantidades de clientes nas Instâncias de Dimensões Menores. Para manter a coerência com os problemas originais, as tabelas de frete foram mantidas idênticas às dos problemas maiores, de 100 clientes. 


\subsection{Instâncias Inspiradas em Dados Reais}

Como afirmado na Introdução e em diversas partes deste trabalho, o FSMVRPTWSC possui características muito frequentes em situações vividas por empresas na prática. Tendo essa informação instâncias inspiradas em dados reais de uma empresa foram geradas.

A empresa, que não deseja ser identificada, é brasileira de grande porte e atua no fornecimento de materiais de construção civil principalmente para obras. Por motivos de segurança da informação, ela não pôde fornecer uma massa grande de dados, limitando o compartilhamento a apenas três dias de entregas para a avaliação.

Os dados foram obtidos de um dos centros de distribuição no interior de São Paulo. O procedimento padrão da empresa se dá da seguinte forma:

- Roteamento é planejado diariamente, no fim de um dia planeja-se o roteiro de entregas do dia seguinte;

- Ao fim do dia, é feito um corte, ou seja, novos pedidos não são mais aceitos para entrega no dia seguinte, e portanto o planejamento é feito com um cenário estático e previamente conhecido;

- O nível de estoque no centro de distribuições de onde partem as entregas para atendimento da demanda do dia seguinte é verificado e quais demandas serão atendidas é determinado;

- A janela dos clientes é determinada das 7 às 17 horas, tendo em vista que se tratam majoritariamente de canteiros de obras;

- Cada visita a um cliente demora uma hora e meia, considerando o processo desde a chegada do veículo até a sua partida.

A Tabela 3 apresenta as dimensões gerais das instâncias inspiradas em dados reais. Para cada dia (coluna "Instância") está apresentado o número de clientes que são atendidos, a soma da demanda de todos os clientes e a distância para o cliente mais distante (Distância Máxima).

A Tabela 4 apresenta a tabela de fretes paga pela empresa. São três tipos de veículo disponíveis, com capacidades de 8, 14 e 20 toneladas. A quantidade de veículos de cada tipo é ilimitada, uma vez que o parceiro logístico da empresa é de grande porte. A 


\begin{tabular}{cccc}
\hline $\begin{array}{c}\text { Instância } \\
\text { (Dia) }\end{array}$ & $\begin{array}{c}\text { Número de } \\
\text { Clientes }\end{array}$ & $\begin{array}{c}\text { Demanda Total } \\
\text { (toneladas) }\end{array}$ & $\begin{array}{c}\text { Distância } \\
\text { Máxima }(\mathrm{km})\end{array}$ \\
\hline 1 & 104 & 789.2 & 39.1 \\
2 & 132 & 693.8 & 50.2 \\
3 & 110 & 714.7 & 52.3 \\
\hline
\end{tabular}

Tabela 3: Características das instâncias inspiradas em dados reais.

\begin{tabular}{ccccccc}
\hline \multicolumn{3}{c}{ Veículo } & \multicolumn{5}{c}{ Faixas de Distância $(\mathrm{km})$} \\
\hline Tipo & Capac. (ton) & até 20 & de 20 a 40 & de 40 a 60 & de 60 a 100 & de 100 a 150 \\
\hline 1 & 8 & 200.0 & 250.0 & 300.0 & 400.0 & 550.0 \\
2 & 14 & 400.0 & 450.0 & 500.0 & 600.0 & 750.0 \\
3 & 20 & 550.0 & 600.0 & 650.0 & 750.0 & 900.0 \\
\hline
\end{tabular}

Tabela 4: Tabela de frete (simplificada) do problema.

distância é dividida em cinco faixas de distância. Caso a distância percorrida por um veículo coincida exatamente com a distância entre as faixas, é sempre escolhida a faixa menor para o cálculo de frete. Para cada combinação de veículo e faixa de distância existe o custo fixo (em Reais). O custo a partir de $150 \mathrm{~km}$ tem crescimento linear com o valor da última faixa (100 a $150 \mathrm{~km})$ mais $\$ 1$ por $\mathrm{km}$ adicional.

A Figura 12 apresenta a localização do centro de distribuição da empresa (em azul), bem como dos clientes (em vermelho) que serão atendidos na instância do dia 2. 


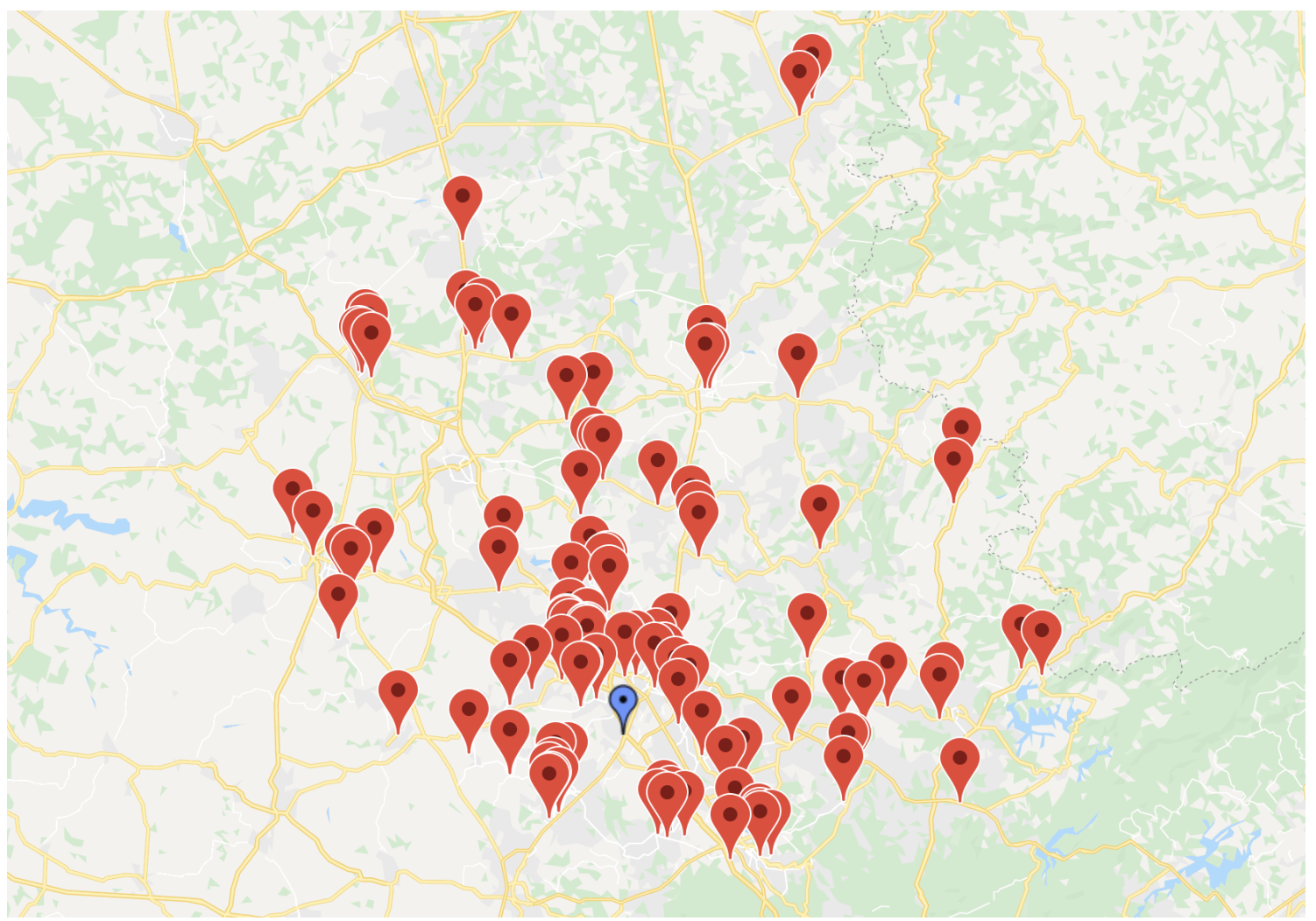

Figura 12: Mapa com a localização de clientes a serem atendidos (pontos em vermelho) e centro de distribuição de onde partem todos os veículos (ponto em azul). 


\section{FORMULAÇÃO MATEMÁTICA}

Neste capítulo é apresentada a formulação de programação linear inteira mista (PLIM) para o FSMVRPTWSC, ela se trata de uma evolução das formulações apresentadas em Manguino e Ronconi (2012), Manguino (2013) e Ronconi e Manguino (2016). Este capítulo está organizado da seguinte forma: na Seção 5.1 estão detalhados cada elemento que compõe a formulação e a notação que é usada para identifica-los; em seguida, na Seção 5.2 o modelo matemático é exposto e detalhado; logo após, na Seção 5.3 . são apresentadas as principais melhorias geradas no modelo matemático entre o apresentado nesse trabalho e as versões anteriores. Ao final, na Seção 5.4 o resultado de testes computacionais é apresentado.

\subsection{Elementos da Formulação}

A seguir os diferentes elementos do modelo matemático são apresentados e a nomenclatura que é usada por todo o trabalho.

\subsubsection{Clientes}

Considerando um conjunto de $n+1$ pontos sendo $N=\{0,1,2, \ldots, n\}$ distribuídos no espaço. O local 0 é o armazém, o ponto de onde partem todos os veículos das rotas geradas e para onde eles retornam ao fim do percurso, portanto está presente em todas as rotas e será sempre o início e fim delas. Todos os outros pontos são clientes.

Para cada par de pontos $(i, j)$ formam arcos de distância $d_{i j}$ e tempo de percurso $t_{i j}$ conhecidos previamente, ambos números reais positivos. A cada cliente $i>0$ é associado uma demanda $q_{i}$, que é conhecida antes do início do processo de roteamento. 


\subsubsection{Frota de Veículos}

Existem $K$ diferentes tipos de veículos disponíveis para executar as rotas,. Cada tipo de veículo $k$ possui uma capacidade $a_{k}\left(a_{1}<a_{2}<a_{3}<\ldots<a_{K}\right)$ e custos escalonados para cada faixa de distância percorrida. Os detalhes das faixas de distâncias e os respectivos custos de cada uma estão detalhados mais a frente nesta sessão.

Considera-se a frota de veículos neste problema ilimitada para todos os tipos. Para permitir a formulação matemática do problema, é pré-estabelecido o número de veículos $V=n$, que é o número máximo possível de rotas, onde cada cliente é atendido por um veículo exclusivamente.

\subsubsection{Janela de Tempo}

Cada ponto $i$ do conjunto $N$ tem janelas de tempo rígidas, definidas pelo intervalo $\left[e_{i}, l_{i}\right]$, sendo que $e_{i}<l_{i}$. Esses parâmetros correspondem, respectivamente, ao início e fim do período em que os clientes podem ser atendidos e no qual os veículos podem partir ou retornar ao armazém. Os atendimentos não podem iniciar nem antes nem depois deste intervalo. O tempo que o veículo deve permanecer nos clientes é representado por $s_{i}$ e $b_{i}$ como o início do serviço no cliente $i$. Não existem valores de $s_{i}$ e $b_{i}$ para o armazém, uma vez que não há serviço a ser executado (é pressuposto que o carregamento dos veículos já ocorreu antes da abertura de sua janela de tempo) e como o armazém está presente duas vezes em todas as rotas, seria necessário duas variáveis desse tipo para cada rota no armazém.

Caso um veículo, partindo do cliente $i$, chegue ao cliente $j$ antes do início da janela de tempo $e_{j}$, ele deve aguardar até a disponibilidade do cliente. Assim, podemos definir $b_{j}=\max \left(e_{j} ; b_{i}+s_{i}+t_{i j}\right)$.

\subsubsection{Faixas de Custo}

No FSMVRPTWSC, o custo total é definido pela soma dos custos de cada veículo, de acordo com o seu tipo e faixa de distância. Ou seja, para cada veículo deve se verificar em qual faixa $f$ a distância percorrida está inserida e então, junto com o tipo de veículo $k$ necessário para transportar a demanda da rota, aferir o custo.

Assim, temos $F$ faixas de distâncias, sendo $f=\{1,2, \ldots, F\}$. Cada faixa tem uma distância correspondente $W_{f}$ que determina o seu limitante inferior, ou seja, a distância 


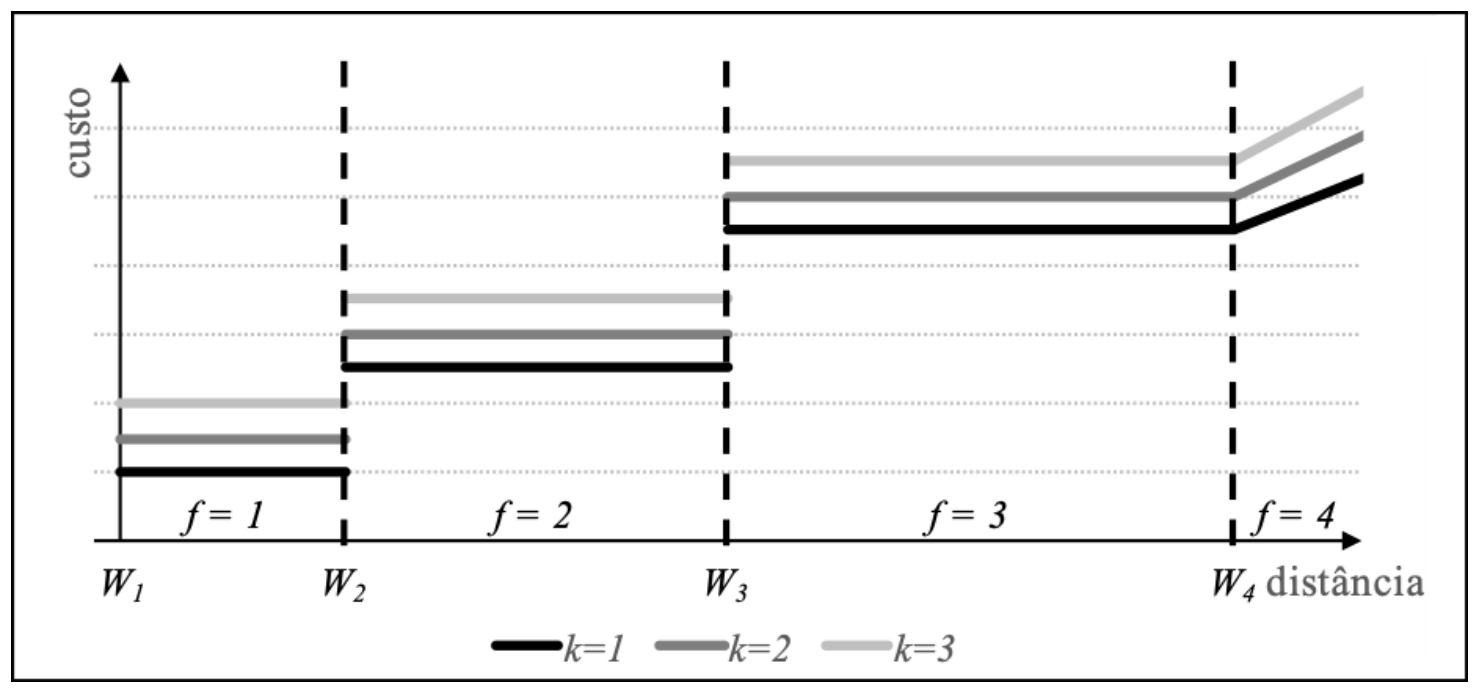

Figura 13: Representação gráfica do valor do custo de uma rota de acordo com as faixas de distância e o tipo de veículo.

mínima percorrida pelo veículo para que ele esteja naquela faixa de custo. Para cada combinação de faixa $f$ com tipo de veículo $k$, existe um custo $C_{k f}$ correspondente. Na última faixa, onde $f=F$, o custo se torna linear com a distância percorrida, iniciando-se no valor da penúltima faixa de custo escalonado. O custo de cada veículo, em função da distância percorrida, é dado por:

$$
C_{k}(d)= \begin{cases}C_{k f} & \text { se } d \leq W_{F} \\ C_{k F-1}+\left(d-W_{F}\right) C_{k F-1} & \text { se } d>W_{F}\end{cases}
$$

Essa forma de custo está ilustrada na Figura 13. Nesta figura é representada uma tabela de fretes com três tipos de veículos $k=1,2,3$, ou seja, $K=3$, e quatro faixas de distância $f=1,2,3,4$, ou seja, $K=4$.

Além das faixas de custo, existe uma faixa fictícia $f=0$. Ela é utilizada para veículos que não são alocados em nenhuma rota e, consequentemente, sua distância total percorrida é zero. Nesta faixa, para qualquer $k, C_{k 0}=0$.

\subsection{Modelo de Programação Linear Inteira Mista}

Nesta sessão, o modelo de programação linear inteira mista para o FSMVRPTWSC é apresentado e explicado linha a linha. Desde primeira vez que um modelo foi proposto para esse problema, em Manguino (2013), diversas melhorias foram geradas, inclusive parte delas já apresentadas em Ronconi e Manguino (2016). Esse modelo, entretanto, 
apresenta novas melhorias que são discutidas e justificadas na seção 5.3

\begin{tabular}{|c|c|}
\hline \multicolumn{2}{|c|}{ Índices } \\
\hline$p, i, j$ & clientes \\
\hline$k$ & tipos de veículos \\
\hline$v$ & veículos \\
\hline$f$ & faixas de distância \\
\hline \multicolumn{2}{|c|}{ Parâmetros: } \\
\hline$n$ & número total de clientes \\
\hline$K$ & número de tipos de veículos \\
\hline$F$ & quantidade de faixas de distância \\
\hline$t_{i j}$ & tempo de transito do cliente $i$ ao $j$ \\
\hline$d_{i j}$ & distância do cliente $i$ ao $j$ (ou depósito, quando $i=0$ ou $j=0$ ) \\
\hline$s_{i}$ & tempo de serviço no cliente $i$ \\
\hline$q_{i}$ & demanda do cliente $i$ \\
\hline$e_{i}$ & início da janela de tempo do cliente $i$ \\
\hline$\ell_{i}$ & fim da janela de tempo do cliente $i$ \\
\hline$a_{k}$ & capacidade do veículo do tipo $k$ \\
\hline$W_{f}$ & limite inferior da distância da faixa $f$ \\
\hline$C_{k f}$ & custo fixo do veículo do tipo $k$ na faixa $f$, onde $f \in\{0,1,2, \ldots, F-1\}$ \\
\hline$C_{k F}$ & custo variável do veículo do tipo $k$ na faixa de distância $F$ \\
\hline$V$ & número máximo possível de veículos (definido por $V=n$ ) \\
\hline$M_{d}$ & número positivo grande para restrições disjuntivas de faixas de distância \\
\hline$M_{t}$ & número positivo grande para restrições disjuntivas de janelas de tempo \\
\hline \multicolumn{2}{|c|}{ Variáveis: } \\
\hline$x_{i j}^{v}$ & assume valor 1 se o veículo $v$ percorre o arco $(i, j), 0$ caso contrário \\
\hline$z_{k f}^{v}$ & assume valor 1 se o veículo $v$ é do tipo $k$ e na faixa $f, 0$ caso contrário \\
\hline$b_{i}$ & início do serviço no cliente $i$ \\
\hline$D_{f}^{v}$ & distância total percorrida pelo veículo $v$ que está na faixa $f$ \\
\hline$P^{v}$ & custo final do veículo $v$ \\
\hline
\end{tabular}

Função Objetivo

$$
\operatorname{Minimize} \sum_{v=1}^{V} P^{v}
$$

sujeito a 


$$
\begin{aligned}
& \sum_{j=0}^{n} x_{0 j}^{v} \leq 1 \quad v=1, \ldots, V, \\
& \sum_{i=0}^{n} x_{i p}^{v}-\sum_{j=0}^{n} x_{p j}^{v}=0 \quad v=1, \ldots, V, p=0, \ldots, n \\
& \sum_{v=1}^{V} \sum_{i=0}^{n} x_{i j}^{v}=1 \quad j=1, \ldots, n \\
& \sum_{i=0}^{n} \sum_{j=1}^{n} q_{j} x_{i j}^{v} \leq \sum_{f=0}^{F} \sum_{k=1}^{K} a_{k} z_{k f}^{v} \quad v=1, \ldots, V \\
& b_{i}+s_{i}+t_{i j}-M_{t}\left(1-\sum_{v=1}^{V} x_{i j}^{v}\right) \leq b_{j} \quad i=1, \ldots, n, j=1, \ldots, n \\
& e_{i} \leq b_{i} \leq \ell_{i} \quad i=1, \ldots, n \\
& b_{i}-t_{0 i}+M_{t}\left(1-\sum_{v=1}^{V} x_{0 i}^{v}\right) \geq e_{0} \quad i, \ldots, n \\
& b_{i}+s_{i}+t_{i 0}-M_{t}\left(1-\sum_{v=1}^{V} x_{i 0}^{v}\right) \leq \ell_{0} \quad i=1, \ldots, n \\
& \sum_{f=1}^{F} D_{f}^{v}=\sum_{i=0}^{n} \sum_{j=0}^{n} x_{i j}^{v} d_{i j} \quad v=1, \ldots, V \\
& \sum_{k=1}^{K} \sum_{f=0}^{F} z_{k f}^{v}=1 \quad v=1, \ldots, V \\
& \sum_{k=1}^{K} z_{k 0}^{v}+\sum_{j=0}^{n} x_{0 j}^{v}=1 \quad v=1, \ldots, V \\
& D_{f}^{v} \leq W_{f+1} \sum_{k=1}^{K} z_{k f}^{v} \quad v=1, \ldots, V, f=1, \ldots, F-1 \\
& D_{F}^{v} \leq M_{d} \sum_{k=1}^{K} z_{k F}^{v} \quad v=1, \ldots, V \\
& D_{F}^{v} \geq W_{F} \sum_{k=1}^{K} z_{k F}^{v} \quad v=1, \ldots, V \\
& P^{v} \geq \sum_{k=1}^{K} \sum_{f=0}^{F-1} z_{k f}^{v} C_{k f} \quad v=1, \ldots, V \\
& P^{v} \geq z_{k F}^{v} C_{k, F-1}+C_{k F}\left(D_{F}^{v}-W_{F}\right) \quad v=1, \ldots, V, k=1, \ldots, K
\end{aligned}
$$




$$
\begin{array}{rr}
D_{f}^{v} \geq 0 & v=1, \ldots, V, f=0, \ldots, F, \\
b_{i} \geq 0 & i=1, \ldots, n \\
P^{v} \geq 0 & v=1, \ldots, V \\
x_{i j}^{v} \in\{0,1\} & v=1, \ldots, V, i=0, \ldots, n, j=0, \ldots, n, \\
z_{k f}^{v} \in\{0,1\} & v=1, \ldots, V, k=1, \ldots, K, f=0, \ldots, F .
\end{array}
$$

A seguir, o modelo é explicado linha a linha.

A função objetivo (5.1) minimiza a soma dos custos de todos os veículos. Cada veículo $v$ recebe, segundo as restrições (5.16) e (5.17), explicadas a seguir, um custo $P^{v}$. O custo total do problema é a soma destes custos.

O conjunto de restrições (5.2), (5.3) e (5.4) é de conservação de fluxo no sistema, ou seja, garante que as rotas tenham seu sequenciamento feito de forma correta, com início e fim sempre no armazém, passando por todos os clientes exatamente uma vez e de forma contínua.

O conjunto (5.2) determina que todos os veículos devem sair do armazém para o primeiro ponto visitado em sua rota. As restrições (5.3), por sua vez, determinam que, se um veículo $v$ chega a um cliente $p$ qualquer, ele deve sair em seguida. As restrições (5.4) garantem que cada cliente será atendido por exatamente um veículo. Desta forma, o modelo garante que todos os clientes serão atendidos e, ao mesmo tempo, que somente um veículo irá atender àquele cliente, o que impede atendimento fracionado.

Esse conjunto de restrições forma as condições que garantem que cada veículo inicie e encerre a sua rota sempre no armazém, uma vez que, devido às restrições (5.2), todo rota se inicia no armazém, e com as restrições (5.3) se o veículo saiu do armazém ele deve entrar nele em alguma momento. Ou seja, para cada rota existente, sempre existe um arco $x_{0 j}^{v}=1$, onde $j$ é o primeiro cliente a ser visitado na rota. Nas restrições 5.3 , quando $p=0, \sum_{i=0}^{n} x_{i 0}^{v}-\sum_{j=0}^{n} x_{0 j}^{v}=0$, portanto, como existe o arco $x_{0 j}^{v}=1$, é obrigatório que exista o $\operatorname{arco} x_{i 0}^{v}=1$, sendo $i$ o último cliente da rota executada por $v$. É relevante notar que as restrições (5.4) não incidem sobre $j=0$, portanto não existe qualquer restrição ao número de veículos retornando ao armazém.

As restrições (5.5) garantem o respeito à limitação de capacidade de cada veículo. Quando o cliente $i$ é atendido pelo veículo $v$, a variável binária $x_{i j}^{v}$ recebe valor 1. Assim, a multiplicação $q_{i} x_{i j}^{v}$ resultará no valor da demanda $q_{i}$ do cliente $i$ somente para o veículo $v$ que atender este cliente. A soma de todos os clientes atendidos 
pelo veículo $v$ deve ser inferior ou igual à capacidade deste tipo de veículo. A capacidade é determinada pelo parâmetro $a_{k}$ associado à variável $z_{k f}^{v}$ que, por sua vez, determina o tipo de veículo a qual pertence v. Estas restrições, juntamente com as restrições (5.10, 5.11 e 5.12, detalhadas a seguir, determinam o valor de $z_{k f}^{v}$.

O conjunto de restrições (5.6), (5.7), (5.8) e (5.9) atendem às restrições de janelas de tempo do problema.

As restrições (5.6) determinam que o início do atendimento em um cliente só acontece após o fim do atendimento no cliente anterior, somado ao tempo de translado entre os dois. Assim, o início do atendimento do veículo $v$ no cliente $j$, que acontece no instante $b_{j}$, somente pode acontecer a partir do instante de início do atendimento no cliente $i$, o antecessor na rota do veículo $v$, adicionado do tempo de atendimento $s_{i}$ e o tempo de translado entre $i$ e $j$, determinado por $t_{i j}$.

Mesmo assim, não necessariamente o início do atendimento em $j$ será exatamente após a soma desses tempos, pois é possível que esta soma resulte em um instante anterior ao seu início da janela de tempo $\left(e_{j}\right)$. Neste caso, o veículo deve aguardar a abertura da janela para iniciar o atendimento. Caso a soma calculada anteriormente resulte em um instante após o fim da janela $\left(\ell_{j}\right)$, o atendimento será impossível e, assim, essa sequência da rota é infactível. Estas duas condições de atendimento à janela de tempo do cliente são garantidas pelas restrições (5.7). Ou seja, o início de atendimento no cliente $i$, determinado pela variável $b_{i}$, deve estar dentro dos limites da sua janela de tempo, dados por $e_{i}$ e $\ell_{i}$.

Devido às restrições (5.6) não é necessária a existência de restrições que evitem a formação de sub-rotas. Isso se deve à necessidade de que o instante de chegada num ponto seja depois da saída do outro. Assim é impossível que uma sub-rota aconteça, pois ao se fechar o subciclo, o instante de chegada do veículo a um ponto será superior ao instante de saída e, dado que $s_{i}$ e $t_{i j}$ são sempre valores positivos, isso é impedido pelas restrições (5.6).

As restrições (5.8) e (5.9) têm funcionamento similar ao do conjunto de restrições (5.7), porém existem especificamente para garantir o atendimento das janelas de tempo do armazém. Assim como os clientes, o armazém possui janelas de tempo de funcionamento, porém todos os veículos passam por este e não apenas um único como acontece para os clientes. Desta forma, uma variável $b_{0}$ não pode ser utilizada. O controle do instante de partida e retorno de cada veículo é feito pelas restrições (5.8) e (5.9), respectivamente. Para garantir que o veículo saia do armazém depois de $e_{0}$, determina-se que o início do primeiro cliente aconteça num instante maior que o início da janela de tempo do armazém 
somado ao tempo de trânsito entre o armazém e este cliente. O retorno, portanto, é determinado a partir do instante de início de atendimento do último cliente da rota somado com o tempo de serviço neste cliente e o tempo de trânsito de volta ao armazém.

A determinação da faixa de distância da rota é feita pelo conjunto de restrições (5.10), 5.11), 5.12), 5.13), 5.14) e (5.15). A variável que de fato determina qual a faixa de distância da rota é a variável $z_{k f}^{v}$, portanto todo o conjunto tem como objetivo garantir que esta variável terá valor 1 somente para a faixa correta. O fato de que essa variável terá valor 1 para apenas uma combinação de faixas de distância e tipo de veículos para cada rota é garantido pelas restrições (5.11).

A restrição (5.12) garante que veículos que não desempenham nenhuma rota, portanto não saem nunca do armazém, terão valor 1 somente em $z_{k 0}^{v}$, que não gera qualquer custo para o problema. Como o veículo parte do armazém para qualquer outro ponto do problema, $\sum_{j=0}^{n} x_{0 j}^{v}=1 \mathrm{e}$, portanto $z_{k 0}^{v}=0$. Entretanto o veículo que não sai do armazém, tem $\sum_{j=0}^{n} x_{0 j}^{v}=0$ e, assim, $z_{k 0}^{v}=1$ e os demais $z_{k f}^{v}$ todos têm valor 0 , garantindo que esse veículo não gerará qualquer custo ao problema.

Para todos os veículos que desempenham rotas, as restrições (5.10 determinam a distância total da rota, porém já alocando-a em uma variável de distância vinculada à faixa de distância. Essa estratégia tem como objetivo que a determinação de $z_{k f}^{v}$ evitando o uso de restrições disjuntivas. As restrições (5.13) garantem que a alocação da distância total na variável de distância de uma faixa tenha no máximo o valor do seu limite superior ou zero. Como a última faixa $F$ não possui limitante superior, mas ainda assim é necessário garantir que quando $z_{k F}^{v}=0$ isso force que $D_{F}^{v}=0$, existem as restrições (5.15). O valor de $M_{d}$, portanto deve ser maior que a maior distância possível de uma rota no problema.

O motivo de se restringir apenas um limitante superior e não um inferior, é que a solução do modelo vai naturalmente buscar alocar a distância na correspondente à menor faixa possível, uma vez que isso gera um custo menor à solução.

A exceção é a última faixa, pois como seu cálculo se dá de forma variável, a cada unidade de distância reduzida da distância o seu custo diminui, portanto atribuir a ela uma distância muito pequena reduz o custo e, assim, é necessário um limitante inferior para essa faixa e para que $z_{k F}^{v}=1$ somente ocorra quando a distância for superior ao seu limitante inferior, $W_{F}$. Este é o papel exercido pelas restrições 5.15).

Finalmente, o custo do veículo é determinado pelo conjunto de restrições (5.16) e 5.17). As primeiras geram o preço do custo fixo quando a rota está em faixas de distância em que $f<F$. A última é específica para o cálculo da última faixa de distância. É 
interessante notar que ambas determinam um limitante inferior ao $P^{v}$, e não determinam o valor diretamente. Como já afirmado, o problema é de minimização de custo, então determinar o limitante inferior de $P^{v}$, na prática, já esta determinando o valor de $P^{v}$.

As restrições (5.18), 5.21) e (5.22) garantem o domínio das variáveis.

\subsection{Melhorias no Modelo}

Nessa seção são detalhadas as contribuições deste trabalho no modelo. Foram duas principais frentes, uma na simplificação das janelas de tempo e outra na determinação da faixa de distância de cada rota. Outros modelos foram propostos para o FSMVRPTWSC, em Manguino e Ronconi (2012), Manguino (2013) e Ronconi e Manguino(2016). O modelo deste trabalho apresenta duas principais melhorias, explicadas a seguir.

\subsubsection{Simplificação das Restrições de Janelas de Tempo}

Em Manguino e Ronconi (2012) e Manguino (2013), a variável de início de atendimento do cliente além da dimensão de cliente, também tem a dimensão de veículos. Ou seja, no lugar de $b_{i}$, ela se torna $b_{i}^{v}$. O motivo dessa escolha é justamente facilitar a combinação entre as variáveis de decisão de fluxo $x_{i j}^{v}$ e as de tempo, $b_{i}^{v}$.

O motivo do uso da variável $b_{i}$ é que apenas um veículo atenderá cada cliente e, assim, caso se utilize $b_{i}^{v}$ somente uma das $V$ variáveis de início de atendimento por cliente terá valor relevante, as demais ficam soltas, sem qualquer significado para a solução. Outro motivo para a troca é o aumento número de variáveis do problema. Enquanto existem $n$ variáveis $b_{i}$, existem $n \times V$ variáveis $b_{i}^{v}$.

Esse aumento de dimensão em uma variável também propaga para o número de restrições do problema. As restrições de respeito a janelas de tempo (5.6), (5.7), (5.8) e (5.9), também devem ser para todo $v=1, \ldots, n$, aumentando o número de restrições do problema.

Em resumo, a melhora que isso causa pode ser sumarizada da seguinte forma:

- Número de variáveis:

$$
\begin{aligned}
& b_{i}^{v} \operatorname{com} v=1, \ldots, V \text { e } i=0, \ldots, n \text { resulta em } V(n+1) \text { variáveis } \\
& b_{i} \operatorname{com} i=1, \ldots, n \text { resulta em } n
\end{aligned}
$$


- Número de restrições:

Para garantir o bom funcionamento do modelo com a variável $b_{i}^{v}$, as restrições de janelas de tempo se somam em $V\left(n^{2}+3 n+1\right)$

Com a variável $b_{i}$, as restrições de janelas de tempo são um total de $n^{2}+3 n$

\subsubsection{Introdução de Variáveis de Distância Percorrida por Faixa}

Outra alteração da formulação proposta em relação às apresentadas em Manguino e Ronconi (2012) e Manguino (2013) é dividir a variável de distância total percorrida $\left(D^{v}\right)$ por veículo em varáveis de distância total atribuídas às faixas de distância correspondentes a essa distância, ou seja, $D_{f}^{v}$ para cada veículo em cada faixa de distância. A estratégia é que, para cada veículo, somente a variável $D_{f}^{v}$ da faixa de distância correspondente tenha valor diferente de zero e todas as outras faixas recebem zero. Dessa forma é possível simplificar a atribuição de $z_{k f}^{v}$, evitando o uso de restrições disjuntivas e, portanto, eliminando o uso do parâmetro big- $M$.

Nas formulações anteriores a este trabalho, a determinação da faixa de distância se dava da seguinte forma:

$$
D^{v}-W_{y} \leq M \sum_{k=1}^{K} \sum_{f=y}^{F} z_{k f}^{v}, v=1, \ldots, V ; y=1, \ldots, F .
$$

para as faixas de distância $f=1, \ldots, F-1$. Nesse caso, a restrição determinar a faixa mínima na qual a distância percorrida pelo veículo deve estar. A exceção é a última faixa que necessita de uma restrição específica para garantir seu funcionamento:

$$
-\left(D^{v}-W_{F}\right) \leq M\left(1-\sum_{k=1}^{K} z_{k F}^{v}\right), v=1, \ldots, V
$$

Sem a utilização do parâmetro $M$ nas restrições de faixas de distância existe um ganho de desempenho na execução do modelo. Além disso, o valor de $M$ pode ser calculado para atender precisamente as restrições de janelas de tempo, também contribuindo para aumentar ainda mais a eficiência da execução da otimização. Ronconi e Birgin (2012) e Jr, Tseng e Gupta (2005) destacam que softwares comerciais de otimização, como o CPLEX, podem apresentar desempenhos diferentes para valores de $M$ diferentes e, portanto, este parâmetro deve ser cuidadosamente calculado.

E resumo, a alteração realizada com essa alteração nas variáveis de distância gera os seguintes impactos: 
- Número de variáveis:

Formulação com $D^{v}$ geram $V$ variáveis de distância;

Formulação com $D_{f}^{v}$ geram $V F$ variáveis;

Um aumento de variável causado pela adição da dimensão de faixa na variável de distância é indesejável. Felizmente, $F$ costuma ter dimensão consideravelmente menor que $V$, sendo que nas Instâncias de Referência, este tem tamanho 100 e aquele no máximo 6.

- Número de restrições:

Formulação com $D^{v}$, com as restrições que determinam a faixa de distância soma $V(K+F+4)$;

Formulação com $D_{f}^{v}$, com as restrições que determinam a faixa de distância soma $V(K+F+5)$;

Apesar das diferentes abordagens, o número de restrições pouco se altera com apenas $V$ restrições a mais, mesmo com a quantidade maior de variáveis.

- Parâmetro $M_{d}$ :

Formulação com $D^{v}$ : O valor de $M_{d}$ deve ser calculado por $M_{d}=C_{K F}-1+$ $C_{K F} \sum_{i=0}^{n} \sum_{j=0}^{n} \times d_{i j} / 2$ e está presente em $V(1+F+K)$ restrições de faixas de distância;

Formulação com $D_{f}^{v}$ : O valor de $M_{d}$ deve ser calculado por $M_{d}=\sum_{i=0}^{n} \sum_{j=0}^{n} \times d_{i j} / 2$ e está presente em apenas $V$ restrições de faixas de distância;

Ou seja, a mudança que resultou no modelo apresentado neste trabalho permitiu que as faixas de distância fossem determinadas com uma quantidade inferior de restrições com $M_{d}$, sendo esse parâmetro com uma dimensão menor.

\subsection{Experimentos Numéricos}

Os testes computacionais foram realizados com um computador Intel Core i5-2520M 2,5GHz, com 3,41GB de memória RAM e resolvidos pelo software CPLEX 12.5 com interface OPL. Os testes foram conduzidos sob o limite de tempo computacional de 2 horas (7200 segundos) e nas configurações padrões do software. 


\begin{tabular}{|c|c|c|}
\hline & Modelo de Manguino $(\overline{2013})$ & Modelo Proposto \\
\hline Soluções ótimas enc & $38(52,8 \%)$ & $42(58,3 \%)$ \\
\hline GAP Médio & $23,3 \%$ & $17,3 \%$ \\
\hline
\end{tabular}

Tabela 5: Comparativo de resultados obtidos entre os modelos matemáticos para o FSMVRPTWSC

Foram testadas as 72 instâncias de dimensões menores, descritas na Seção 4.2 e os resultados são apresentados na Tabela 5. A relação completa de resultados obtidos com as pequenas instâncias de referência está disponível no Anexo B.2 deste trabalho.

A diferença de desempenho entre os dois modelos mostra o benefício das adaptações realizadas, que geraram redução no número de variáveis e restrições, bem como diminuição na dimensão do $M$ e número de restrições em que ele está presente. Ronconi e Birgin (2012) e Jr, Tseng e Gupta (2005) destacam que softwares comerciais de otimização, como o CPLEX, podem apresentar desempenhos diferentes para valores de $M$ diferentes e, portanto, este parâmetro deve ser cuidadosamente calculado, o que reafirma a conclusão do benefício da redução de sua utilização e dimensão. 


\section{HEURÍSTICAS CONSTRUTIVAS}

Neste capítulo são apresentadas as heurísticas construtivas desenvolvidas para solucionar o FSMVRPTWSC. Os métodos propostos são construtivos de inserção sequenciais, já amplamente utilizados na literatura em problemas de roteamento de veículos.

A inserção sequencial foi apresentada originalmente por Solomon (1987) para VRPTW e, desde então, foi aplicada com sucesso para diversas variações do VRP em diversas publicações por sua grande flexibilidade de utilização com diferentes critérios para seleção de qual cliente inserir a cada rodada. Por exemplo, Dullaert et al. (2002) aplicaram este método para o FSMVRPTW ao adicionar aos critérios de inserção, diferentes formas de avaliar o custo fixo dos veículos que executam as rotas. Já Kritikos e Ioannou (2013) adaptaram método para o caso do FSMVRPTW em que se é permitido sobrepeso nos veículos, ou seja, a carga pode ultrapassar a capacidade máxima do veículo a um custo extra. Em outro caso particular, Belfiore e Yoshizaki (2009) investigam um caso real de roteamento de veículos com entregas parceladas, ou seja, mais de um veículo pode atender o mesmo cliente.

A organização da apresentação dos métodos se dá da seguinte forma. Primeiro são apresentadas as características gerais da inserção sequencial (Seção 6.1) e, em seguida, as caraterísticas específicas das heurísticas cada uma é detalhada (Seção 6.2). Finalmente, os testes numéricos são executados na Seção 6.3 primeiro para calibrar parâmetros dos métodos (Seção 6.3.1) e, em seguida (Seção 6.3.2), avaliar a efetividade dos mesmos são discutidos.

\subsection{Características Gerais}

A heurística de inserção sequencial se inicia pela criação de uma rota exclusiva com um cliente. A escolha desse cliente pode ser feita de diversas formas. Neste trabalho, a rota é iniciada com o cliente mais distante do armazém. Após o início de uma rota, todos os clientes não roteados são avaliados para a inserção nessa rota. A avaliação passa 
por calcular o impacto negativo da inserção - como aumento de custos da rota, distância percorrida, etc. - e esse é comparado com os impactos negativos de gerar uma rota exclusiva para o cliente sendo avaliado.

Caso o resultado se mostre favorável e todas as restrições sejam respeitadas, a inserção é feita. O processo se repete até que não haja mais clientes não roteados cuja inserção seja benéfica com os critérios citados. Quando não existem mais inserções benéficas, uma nova rota é criada ou, se não houver mais clientes não roteados, o procedimento é encerrado.

O cálculo do impacto negativo da inserção do cliente na rota é denominado critério C1 e abrange fatores como a diferença de distância percorrida, o tempo de serviço na rota, custo de frete e ocupação do veículo. O cálculo do benefício de não ter de criar uma rota exclusiva para o cliente sendo avaliado é denominado C2 e carrega as mesmas características de C1. Diferentes definições de C1 e C2 são o que diferencia as duas heurísticas propostas entre si.

O procedimento pode ser descrito em quatro passos:

1. Inicialização de rota: Selecione o cliente não roteado mais distante do depósito e crie uma rota exclusiva para ele. Se todos os clientes já foram roteados, encerre o procedimento.

2. Lista de candidatos: Faça uma lista de clientes candidatos para adição à rota. É candidato um cliente não roteado cuja demanda, quando somada à da rota, resulte em valor inferior à capacidade do maior veículo disponível. Se a lista possuir ao menos um cliente candidato, siga para o Passo 3. Caso contrário, retorne ao Passo 1.

3. Cálculo critérios: Para cada cliente da lista de candidatos, calcule os critérios C1 e C2 e registre a correspondente melhor posição para inserção na rota e o valor final de C2. Caso a inserção seja impossível devido às restrições de janelas de tempo, exclua-o da lista de candidatos. Caso seja factível, escolha o cliente com maior valor positivo de C2 e siga para o passo 4, caso não haja nenhum C2 positivo, retorne ao Passo 1.

4. Inserção: Insira na rota o cliente selecionado no passo 3 na posição determinada. Retorne ao passo 2.

Como mostrado no passo a passo, os critérios C1 e C2 são decisivos ao se avaliar as características do problema e os impactos da inserção de cada cliente naquela rota. A 


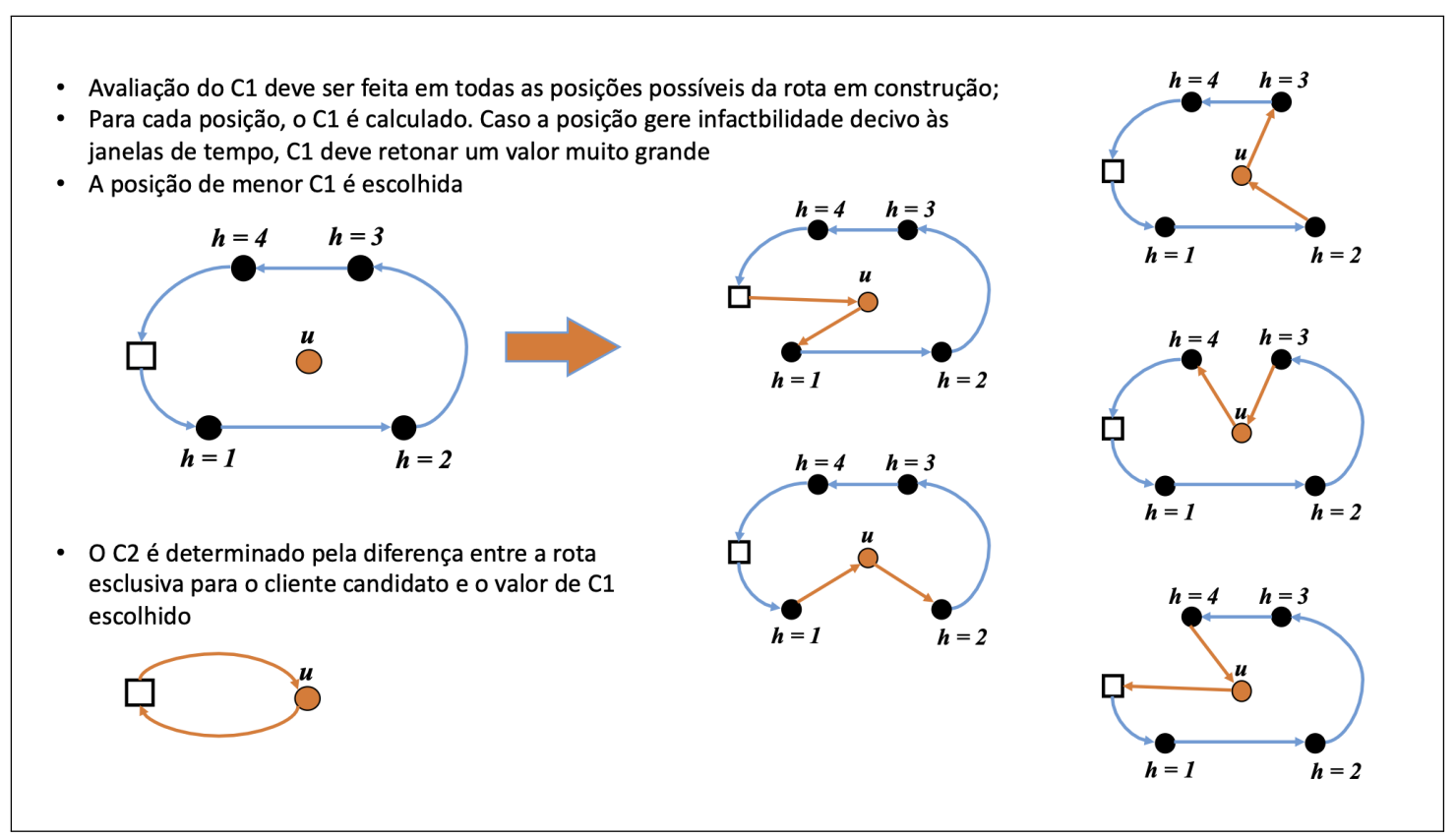

Figura 14: Ilustração de C1 e C2

figura 14 ilustra como C1 e C2 são avaliados na inserção de um cliente candidato $u$ na rota em construção.

C1 tem como principal característica avaliar o quanto a inserção de um cliente na rota pode piorar a solução, ou seja, o impacto negativo da inserção. Ao avaliar este critério para cada cliente não roteado para ser inserido na rota, é desejável encontrar a posição de inserção que gera o menor valor possível. Portanto, C1 deve ser calculado para todas as possíveis posições de inserção na rota para buscar a que gere o menor impacto.

Enquanto o cálculo é feito, deve ser verificado se a inserção do cliente naquela posição faz com que o início do seu atendimento, bem como o dos demais clientes na rota não ocorra após o fim da sua janela de tempo. A inserção de um cliente em uma posição faz com que todos os subsequentes tenham que ser atendidos em algum momento mais tarde que antes da inserção, a não ser que existia uma espera grande antes do atendimento do cliente, o suficiente que pode absorver o tempo adicional necessário para atender o cliente sendo inserido.

A avaliação do critério $\mathrm{C} 1$, portanto, tem três aspectos relevantes: o cálculo deste fator, a verificação da viabilidade da inserção frente às janelas de tempo dos clientes que já estão na rota e a determinação da melhor posição para inserção de cada cliente na rota sendo avaliada.

C2, por sua vez, tem o objetivo de comparar o impacto de adicionar o cliente na 
posição da rota que gera o menor C1 com o benefício de deixar de atender esse cliente em uma rota exclusiva. O impacto de gerar uma rota exclusiva do cliente com o depósito é avaliado de forma semelhante a C1, para manter coerência entre os critérios.

Os dois critérios podem ser compostos por diversos elementos, como foi feito na literatura em métodos de inserções sequenciais onde foram aplicados. Para o as duas heurísticas que são apresentadas nesse trabalho, levamos em conta os impactos nas seguintes características do problema:

- Custo: Se a inserção de um cliente causar mudança de tipo de veículo ou de faixa de distância, isso leva a um impacto no custo e pode ser avaliado;

- Distância: A inserção do cliente na rota faz com que ela aumente a distância total percorrida. Embora a distância não seja diretamente impactante na função objetivo, um aumento nessa dimensão pode causar uma mudança de faixa de distância e aumentar o custo da rota. Mesmo que não haja a mudança de faixa, diminuir o espaço até a próxima faixa diminui a oportunidade de inserir futuros clientes na rota sem aumento de faixa de distância;

- Tempo: Embora não tenha qualquer relação direta com a função objetivo e não consiga causar variação de custo, um aumento de tempo no atendimento dos clientes da rota, causado pela inserção do cliente na rota, tanto pelo tempo em trânsito, como em serviço ou até tendo que esperar a abertura da janela de tempo no cliente, pode tornar a rota com menos margem para novas inserções, fazendo com que beire a infactibilidade;

- Ocupação: O aumento de demanda causada pelo atendimento de um cliente a mais, pode fazer com que seja necessário mudar o tipo de veículo da rota para um de maior capacidade. Da mesma forma que para a distância, mesmo que não seja necessário alterar o tipo de veículo, ainda existe o impacto de diminuir a oportunidade de atender mais clientes nessa mesma rota sem a necessidade de um veículo maior.

Todos esses aspectos são considerados em C1 e C2 e seu cálculo em cada uma das heurísticas propostas na próxima seção.

Como existem diferentes aspectos, alguns de maior e outros de menor relevância para a função objetivo ou conforme os objetivos da heurística proposta, além de que a dimensão de um elemento é muito diferente de outro, os valores de cada elemento são multiplicados por fatores com variação de 1,0 a 0,0. Para tornar a leitura mais fácil, os elementos de C1 são denominados $\alpha$ e os de $\mathrm{C} 2, \beta$. 
Os fatores $\alpha$ e $\beta$ de C1 e C2 não são constantes pré-determinaras para cada heurística, pelo contrário, eles podem ser determinados para cada instância sendo avaliada. Isso ocorre uma vez que as dimensões podem variar e características de um problema faz a importância de cada elemento mudar.

Um exemplo de aspecto que muda os fatores a serem utilizados é compatibilização de unidades de medidas. Cada dimensão tem diversas unidades de medida, por exemplo, distâncias podem ser medidas em metros, quilômetros, polegadas, milhas, jardas, etc., enquanto capacidade do veículo pode ser dada por quilograma, toneladas, libras ou até ser calculada por volume, em metros cúbicos ou litros. Se um problema está com unidades de distância em metros e capacidade de caminhões em metros cúbicos, os fatores $\alpha$ e $\beta$ são muito diferentes do que se a distância fosse medida em milhas e a capacidade do caminhão em quilogramas.

A relação entre cada elementos, mesmo que mantidas unidades padrão, também muda sua relevância conforme o cenário em que o problema está inserido. Veja, por exemplo, a distribuição de refrigerantes em um bairro central de uma cidade grande. A distância naquela região não varia mais que 5 quilômetros entre os clientes mais distantes entre si, mesmo assim o tempo de viagem não é tão curto e o peso das bebidas no veículo tem grande relevância. Contraste esse exemplo à distribuição de fertilizantes em propriedades agrícolas em uma área rural. Nesse cenário as menores distâncias entre clientes podem superar 20 quilômetros, mudando completamente a relação entre distância, tempo e capacidade do veículo do que no cenário urbano. Isso sem levar em conta, obviamente, que o tipo de veículo usado em um exemplo não pode ser o mesmo que em outro, por questões de regulamentação e segurança.

A seguir, detalhamos de forma mais específica os dois métodos de heurística gerados nesse trabalho para o FSMVRPTWSC.

\subsection{Heurísticas Propostas}

Nessa seção, são apresentadas as duas heurísticas construtivas propostas para o FSMVRPTWSC. Como mencionado anteriormente, ambos os métodos seguem o mesmo procedimento de inserção sequencial que é apresentado no pseudocódigo 1

O algoritmo mostra que o método parte dos dados da instância e gera resultados por métodos construtivos. Na linha 2, todos os clientes são marcados como não atendidos. A Etapa 1 do processo se inicia na linha 6 com a escolha do cliente mais distante para a 


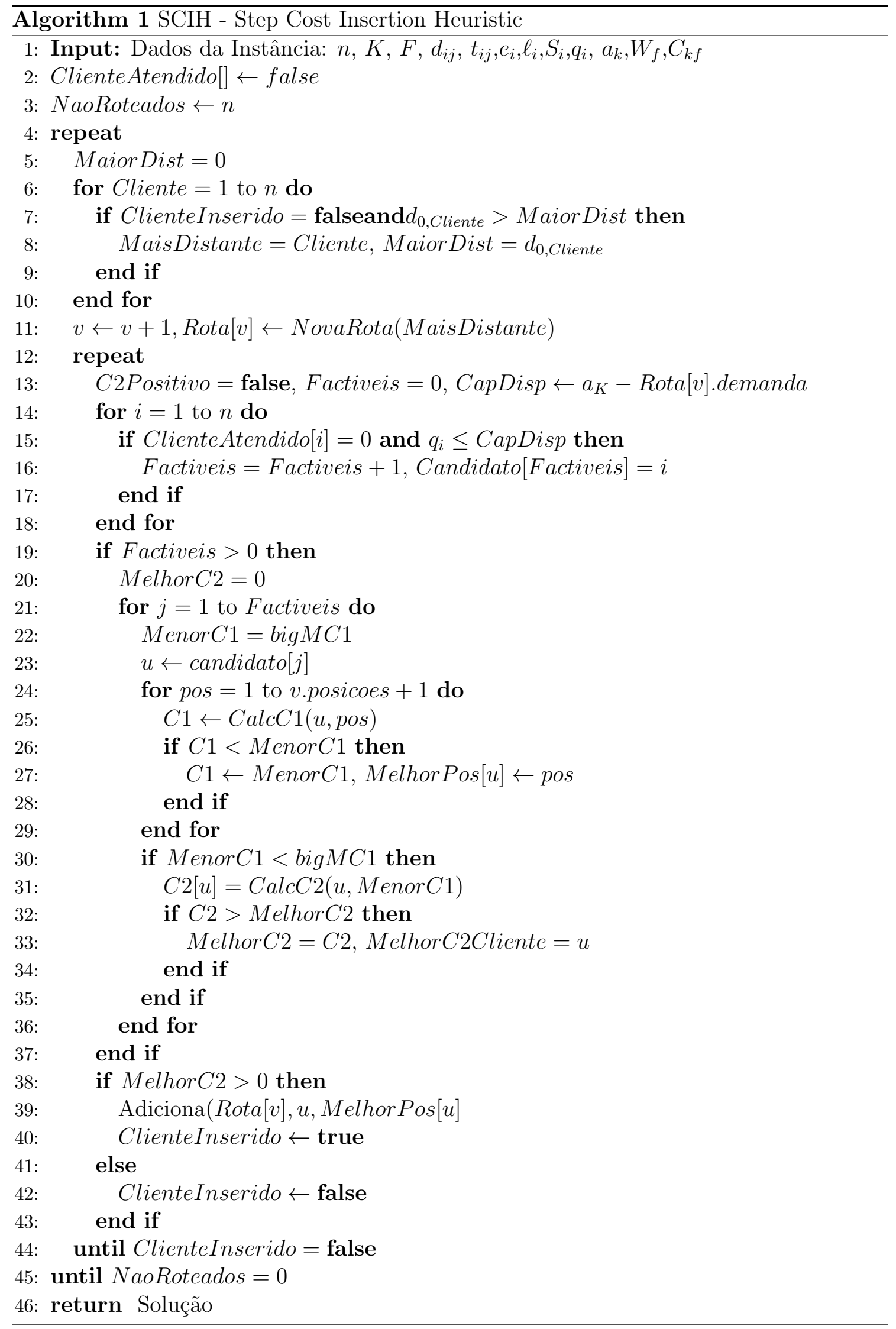


geração de uma nova rota $v$ na linha 11

A partir da nova rota, se inicia o processo de inserção (linha 12), com a Etapa 2, a avaliação de quais cliente são candidatos por terem demanda inferior à capacidade disponível no maior veículo, a partir da linha 14. Caso exista pelo menos um candidato, inicia-se a Etapa 3, a partir da linha 19 em que os candidatos são avaliados a partir do cálculo dos critérios $\mathrm{C} 1$ e $\mathrm{C} 2$. O critério $\mathrm{C} 1$ é calculado na função $C a l c C 1(u, p o s)$ na linha 25, dentro de uma busca por todas as posições possíveis da rota. A factibilidade da inserção é avaliada na linha 30, uma vez que caso a inserção viole restrições de janelas de tempo a função $\operatorname{CalcC} 1(u, p o s)$ retorna big $M C 1$.

Caso a inserção do cliente seja factível, o C2 é calculado na função CalcC2(u,MenorC1) na linha 31 para a melhor posição e, conforme os C2 dos diferentes clientes são calculados, o maior valor de C2 e seu respectivo cliente são armazenados. Caso o maior valor de $\mathrm{C} 2$ seja positivo, passamos à Etapa 4, em que esse cliente é inserido à rota na linha 39. Marca-se que houve uma inserção e por isso retornamos à Etapa 2. Caso contrário, retorna-se à Etapa 1 até que todos os clientes estejam roteados.

Nas seções a seguir estão detalhadas as duas heurísticas SCIH1 e SCIH2.

\subsubsection{Heurística 1}

A heurística Step Cost Insertion Heuristics 1 (SCIH1) tem como objetivo explorar diretamente as características do problema abordado, observando as mudanças necessárias na avaliação de custos escalonados frente ao que é feito tradicionalmente para custos lineares.

Isso fica evidenciado com a forma de abordar o impacto da variação na distância total da rota sendo avaliada. Diferentemente do que se faria em um problema em que o custo pela distância percorrida é linear, o impacto em distância só causa impacto à função objeto se houver uma mudança na faixa de distância da rota. Seguindo esse princípio, o impacto está na diminuição da oportunidade de adicionar clientes à rota sendo avaliada sem mudar a faixa de distância.

O princípio é similar ao apresentado por Golden et al. (1984) na avaliação de oportunidades no FSMVRP. Os métodos heurísticos de oportunidades se atentam ao potencial de adição de novos clientes a uma rota sem a troca do tipo de veículo por um maior. Assim, ao invés de avaliar apenas o aumento de custo por se utilizar um veículo maior, ou avaliar a redução de espaço no veículo devido a essa adição, existe uma bonificação pela 
capacidade ainda disponível no veículo após a adição de um cliente.

Os critérios C1 e C2 para essa heurística são denominados $C 1^{S 1}$ e $C 2^{S 1}$, respectivamente, e os quatro elementos que compõe o critério $C 1^{S 1}$ são $C 1_{1}^{S 1}, C 1_{2}^{S 1}, C 1_{3}^{S 1}$ e $C 1_{4}^{S 1}$. A seguir, é apresentado o critério $C 1^{S 1}$ com o detalhamento de cada um dos elementos que a compõe.

$$
C 1^{S 1}(u)=\min _{h=1, \ldots, m}\left\{-\alpha_{1} C 1_{1}^{S 1}(u, h)+\alpha_{2} C 1_{2}^{S 1}(u, h)+\alpha_{3} C 1_{3}^{S 1}(u, h)-\alpha_{4} C 1_{4}^{S 1}(u, h)\right\}
$$

onde:

$$
\begin{aligned}
& C 1_{1}^{S 1}(u, h)= \begin{cases}W_{f^{n e w}+1}-D^{\text {new }} & \text { se } f^{n e w}(u, h)<F \\
0 & \text { se } f^{n e w}(u, h)=F\end{cases} \\
& C 1_{2}^{S 1}(u, h)=b_{i h}^{\text {new }}-b_{i h} \\
& C 1_{3}^{S 1}(u, h)=P^{\text {new }}-P \\
& C 1_{4}^{S 1}(u, h)=a_{k}^{\text {new }}-Q^{\text {new }}
\end{aligned}
$$

onde $h$ é a posição na rota sendo avaliada, $m$ o número de posições da rota e $u$ é o cliente candidato a ser inserido na rota e as demais variáveis e parâmetros seguem a mesma notação da formulação matemática apresentada são Seção 5.2 .

O cálculo do critério $C 1^{S 1}$, para cada cliente candidato, é feito se obtendo o menor valor calculado em todas as posições da rota. As posições na rota variam de 1 a $m$, sendo 1 a posição logo depois do veículo sair do depósito e $m$ a última posição antes do regresso. Os elementos que compõe o critério são todos ponderados pelos fatores $\alpha_{1}, \alpha_{2}, \alpha_{3}$ e $\alpha_{4}$, positivos, cada um multiplicando o seu respectivo elemento, que devem ser calibrados conforme o exemplo que é resolvido.

O elemento $C 1_{1}^{S 1}$ tem o objetivo de capturar a oportunidade de inserção futura de mais clientes na rota sem a alteração na faixa de distância. Isso é avaliado considerando a diferença da nova distância da rota após a inserção do cliente $u\left(D^{n e w}\right)$ e a distância do início da próxima faixa $\left(W_{f+1}\right)$. A figura 15 ilustra como é obtido o valor de $C 1_{1}^{S 1}$. Como a última faixa $F$ não tem um limite final e nela o custo cresce linearmente com a distância, caso o problema atinja essa faixa após a inserção do cliente candidato, esse elemento deve ter valor zero, pois não haverá qualquer oportunidade a ser explorada.

É relevante notar que $C 1_{1}^{S 1}$ tem efeito benéfico para a inserção do cliente na rota, uma vez que quanto maior a oportunidade deixada por uma inserção, melhor para a rota. 


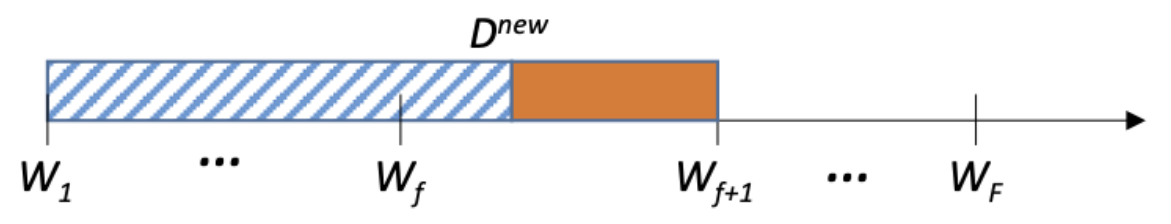

Distância da Rota após adicionar cliente candidato $u$ $\mathrm{C}^{\mathrm{S1}}{ }_{1}(\mathrm{u}, \mathrm{h})$

Figura 15: Gráfico ilustrativo do cálculo de $C 1_{1}^{S 1}$

Desta forma, ele é somado ao critério $C 1^{S 1}$ com sinal negativo, contribuindo para que $C 1^{S 1}$ seja menor quando $C 1_{1}^{S 1}$ for maior.

O segundo elemento de $C 1^{S 1}$ é $C 1_{2}^{S 1}$. Este elemento avalia o impacto em tempo na rota. A avaliação é o quanto a inserção do cliente u faz com que o cliente que ocupava a posição $h$, para a qual ele está sendo avaliado, tem o seu início de atendimento postergado, ou seja, a diferença do início de atendimento após a inserção $\left(b_{i_{h}}^{\text {new }}\right)$ e do início de atendimento sem a inserção $\left(b_{i_{h}}\right)$. Essa avaliação é feita somente com o cliente que ocupava a posição a ser avaliada justamente para explorar melhor tempos de espera disponíveis na rota. Se um cliente tem o início da janela de tempo num momento superior ao fim do atendimento no cliente anterior da rota somado ao tempo de trânsito entre eles, o veículo deve ficar ocioso esperando essa abertura. Esse tempo ocioso pode ser aproveitado com a inserção de um novo cliente na rota e é mais benéfico do que adiar o início do atendimento em um cliente que não gera espera na rota.

O terceiro elemento de $C 1^{S 1}$ é o $C 1_{3}^{S 1}$ que avalia a variação no custo total da rota de forma direta. Ele avalia a diferença do custo da rota após a inserção do cliente na rota $\left(P^{n e w}\right)$ e o custo antes da inserção $(P)$. É uma medida bem direta do impacto da inserção do cliente na rota e elemento fundamental para essa avaliação.

O quarto elemento de $C 1^{S 1}$, e contribuição deste trabalho ao problema, é o $C 1_{4}^{S 1}$. Esse elemento aborda o impacto da inserção do cliente na capacidade do veículo. O funcionamento desse elemento é algo semelhante ao que captura $C 1_{1}^{S 1}$ para a distância. A variação da demanda somente altera custo do problema caso seja necessário alterar o tipo de veículo para um maior. Enquanto for possível inserir clientes na rota que não causem essa troca de tipo de veículo, melhor para a função objetivo. Portanto, quanto mais a inserção de um cliente na rota deixar de capacidade disponível no tipo de veículo em uso, melhor. Isso é mensurado pela diferença entre a capacidade total do veículo usado após a 
inserção do cliente $\left(a_{k}^{n e w}\right)$ e a demanda total da rota com a inserção desse cliente $\left(Q^{\text {new }}\right)$.

Similarmente a $C 1_{1}^{S 1}, C 1_{4}^{S 1}$ gera um valor que quanto maior for, mais interessante é a inserção do cliente na rota e, portanto, menor deve ser o valor de $C 1^{S 1}$. Por isso, o valor de $C 1_{4}^{S 1}$ será subtraído de $C 1^{S 1}$.

O critério $C 2^{S 1}$ aborda os elementos do problema de forma semelhante à feita em $C 1^{S 1}$, e é calculado de forma a avaliar o benefício de evitar a rota de viagem exclusiva do depósito para o cliente candidato, comparado com o impacto negativo avaliado em $C 1^{S 1}$, conforme detalhado a seguir:

$$
C 2^{S 1}(u)=-\beta_{1} C 2_{1}^{S 1}(u)+\beta_{2} C 2_{2}^{S 1}(u)+\beta_{3} C 2_{3}^{S 1}(u)-\beta_{4} C 2_{4}^{S 1}(u)-C 1^{S 1}(u)
$$

onde:

$$
\begin{aligned}
& C 2_{1}^{S 1}(u)=\left\{\begin{array}{lr}
W_{f(0, u)+1}-d_{o u} & \text { se } f(0, u)<F \\
0 & \text { se } f(0, u)=F
\end{array}\right. \\
& C 2_{2}^{S 1}(u)=t_{0 u}+s_{u} \\
& C 2_{3}^{S 1}(u)=P(0, u) \\
& C 2_{4}^{S 1}(u)=a_{k}(u)-q_{u}
\end{aligned}
$$

os elementos que compõe o critério são todos ponderados pelos fatores $\beta_{1}, \beta_{2}, \beta_{3}$ e $\beta_{4}$, todos positivos, cada um multiplicando o seu respectivo elemento, que devem ser calibrados conforme o problema que é resolvido.

\subsubsection{Heurística 2}

A Step Cost Insertion Heuristics 2 (SCIH2) surgiu como uma evolução do método SCIH1. Esse método explora características do problema e considera, para cada candidato a ser inserido na rota, a oportunidade que sua inserção deixará para futuras inserções sem aumento de custos. Entretanto, esse problema não estuda os demais clientes não roteados para avaliar se, mesmo havendo oportunidades para futuras inserções, algum cliente poderá aproveitar essas oportunidades.

Essa situação de haver a oportunidade, mas não haver clientes disponíveis para utilizálas, pode ocorrer principalmente no fim do roteamento, quando não existem muitos clientes ainda disponíveis. Nesse momento, a rota sendo criada por estar indo em uma direção do depósito e os demais clientes disponíveis estarem na direção oposta do espaço. Neste 
caso, mesmo deixando uma boa distância disponível na faixa, ela nunca será suficiente para atravessar o mapa até os outros clientes disponíveis. Por isso, o elemento $C 1_{1}^{S 1}$ pode até gerar um valor que melhora a avaliação de $C 1^{S 1}$, mas na verdade está avaliando erroneamente, pois não existe oportunidade alguma.

O método SCIH2 busca justamente olhar para os demais clientes candidatos a serem inseridos na rota e verificar se algum pode ainda aproveitar as oportunidades deixadas após a inserção do cliente candidato e, para todos os clientes candidatos que puderem aproveitar a oportunidade, SCIH2 utiliza o maior atributo dos clientes candidatos que podem se beneficiar com essa oportunidade.

$$
C 1^{S 2}(u)=\min _{h \in H(u)}\left\{-\alpha_{1} C 1_{1}^{S 2}(u, h)+\alpha_{2} C 1_{2}^{S 2}(u, h)+\alpha_{3} C 1_{1,3}^{S 2}(u, h)-\alpha_{4} C 1_{1,4}^{S 2}(u, h)\right\},
$$

onde

$$
\begin{aligned}
C 1_{1}^{S 2}(u, h) & = \begin{cases}\max _{\left\{(j, y) \in Y_{1}\right\}}\left\{d_{i_{y}, j}+d_{j, i_{y+1}}-d_{i_{y}, i_{y+1}}\right\}, & \text { se } f^{\text {new }}(u, h)<F, \\
0, & \text { se } f^{\text {new }}(u, h)=F,\end{cases} \\
C 1_{2}^{S 2}(u, h)= & b_{i_{h}}^{\text {new }}(u, h)-b_{i_{h}} \\
C 1_{3}^{S 2}(u, h)=P^{\text {new }}-P & \max _{\left\{j \in Y_{2}\right\}}\left\{q_{j}\right\} \\
C 1_{4}^{S 2}(u, h)= & \begin{array}{l}
(j, y) \mid \begin{array}{l}
j \text { não roteado, } \\
y \in\{0, \ldots, m\}, \text { e } \\
d_{i_{y}, j}+d_{j, i_{y+1}}-d_{i_{y}, i_{y+1}} \leq W_{f^{\text {new }}(u, h)+1}-D^{\text {new }}(u, h)
\end{array} \\
Y_{2}=\left\{j \text { não roteado } \mid q_{j} \leq a_{k^{\text {new }}(u, h)}-Q^{\text {new }}(u)\right\} .
\end{array}
\end{aligned}
$$

onde $Y_{1}$ é o conjunto de arcos que ligam os clientes não atendidos aos clientes que estão na rota e os clientes na rota e cuja distância é inferior ao remanescente na faixa de distância na rota após a inserção do cliente candidato em cada posição da rota. $Y_{2}$ é similar ao $Y_{1}$, porém são os clientes com demanda inferior à capacidade remanescente no tipo de veículo utilizado na rota após a inserção o cliente candidato. Os demais parâmetros são os mesmos dos utilizados no SCIH1.

O elemento $C 1_{1}^{S 2}$, para avaliação da distância remanescente na faixa após a inserção do cliente sendo avaliado $(u)$, avalia a diferença em distância de futuras inserções de todos os demais clientes candidatos em todas as posições da rota sendo construída e avaliar qual a maior variação de distância inferior ou igual a essa distância remanescente na faixa. A Figura 16 oferece um exemplo ilustrativo de como essa avaliação é feita.

O objetivo é buscar avaliar uma verdadeira oportunidade do problema, e não apenas 


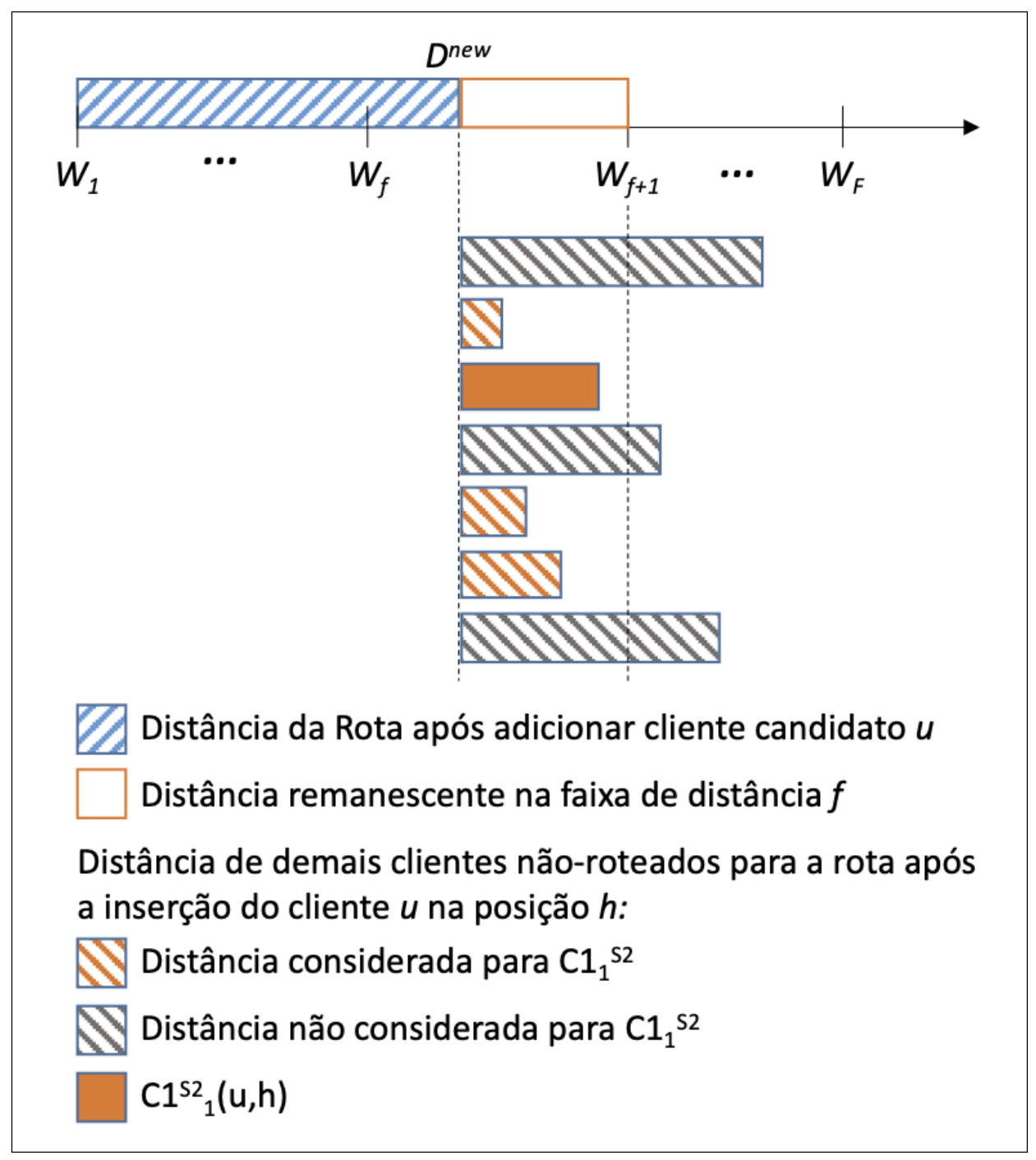

Figura 16: Gráfico ilustrativo do cálculo de $C 1_{1}^{S 2}$

a distância toda remanescente na faixa que pode não haver cliente para ser aproveitado dentro da oportunidade ou, ao menos, não em sua totalidade. É sabido que para essa inserção considerada como oportunidade ser de fato executada existem uma série de avaliações a serem feitas, inclusive de factibilidade de janelas de tempo e dos critérios $\mathrm{C} 1$ e C2 na próxima rodada de inserção, mas o objetivo da avaliação do $C 1_{1}^{S 2}$ é identificar oportunidades e não realizar um roteamento dentro do roteamento.Como a última faixa $F$ não tem um limite final e nela o custo cresce linearmente com a distância, caso o problema atinja essa faixa após a inserção do cliente candidato, esse elemento deve ter valor zero, pois não haverá qualquer oportunidade a ser explorada.

Similarmente, o elemento $C 1_{4}^{S 2}$, que avalia a oportunidade de capacidade remanescente no tipo de veículo após a inserção do cliente sendo avaliado $(u)$, irá buscar dentre os demais 
clientes candidatos qual a maior demanda $\left(q_{i}\right)$ que pode ser carregada na capacidade ainda disponível no tipo veículo após a inserção do cliente sendo avaliado.

Os elementos $C 1_{2}^{S 2}$ e $C 1_{3}^{S 2}$, por sua vez, se mantém iguais aos utilizados na heurística SCIH1. O critério $C 2^{S 2}$ mantém as mesmas características de $C 1^{S 2}$ para avaliar a rota exclusiva de atendimento ao cliente sendo avaliado. O critério é detalhado a seguir.

$$
C 2^{S 2}(u)=\left[-\beta_{1} C 2_{1}^{S 2}(u)+\beta_{2} C 2_{2}^{S 2}(u)+\beta_{3} C 2_{3}^{S 2}(u)-\beta_{4} C 2_{4}^{S 2}(u)\right]-\mathcal{C}_{1}^{S 2}(u),
$$

onde

$$
\begin{aligned}
C 2_{1}^{S 2}(u) & = \begin{cases}\max _{\left\{(j, y) \in Y_{3}\right\}}\left\{d_{i_{y}, j}+d_{j, i_{y+1}}-d_{i_{y}, i_{y+1}}\right\}, & \text { if } f(0, u)<F, \\
0, & \text { if } f(0, u)=F,\end{cases} \\
C 2_{2}^{S 2}(u) & =t_{0 u}+s_{u}, \\
C 2_{3}^{S 2}(u) & =P(0, u), \\
C 2_{4}^{S 2}(u) & =\max _{\left\{j \in Y_{2}\right\}}\left\{q_{j}\right\},
\end{aligned}
$$

and

$$
Y_{3}=\left\{(j, y) \mid j \text { não roteado, } y \in\{0,1\}, 2 d_{i_{y}, j}+d_{j, i_{y+1}}-d_{i_{y}, i_{y+1}} \leq W_{f_{(0, u)}+1}-d_{0, u}\right\} .
$$

onde $Y_{3}$ é o conjunto de arcos que ligam os clientes não atendidos ao cliente candidato, cuja distância é inferior à distância remanescente na faixa de distância da rota exclusiva. Os demais parâmetros são os mesmos dos utilizados no SCIH1.

\subsection{Experimentos Numéricos}

Testes numéricos foram realizados com as heurísticas construtivas. Tanto para calibrar os índices $\alpha$ e $\beta$ ultizados nos dois métodos, que são apresentados na Seção 6.3.1. como para avaliar seu desempenho nas diferentes instâncias propostas na Seção 6.3.2.

Os experimentos numéricos foram realizados com um computador Intel Core i5-2520M 2,5GHz, com 3,41GB de memória RAM e programados na linguagem $\mathrm{C}$ usando o editor Microsoft Visual Studio 2015. 


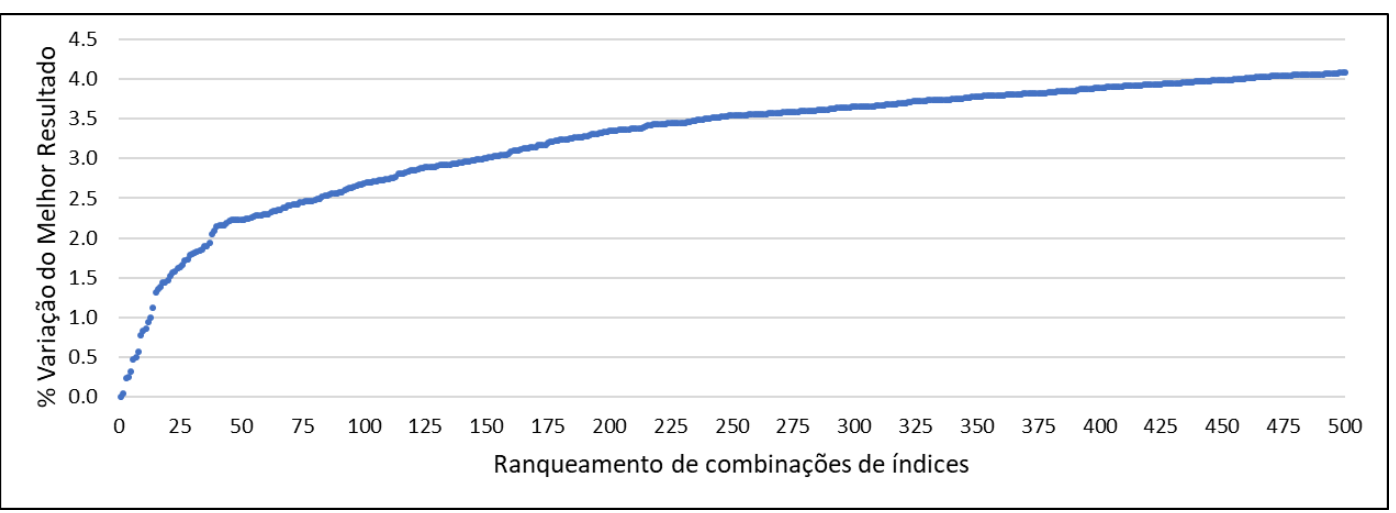

Figura 17: Ranking das melhores 500 combinações de índice $\alpha$ e $\beta$ na SCIH2, segundo o valor médio da função objetivo, em comparação ao melhor resultado obtido quando aplicadas à instâncias com distribuição espacial do tipo R.

\subsubsection{Calibração de Índices}

Cada heurística possui um grupo de fatores $\alpha$ e $\beta$ que multiplicam os elementos de $\mathrm{C} 1$ e $\mathrm{C} 2$, respectivamente, que deve ser determinado para cada problema com características comuns entre si. Devido a importância da distribuição espacial dos clientes na avaliação de cada índice, para determinar a melhor combinação de índices, os fatores foram calibrados para grupos de distribuição física similares, ou seja, para problemas do tipo R (distribuição aleatória no espaço), tipo C (clientes agrupados em pequenos grupos) e RC (parte dos clientes agrupados, outra parte distribuída aleatoriamente) foram resolvidos com índices específicos do grupo.

A calibração foi executada com as 54 Instâncias de Calibração, detalhadas na Seção 4.1.1. Essas instâncias foram executadas para todas as combinações de $\alpha_{1}, \alpha_{2}, \alpha_{3}, \alpha_{4}, \beta_{1}$, $\beta_{2}, \beta_{3}$ e $\beta_{4}$ variando de 0 a 1 , com passo de 0,1 . Ou seja, $\{0 ; 0,1 ; 0,2 ; \ldots ; 1,0\}$, resultando em $11^{8}$ rodadas para essas instâncias nas duas heurísticas propostas.

Apesar da grande velocidade de execução das heurísticas construtivas, em torno de 0,001 segundos, o tempo total de calibração passaria de 100 dias diretos. Portanto o trabalho foi feita com estratégia de primeiro avaliar com passos maiores, de 0,2 e, no entorno das melhores soluções, novas rodadas de passo 0,1 . foram executadas. Isso reduziu o esforço computacional e permitiu alcançar os valores de índices apresentados neste trabalho.

Os resultados obtidos para cada combinação foram comparados e os que tiveram menor média simples para cada grupo de distribuição física foram selecionados para os testes computacionais. 


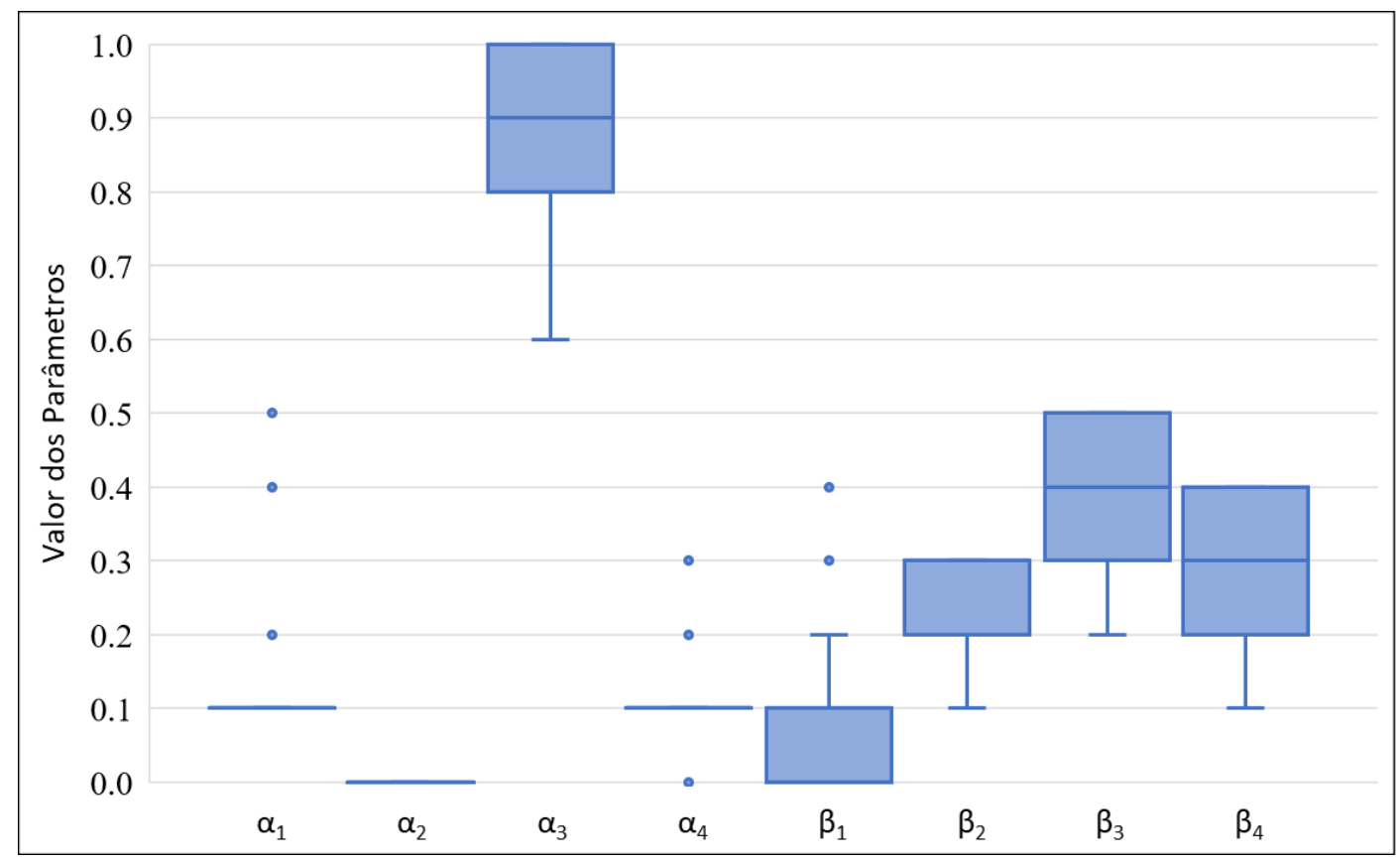

Figura 18: Box Plot dos parâmetros $\alpha$ e $\beta$ considerando as top 50 combinações no SCIH2 aplicadas a instâncias com distribuição espacial do tipo $\mathrm{R}$

\begin{tabular}{cccccccccc}
\hline Heurística & Grupos & $\alpha_{1}$ & $\alpha_{2}$ & $\alpha_{3}$ & $\alpha_{4}$ & $\beta_{1}$ & $\beta_{2}$ & $\beta_{3}$ & $\beta_{4}$ \\
\hline \multirow{3}{*}{ SCIH1 } & R1, R2 & 0.1 & 0.0 & 0.9 & 0.2 & 0.1 & 0.0 & 0.5 & 0.1 \\
& C1, C2 & 0.4 & 0.0 & 0.9 & 0.1 & 0.0 & 0.1 & 0.3 & 0.1 \\
& RC1, RC2 & 0.2 & 0.0 & 1.0 & 0.1 & 0.0 & 0.3 & 0.1 & 0.1 \\
\hline \multirow{3}{*}{ SCIH2 } & R1, R2 & 0.1 & 0.0 & 0.9 & 0.1 & 0.0 & 0.2 & 0.5 & 0.4 \\
& C1, C2 & 0.4 & 0.0 & 1.0 & 0.1 & 0.0 & 0.1 & 0.2 & 0.3 \\
& RC1, RC2 & 0.2 & 0.0 & 1.0 & 0.1 & 0.1 & 0.3 & 0.3 & 0.2 \\
\hline
\end{tabular}

Tabela 6: Valores dos índices $\alpha_{1}, \alpha_{2}, \alpha_{3}, \alpha_{4}, \beta_{1}, \beta_{2}, \beta_{3}$, e $\beta_{4}$ para cada heurística e cenário

A Figura 17 apresenta a variação do resultado médio das 500 melhores combinações de índices em relação ao melhor resultado, com variações que passam de 4\%, para a heurística SCIH2 nas instâncias do tipo R.

A Figura 18, por sua vez, apresenta o Box-Plot da distribuição de $\alpha$ e $\beta$ para as melhores 50 combinações no SCIH2 para instâncias com distribuição do tipo R. A figura mostra que os parâmetros tem uma pequena variabilidade e estão concentrados no entorno do valor médio, com poucos ouliers (apresentados como pontos no gráfico). Conclusões análogas são possíveis de se obter para outros cenários e para a SCIH1.

O resultado da calibração, ou seja, os valores de $\alpha$ e $\beta$ que serão utilizados em todas as execuções de SCIH1 e SCIH2 pelo restante deste trabalho, estão apresentados na Tabela 6. 
Apesar do método de calibração bem claro e objetivo, chama a atenção que a calibração de $\alpha_{2}$ resulta em valor zero para os dois métodos e para todos os tipos de instância. Esse índice é o que avalia o impacto em janelas de tempo da inserção de um cliente na rota, uma característica tão importante para o problema surpreende ter sua contribuição nos critérios de inserção anulada. Para garantir que não foi algum erro de programação ou análise de dados, os resultados da calibração foram investigados e o valor de $\alpha_{2}$ é consistentemente igual a zero dentre as melhores combinações obtidas.

Com a confirmação do valor zero para esse índice, a interpretação matemática é que as janelas de tempo tem um impacto forte de outra forma, o de que elas podem, simplesmente, inviabilizar a inserção da rota. Então antes de ser um elemento na avaliação do impacto da inserção, as janelas de tempo decidem se a inserção é ou não factível e somente depois que o cálculo de C1 acontece, onde esse critério já foi avaliado e, portanto, não tem mais relevância comparado aos demais elementos.

\subsubsection{Resultados Obtidos}

Os métodos heurísticos propostos neste capítulo foram avaliados nas instâncias explicadas no Capítulo 4. Para cada grupo diferentes comparações foram executas, uma vez que não existem resultados de referência na literatura.

\subsubsection{Instâncias de Referência}

Para comparação com o desempenho das heurísticas propostas nas 168 instâncias de referência (ver Seção 4.1) também foram programadas e executadas duas heurísticas construtivas consagradas na literatura. A Adapted Combined Savings (ACS) de Dullaert et al. (2002), que também é um método de inserção sequencial baseado em Solomon (1987), e a Savings Heuristics (SH), adaptada por Liu e Shen (1999), foram implementadas. Para ambas, foram utilizados os parâmetros sugeridos em seus respectivos artigos e o melhor resultado de cada instância considerados para combinação. A Tabela 7 apresenta os resultados obtidos com esses quatro métodos.

As primeiras duas colunas indicam qual grupo de instâncias está sendo avaliado, seguindo entre tipo de distribuição espacial, tipo de janela de tempo e custo de veículo (coluna "Grupo"). Para cada grupo indica-se quantas instâncias estão no grupo (Coluna "Qt de Instâncias") As colunas seguintes apresentam o valor médio da função objetivo obtido naquele grupo (coluna Média) e quantas das soluções que o método encontrou naquele grupo são as melhores conhecidas (colunas \%best). Uma solução é a melhor 


\begin{tabular}{|c|c|c|c|c|c|c|c|c|c|}
\hline \multirow{2}{*}{ Grupo } & \multirow{2}{*}{$\begin{array}{c}\text { Qt de } \\
\text { instâncias }\end{array}$} & \multicolumn{2}{|c|}{ ACS } & \multicolumn{2}{|c|}{$\mathrm{SH}$} & \multicolumn{2}{|c|}{ SCIH1 } & \multicolumn{2}{|c|}{ SCIH2 } \\
\hline & & Média & \%best & Média & \%best & Média & \%best & Média & \%best \\
\hline C1a & 9 & $10,096.4$ & 0.0 & $6,154.5$ & 77.8 & $6,171.2$ & 22.2 & $6,196.5$ & 0.0 \\
\hline $\mathrm{C} 1 \mathrm{~b}$ & 9 & $2,672.0$ & 0.0 & $1,608.7$ & 55.6 & $1,611.2$ & 11.1 & $1,616.4$ & 33.3 \\
\hline $\mathrm{C} 1 \mathrm{c}$ & 9 & $1,648.4$ & 0.0 & $1,028.3$ & 44.4 & $1,041.2$ & 0.0 & $1,035.8$ & 55.6 \\
\hline $\mathrm{C} 1$ & 27 & $4,805.6$ & 0.0 & $2,930.5$ & 59.3 & $2,941.2$ & 11.1 & $2,949.6$ & 29.6 \\
\hline $\mathrm{C} 2 \mathrm{a}$ & 8 & $8,394.4$ & 0.0 & $6,183.4$ & 12.5 & $5,315.6$ & 37.5 & $5,302.6$ & 87.5 \\
\hline $\mathrm{C} 2 \mathrm{~b}$ & 8 & $2,091.4$ & 0.0 & $1,487.0$ & 12.5 & $1,315.6$ & 37.5 & $1,302.6$ & 87.5 \\
\hline $\mathrm{C} 2 \mathrm{c}$ & 8 & $1,352.9$ & 0.0 & 894.6 & 0.0 & 792.8 & 75.0 & 820.4 & 62.5 \\
\hline $\mathrm{C} 2$ & 24 & $3,946.2$ & 0.0 & $2,855.0$ & 8.3 & $2,474.7$ & 50.0 & $2,475.2$ & 79.2 \\
\hline R1a & 12 & $4,359.9$ & 0.0 & $2,868.4$ & 66.7 & $3,001.5$ & 0.0 & $2,885.0$ & 33.3 \\
\hline R1b & 12 & $1,154.2$ & 0.0 & 819.0 & 58.3 & 836.4 & 0.0 & 813.1 & 41.7 \\
\hline $\mathrm{R} 1 \mathrm{c}$ & 12 & 767.9 & 0.0 & 545.7 & 41.7 & 547.3 & 41.7 & 555.9 & 16.7 \\
\hline $\mathrm{R} 1$ & 36 & $2,094.0$ & 0.0 & $1,411.0$ & 55.6 & $1,461.7$ & 13.9 & $1,418.0$ & 30.6 \\
\hline R2a & 11 & $5,425.9$ & 0.0 & $3,498.6$ & 9.1 & $2,826.6$ & 27.3 & $2,891.0$ & 63.6 \\
\hline $\mathrm{R} 2 \mathrm{~b}$ & 11 & $1,819.0$ & 0.0 & $1,035.2$ & 9.1 & 911.4 & 63.6 & 942.9 & 27.3 \\
\hline $\mathrm{R} 2 \mathrm{c}$ & 11 & $1,347.2$ & 0.0 & 672.2 & 18.2 & 641.8 & 63.6 & 651.5 & 18.2 \\
\hline R2 & 33 & $2,864.0$ & 0.0 & $1,735.3$ & 12.1 & $1,459.9$ & 51.5 & $1,495.1$ & 36.4 \\
\hline $\mathrm{RC} 1 \mathrm{a}$ & 8 & $4,778.8$ & 0.0 & $3,545.0$ & 0.0 & $3,365.8$ & 50.0 & $3,352.3$ & 50.0 \\
\hline RC1b & 8 & $1,383.9$ & 0.0 & $1,068.0$ & 50.0 & $1,071.8$ & 12.5 & $1,061.9$ & 37.5 \\
\hline $\mathrm{RC} 1 \mathrm{c}$ & 8 & 932.6 & 0.0 & 708.3 & 25.0 & 711.6 & 25.0 & 698.2 & 50.0 \\
\hline $\mathrm{RC} 1$ & 24 & $2,365.1$ & 0.0 & $1,773.8$ & 25.0 & $1,716.4$ & 29.2 & $1,704.1$ & 45.8 \\
\hline $\mathrm{RC} 2 \mathrm{a}$ & 8 & $6,340.7$ & 0.0 & $3,268.3$ & 0.0 & $3,169.3$ & 37.5 & $3,151.0$ & 62.5 \\
\hline $\mathrm{RC} 2 \mathrm{~b}$ & 8 & $2,144.2$ & 0.0 & 916.4 & 0.0 & 872.3 & 37.5 & 872.5 & 62.5 \\
\hline $\mathrm{RC} 2 \mathrm{c}$ & 8 & $1,526.1$ & 0.0 & 568.0 & 0.0 & 538.4 & 50.0 & 534.6 & 62.5 \\
\hline $\mathrm{RC} 2$ & 24 & $3,337.0$ & 0.0 & $1,584.2$ & 0.0 & $1,526.6$ & 41.7 & $1,519.4$ & 62.5 \\
\hline Méc & ia geral & $3,161.9$ & & $2,001.8$ & & $1,889.5$ & & $1,885.7$ & \\
\hline & best & & 0.0 & & 28.6 & & 32.1 & & 45.2 \\
\hline
\end{tabular}

Tabela 7: Resultados obtidos com as heurísticas propostas, apresentando o resultado médio das funções objetivo e as percentagem de melhores resultados encontrados para cada grupo de instâncias resolvidas pelos métodos construtivos ACS, SH, SCIH1, e SCIH2. 
conhecida se o valor de sua função objetivo é o menor. Naturalmente, para o mesmo grupo, os percentuais podem somar mais de 100\%, uma vez que dois métodos podem encontrar a mesma solução e essa ser a melhor conhecida. Os valores em negrito indicam que são os melhores conhecidos para cada grupo, dentre os métodos aplicados, ou seja, o menor valor médio da função objetivo ou o maior percentual de melhores soluções.

Todos os métodos analisados apresentaram tempo de execução similar, sem nunca exceder 0,2 segundos por instância.

Os valores na Tabela 7 mostram que, considerando tanto o valor médio total como o percentual de melhores soluções, SCIH1 e SCIH2 são superiores aos demais métodos avaliados, superando os métodos de referências SH e ACS. Essa conclusão já era esperada, uma vez que SCIH1 e SCIH2 foram pensadas e têm caraterísticas e critérios pensados em características do FSMVRPTWSC. A heurística ACS apresentou os piores resultados no experimento, uma vez que não encontrou nenhuma melhor solução dentre as 168 melhores e a sua média geral ficou $68 \%$ acima da média da melhor média, do SCIH2. Já a heurística SH chegou a apresentar os melhores resultados para os grupos C1 e R1, apesar de muito próximos dos valores de $\mathrm{SCIH} 2$, com resultados para $\mathrm{C} 1$ em média apenas $0,65 \%$ menores que nos $\mathrm{R} 1$ apenas $0,49 \%$.

Analisando os dois melhores métodos, SCIH1 e SCIH2, é possível notar que ambos apresentam desempenho similar. SCIH2 obteve a maior porcentagem de melhores resultados, aproximadamente 45\%, apesar de a média geral ter sido apenas 0,2\% menor que a média de SCIH1. A maior diferença entre as duas foi encontrada no grupo R1a, em que SCIH2 gerou valor médio $4 \%$ menor que SCIH1.

A fim de identificar se a diferença é estatisticamente significativa entre os métodos, testes estatísticos, conforme descritos em Devore (2015), foram conduzidos usando o valor da função objetivo para cada método nas 168 instâncias de referência. Primeiro, o teste de Kolmogorov-Smirnov deixou claro que os dados não apresentam uma distribuição normal. Em seguida, aplicando o teste dos postos sinalizados de Wilcoxon. os métodos foram comparados um a um e a percepção que SCIH1 e SCIH2 tem comportamentos similares e se diferem de SH e ACS foi confirmada com $5 \%$ de significância.

\subsubsection{Instâncias de Dimensões Menores}

Para avaliar os resultados frente a resultados ótimos conhecidos, os métodos foram avaliados nas 72 instâncias de dimensões menores das quais 42 têm resultados ótimos conhecidos. O principal objetivo dessa análise é entender quantos ótimos globais esses 


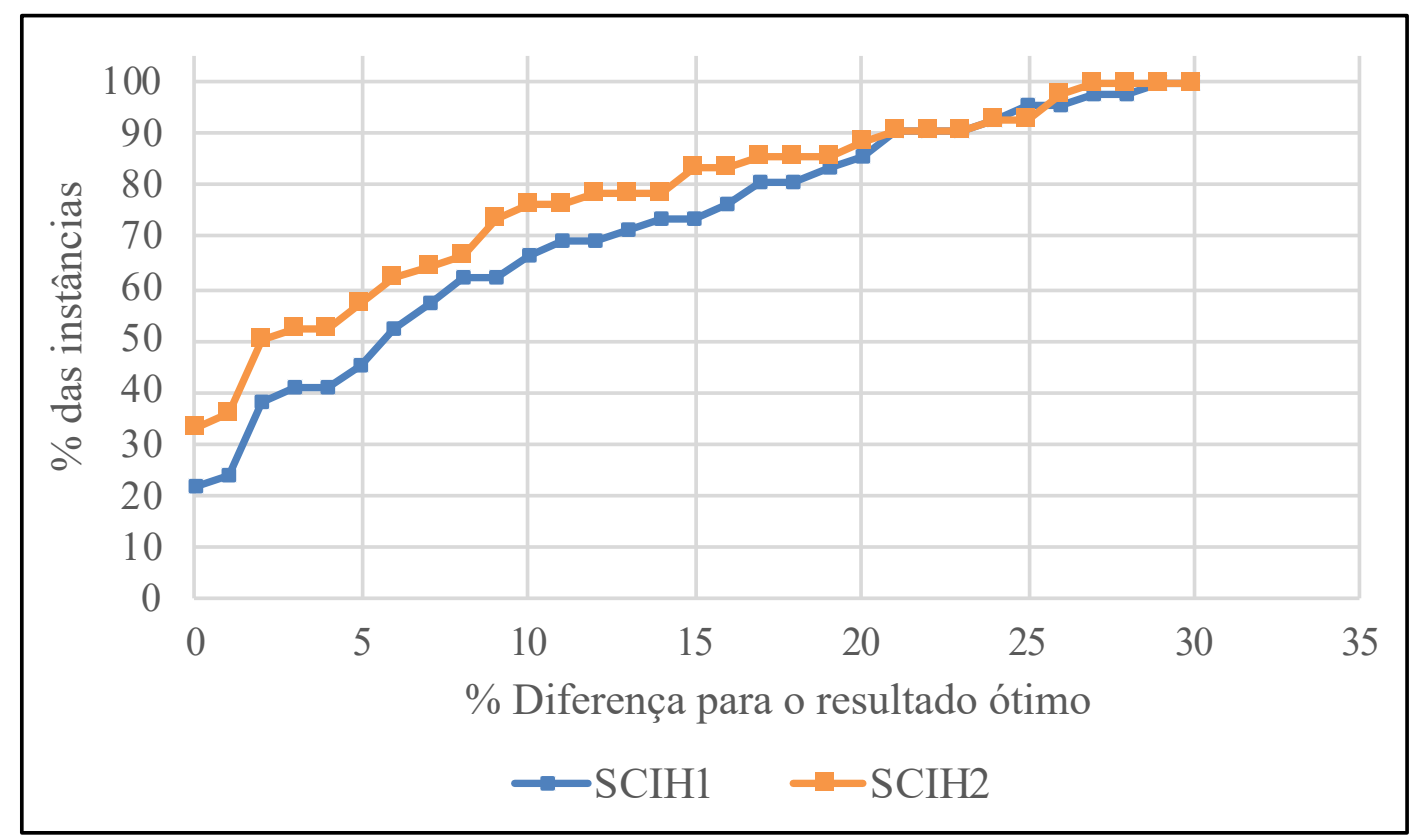

Figura 19: Análise do desempenho de SCIH1 e SCIH2 comparados com os Resultados ótimos conhecidos.

métodos construtivos conseguem encontrar, ou o quão distante eles chegam em décimos de segundo.

A execução foi feita utilizando os parâmetros apresentados na Tabela 6 e os resultados, em termos de distâncias dos 42 ótimos conhecidos, são apresentados na Figura 19.

O gráfico apresentado na Figura 19 é do tipo cumulativo. Enquanto no eixo horizontal os valores são a distância do valor obtido pelas heurísticas em relação ao ótimo encontrado no CPLEX, no eixo vertical os valores indicam quantas instâncias o valor encontrado é inferior ou igual ao desvio indicado no eixo horizontal. Desta forma, é possível que para $0 \%$ de desvio (ou seja, valores que são o próprio ótimo global), a SCIH1 encontrou mais de $20 \%$ e a SCIH1 pouco mais de $30 \%$. Para um desvio de 10\%, SCIH1 encontrou cerca de $65 \%$ de resultados iguais ou inferior a $10 \%$ e a SCIH2 encontrou entre $75 \%$ e $80 \%$ com diferença menor ou igual a essa.

A partir da Figura 19 é possível confirmar a percepção obtida com as instâncias de referência que a SCIH1 e SCIH2 tem desempenhos semelhantes, apesar de uma consistente superioridade da SCIH2. Enquanto SCIH1 encontra 9 soluções ótimas das 42 possíveis $(21,4 \%)$ e a diferença média para o ótimo é de 8,4\%, SCIH2 encontra 14 soluções ótimas $(33,3 \%)$ e a diferença para o ótimo fica em $6,7 \%$. Com esses resultados, fica perceptível o bom desempenho de ambas as heurísticas, que mesmo sendo heurísticas construtivas com resultados obtidos muito rapidamente, conseguem manter um valor em média $6,7 \%$ do 


\begin{tabular}{c|cr|crr|rrr}
\hline \multirow{2}{*}{ Dia } & \multicolumn{2}{|c|}{ Reportado } & \multicolumn{3}{c|}{ SCIH1 } & \multicolumn{3}{c}{ SCIH2 } \\
& Custo & Rotas & Custo & Rotas & \%Dif. & Custo & Rotas & \%Dif. \\
\hline 1 & $27,676.6$ & 58 & $28,200.0$ & 71 & 1.89 & $27,189.0$ & 66 & -1.76 \\
2 & $35,151.3$ & 65 & $29,457.1$ & 66 & -16.20 & $28,307.1$ & 62 & -19.47 \\
3 & $32,379.9$ & 59 & $28,857.4$ & 68 & -10.88 & $28,654.2$ & 67 & -11.51 \\
\hline Total & $95,207.8$ & 182 & $86,514.5$ & 205 & -9.13 & $84,150.3$ & 195 & -11.61 \\
\hline
\end{tabular}

Tabela 8: Resultados obtidos nas instâncias inspiradas em dados reais.

ótimo. Vidal et al. (2013a) afirmam que os métodos heurísticos geralmente apresentam resultados entre $10 \%$ e $15 \%$ do valor ótimo do problema. Portanto, os resultados obtidos pelas heurísticas SCIH1 e SCIH2 são melhores do que o geralmente esperado para heurísticas similares.

\subsubsection{Instâncias inspiradas em Dados Reais}

Os métodos construtivos propostos também foram avaliados nas instâncias inspiradas em dados reais. Essas instâncias são interessantes por permitirem avaliar a heurística em um cenário real com características que vão além de instâncias teóricas de referência. Pela característica dos problemas, os índices de $\alpha$ e $\beta$ utilizados são os das instâncias RC1 e RC2. Os resultados são apresentados na Tabela 8

Como pode ser visto, ambas as heurísticas geram melhorias em relação aos valores reportados pela empresa em todas as instâncias, com exceção do Dia 2, no qual a SCIH1 gera um resultado $6,43 \%$ mais caro que o reportado pela empresa. Neste caso a empresa relatou um desempenho muito próximo aos das duas heurísticas propostas. Como um todo, os dois métodos superam os resultados reportados pela empresa e tem desempenho similar, com desempenho consistentemente superior da SCIH2. 


\section{BUSCAS LOCAIS}

As heurísticas apresentadas no Capítulo 6 são construtivas de inserção sequencial, que produzem em tempo muito curto resultados de boa qualidade. Entretanto, é possível melhorar o resultado obtido a partir da implementação métodos de busca em vizinhança.

Vidal et al. (2013a) definem esses procedimentos de busca local da seguinte forma: a partir de uma solução $s$, o método explora uma vizinhança $N(s)$, definida por movimentos ou perturbações em $s$. Nesta vizinhança, busca-se encontrar uma nova solução $s^{\prime}$ que possui um valor da função objetivo melhor que $s$. Quando encontrada, $s^{\prime}$ passa a ser a nova solução do problema e, portanto, s cuja vizinhança será explorada na próxima iteração. O processo é repetido até que se encontre uma solução $\bar{s}$ cuja vizinhança, $N(\bar{s})$, não possui nenhuma solução melhor. Essa solução $\bar{s}$ é um ótimo local do problema.

Uma vizinhança é um subconjunto de soluções, dentre o universo de soluções para um problema combinatório, que podem ser geradas a partir de alterações específicas em uma solução conhecida. As alterações na solução que geram sua vizinhança são denominadas movimentos. A determinação de quais movimentos são feitos e o critério de escolha de cada um varia conforme o problema abordado e a técnica de solução escolhida.

Neste capítulo são apresentados procedimentos de busca local para o FSMVRPTWSC. Na revisão bibliográfica, (Seção ??) foram apresentados movimentos para geração de vizinhanças presentes na literatura para problemas de roteamento de veículos, a partir destes movimentos, na Seção 7.1 discute-se os procedimentos que são utilizados nesse trabalho, na Seção 7.2 é apresentada a implementação dos movimentos e na Seção 7.3 são apresentados os resultados computacionais obtidos com a aplicação de busca local utilizando os movimentos escolhidos para a geração de vizinhança. 


\subsection{Escolha de Movimentos}

Conforme descrevem Vidal et al. (2013a), os algoritmos de busca devem ser eficientemente escolhidos, uma vez que eles são responsáveis pela maior parte do esforço computacional de uma metodologia que utiliza esses movimentos. A partir dessa constatação, a escolha dos movimentos para a busca local do FSMVRPTWSC foi feita com cuidado de buscar movimentos que respeitem suas características.

No trabalho de Potvin e Rousseau (1995), afirma-se que para problemas de roteamento de veículos com janelas de tempo cada alteração na rota deve ter sua factibilidade verificada. Isso torna o esforço computacional ainda mais relevante que em problemas sem essas restrições. Em problemas sem janelas de tempo, cuja infactibilidade somente pode ocorrer caso a capacidade máxima seja superada, o tempo de verificação é muito mais rápido e direto, uma vez que a ordem de atendimento dos clientes numa mesma rota não muda a demanda total sendo transportada e, consequentemente, não muda a condição de factibilidade.

Para os problemas de roteamento de veículos com janelas de tempo, destacam Potvin e Rousseau (1995), as mudanças do tipo k-opt são ainda mais complexas de verificar a factibilidade uma vez que elas geram mudança de sentido de arcos da rota. Principalmente em problemas com janelas de tempo apertadas, a ordem em que os clientes são roteados tem muita relação com a factibilidade das janelas de tempo. Em problemas com janelas de tempo largas, porém, esse problema de infactibilidade é menos frequente. Desta forma, nesta tese entende-se que, para evitar gerar diversas rotas infactíveis, é dada preferência para movimentos de troca que não geram mudança de direção, como RELOCATE, $S W A P$, Or-opt e 2-opt*.

Para determinar quais movimentos são utilizados nesse trabalho para geração de vizinhanças da busca local, foram investigados trabalhos recentes de sucesso nos problemas de roteamento de veículos com janelas de tempo que utilizam buscas locais.

Paraskevopoulos et al. (2008) apresentam o método ReVNTS para abordar o HFVRPTW, problema de roteamento de veículos com frota heterogênea e janelas de tempo. O método é uma variação do VNS (Variable Neighborhood Search. No momento de fazer a busca em vizinhança, o método aplica Busca Tabu com movimentos de troca do tipo GENI, Or-opt, 2-opt, CROSS, RELOCATE e EXCHANGE, nessa ordem. A nova solução incumbente é sempre a primeira que gerar melhoria.

Bräysy e Gendreau (2005a) abordam o FSMVRPTW propondo uma meta-heurística 
que combina Threshold Acceptance com Buscal Local Guiada, o TAGLS. Ao aplicar movimentos de busca local, eles são derivações de RELOCATE, CROSS e Or-opt. As derivações feitas nos movimentos fazem com que se diminua a vizinhança pesquisada para que somente clientes próximos entre si sejam investigados, evitando que esforço computacional seja despendido em avaliações de movimentos com pouca possibilidade de sucesso. Para acelerar a investigação, neste trabalho, a busca local é do tipo first accept, aceitando a primeira melhoria para assumir como solução incumbente.

Repoussis e Tarantilis (2010) abordam o FSMVRPTW, que é o problema mais semelhante ao FSMVRPTWSC abordado no presente trabalho, a partir do método AMP Adaptive Memory Programming. O AMP é um procedimento que gera soluções iterativamente enquanto atualiza a memória conforme a busca progride e experiência é acumulada. O processo gera múltiplas soluções, as quais são aprimoradas por busca local e o caminho realizado nas buscas locais é memorizado para gerar novas soluções melhoradas. Sobre estas soluções, nova busca local é realizada, realimentando a memória de caminhos realizados. Iterativamente, o processo se repete. Durante a geração de novas rotas e na fase de aprimoramento, o AMP utiliza Busca Tabu com vizinhanças geradas pela utilização de movimentos tipo 2-opt, 2opt*, RELOCATE, SWAP e CROSS. A escolha de qual movimento realizar é feita aleatoriamente.

Vidal et al. (2013b) abordam o VRPTW com um método genético denominado HGSADC - busca genérica híbrida com controle de diversidade adaptativa. A cada iteração, este método gera novos indivíduos e os educa (melhora seu resultado) realizando uma busca local separada em duas etapas, primeiro o movimento RELOCATE inter e intrarrotas é realizado e, em seguida, escolhe-se aleatoriamente um dos dentre os movimentos: SWAP, 2-opt* e 2-opt.

Vidal et al. (2014) trazem uma abordagem genérica para os problemas de roteamento de veículos. Os autores propõem o UHGS - Unified Hybrid Genetic Search - com o propósito apresentar bom desempenho ao resolver diferentes tipos de problemas de roteamento de veículos que os autores se referem por MAVRPs - problemas de roteamento de veículos com múltiplos atributos (Multi-Attribute Vehicle Routing Problem). O UHGS, como todos os algoritmos genéticos, deve gerar novos indivíduos a partir do crossover de dois indivíduos da população e, a cada indivíduo gerado, uma busca local é realizada na chamada fase de educação. Nesta fase de educação, movimentos do tipo 2-opt*, 2-opt, Or-Opt e CROSS são utilizados. Para reduzir o impacto da avaliação das novas rotas geradas após os movimentos executados, Vidal et al. (2014) propõem métodos que reduzem o esforço computacional destas avaliações. 
Koç et al. (2015) abordam o HFVRPTW - problema de roteamento de veículos com frota heterogênea e janelas de tempo - utilizando um algoritmo evolutivo híbrido (Hybrid Evolutive Algorithim - HEA). Neste algoritmo, do tipo genético, durante a geração de novos indivíduos para a população, existe uma fase de educação que, de fato, significa a execução de busca local para a solução obtida a partir do crossover de outras duas soluções. Nessa etapa de educação, Koç et al. (2015) utilizam movimentos dos tipos Destruir e Reparar. Nestes tipos de movimentos, clientes são removidos das rotas existentes e, em seguida, eles são re-inseridos nas rotas, seja a mesma ou uma outra rota da solução. Os critérios de remoção e de realocação são determinados conforme critérios pré-estabelecidos pelos autores. Esse movimento é uma forma elaborada de usar o movimento do tipo RELOCATE, uma vez que na prática o que ele faz é remover clientes de uma posição em uma rota e inserir em outra posição e/ou rota, porém com uma série de critérios para cada uma dessas ações.

Wang, Li e Hu (2015) estudam o HVRPTW-ILC (Heterogeneous multi-type fleet Vehicle Routing Problem with Time Windows and Incompatible Loading Constraint). O problema consiste na distribuição de diferentes produtos que demandam diferentes tipos específicos de veículos que podem transportá-los, sendo que cada tipo de veículo pode ter diferentes tamanhos, com diferentes capacidades e custos. Além dessa característica da frota, existem janelas de tempo nos clientes a serem atendidos. Wang, Li e Hu (2015) abordam o problema propondo algumas heurísticas construtivas e uma busca tabu. Essa busca utiliza movimentos 2-opt*, RELOCATE e CROSS, sendo escolhidos a cada rodada pelo sorteio aleatório.

A Tabela 9 organiza os métodos conforme sua utilização nos trabalhos descritos nessa seção. É possível notar que o movimento RELOCATE é usado em seis dos sete trabalhos apresentados, enquanto CROSS é o segundo mais utilizado, sendo aplicado em cinco dos sete trabalhos apresentados. Ao mesmo tempo, é notável a pouca utilização de EXCHANGE e SWAP.

O trabalho de Koç et al. (2015) apresenta uma comparação de desempenho entre o seu método proposto, o HEA, e outros métodos para solução do FSMVRPTW, que é o problema mais próximo do FSMVRPTWSC. As comparações foram feitas sobre as instâncias de Liu e Shen (1999) e, entre os avaliados, estavam o ReVNTS de Paraskevopoulos et al. (2008), o AMP de Repoussis e Tarantilis (2010) e o UHGS de Vidal et al. (2014). Nesta comparação, o HEA apresenta o melhor desempenho dentre os métodos comparados, seguido pelo UHGS. 


\begin{tabular}{|c|c|c|c|c|c|c|c|}
\hline Artigo & 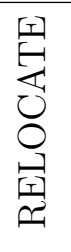 & $\sum_{0}^{\infty}$ & 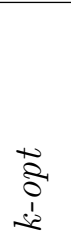 & $\begin{array}{l}\vec{s} \\
\hat{\sigma}^{1} \\
\hat{\sigma}^{2}\end{array}$ & 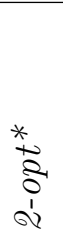 & 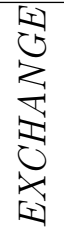 & 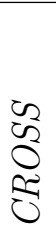 \\
\hline Wang, Li e Hu (2015) & $\mathrm{X}$ & & & & $\mathrm{X}$ & & $\mathrm{X}$ \\
\hline$\overline{\text { Koç et al. }(2015)}$ & $\mathrm{X}$ & & & & & & \\
\hline Vidal et al. (2014) & & & $\mathrm{X}$ & $\mathrm{X}$ & $\mathrm{X}$ & & $\mathrm{X}$ \\
\hline$\overline{\text { Vidal et al. }}(\overline{\overline{2013} \mathrm{~b}})$ & $\mathrm{X}$ & $\mathrm{X}$ & $\mathrm{X}$ & & $\mathrm{X}$ & & \\
\hline Repoussis e Tarantilis (2010) & $\mathrm{X}$ & $\mathrm{X}$ & $\mathrm{X}$ & & $\mathrm{X}$ & & $\mathrm{X}$ \\
\hline Bräysy et al. $(2009)$ & $\mathrm{X}$ & & & $\mathrm{X}$ & & & $\mathrm{X}$ \\
\hline Paraskevopoulos et al. (2008) & $\mathrm{X}$ & & $\mathrm{X}$ & $\mathrm{X}$ & & $\mathrm{X}$ & $\mathrm{X}$ \\
\hline
\end{tabular}

Tabela 9: Publicações e os movimentos utilizados nas buscas locais de seus métodos.

A partir desta exposição e tendo em vista o bom desempenho da HEA e UHGS, assim como a ponderação sobre o alto esforço computacional de realizar movimento tipo k-opt para janelas de tempo, este trabalho irá aplicar os tipos de movimento RELOCATE, 2-opt* e CROSS, que tem utilização ampla entre os trabalhos avaliados que apresentam bons resultados.

\subsection{Implementação dos Movimentos de Busca em Vi- zinhança}

Com a definição de quais movimentos são aplicados no FSMVRPTWSC, nesta seção é detalhada a implementação de cada um deles, com avaliação dos resultados obtidos em testes computacionais.

\subsubsection{Relocate}

Como explicado na Seção 7.1, o movimento RELOCATE consiste em retirar um ou mais clientes de sua posição atual em uma rota e inseri-lo em outra posição, que pode ser na mesma rota ou em outra. Desta forma o movimento possui uma etapa de remoção seguido por outra de inserção cujos critérios e forma de serem executados devem ser definidos.

A seguir é apresentado o Pseudocódigo 2 da busca local que utiliza somente o movimento RELOCATE. O procedimento recebe uma solução inicial na linha 2 a partir do parâmetro de entrada SolInicial. Em seguida, repete-se o movimento RELOCATE enquanto forem obtidas soluções de custo menor. Dentro do laço apresentado 
da linha 6 à 13, um número de clientes pré-determinado no parâmetro NumClientes será escolhido para realocação, sendo um realocado por vez, não simultaneamente. A função RemoveCliente irá remover um cliente da solução de acordo com um critério pré-estabelecido (CriterioRemocao) e evitando repetir o cliente removido numa mesma iteração. Em seguida, a função InsereCliente insere o cliente $u$ na solução conforme um critério (CriterioInsercao). Caso a nova solução gere um resultado melhor que a solução atual esta é armazenada para, depois de a quantidade total de clientes serem realocados, a melhor solução ser incorporada à solução atual da busca local. Quando não houver mais mudanças, o procedimento é encerrado.

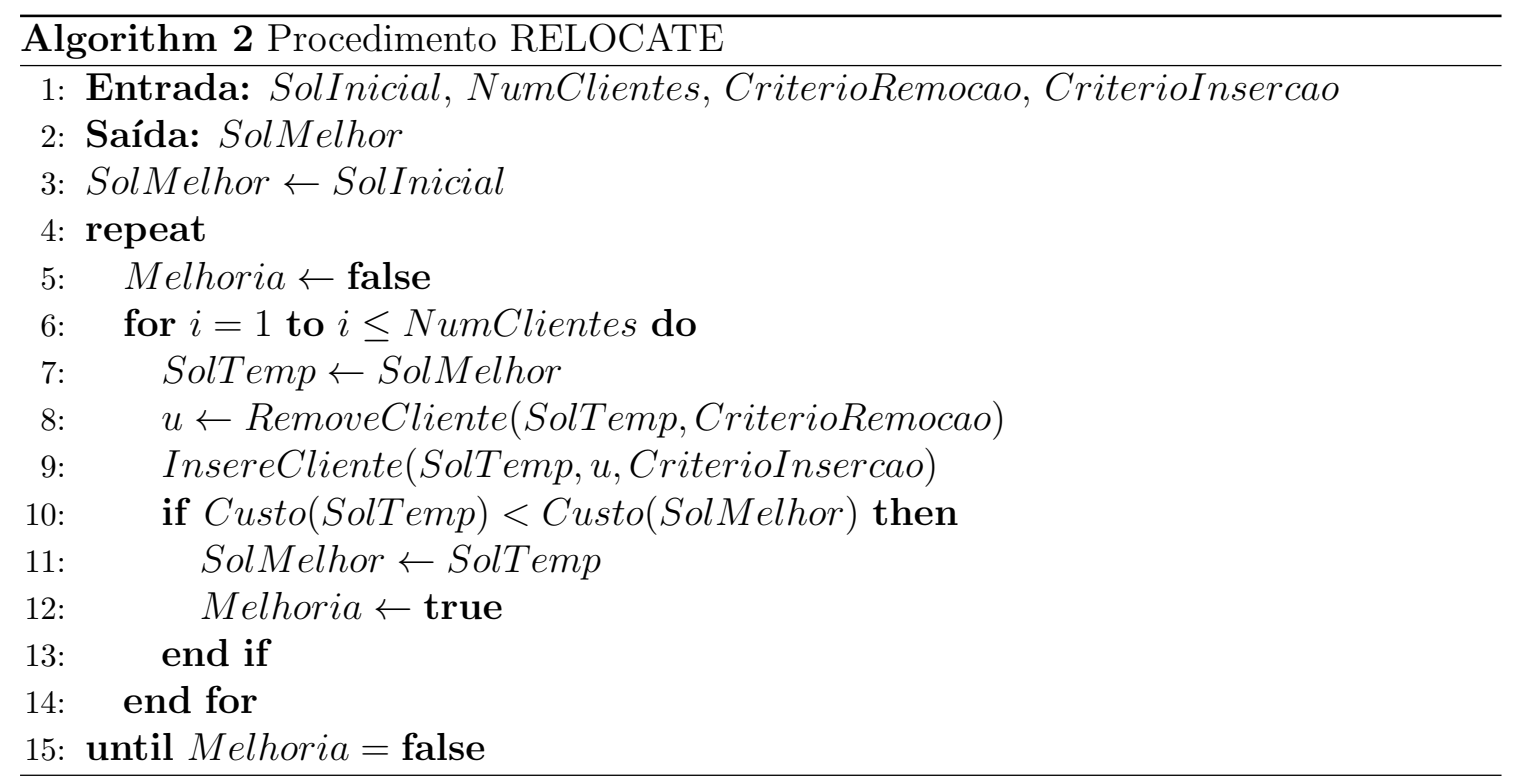

Conforme visto no pseudocódigo, podemos estimar que o movimento Relocate gera uma vizinhança de tamanho:

$$
\text { TamanhoVizinhanca }(\text { Relocate })=\text { NumCliente } \times(N-1+V)
$$

onde NumCliente é o número de clientes que são removidos, $N$ é o total de clientes do problema e $V$ é o número de rotas. Esse cálculo é obtido uma vez que um número de clientes (NumCliente) é removido, a cada remoção qualquer um dos $N$ clientes pode ser removido. Em seguida, é avaliada a inserção em todas as posições possíveis na solução vigente. Existem tantas posições quanto existem clientes, exceto o próprio cliente que foi removido, além de uma posição adicional da volta para o depósito por rota. Portanto, a ordem de grandeza do movimento Relocate é $O\left(N^{2}\right)$.

No movimento de RELOCATE proposto por Koç et al. (2015) existem nove operadores de remoção e três de inserção. A escolha entre esses operadores para cada uma das duas 
etapas é realizada através de sorteio enviesado com base no histórico de sucesso dos movimentos no desenvolvimento de soluções. Isso significa que todos os operadores têm a mesma probabilidade de serem escolhidos e, conforme os operadores são aplicados e geram resultados melhores ou piores, sua probabilidade de serem novamente escolhidos cresce ou diminui.

O movimento RELOCATE apresentado neste trabalho se baseia em Koç et al. (2015), oferecendo diferentes operadores de remoção e de inserção. Três operadores de remoção e um de inserção são mantidos como formulado pelos autores, enquanto dois operadores de remoção e dois de inserção são propostos por este trabalho, a fim de explorar características específicas do FSMVRPTWSC.

É relevante ressaltar que a cada avaliação de um movimento de inserção, a factibilidade da nova solução é verificada. A infactibilidade pode ser gerada tanto por uma demanda total superior à capacidade máxima do maior veículo, como por uma impossibilidade de respeitar as janelas de tempo de clientes e do armazém. Caso uma solução seja inviável, ela é descartada.

A seguir, detalhamos os movimentos de remoção. Os três primeiros são originais de Koç et al. (2015), enquanto os dois últimos são proposições deste trabalho.

- Remoção aleatória (RR - Random Removal): um cliente é escolhido a partir de sorteio aleatório e removido de sua rota;

- Remoção do pior tempo (WTR - Worst Time Removal): o cliente cujo atendimento gera o maior tempo de espera pela abertura da janela de tempo é escolhido. Para um cliente $u$, que sucede um cliente $i$ em uma dada rota, o tempo de espera $w_{u}$, se houver, é dado pela diferença entre o momento a chegada do veículo ao seu local e o início do seu atendimento. Ou seja, dado pelo início do serviço no cliente anterior $\left(b_{i}\right)$, somada ao tempo de atendimento no cliente anterior $\left(s_{i}\right)$ e o tempo de trânsito entre os dois clientes $\left(t_{i u}\right)$ e a abertura da janela de tempo de atendimento em $u\left(e_{u}\right)$. Escrevendo na forma de equação, o tempo de espera é dado por: $w_{u}=$ $\operatorname{Max}\left(0, e_{u}-\left(b_{i}+s_{i}+t_{i u}\right)\right)$. O cliente com maior $w_{u}$ é removido;

- Remoção da pior distância (WDR - Worst Distance Removal): O cliente u cuja remoção gerar a maior redução de custo total é executada. Se $u$ é precedido por $i$ e sucedido por $j$, a troca dos $\operatorname{arcos}(i, u)$ e $(u, j)$ por $(i, j)$ gera a redução de distância calculada por $\Delta D(u)=D^{v}-\left(d_{i u}+d_{u j}\right)+d_{i j}$. O cliente com maior $\Delta D(u)$ é removido por esse operador; 
- Remoção gananciosa (GR - Greedy Removal): O cliente u cuja remoção gerar a maior redução de custo total é executada. Caso a remoção de mais de um cliente gerar a menor redução de custo, o desempate é feito pela remoção que gera a maior redução de distância;

- Remoção C1 (C1R): Este operador é baseado na heurística construtiva SCIH1, apresentada na Seção 6.2.1. deste trabalho. Para cada cliente $u$ simula-se o seu valor de $C 1^{S 1}(u, h)$ para sua atual posição $h$. C1 é o critério usado nas heurísticas SCIH que avalia o impacto negativo na rota da inserção de um cliente $u$ na posição $h$. O critério pondera entre diferentes aspectos do problema como distância, tempo, custo e capacidade. Quanto maior o valor de C1, pior é o impacto dessa inserção para o problema. Por isso, no operador C1R, o cliente com o maior $\mathrm{C} 1$ é removido. $C 1^{S 1}(u, h)$ pode ser definido conforme descrito na Seção 6.2.1 e, na apresentação a seguir, estão mantidas todas as nomenclaturas utilizadas anteriormente:

$$
C 1^{S 1}(u)=\min _{h=1, \ldots, m}\left\{-\alpha_{1} C 1_{1}^{S 1}(u, h)+\alpha_{2} C 1_{2}^{S 1}(u, h)+\alpha_{3} C 1_{3}^{S 1}(u, h)-\alpha_{4} C 1_{4}^{S 1}(u, h)\right\}
$$

onde:

$$
\begin{gathered}
C 1_{1}^{S 1}(u, h)= \begin{cases}a_{r^{n e w}+1}-d^{\text {new }} & \text { if } r<R \\
0 & \text { if } r=R\end{cases} \\
C 1_{2}^{S 1}(u, h)=b_{i h}^{\text {new }}-b_{i h} \\
C 1_{3}^{S 1}(u, h)=y^{\text {new }}-y \\
C 1_{4}^{S 1}(u, h)=f_{k}^{\text {new }}-Q^{\text {new }}
\end{gathered}
$$

onde, na notação acima, o termo "new" significa o valor após a inserção do cliente, ou seja, o valor do parâmetro para a rota com o cliente u na posição h. $C 1_{1}^{S 1}(u, h)$ se refere ao impacto na distância do problema, onde $D^{\text {new }}$ é a distância total da rota com o cliente $u$ e $W_{f+1}$ é a distância do o início da faixa de distância seguinte a $D^{\text {new }} \cdot C 1_{2}^{S 1}(u, h)$ é o impacto em tempo do problema, sendo que $b_{i_{h}}$ é o início do atendimento no cliente que

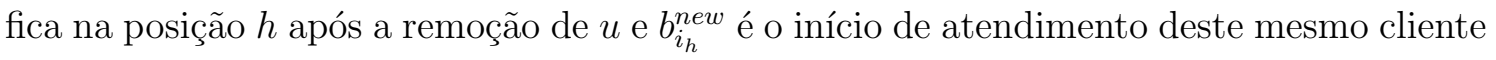
com $u$ já inserido na rota na posição $h . C 1_{2}^{S 1}(u, h)$ avalia o impacto em custo na rota, sendo $P^{\text {new }}$ o custo da rota com o cliente $u$ na posição $h$ e $P$ o custo sem este cliente. Finalmente, $C 1_{4}^{S 1}(u, h)$ avalia o impacto no uso da capacidade do veículo, onde $a_{k}^{\text {new }}$ é a capacidade do veículo utilizado para a rota com a inserção de $u$ e $Q^{\text {new }}$ a demanda total da rota com $u$ inserido.

O motivo de utilizar o critério C1 da heurística SCIH1 e não SCIH2, que teve melhores resultados, é que SCIH1 não possui em sua composição critérios que avaliam clientes ainda 
não roteados, como SCIH2 faz. Dado que as rotas já estão formadas, não existem clientes não-roteados para avaliar durante a avaliação de $\mathrm{C} 1 \mathrm{e}$, portanto, $C 1^{S 1}$ é mais adequado.

Após a remoção de um cliente, ele deve ser inserido conforme um dos operadores a seguir. O primeiro operador é original de Koç et al. (2015) enquanto os demais são contribuições deste trabalho.:

- Inserção de menor distância (SDI - Smallest Distance Insertion): o cliente é adicionado no arco das rotas mais próximo a ele. Isso é feito buscando, para o cliente $u$, o arco $(i, j)$ com a menor soma de $(i, u)$ e $(u, j)$. Com o acréscimo de distância dado por $\Delta D(i, j)=D^{v}+\left(d_{i u}+d_{u j}\right)-d_{i j}$ a posição nas rotas do problema que gerar o menor $\Delta D(i, j)$ é inserido;

- Inserção gananciosa (GI - Greedy Insertion): A inserção do cliente é avaliada em todas as posições $h$ de todas as rotas da solução. A posição que gerar o menor aumento de custo receberá o cliente. Se uma ou mais inserções gerarem o mesmo custo, o desempate é feito escolhendo a que gerar o menor aumento de distância total;

- Inserção C1 (C1I - C1 Insertion): Para todas as posições $h$ em todas as rotas da solução é calculado o $C 1^{S 2}(u, h)$ do cliente $u$. O cliente é inserido na posição que gerar o menor valor deste critério. O cálculo de $C 1^{S 2}(u, h)$ é feito da mesma forma que no operador de remoção C1R, sendo "new" o valor do parâmetro após a inserção do cliente;

- Inserção Aleatória (RI -Random Insertion): Uma posição de inserção é escolhida aleatoriamente em um rota também escolhida aleatoriamente. Caso a posição de inserção gere uma solução infactível, uma nova posição em rota é selecionada novamente até se obter uma solução factível.

\subsubsection{CROSS}

O movimento Cross, proposto pela primeira vez por Taillard et al. (1997), assim como explicado na Seção 7.1, consiste em trocar trechos de rotas entre si. Neste processo, duas sequencias de clientes presentes em duas rotas diferentes são selecionados e trocados de posição entre si. Ou seja, de uma rota deve ser selecionados dois trechos de duas rotas distintas e trocado entre elas. O procedimento deve fazer as seguintes escolhas:

- Seleciona uma rota $(V 1)$ da solução atual, onde $V 1 \in[1,2, . ., V]$; 


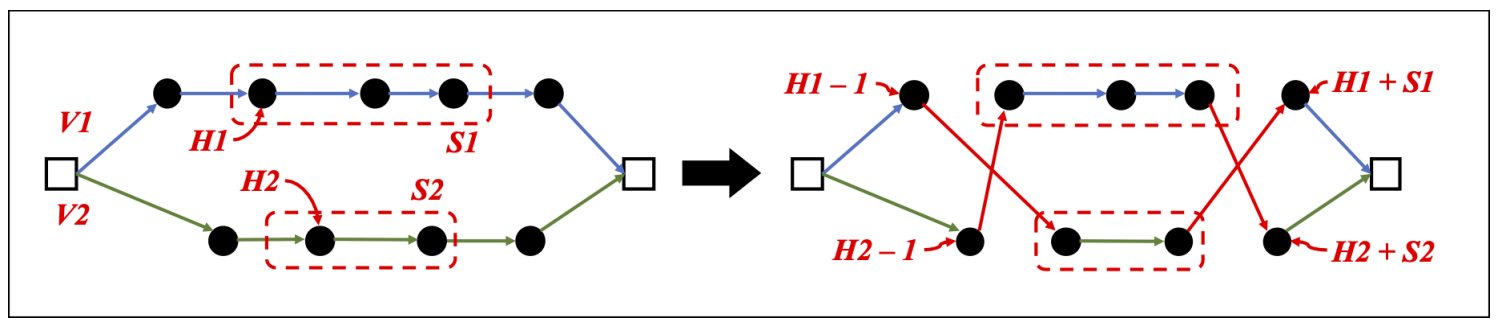

Figura 20: Ilustração do movimento CROSS com os respectivos parâmetros

- Escolhe a posição $(H 1)$ da rota $V 1$ para ser o início do primeiro trecho. Se a rota $V 1$ atende $M 1$ clientes, $H 1 \in[1, . ., M 1]$

- Determina o tamanho do trecho $(S 1)$ a ser extraído da rota que deve ser entre o tamanho de 1 cliente até todos os clientes restantes na rota $V 1$, ou seja: $1 \leq S 1 \leq$ $M 1-H 1$

- Desta forma o primeiro trecho é composto pelos clientes entre a posição $H 1$ e $H 1+$ $S 1-1$ da rota $V 1$;

- A escolha do segundo trecho é feita de forma similar, apenas com o cuidado de que não seja selecionado um trecho da mesma rota;

- Desta forma, seleciona-se a rota $V 2$ sendo que $V 2 \in[1,2, . ., V, V 2 \neq V 1]$;

- Posição $H 2$ da rota $V 2$ : dentro da segunda rota escolhida, uma posição para início do trecho é escolhida. Se a rota $V 2$ atende $M 2$ clientes, $H 2 \in 1,2, . ., M 2$;

- Tamanho $S 2$ do trecho: o número de clientes que são trocados no trecho, que pode ser de 1 até o número de clientes na rota após a posição $h_{2}$, ou seja, $1 \leq S 2 \leq$ $M 2-H 2$.

Conforme explicam Taillard et al. (1997), a troca é feita desconectando as arestas $(H 1-1, H 1)$ e $(H 1+S 1-1, H 1+S 1)$ da rota $V 1$ e $(H 2-1, H 2)$ e $(H 2+S 2-1, H 2+S 2)$ da rota $V 2$ e, em seguida, conecta-se as arestas $(H 1-1, H 2)$ e $(H 2+S 2-1, H 1+S 1)$ na rota $V 1$ e as $\operatorname{arestas}(H 2-2, H 1)$ e $(H 1+S 1-1, H 2+S 2)$ na rota $V 2$. A Figura 20 ilustra os parâmetros e movimentos explicados acima.

O movimento CROSS é detalhado no Algoritmo 3 As entradas são a última solução do problema (SolInicial), o número de trocas que serão testadas (NumTrocas) e o critério de escolha das rotas que serão trocadas, bem como das posições e tamanho do trecho de cada rota (CriterioEscolha). A função EscolheRota escolhe as rotas (V1 e V2) conforme 
o critério adotado (CriterioEscolha), assim como EscolheParametros define para cada rota escolhida a posição inicial do trecho (H1 e H2) e o tamanho de cada trecho ( $S 1$ e S2). Após essa etapa a troca é executada com a função FazTroca. A viabilidade das novas rotas geradas com a troca é avaliada pela função binária viável que verificará as limitações de janelas de tempo de cada cliente das duas rotas trocadas, bem como se a demanda ultrapassa a capacidade do maior veículo. Se as rotas geradas forem viáveis, é a avaliado se o custo da nova configuração é inferior ao custo da original e, se for, essa se torna a solução vigente. O processo é repetido enquanto houver redução dos custos das soluções.

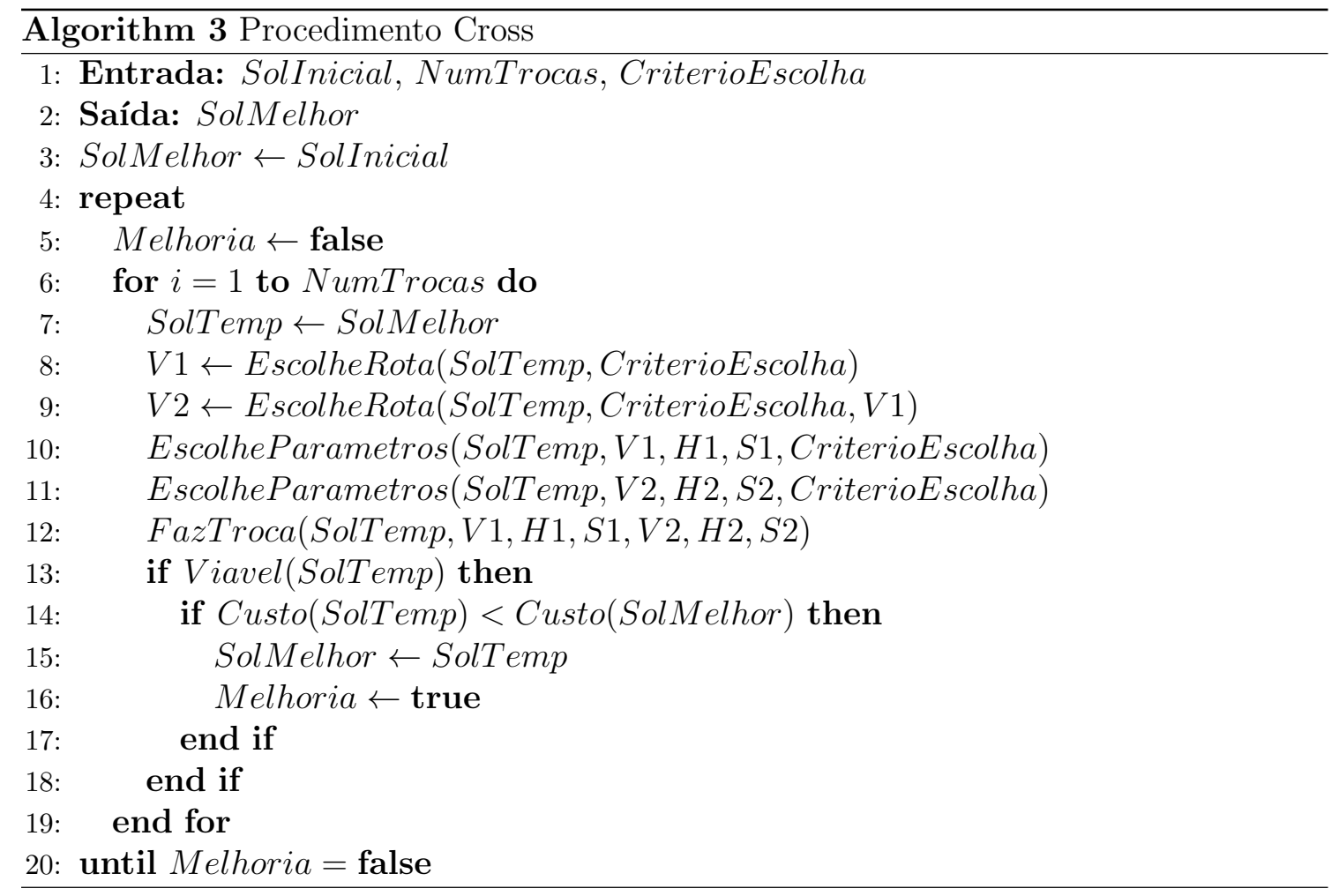

Conforme visto no pseudocódigo, podemos estimar que o movimento Relocate gera uma vizinhança de tamanho:

$$
V \times\left(\frac{N}{V}\right) \times\left(\frac{N}{2 V}-1\right) \times(V-1) \times\left(\frac{N}{V}\right) \times\left(\frac{N}{2 V}-1\right)
$$

onde NumTrocas é o número de clientes que são removidos, $N$ é o total de clientes do problema e $V$ é o número de rotas. Esse cálculo é obtido uma vez que um número de trocas (NumTrocas) será executada, a cada troca qualquer par de rotas pode ser escolhido e para cada rota uma posição e um tamanho de trecho será escolhido para troca. Desta forma $V \times(V-1)$ rotas podem ser escolhidas. Em seguida, qualquer posição das duas 
rotas pode ser selecionada e qualquer tamanho de trecho pode ser selecionado. Como o tamanho da rota pode variar de um cliente apenas para uma grande rota única com todos os clientes, avaliemos um número médio de clientes por rota: $N / V$, ou seja, a quantidade de clientes dividida pela quantidade de rotas. Dado que qualquer tamanho de trecho pode ser escolhido, desde que não seja o trecho total remanescente da rota, pois assim teríamos a 2-opt*, na média seria a quantidade de clientes dividia por dois, ou seja $N / 2 V-1$.

\subsubsection{2-Opt*}

O movimento 2-opt* consiste na troca de trechos de duas rotas entre si. Proposto pela primeira vez por Potvin e Rousseau (1995), consiste na troca de trechos finais entre duas rotas. Desta forma, a partir de um ponto determinado de uma rota, essa é conectada ao ponto de outra rota e vice-versa. Semelhantemente ao Cross, o movimento 2-opt* gera troca de trechos inter-rotas, porém, diferente do Cross, não se extrai um trecho de cada rota, mas sim, há uma troca total de final de rotas.

Uma das características que tornam o movimento 2-opt* interessante para o problema deste trabalho é que essa troca não causa uma inversão de sentido e, assim, não tende a causar infactibilidades mesmo com a existência da restrição de janelas de tempo. Caso houvesse uma mudança de direção na direção de algum trecho das rotas, o primeiro cliente

atendido na rota se tornaria o último. É possível esse cliente havia sido roteado como o primeiro a ser atendido na rota justamente por ter uma janela de tempo que tem início e fim logo no início do horizonte de planejamento. Portanto a troca que o colocaria como último, tornaria seu atendimento infactível.

Neste processo, o início de uma rota e fim de duas rotas são trocadas entre si. Desta forma, ao selecionar rotas $a$ e $b$ com clientes $\left(0, a_{1}, a_{2}, \ldots, a_{n}, 0\right)$ e $\left(0, b_{1}, b_{2}, \ldots, b_{m}, 0\right)$, respectivamente, um possível resultado seriam duas novas rotas que combinam o início de uma com o fim de outra: $\left(0, a_{1}, a_{2}, \ldots, b_{m}, 0\right) e\left(0, b_{1}, b_{2}, \ldots, a_{n}, 0\right)$.

O procedimento deve fazer as seguintes escolhas:

- Seleciona-se uma rota $(V 1)$ da solução atual, onde $V 1 \in[1,2, . ., V]$;

- Escolhe-se a posição $(H 1)$ da rota $V 1$ para ser o início do arco que será removido. Se a rota $V 1$ atende $M 1$ clientes, $H 1 \in[1,2, . ., M 1]$;

- Seleciona outra rota $(V 2)$ desta solução, que deve ser diferente de $V 1, V 1 \in$ $[1,2, . ., V: V 1 \neq V 2]$ 


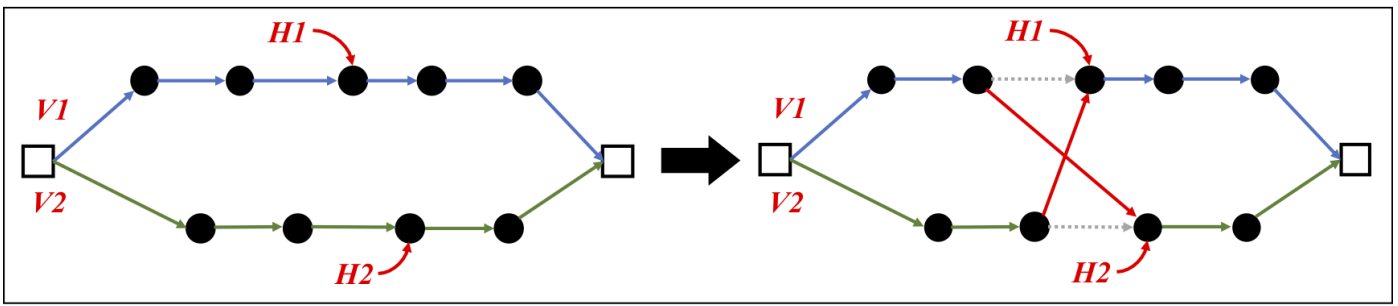

Figura 21: Ilustração do movimento 2-Opt* com os respectivos parâmetros

- Escolhe a posição $H 2$ da rota $V 2$ para ser o início do segundo arco. Se a rota $V 2$ atende $M 2$ clientes, $H 2 \in[1,2, . ., M 2]$.

A troca é feita a partir da remoção do $\operatorname{arco}(H 1-1, H 1)$ da Rota $V 1$ e do arco $(H 2-1, H 2)$ da Rota $V 2$ e, em seguida, criam-se os $\operatorname{arcos}(H 1-1, H 2)$ na Rota $V 1$ e $(H 2-1, H 1)$ da Rota $V 2$. A Figura 21 ilustra os parâmetros expostos e as alterações.

Como se trata de um movimento de rápida execução, cada escolha de par de rotas e posição é feita de forma direta e, em seguida apenas se deve avaliar factibilidade e custo da nova solução, o movimento será executado em todas as combinações de rotas e posições $(V 1, V 2, H 1, H 2)$ possíveis e a troca que gerar o melhor resultado (menor valor de função objetivo) é usado como a nova solução. A busca é repetida até que não se obtenha melhora na função objetivo.

O movimento 2-opt* é detalhado no Algoritmo 4 a seguir. As entradas são a última solução do problema (SolInicial), o número de trocas que são testadas (NumTrocas) e o critério de escolha das rotas que são trocadas, bem como das posições e tamanho do trecho de cada rota (CriterioEscolha). A função EscolheRota escolhe as rotas (V1 e $V 2$ ) conforme o critério adotado (CriterioEscolha), assim como EscolhePosicao define para cada rota escolhida a posição inicial do trecho ( $H 1$ e $H 2)$. Após essa etapa a troca é executada com a função FazTroca. A viabilidade das novas rotas geradas com a troca é avaliada pela função binária Viavel que verificará as limitações de janelas de tempo de cada cliente das duas rotas trocadas, bem como se a demanda ultrapassa a capacidade do maior veículo. Se as rotas geradas forem viáveis, é a avaliado se o custo da nova configuração é inferior ao custo da original e, se for, essa se torna a solução vigente. O processo é repetido enquanto houver redução dos custos das soluções.

Conforme visto no pseudocódigo, podemos estimar que o movimento 2-Opt* gera uma vizinhança de tamanho: 


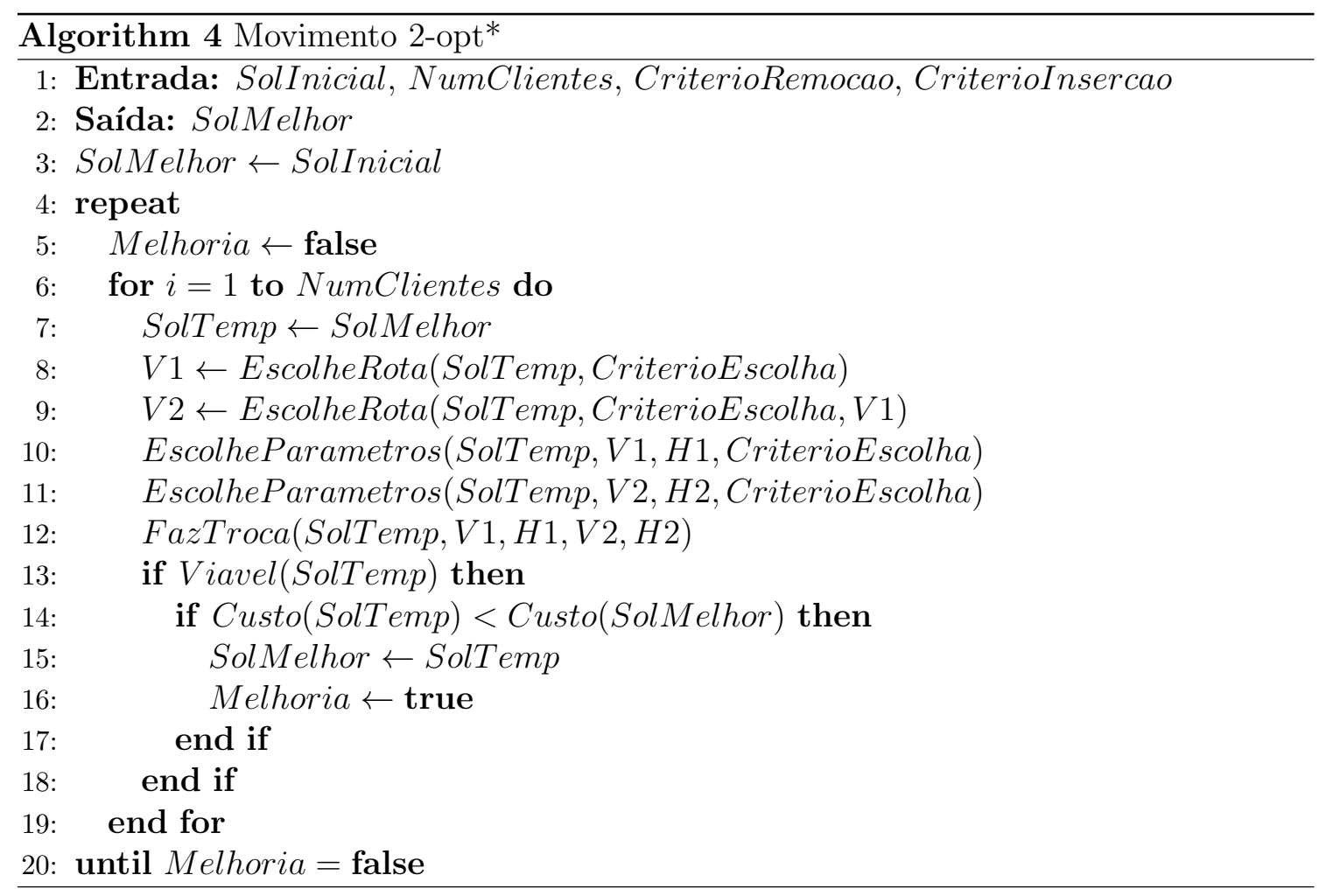

$$
\text { TamanhoVizinhanca }\left(2-\mathrm{Opt}^{*}\right)=\text { NumTrocas } \times V \times \frac{N}{V} \times(V-1) \times \frac{N}{V}
$$

onde NumTrocas é o número de clientes que serão removidos, $N$ é o total de clientes do problema e $V$ é o número de rotas. Esse cálculo é obtido uma vez que um número de trocas (NumTrocas) será executada. A cada troca qualquer par de rotas pode ser escolhido e para cada rota uma posição será escolhido para troca. Desta forma $V \times(V-1)$. Em seguida, qualquer posição das duas rotas pode ser selecionada, usando a média de clientes por rotas, teríamos $\frac{N}{V}$ em média para cada rota. Simplificando a fórmula, chegaríamos em:

$$
N^{2} \times\left(1-\frac{1}{V}\right)
$$

Essa expressão tem dimensão $O\left(N^{2}\right)$. 


\subsection{Experimentos Numéricos}

Os experimentos numéricos foram executados com dois objetivos, calibração e avaliação da qualidade dos movimentos.

Primeiro para calibração dos movimentos, como na Seção 7.3.1 para determinar quais operadores de movimentos de inserção e remoção, além de quantos clientes serão relocados por rodada para o Relocate e na Seção 7.3.2 para determinar o tamanho máximo do trecho a ser trocado no Cross. Para o movimento 2-opt*, não existem parâmetros a serem calibrados. Assim como feito nos testes para determinar os índices de $\alpha$ e $\beta$ na Seção 6.3. os testes são calibradas nas 54 instâncias de teste (ver Seção 4.1.1).

Finalmente, para avaliar a qualidade dos movimentos de busca local e seus operadores propostos neste trabalho e para calibrar alguns parâmetros necessários, testes computacionais foram realizados nas 168 instâncias de referência detalhadas na Seção 4.1.

Os experimentos numéricos foram realizados com um computador Intel Core i5-2520M 2,5GHz, com 3,41GB de memória RAM e programados na linguagem C usando o editor Microsoft Visual Studio 2015.

\subsubsection{RELOCATE}

Para delinear e calibrar o movimento RELOCATE, o movimento foi executado usando operadores de remoção RR, WDR e GR e com operador de inserção SCI, SDI, C1I e RI. Cada combinação de operadores de remoção e inserção foi testada para que seu impacto seja avaliado. Cada iteração da busca local usou como critério de aceitação o best accept, ou seja, a solução escolhida é a que apresenta o melhor resultado. O número de clientes avaliados por rodada, algo a ser determinado em seguida, foi testado de $10 \%$ a $60 \%$ do total de clientes da instância, aumentando a cada $10 \%$ para que o volume de avaliações por rodada não comprometa a avaliação dos movimentos.

Na Tabela 10 estão expostos os valores médios da função objetivo obtidos após a execução da heurística construtiva SCIH2 e a busca local com movimento RELOCATE. Em negrito estão destacados as combinações de movimentos que, para cada percentual de clientes avaliados, geraram o melhor valor de função objetivo.

Os resultados deixam claro que os movimentos GR (Remoção Gananciosa) e GI (Inserção Gananciosa) geram a maior redução de custo. Ambos tem em comum no critério a avaliação de impacto direto na função objetivo. 


\begin{tabular}{cc|cccccc}
\hline \multicolumn{2}{c}{ Operador Relocate } & \multicolumn{5}{|c}{ Custo total para cada \% de clientes relocados por rodada } \\
\hline Remoção & Inserção & $10 \%$ & $20 \%$ & $30 \%$ & $40 \%$ & $50 \%$ & $60 \%$ \\
\hline RR & SDI & $1,925.5$ & $1,924.5$ & $1,921.8$ & $1,922.5$ & $1,921.6$ & $1,920.6$ \\
RR & GI & $1,926.0$ & $1,920.3$ & $1,915.5$ & $1,912.8$ & $1,912.2$ & $1,911.4$ \\
RR & C1I & $1,926.2$ & $1,920.3$ & $1,922.3$ & $1,918.4$ & $1,916.3$ & $1,916.1$ \\
RR & RI & $1,932.2$ & $1,931.3$ & $1,927.4$ & $1,930.5$ & $1,929.6$ & $1,928.5$ \\
WDR & SDI & $1,924.9$ & $1,923.0$ & $1,922.0$ & $1,921.1$ & $1,917.3$ & $1,917.2$ \\
WDR & GI & $1,921.4$ & $1,917.2$ & $1,915.2$ & $1,913.5$ & $1,912.4$ & $1,911.3$ \\
WDR & C1I & $1,922.5$ & $1,918.8$ & $1,915.7$ & $1,914.9$ & $1,913.9$ & $1,913.9$ \\
WDR & RI & $1,931.6$ & $1,927.1$ & $1,930.0$ & $1,928.7$ & $1,927.3$ & $1,925.3$ \\
GR & SDI & $1,921.1$ & $1,919.3$ & $1,917.8$ & $1,916.9$ & $1,916.3$ & $1,916.3$ \\
GR & GI & $\mathbf{1 , 9 1 4 . 6}$ & $\mathbf{1 , 9 1 2 . 1}$ & $\mathbf{1 , 9 1 1 . 4}$ & $\mathbf{1 , 9 1 0 . 1}$ & $\mathbf{1 , 9 1 0 . 4}$ & $\mathbf{1 , 9 1 0 . 3}$ \\
GR & C1I & $1,916.8$ & $1,915.0$ & $1,914.5$ & $1,913.6$ & $1,913.5$ & $1,913.4$ \\
GR & RI & $1,927.5$ & $1,927.4$ & $1,929.8$ & $1,927.0$ & $1,923.8$ & $1,925.2$ \\
WTR & SDI & $1,928.9$ & $1,927.8$ & $1,925.7$ & $1,924.1$ & $1,923.0$ & $1,922.7$ \\
WTR & GI & $1,928.1$ & $1,924.3$ & $1,921.3$ & $1,919.0$ & $1,918.1$ & $1,917.4$ \\
WTR & C1I & $1,928.8$ & $1,924.9$ & $1,922.3$ & $1,920.6$ & $1,919.6$ & $1,919.5$ \\
WTR & RI & $1,932.1$ & $1,931.7$ & $1,930.9$ & $1,929.5$ & $1,928.0$ & $1,928.5$ \\
C1R & SDI & $1,924.3$ & $1,923.7$ & $1,922.4$ & $1,920.7$ & $1,920.3$ & $1,919.2$ \\
C1R & GI & $1,921.6$ & $1,917.9$ & $1,916.7$ & $1,914.5$ & $1,913.4$ & $1,912.8$ \\
C1R & C1I & $1,922.5$ & $1,919.3$ & $1,918.5$ & $1,916.6$ & $1,915.9$ & $1,915.7$ \\
C1R & RI & $1,928.5$ & $1,929.3$ & $1,929.2$ & $1,925.5$ & $1,929.6$ & $1,926.8$ \\
\hline
\end{tabular}

Tabela 10: Resultados da função objetivo dos problemas de calibração para escolha dos movimentos de remoção e inserção do movimento RELOCATE. 


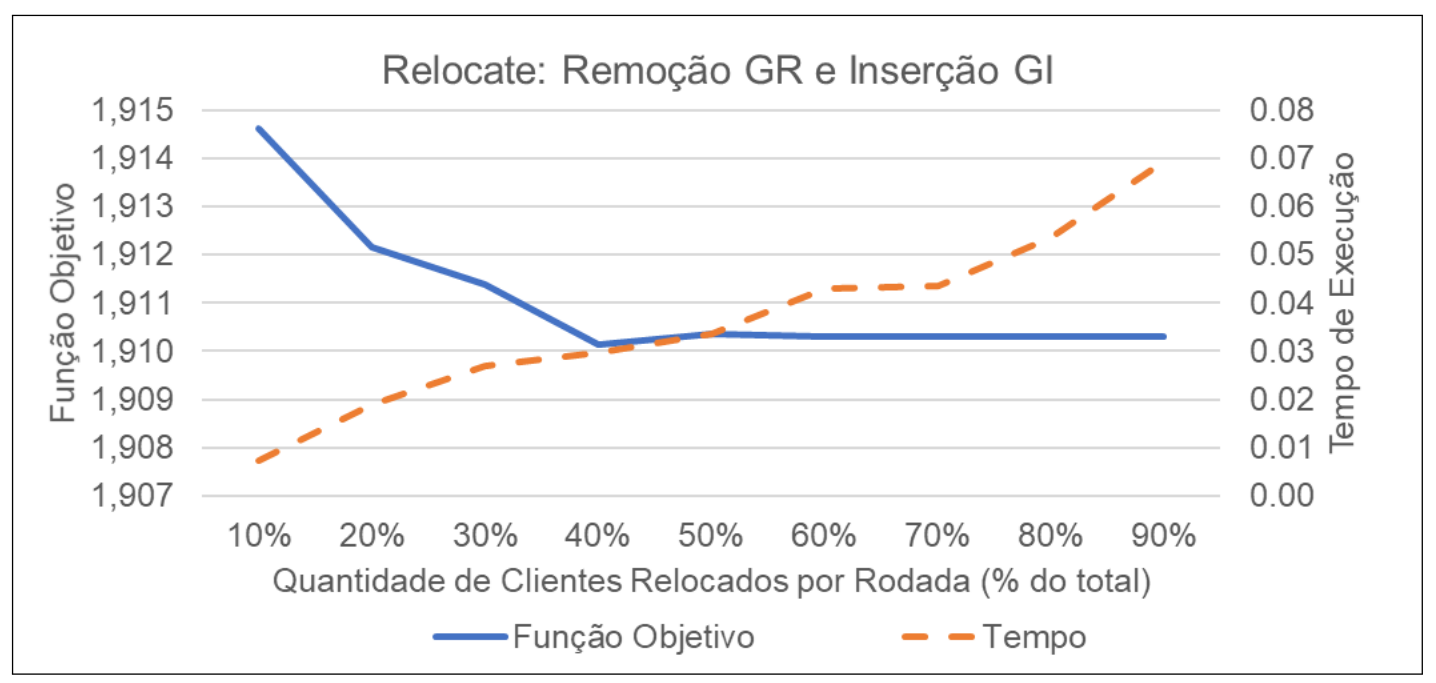

Figura 22: Valor médio da função objetivo e tempo gasto por percentagem de clientes trocados a cada interação.

Após entender qual combinação de movimentos gera os melhores resultados, é preciso determinar qual percentual de clientes deve ser trocado por rodada para se obter um balanço adequado de tempo de execução e melhoria na função objetivo.

Para isso, foi gerado o gráfico da Figura 22 que mostra duas curvas, a de média do custo total das instâncias (função objetivo) e o tempo médio de execução. Todas as 168 instâncias de referência foram resolvidas a partir da heurística SCIH2 e, em seguida, realizado o movimento de busca local com o operador de remoção GR e de inserção GI, com a relocação de cada percentual de clientes apresentados no eixo horizontal do gráfico

A partir da Figura 22 nota-se que a partir de $40 \%$ dos clientes, o ganho em redução de custo total passa a ser muito pouco significativo. De fato, em $40 \%$ o valor médio das funções objetivo é de 1860,71 e em 100\% esse valor se reduz até 1860,48, uma redução de 0,01\%. Entretanto, o valor médio para o RELOCATE com 30\% é de 1862,32, portanto ainda existe um ganho de $0,09 \%$ com o aumento para $40 \%$.

Desta forma, o movimento RELOCATE será utilizado nas buscas locais com os operadores GR para remoção da solução e GI para a re-inserção na solução.

\subsubsection{Cross}

Assim como feito para o Relocate, testes foram realizados nas 54 instâncias de teste (ver Seção 4.1.1) para determinar critérios e parâmetros do movimento.

Para garantir que a vizinhança do Cross seja explorada da melhor forma, a busca foi 


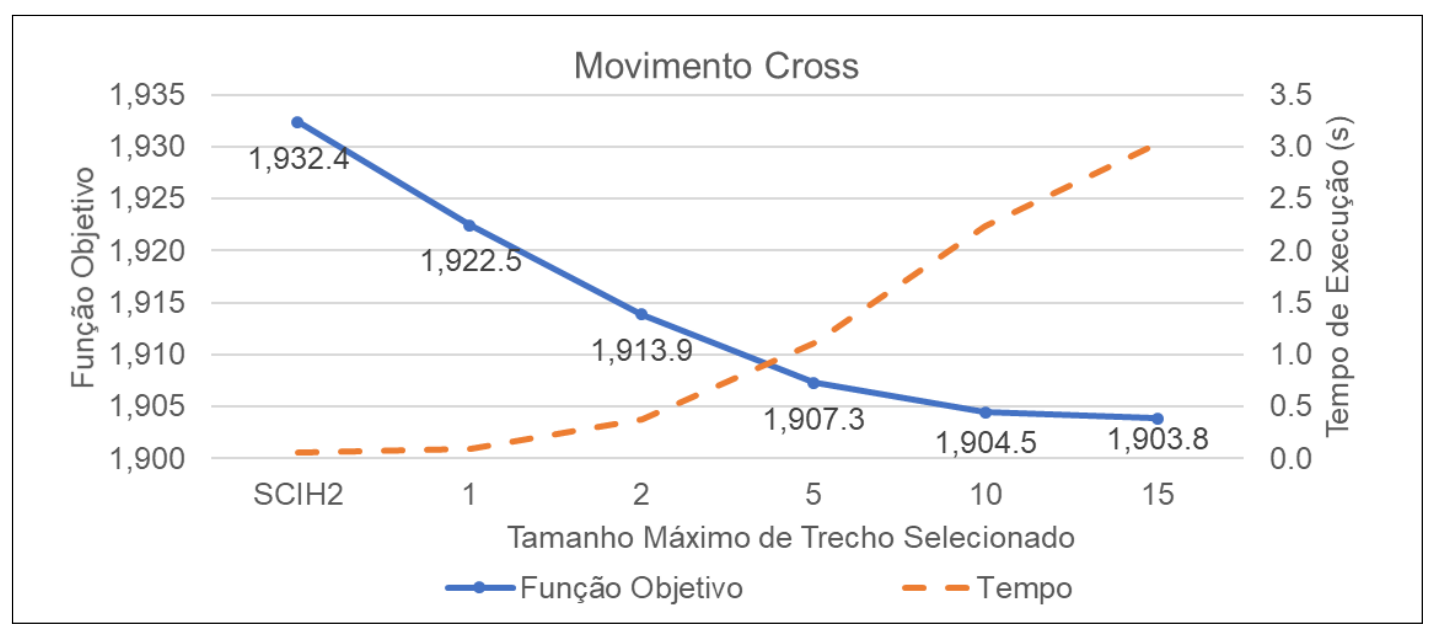

Figura 23: Valor médio da função objetivo e tempo gasto por tamanho máximo de trecho a ser trocado de cada rota a cada interação.

realizada avaliando todas as trocas possíveis, ou seja, para todos os pares possíveis de rotas, todos os trechos possíveis devem ser extraídos. Entretanto, para evitar um esforço computacional exageradamente grande, o tamanho máximo dos trechos a serem trocados entre as rotas foi limitado. Para determinar esses limites, testes foram executados com trechos máximos de apenas 1 2, 5, 10 e 15 clientes.

O resultado está apresentado na Figura 23 em que o valor médio da função objetivo e o tempo de execução é apresentado para visualização do ganho de função objetivo ao ser comparado com o tempo necessário para execução

A partir da Figura 23 pode se determinar que limitar o trecho máximo a 5 clientes alcança um ganho em função objetivo relevante sem gerar um aumento de tempo grande, como acontece com o caso de passar o trecho máximo para 10 clientes, com o qual a função objetivo média reduz em $0.15 \%$ e o tempo de execução mais do que dobra.

\subsubsection{Comparação entre Buscas Locais}

Finalmente, para se avaliar a qualidade das buscas locais geradas, a Tabela 11 apresenta o resultado obtidos com as buscas locais executadas com cada movimento para as 168 instâncias de referência, detalhadas na Seção 4.1 .

Os critérios para as buscas foram:

- Critério Best Accept, ou seja, a cada rodada a melhor solução encontrada (menor custo de função objetivo) é aceita como nova solução incumbente. 
- Somente soluções factíveis são consideradas.

- A Busca Local é executada até que não se encontre uma solução melhor à atual, ou seja, com custo da função objetivo menor.

Para cada vizinhança, os seguintes critérios são considerados:

- Relocate: O operador de remoção utilizado é o GR e o de inserção é o GI. A cada rodada $40 \%$ dos clientes são removidos e reinseridos (um por vez) e a relocação que gera a maior redução de custo é executada;

- 2-Opt*: Todas as combinações possíveis de rotas são tentadas e para cada par de rotas, todos os pontos de troca são feitos. O que gerar a maior redução de custo é executada;

- Cross: Todas as combinações possíveis de rotas são tentadas e para cada par de rotas, todos os possíveis trechos, limitados a 5 clientes, são trocados. O que gerar a maior redução de custo é executada.

A partir da Tabela 11 vemos que os três movimentos geram vizinhanças com desempenho similar, com melhorias na casa de $2 \%$ em relação ao valor obtido pela SCIH2. O movimento Cross se destaca dentre as instâncias de janelas de tempo apertada (R1, C1 e $\mathrm{RC} 1)$ e na média geral das instâncias obtém o melhor resultado. O movimento Relocate tem melhor desempenho nas janelas menos apertadas (C2 e R2 e RC2), dividindo com o 2-Opt* os melhores resultados desses grupos.

Os três métodos, portanto, geram melhorias com reduções totais próximas, embora cada um se destacando em diferentes tipos de problema e com tempo de execução de no máximo 2,5 segundos. É possível concluir que nesse capítulo foram gerados movimentos com características distintas e de execução em tempo factível e que respeitam as características do problema, como as janelas de tempo. 


\begin{tabular}{|c|c|c|c|c|c|c|c|c|c|c|c|}
\hline \multirow{2}{*}{ Grupo } & \multirow[t]{2}{*}{ Qtd } & \multirow{2}{*}{$\begin{array}{l}\text { SCIH2 } \\
\text { Méd. }\end{array}$} & \multicolumn{3}{|c|}{ Relocate } & \multicolumn{3}{|c|}{ 2-Opt* } & \multicolumn{3}{|c|}{ Cross } \\
\hline & & & Méd. & $\%$ Red & Tempo & Méd. & $\%$ Red & Tempo & Méd. & $\%$ Red & Tempo \\
\hline C1a & 9 & $6,196.5$ & $6,179.0$ & 0.3 & 0.04 & $6,180.4$ & 0.3 & 0.15 & $6,168.8$ & 0.4 & 1.42 \\
\hline $\mathrm{C} 1 \mathrm{~b}$ & 9 & $1,616.4$ & $1,603.4$ & 0.8 & 0.05 & $1,603.3$ & 0.8 & 0.15 & $1,597.5$ & 1.2 & 1.05 \\
\hline $\mathrm{C} 1 \mathrm{c}$ & 9 & $1,035.8$ & $1,030.9$ & 0.5 & 0.04 & $1,030.9$ & 0.5 & 0.09 & $1,025.7$ & 1.0 & 0.74 \\
\hline $\mathrm{C} 1$ & 27 & 2,949.6 & $2,937.8$ & 0.4 & 0.04 & $2,938.2$ & 0.4 & 0.13 & $2,930.7$ & 0.6 & 1.07 \\
\hline $\mathrm{C} 2 \mathrm{a}$ & 8 & $5,302.6$ & $5,285.3$ & 0.3 & 0.15 & $5,295.4$ & 0.1 & 0.18 & $5,292.0$ & 0.2 & 0.87 \\
\hline $\mathrm{C} 2 \mathrm{~b}$ & 8 & $1,302.6$ & $1,285.3$ & 1.3 & 0.18 & $1,295.4$ & 0.6 & 0.18 & $1,292.0$ & 0.8 & 0.87 \\
\hline $\mathrm{C} 2 \mathrm{c}$ & 8 & 820.4 & 803.0 & 2.1 & 0.17 & 795.1 & 3.1 & 0.21 & 802.6 & 2.2 & 0.99 \\
\hline $\mathrm{C} 2$ & 24 & $2,475.2$ & $2,457.8$ & 0.7 & 0.17 & $2,462.0$ & 0.5 & 0.19 & $2,462.2$ & 0.5 & 0.91 \\
\hline R1a & 12 & $2,885.0$ & $2,833.6$ & 1.8 & 0.09 & $2,838.6$ & 1.6 & 0.45 & $2,805.7$ & 2.7 & 2.48 \\
\hline $\mathrm{R} 1 \mathrm{~b}$ & 12 & 813.1 & 806.4 & 0.8 & 0.06 & 808.0 & 0.6 & 0.15 & 799.8 & 1.6 & 1.06 \\
\hline $\mathrm{R} 1 \mathrm{c}$ & 12 & 555.9 & 544.3 & 2.1 & 0.07 & 547.6 & 1.5 & 0.19 & 539.8 & 2.9 & 1.50 \\
\hline $\mathrm{R} 1$ & 36 & $1,418.0$ & $1,394.8$ & 1.6 & 0.07 & 1,398.0 & 1.4 & 0.26 & $1,381.7$ & 2.6 & 1.68 \\
\hline $\mathrm{R} 2 \mathrm{a}$ & 11 & $2,891.0$ & $2,777.4$ & 3.9 & 0.28 & $2,697.1$ & 6.7 & 0.38 & $2,709.8$ & 6.3 & 2.72 \\
\hline $\mathrm{R} 2 \mathrm{~b}$ & 11 & 942.9 & 880.8 & 6.6 & 0.27 & 894.4 & 5.2 & 0.34 & 887.9 & 5.8 & 2.07 \\
\hline $\mathrm{R} 2 \mathrm{c}$ & 11 & 651.5 & 648.4 & 0.5 & 0.19 & 648.5 & 0.4 & 0.24 & 648.5 & 0.4 & 0.77 \\
\hline $\mathrm{R} 2$ & 33 & $1,495.1$ & $1,435.5$ & 4.0 & 0.25 & $1,413.3$ & 5.5 & 0.32 & $1,415.4$ & 5.3 & 1.85 \\
\hline $\mathrm{RCla}$ & 8 & $3,352.3$ & $3,342.4$ & 0.3 & 0.04 & $3,342.1$ & 0.3 & 0.20 & $3,313.8$ & 1.1 & 1.06 \\
\hline $\mathrm{RC} 1 \mathrm{~b}$ & 8 & $1,061.9$ & $1,053.3$ & 0.8 & 0.04 & $1,051.0$ & 1.0 & 0.17 & $1,036.7$ & 2.4 & 1.01 \\
\hline $\mathrm{RC} 1 \mathrm{c}$ & 8 & 698.2 & 679.0 & 2.8 & 0.06 & 691.5 & 1.0 & 0.15 & 683.5 & 2.1 & 1.17 \\
\hline $\mathrm{RC} 1$ & 24 & $1,704.1$ & $1,691.5$ & 0.7 & 0.05 & $1,694.8$ & 0.5 & 0.17 & $1,678.0$ & 1.5 & 1.08 \\
\hline $\mathrm{RC} 2 \mathrm{a}$ & 8 & $3,151.0$ & $3,107.8$ & 1.4 & 0.10 & $3,124.5$ & 0.8 & 0.18 & $3,119.9$ & 1.0 & 1.11 \\
\hline $\mathrm{RC} 2 \mathrm{~b}$ & 8 & 872.5 & 871.5 & 0.1 & 0.09 & 871.5 & 0.1 & 0.15 & 871.5 & 0.1 & 0.64 \\
\hline $\mathrm{RC} 2 \mathrm{c}$ & 8 & 534.6 & 534.6 & 0.0 & 0.10 & 534.6 & 0.0 & 0.15 & 534.6 & 0.0 & 0.52 \\
\hline $\mathrm{RC} 2$ & 24 & $1,519.4$ & $1,504.6$ & 1.0 & 0.10 & $1,510.2$ & 0.6 & 0.16 & $1,508.7$ & 0.7 & 0.76 \\
\hline Méd & & $1,885.7$ & $1,849.7$ & 1.9 & 0.11 & $1,848.0$ & 2.0 & 0.21 & 1,841.1 & 2.4 & 1.28 \\
\hline
\end{tabular}

Tabela 11: Valor Médio da função objetivo, redução do valor em relação à heurística construtiva e tempo médio de execução em segundos obtido pelos três movimentos de busca local propostos neste capítulo e percentual de redução obtido a partir da heurística SCIH2 agrupados por grupos de instância. 


\section{META-HEURÍSTICAS}

A partir das heurísticas construtivas propostas e das buscas locais definidas, abordagens de meta-heurísticas foram propostas com o objetivo de gerar uma solução robusta e mais próxima do ótimo global. Seu intuito é melhorar os resultados já obtidos a partir da exploração de diferentes vizinhanças e escapar dos ótimos locais encontrados pelas buscas locais.

Para a escolha de métodos a serem aplicados, foi levado em consideração o apontamento de Penna et al. (2019) de que não existe uma meta heurística que é a melhor para qualquer problema, sendo que o desempenho de cada uma varia de acordo com o problema, variando até mesmo entre instâncias do mesmo tipo de problema. Os autores apontam que o sucesso de um método não está determinado de antemão, pelo enunciado, mas sim em seus componentes específicos, buscas em vizinhança bem estruturadas, um cuidadoso balanço entre estratégias de intensificação e diversificação. Concordando com essa visão esse trabalho buscou métodos que atendam às características citadas e encontrou no VNS e no GRASP as melhores opções a serem aplicadas.

Esses métodos têm esquema de utilização simples e requerem poucos parâmetros para se obter uma boa execução. Assim, além de gerar soluções muito boas, de forma mais simples que outros métodos, o VNS e GRASP ainda permitem entender o que geram seu desempenho e o que pode auxiliar nas suas implementações de forma mais eficiente e sofisticada, como está detalhado a seguir.

Finalmente, experimentamos a combinação dos dois métodos em uma meta-heurística híbrida. Como se tratam de dois métodos que seguem princípios similares de se aproveitar de características do problema para gerar soluções, mas tem atuação em momentos diferentes, é possível gerar um método que combina os dois e busca aproveitar as duas estratégias na busca de soluções melhores

Nesse capítulo, a Seção 8.1 apresenta o VNS, a Seção 8.2 apresenta o GRASP e a Seção 8.3. Em cada seção, é feita uma apresentação geral do método, exploram-se casos 
de sucesso na literatura, detalha-se sua definição e como ele será utilizado neste trabalho, calibram-se parâmetros e avaliam-se seu desempenho ao resolver as instâncias propostas neste trabalho.

\subsection{Busca em vizinhança variável (VNS)}

O VNS (Variable Neighborhood Search) foi proposto inicialmente por Mladenović e Hansen (1997). Desde então o método foi amplamente usado para resolver diversos tipos de problemas e sua forma de aplicação passou por diversos novos desenvolvimentos para melhorar os resultados obtidos. Em um survey sobre o tema, Hansen, Mladenović e Pérez (2010) enumeraram os três fatos nos quais o VNS se baseia:

Fato 1: Um mínimo local para uma vizinhança não é necessariamente o mínimo local para outra vizinhança;

Fato 2: O mínimo global é um mínimo local em relação a todas as vizinhanças possíveis;

Fato 3: Para muitos problemas, os mínimos locais de diversas vizinhanças estão relativamente próximos uns aos outros.

O Fato 3 é empírico e, a partir dele, é possível entender que um mínimo local já fornece algumas informações sobre o mínimo global. De fato, é provável que grande parte das variáveis já possua o mesmo valor na solução de ótimo global e, portanto, busca na vizinhança em torno de uma solução obtida é uma boa estratégia para encontrar o próximo mínimo local e se aproximar cada vez mais do ótimo global.

A partir de uma solução inicial, a busca local é feita utilizando diferentes estruturas de vizinhança. Ao encontrar pelo menos uma solução melhor, o método migra para essa nova solução onde a sequência de buscas locais em diferentes estruturas de vizinhança é feita novamente. Para expandir as buscas locais, uma perturbação, com base em mudanças aleatórias, é aplicada à solução para que novas vizinhanças sejam exploradas e, assim, escapar de mínimos locais.

A Figura 24, extraída de Hansen, Mladenović e Pérez (2010), ilustra o procedimento. A partir de uma solução inicial $x$, buscas nas vizinhanças $N_{i}(x)$, onde $i=1,2, . ., k$, são

feitas para se encontrar um novo mínimo local expresso por $x^{\prime}$. Cada vizinhança está expressa por um tom de cinza diferente. As buscas são expandidas por perturbações que são representadas na Figura 24, pelo pontos em formato de losango e, a partir desta 


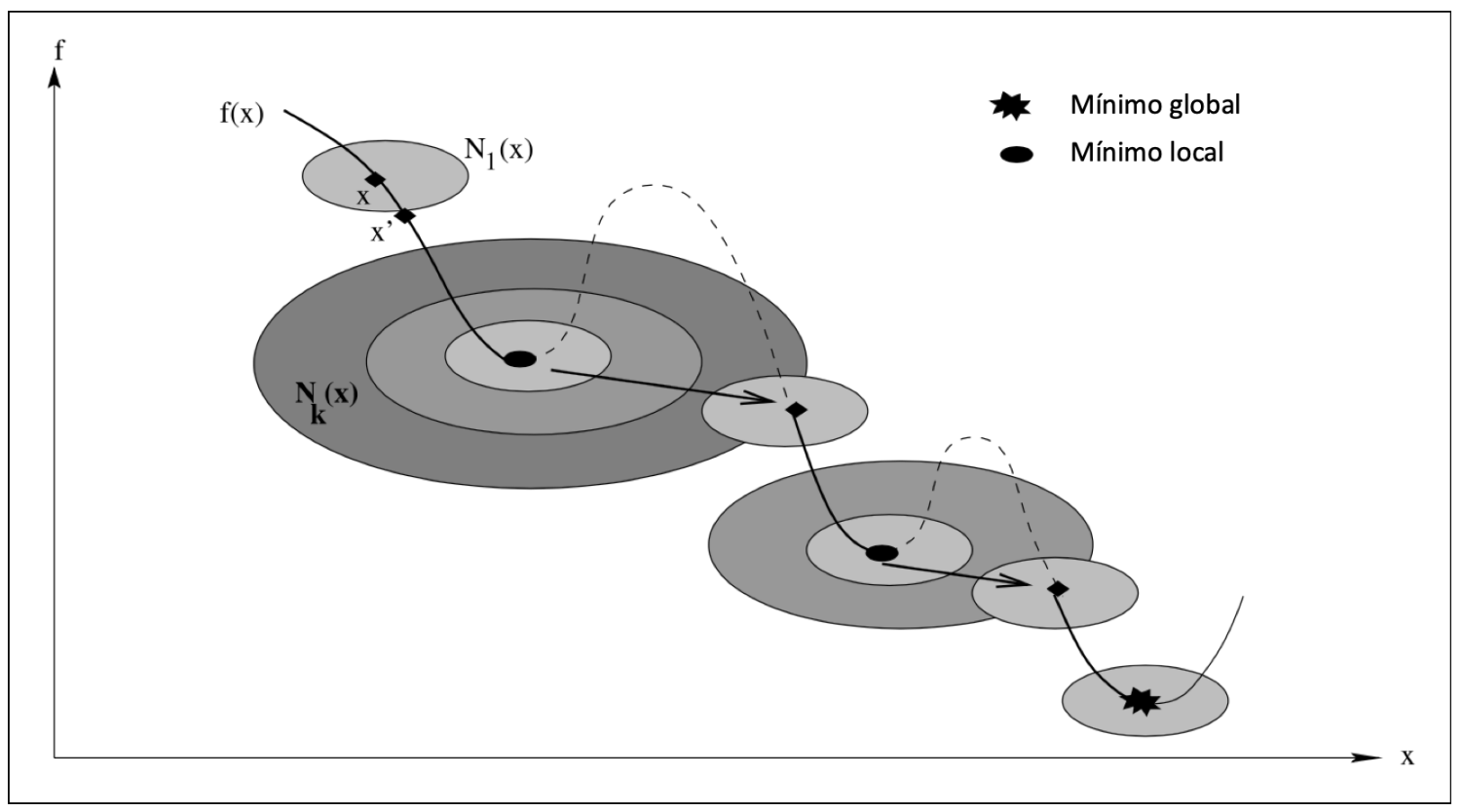

Figura 24: Representação gráfica da dinâmica de funcionamento básico do VNS. Figura extraída de Hansen, Mladenović e Pérez (2010).

solução nova busca local é executada para encontrar um novo mínimo local. O processo se repete até o que, se espera, ser o ótimo global.

\subsubsection{Aplicações bem-sucedidas}

O VNS método foi destacado no trabalho de Bräysy e Gendreau (2005b) por gerar bons resultados para problemas de roteamento de veículos com janelas de tempo. Laporte (2009) também ressaltou o uso do método em diversas variações para o problema VRP, assim como Vidal et al. (2013b) que também destacam este método ressaltando a sua versatilidade que permite inclusive o uso em meta-heurísticas híbridas, que combinam diferentes métodos conhecidos na busca da solução ótima.

O trabalho de Hansen, Mladenović e Pérez (2010) é dedicado a expor o VNS, abordar os diferentes problemas em que pode ser aplicado e sua evolução com novas estratégias sendo inclusas. O trabalho evidencia a grande versatilidade do método e as muitas possibilidades de aplicação em problemas desde telecomunicações ao problema da mochila, programação de produção e roteamento. Em uma seção deste trabalho, 29 diferentes artigos de diversos tipos de problemas de roteamento de veículos resolvidos por VNS são apresentados.

Como já apresentado na Seção 7.1. Paraskevopoulos et al. (2008) apresentam o método 
ReVNTS para abordar o HFVRPTW, problema de roteamento de veículos com frota heterogênea e janelas de tempo. O VNS é executado juntamente com Busca Tabu no momento de fazer a busca em vizinhança para expandir as vizinhanças exploradas pelo método.

Kytöjoki et al. (2007) aplicaram este método ao problema de roteamento de veículo capacitados com instâncias de larga escala, ou seja, problemas de roteamento de veículos com mais de 500 clientes, podendo chegar a dezenas de milhares. Já Imran, Salhi e Wassan (2009) geram uma variação do VNS para a solução do HFVRP (Heterogeneous Fleet Vehicle Routing Problem).

Hemmelmayr, Doerner e Hartl (2009) abordaram o PVRP (Periodic Vehicle Routing Problem), problema de roteamento de veículos em que as rotas são feitas em diferentes períodos de entrega, com cada veículo partindo uma vez por período e não apenas uma única vez como no tradicional VRP. O VNS foi aplicado com sucesso ao problema, utilizando critérios similares ao Simulated Annealing (SA) para controlar a busca por novas vizinhas mesmo quando a solução inicial da busca nessa nova vizinhança é pior do que a solução incumbente, e apresentou resultados consistentemente superiores aos demais métodos para solução do PVRP à época.

Gahm, Brabänder e Tuma (2017) aplicam o VNS para a resolução do VRPPCdR, o problema de roteamento de veículos com frota privada, múltiplos fornecedores de transporte com descontos por volume transportado, e opções de locação de frota. Esse problema busca decidir quais clientes deixar para os fornecedores de transporte entregarem, qual fornecedor utilizar para cada entrega e, para os que forem entregues pela frota própria, considerar a locação de veículos extras e fazer o roteamento desta entrega. Este problema foi resolvido com três meta-heurísticas derivadas do VNS.

Mais recentemente, Simeonova et al. (2018) propõe uma variação do VNS combinado com memória adaptiva (AMP) para um problema de VRP rico em restrições reais.

Adicionalmente, é possível perceber o interesse da comunidade científica nesse método pela sua aplicação em outros campos e edições de periódicos dedicadas a explorar o método. Em 2014, o periódico Computers $\&$ Operations Research lançou o volume 52 dedicado a artigos com solução a partir do VNS. O periódico International Transactions in Operational Research (ITOR) também lançou, em 2016, uma edição dedicada ao tema, que abordou diversos problemas solucionados por esse método.

Portanto, é possível identificar benefícios em se utilizar o VNS para solucionar o FSMVRPTWSC, podendo aplicar algumas derivações a ele conforme as características 
do problema mostrarem ser oportunas.

A seguir são apresentados um leiaute geral do procedimento, o detalhamento de como ele é executado no problema deste trabalho e seus resultados.

\subsubsection{Procedimento básico}

Dentre suas diversas variações, o VNS possui etapas que constituem sua essência e podem ser incrementadas com outros métodos. Essas etapas são:

- Inicialização: Uma solução inicial é gerada.

- Busca local: O ótimo local é encontrado usando busca em vizinhança.

- Perturbação (shake, jump): Um movimento diferente dos utilizados na busca local é utilizado para levar a busca a uma nova vizinhança onde uma nova busca local deve ser feita.

- Recorrência: Até o critério de parada ser atingido, repete-se iterativamente a busca local seguida de perturbação.

O Algorítimo 5 apresenta um pseudo-código do procedimento geral do VNS.

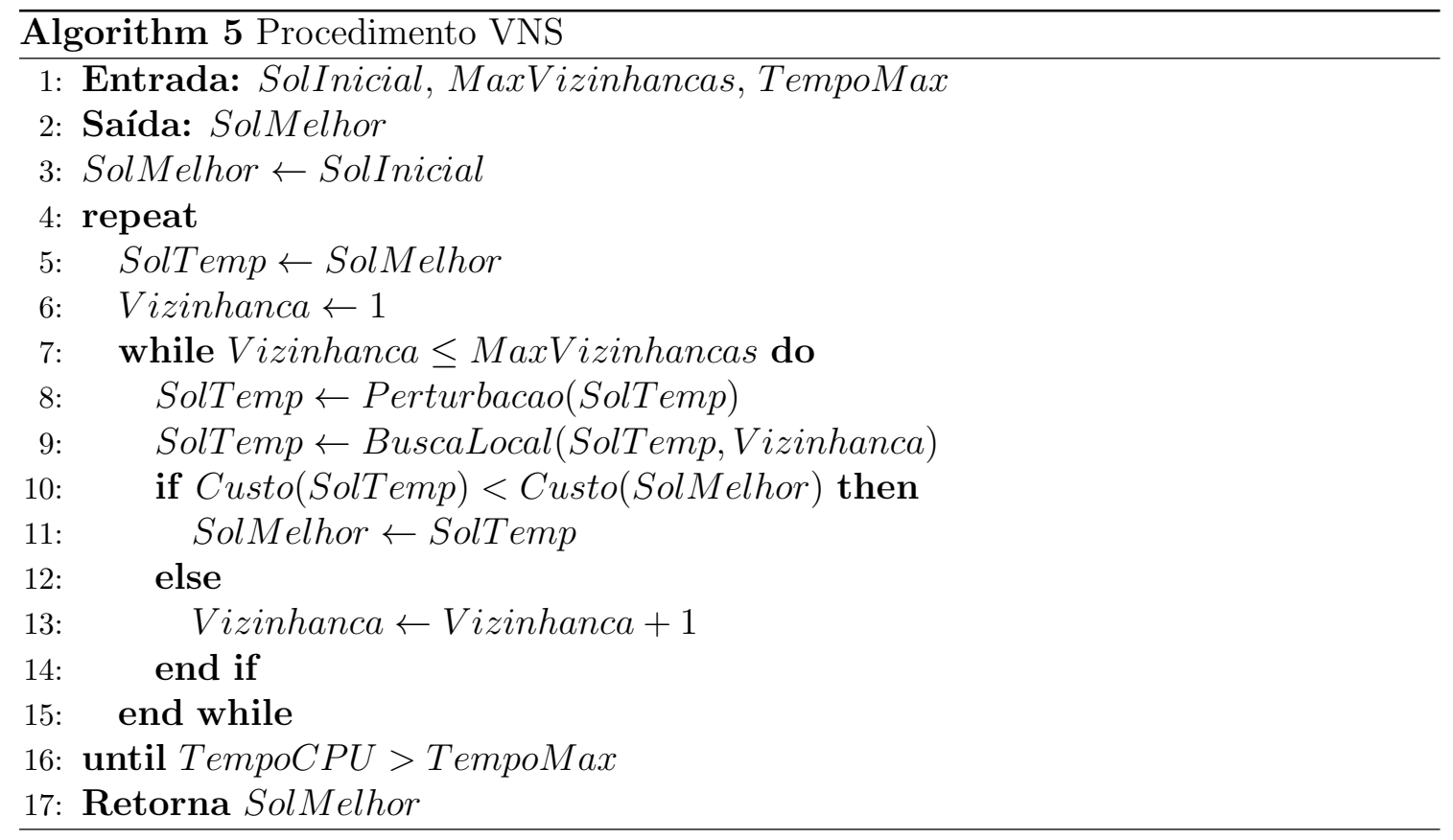

O processo parte de uma solução inicial, e realiza uma sequência de buscas locais. Cada uma delas é precedida por uma perturbação afim de gerar um deslocamento na 


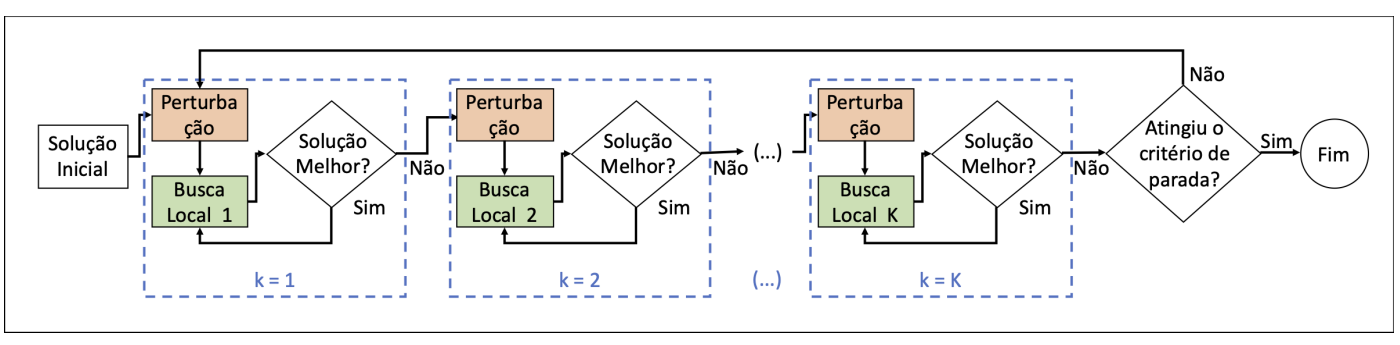

Figura 25: Fluxograma do VNS básico.

vizinhança para buscar mínimos locais diferentes e, eventualmente, melhores. A cada busca local realizada, a qualidade da nova solução obtida é avaliada e, caso ela seja melhor que a solução atual, essa é substituída e repete-se a busca na vizinhança a partir da nova solução. Caso a nova solução obtida não seja melhor, mantém-se a solução atual e uma nova vizinhança é avaliada. O processo é repetido até que o critério de parada seja encontrado, neste caso, dado pelo tempo computacional de execução do método. Para facilitar a visualização desse procedimento, a Figura 25 apresenta o fluxograma do VNS básico.

Por essa explicação aliada ao pseudo-código 5 e ao fluxograma da Figura 25, é possível concluir a importância de uma seleção de movimentos para geração de vizinhanças de busca local bem calibrado e coerente com o problema executado. Ao mesmo tempo que deve ser capaz de gerar diversidade de soluções para fugir de mínimos locais, não deve ser exageradamente amplo a ponto de tomar tempo computacional explorando vizinhanças pouco interessantes ou infactíveis.

A perturbação é outro importante fator do VNS que está presente em cada uma das vizinhanças. Deve ser elaborada de modo a não ser brusca demais a ponto de afastar demais da solução atual e perder qualidade e nem suave a ponto de não mover a solução para uma vizinhança com um novo mínimo local menor que o atual. Como mencionado em Paraskevopoulos et al. (2008), se a perturbação for muito forte, o método pode degenerar para uma meta-heurística multi-start simples.

A perturbação pode ser feita de duas formas. Busca em uma vizinhança gerada de forma diferente da vizinhança em andamento, como apresentado em Hemmelmayr, Doerner e Hartl (2009). Um movimento aleatório na vizinhança sendo explorada, como apresentado em Paraskevopoulos et al. (2008), Hansen, Mladenović e Pérez (2010), Imran, Salhi e Wassan (2009) e Palomo-Martínez et al. (2017).

Conforme rodadas são executadas sem a obtenção de melhoria na função objetivo, é necessário aumentar a intensidade da perturbação para passar a explorar vizinhanças mais 
distantes. Essa expansão, entretanto, deve ser cuidadosa para que antes de se expandir a busca, se permita uma busca cuidadosa das vizinhanças mais próximas antes de diversificar mais. Portanto, um dos parâmetros a serem calibrados é a quantidade de iterações sem melhoria $(I S M)$ antes de expandir a perturbação. Apesar de se acumularem iterações sem melhoria, a expansão da perturbação deve ser limitada até uma quantidade de movimentos que não descaracterize totalmente a solução explorada. Essa limitação, entretanto, deve ser determinada por vizinhança, uma vez que a perturbação é específica para cada uma.

\subsubsection{VNS Aplicado ao FSMVRPTWSC}

Neste trabalho, o VNS é aplicado para o solucionar o FSMVRPTWSC. Para tal, como visto na Seção 8.1.2, os parâmetros são escolhidos para explorar as características do problema da melhor forma.

Como visto na Seção 6.3 a heurística proposta SCIH2 é a que traz melhores resultados em diferentes tipos de instâncias. Tendo em vista que o VNS tem o princípio que boas soluções estão próximas umas das outras no espaço das soluções, portanto, a SCIH2 fornece a solução inicial para o VNS. As vizinhanças para exploração no VNS são as que foram determinadas no Capítulo 7. Elas são a Relocate, Cross e 2-opt*. A ordem de geração das vizinhanças, por sua vez, segue a recomendação de Hansen e Mladenovic (2003) de que as vizinhanças devem ser exploradas em ordem ascendente de tamanho de vizinhança. A justifica deriva, novamente, do Fato 3, apresentado no início desse capítulo, que diz que os mínimos locais para diferentes vizinhanças se encontram próximos entre si. A partir disso, a busca deve partir da vizinhança mais próxima do seu mínimo local conhecido e expandir conforme um novo mínimo local não é encontrado.

Desta forma a ordem das vinhanças a serem exploradas no VNS foi feita com base no tamanho das vizinhanças determinadas na Seção 7.2 e ficou definida como:

1. 2-opt*: A menor das vizinhanças, como deve ser feita a seleção de duas rotas diferentes e de um ponto qualquer em cada uma das rotas.

2. Cross: Segunda maior vizinhança, é semelhante à 2-opt*, porém além de selecionar duas rotas e um ponto em cada rota, também deve ser escolhido um trecho para troca.

3. Relocate: A maior vizinhança de todas pois permite a escolha de qualquer cliente para ser removido e re-inserido em qualquer posição disponível em qualquer rota. 
A perturbação (shake ou jump) é feita a partir da escolha aleatória de um movimento na vizinhança sendo explorada e, a cada quantidade pré-determinada de iterações sem melhora $(I S M)$ na função objetivo, a perturbação é intensificada visando que mais movimentos aleatórios permitam levar a solução a novas vizinhanças com novos mínimos locais. A forma de gerar a perturbação foi determinada da seguinte forma:

- Perturbação no 2-Opt*: A escolha das duas rotas é feita aleatoriamente, assim como a posição em que se trocam as rotas. Inicialmente, somente uma troca aleatória é executada e, a cada intensificação da perturbação, mais uma troca é feita até atingir o limitante de MaxShake2opt.

- Perturbação no Cross: A escolha das duas rotas é feita aleatoriamente, assim como a posição de início do trecho a ser trocado em cada uma delas. O tamanho do trecho da troca é escolhido aleatoriamente limitado, assim como no cross normal, ao tamanho limite de cinco clientes. Inicialmente, somente uma troca aleatória é feita e a cada intensificação da perturbação, mais uma trocas é executada, até o limite de cinco trocas aleatórias MaxShakeCross.

- Perturbação no Relocate: O movimento é feito com o critério de remoção RR (remoção aleatória) e de inserção RI (inserção aleatória). Como mencionado anteriormente, inicialmente, somente um cliente é realocado e, a cada intensificação da perturbação, o número de cliente relocados aumenta progressivamente até chegar a MaxShakeRelocate;

O critério de parada, como determinado em Hansen e Mladenovic (2003), é determinado pelo tempo de execução do procedimento.

\subsubsection{Experimentos Numéricos}

Experimentos numéricos foram feitos no VNS para calibrar seus parâmetros e avaliar seu impacto na obtenção de uma melhor função objetivo.

Os experimentos numéricos foram realizados com um computador Intel Core i5-2520M 2,5GHz, com 3,41GB de memória RAM e programados na linguagem C usando o editor Microsoft Visual Studio 2015. 


\subsubsection{Processo de Calibração de Parâmetros}

Como mencionado na Seção 8.1.2, uma das vantagens do VNS é possuir poucos parâmetros para sua execução. Devemos determinar parâmetros da perturbação e o tempo que o método deve ser executado.

Primeiramente, a calibração da Perturbação foi executada. Como explicado na Seção 8.1.3, é necessário determinar o número de iterações sem melhorias $(I S M)$ antes da intensificação da perturbação, bem como a intensidade máxima de movimentos de cada perturbação em cada vizinhança, ou seja, MaxShake2opt para o movimento 2-opt*, MaxShakeCross para o Cross e MaxShakeRelocate para o Relocate.

Os parâmetros a serem avaliados são baseados nos parâmetros definidos no Capítulo 7 para cada busca local.

Assim, os valores parâmetros avaliados para cada vizinhança foram os seguintes:

- ISM: 1, 5 ou 10 iterações sem melhoria até a intensificação da perturbação;

- MaxShake2opt: Perturbação limitada a trocas até 25\%, 50\% e 75\% do número de rotas da instância;

- MaxShakeCross: Trocas aleatórias limitadas a apenas 1\%, 5\% e 10\% do número de rotas da instância;

- MaxShakeRelocate: Relocate com remoção e inserção aleatórios limitados a 20\%, $30 \%$ e $40 \%$ do número de clientes.

O objetivo dessa avaliação é obter a melhor combinação de parâmetros para a perturbação, e não avaliar o critério de parada, o tempo de execução. Desta forma, o tempo por instância foi limitado a 5 minutos (300 segundos) por instância.

Todas as combinações dos parâmetros acima foram avaliadas, o que gera um total de 81 combinações possíveis. Assim, para a execução de cada instância, de cada combinação, portanto, necessários 405 minutos. Desta forma, as Instâncias de Calibração (descritas na Seção 4.1 .1 foram utilizadas reduzidas para 36 instâncias, sendo 2 para cada combinação, o que gera um total de 243 horas (mais de 10 dias) para executar toda a calibração.

Após a calibração, a Perturbação ficou parametrizada por:

- ISM: 10 iterações sem melhoria até a intensificação da perturbação; 


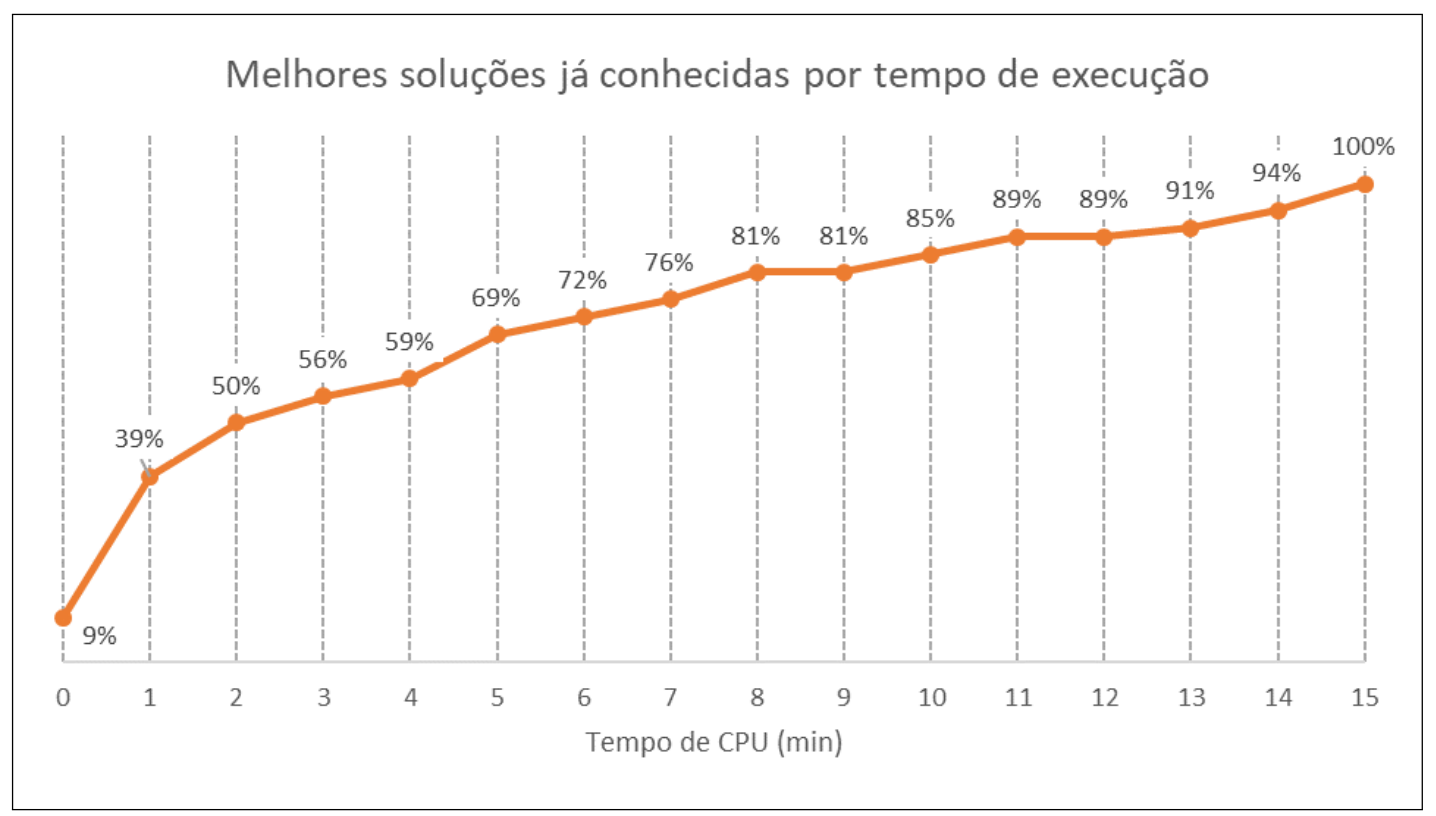

Figura 26: Quantidade de instâncias para as quais a melhor solução já é conhecida a cada minuto de execução.

- MaxShake2opt: $50 \%$ do número de rotas da instância;

- MaxShakeCross: 1\% do número de rotas da instância;

- MaxShakeRelocate: $40 \%$ do número de clientes.

Uma vez conhecidos os parâmetros da Perturbação, passou-se à calibração do critério de parada, que é o tempo de execução. A estratégia, nesse caso, é executar as 54 Instâncias de Calibração por um período longo de tempo e registrar o momento de cada melhoria até se encontrar o tempo em que as melhorias passam a ser menos frequentes, quando o método tem dificuldade de encontrar novos mínimos locais por já ter executada uma ampla busca no espaço das soluções.

O tempo considerado foi de 900 segundos (15 minutos) obtendo os resultados que são apresentados nas Figura 27. Note que, para o R1, a evolução se concentra nos primeiros segundos de execução, mas ainda apresentam frequentes melhoras até 120 segundos, a partir do qual existem novas evoluções, mas mais espalhadas no tempo.

Como visto, a dispersão dos momentos em que novas melhorias são encontradas variam até mesmo entre instâncias de tipos similares. Desta forma a análise foi feita avaliando todas as instâncias em conjunto, buscando perder o mínimo de movimentos de melhorias ao determinar um tempo limite.

Assim, a Figura 26 foi elaborada com o objetivo de tornar mais claro a evolução 


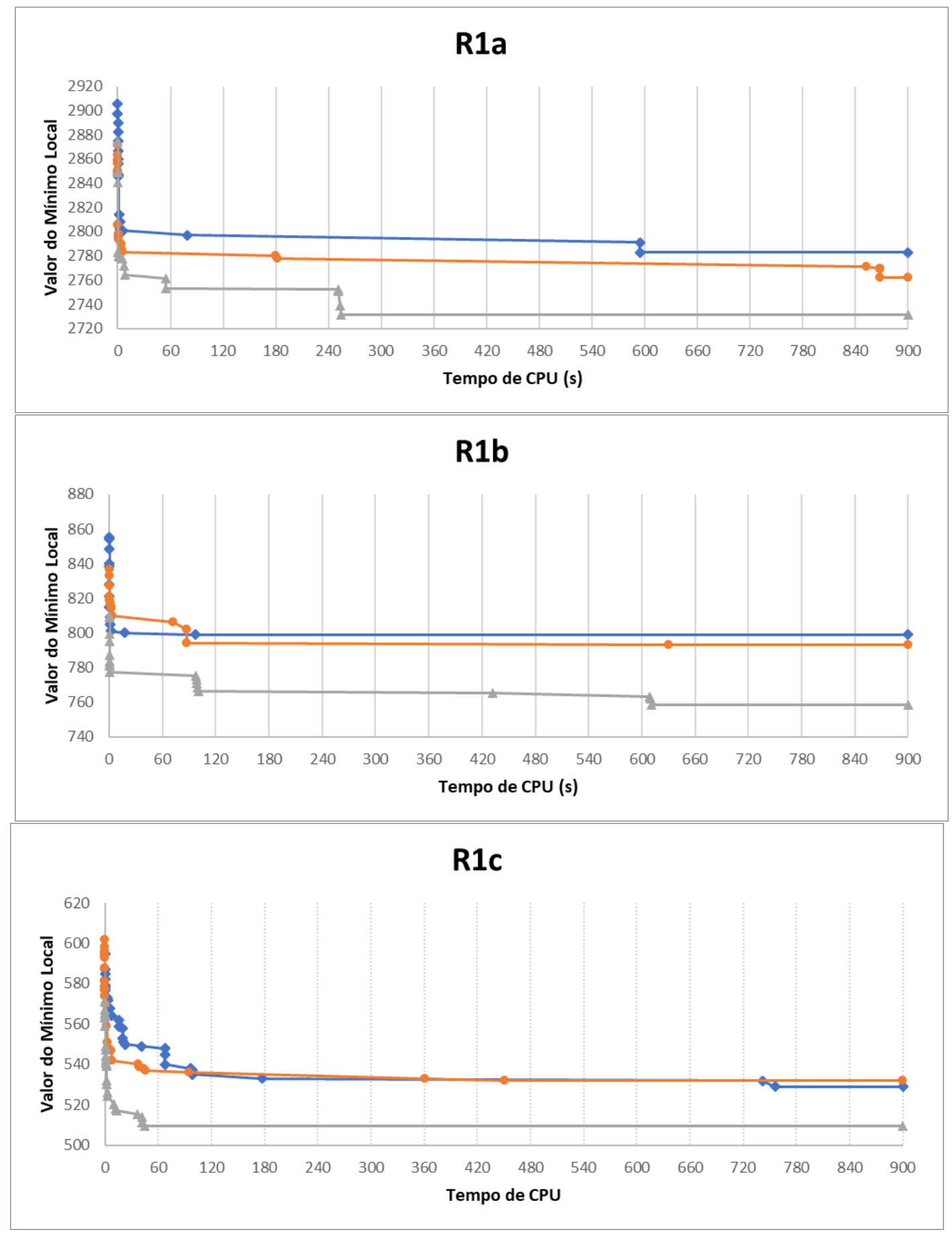

Figura 27: Gráficos da evolução no tempo do mínimo local conhecido para as 3 instâncias de calibração de cada tipo R1a, R1b e R1c. 
no tempo para todas as 54 Instâncias de Calibração. Nesta figura, a cada minuto de execução são contados quantas instâncias o melhor resultado já é conhecido. Por exemplo, no primeiro minuto, $9 \%$ das instâncias não melhoram em nenhum momento, portanto no instante 0 sua melhor solução já é conhecida. Ao fim do primeiro minuto, 39\% das instâncias já encontrou a melhor solução que será encontrada até o fim dos 15 minutos e assim por diante, até que ao fim do minuto $100 \%$ das instâncias vai ter encontrado seu melhor resultado do experimento.

Com esses dados, é notável que ao final do $10^{\circ}$ minuto já foram encontradas as melhores soluções de $85 \%$ das instâncias e, a partir deste ponto a evolução, se torna vagarosa, sendo necessário 33\% do tempo para encontrar os melhores resultados para apenas 15\% dos problemas. Entretanto, nesses problemas cuja melhor solução ainda não era conhecida após 10 minutos, a solução conhecida nesse momento tem o valor da função objetivo apenas $2 \%$ maior que a melhor solução conhecida após 15 minutos.

Portanto, o critério de parada do problema foi definido em 10 minutos.

\subsubsection{Instâncias de Referência}

Para avaliar o desempenho do VNS, a primeira forma é verificar os resultados nas Instâncias de Referência. A execução foi feita com os parâmetros determinados na calibração de parâmetros e estão apresentados na Tabela 12 .

A Tabela 12 apresenta na primeira coluna "Grupo"para qual grupo de instâncias os valores pertencem. Na coluna "Qtd" o número de instâncias que pertence ao grupo é destacado. Em seguida os valores da função objetivo "Custo"para a heurísitca SCIH2 seguida pela busca local Cross é apresentada. Esses valores foram escolhidos para comparação uma vez que são os melhores resultados conhecidos antes da utilização de uma meta-heurística. Finalmente, os valores do VNS são apresentados sob o título "VNS". "Custo"apresenta o valor médio da função objetivo para cada grupo, "\%Imp" o percentual de redução de custo que a VNS permitiu e "\%best"indica em quantas instâncias, percentualmente, de cada grupo a VNS trouxe resultados melhores.

Os resultados mostram que o VNS traz melhorias em 86\% das instâncias analisadas, mesmo quando comparado a um método que já passou por melhorias da melhor busca local conhecida neste trabalho. O valor de redução de custo obtido tem diferentes comportamentos, apesar da redução da média total ser de $2 \%$, em grupos como C2c, R1c e $\mathrm{RC} 1 \mathrm{c}$ a redução é superior a 7\%, além de outros grupos com melhorias como $6 \%$ no grupo R2b. 


\begin{tabular}{|c|c|c|c|c|c|}
\hline Grupo & Qtd & $\begin{array}{c}\text { SCIH } 2+\text { Cross } \\
\text { Custo }\end{array}$ & Custo & $\begin{array}{l}\text { VNS } \\
\% \operatorname{Imp}\end{array}$ & \%best \\
\hline C1a & 9 & $6,168.8$ & $6,145.6$ & 0.40 & 88.9 \\
\hline $\mathrm{C} 1 \mathrm{~b}$ & 9 & $1,597.5$ & $1,584.0$ & 0.80 & 66.7 \\
\hline $\mathrm{C} 1 \mathrm{c}$ & 9 & $1,025.7$ & $1,011.8$ & 1.40 & 88.9 \\
\hline $\mathrm{C} 1$ & 27 & $2,930.7$ & $2,913.8$ & 0.60 & 81.5 \\
\hline $\mathrm{C} 2 \mathrm{a}$ & 8 & $5,292.0$ & $5,243.3$ & 0.90 & 100.0 \\
\hline $\mathrm{C} 2 \mathrm{~b}$ & 8 & $1,292.0$ & $1,240.1$ & 4.00 & 100.0 \\
\hline $\mathrm{C} 2 \mathrm{c}$ & 8 & 802.6 & 743.0 & 7.40 & 100.0 \\
\hline $\mathrm{C} 2$ & 24 & $2,462.2$ & $2,408.8$ & 2.20 & 100.0 \\
\hline $\mathrm{R} 1 \mathrm{a}$ & 12 & $2,805.7$ & $2,750.9$ & 2.00 & 100.0 \\
\hline $\mathrm{R} 1 \mathrm{~b}$ & 12 & 799.8 & 766.5 & 4.20 & 100.0 \\
\hline $\mathrm{R} 1 \mathrm{c}$ & 12 & 539.8 & 502.0 & 7.00 & 100.0 \\
\hline $\mathrm{R} 1$ & 36 & $1,381.7$ & $1,339.8$ & 3.00 & 100.0 \\
\hline $\mathrm{R} 2 \mathrm{a}$ & 11 & $2,709.8$ & $2,640.2$ & 2.60 & 90.9 \\
\hline $\mathrm{R} 2 \mathrm{~b}$ & 11 & 887.9 & 832.9 & 6.20 & 90.9 \\
\hline $\mathrm{R} 2 \mathrm{c}$ & 11 & 648.5 & 624.6 & 3.70 & 81.8 \\
\hline $\mathrm{R} 2$ & 33 & $1,415.4$ & $1,365.9$ & 3.50 & 87.9 \\
\hline $\mathrm{RC} 1 \mathrm{a}$ & 8 & $3,313.8$ & $3,292.9$ & 0.60 & 100.0 \\
\hline $\mathrm{RC} 1 \mathrm{~b}$ & 8 & $1,036.7$ & 997.4 & 3.80 & 100.0 \\
\hline $\mathrm{RC} 1 \mathrm{c}$ & 8 & 683.5 & 635.4 & 7.00 & 100.0 \\
\hline $\mathrm{RC} 1$ & 24 & $1,678.0$ & $1,641.9$ & 2.20 & 100.0 \\
\hline $\mathrm{RC} 2 \mathrm{a}$ & 8 & $3,119.9$ & $3,086.5$ & 1.10 & 75.0 \\
\hline $\mathrm{RC} 2 \mathrm{~b}$ & 8 & 871.5 & 864.5 & 0.80 & 37.5 \\
\hline $\mathrm{RC} 2 \mathrm{c}$ & 8 & 534.6 & 534.6 & 0.00 & 0.0 \\
\hline $\mathrm{RC} 2$ & 24 & $1,508.7$ & $1,495.2$ & 0.90 & 37.5 \\
\hline \multicolumn{2}{|c|}{ Média } & $1,852.1$ & $1,816.0$ & 2.00 & 85.7 \\
\hline
\end{tabular}

Tabela 12: Resultados da instâncias de referência resolvidas com a Meta-Heurística VNS comparados com os resultados da Heurística construtiva SCIH2 e com os resultados da heurística após a busca local Cross. 


\begin{tabular}{c|cc|cc|cc}
\hline \multirow{2}{*}{ Dia } & \multicolumn{2}{|c|}{ Reportado } & \multicolumn{2}{|c|}{ SCIH2 } & \multicolumn{2}{c}{ VNS } \\
& Custo & Rotas & Custo & Rotas & Custo & Rotas \\
\hline 1 & $27,676.6$ & 58 & $27,189.0$ & 66 & $24,433.5$ & 41 \\
2 & $35,151.3$ & 65 & $28,307.1$ & 62 & $27,500.0$ & 50 \\
3 & $32,379.9$ & 59 & $28,654.2$ & 67 & $25,604.5$ & 43 \\
\hline Total & $95,207.8$ & 182 & $84,150.3$ & 195 & $77,538.0$ & 130 \\
\hline
\end{tabular}

Tabela 13: Custo e quantidade de rotas geradas a partir de cada método de solução para as instâncias inspiradas em dados reais.

Quando comparado à heurística SCIH2, antes de ser realizada a busca local, a redução na função objetivo chega a 4\%, e contrando melhorias em $89 \%$ das instâncias.

\subsubsection{Instâncias de Dimensões Menores}

A avaliação dos métodos propostos também foram avaliados nas pequenas instâncias de ótimos conhecidos.

Conforme apresentado na Seção 4.2 das 72 instâncias geradas, 42 resultados ótimos foram encontrados. A heurística SCIH2 encontrou 14 dos otimos conhecidos, com uma diferença média de $6.7 \%$ dos ótimos.

Já a VNS encontrou todos os 42 ótimos conhecidos, o que mostra o bom desempenho do procedimento. Quando comparado a Limitante Inferior informado pelo software, a diferença fica em $17 \%$.

\subsubsection{Instâncias Inspiradas em Dados Reais}

Os resultados das soluções obtidas para as instâncias inspiradas em dados reais usando o VNS está exposto na Tabela 13. São comparados o desempenho da meta-heurística VNS com a heurística construtiva de melhor desempenho, a SCIH2 e o que a empresa reportou de seu desempenho. Nesta tabela, na primeira coluna "Dia", apresenta-se o número do dia que está sendo avaliado. Em seguida, para cada método de solução são apresentados o custo daquela instância, nas colunas "Custo", bem como quantas rotas foram geradas, nas colunas "Rotas". A linha final, "Total" apresenta uma soma simples dos três dias de teste.

Na avaliação de desempenho, ao resolver as instâncias inspiradas em dados reais, o desempenho do VNS se destaca uma vez que ele é capaz de gerar reduções significativas tanto sobre os dados reportados, como sobre o valor heurístico. Sobre os dados reportados, 
a redução de custo é de aproximadamente $20 \%$ e a de número de rotas $26 \%$. Já sobre a SCIH2, a redução de custo passa de $10 \%$ e a de número de rotas é de mais de $30 \%$.

Esse desempenho do método meta-heurístico mostra que em problemas maiores, como as inspiradas em dados reais que chegam a 131 clientes, num cenário com particularidades que somente o dia-a-dia das empresas pode mostrar, os benefícios deste método ficam mais evidentes.

\subsection{GRASP}

O Greedy Randomized Adaptive Search Procedure foi proposto pela primeira vez no trabalho de Feo e Resende (1989) e foi amplamente aceito na comunidade acadêmica. O método se trata de um procedimento multistart em que um procedimento construtivo é executado e, em seguida, uma busca local é feita. Para permitir a busca de diferentes vizinhanças, elementos de aleatoriedade são inseridos ao procedimento, geralmente em momentos de escolhas chave. Assim, o desenho da heurística construtiva feito de forma a explorar características do problema para gerar soluções de boa qualidade é mantido, mas com essas decisões tomadas com aleatoriedades, é permitido gerar uma variedade de soluções para a posterior busca em vizinhança. Por um lado que permite explorar novos mínimos locais que estariam fora das vizinhanças da solução obtida no método construtivo e, ao mesmo tempo, não se obtém soluções de baixa qualidade cujas vizinhanças não vão gerar mínimos locais relevantes.

É interessante observar que o GRASP e o VNS têm em comum a premissa de que soluções de boa qualidade estão próximas entre si, uma vez que o GRASP adiciona uma aleatoriedade controlada a um processo construtivo e o VNS, a partir de uma solução inicial busca soluções em vizinhança com perturbações controladas. Isso as diferencia de outros métodos que tendem a gerar grandes diversificações no processo de busca de um novo mínimo local, como os métodos populacionais.

\subsubsection{Características do Procedimento}

O algorítmo 6 foi extraído de Feo e Resende (1995) e apresenta a forma-base do GRASP. Se inicia com a coleta dos dados da instância (InputInstance()), em seguida recorrentemente, até o critério de parada ser atendido, a construção aleatorizada (ConstructGreedyRandomizedSolution) seguida por uma busca local (LocalSearch) são executadas. A cada rodada é verificado se uma nova melhor solução é encontrada e a melhor é 
sempre armazenada.

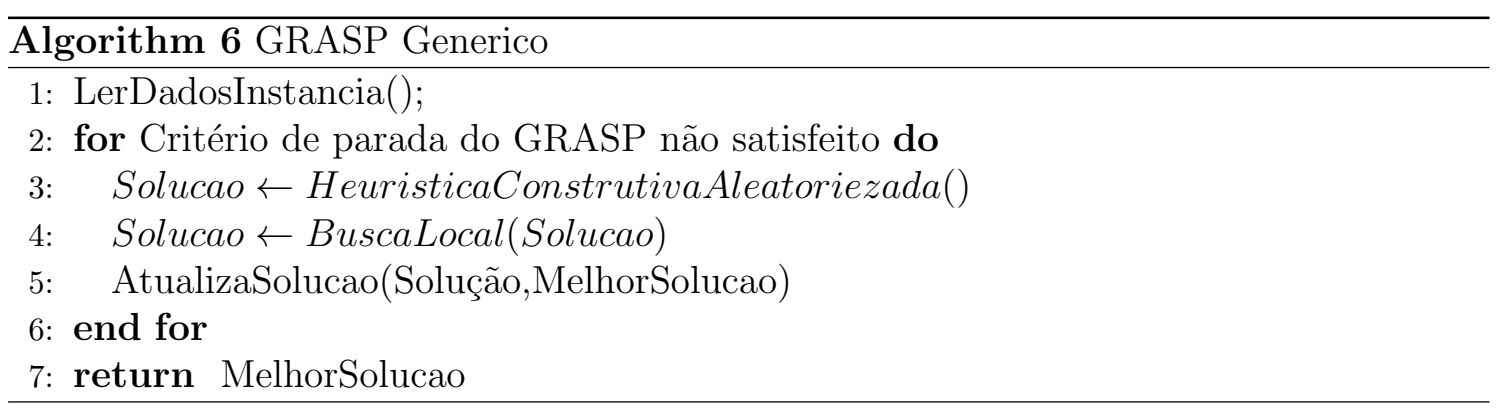

A partir do algorítimo 6, é possível notar a outra semelhança entre os dois métodos, os poucos parâmetros a serem definidos. Como visto, no GRASP é necessário determinar o critério de parada, a busca local e como inserir as aleatoriedades ao método construtivo.

A aleatoriedade no método construtivo é inserido a partir da utilização de uma Lista Restrita de Candidatos (LRC) em decisões chave. Por exemplo, no momento em que se escolhe um cliente para ser adicionado à rota em construção, ao invés de escolher o cliente com o melhor critério de inserção, uma LRC é gerada com uma quantidade de clientes com os melhores critérios e, um membro da LRC é escolhido de forma aleatória.

A LRC pode ser gerada de diversas formas. A seguir são destacas as três que são avaliadas para o problema deste trabalho, extraídas de Resende e Ribeiro (2010)

- LRCf: LRC com número fixo de elementos.

- LRCd: LRC com base na diferença entre melhor e pior candidato.

- LRCt: LRC com base na tolerância de piora em relação ao melhor candidato.

Na LRCf, um número pré-determinado de elementos para a lista é utilizado. Sempre que a LRC for alimentada, esse número de candidatos é utilizado a não ser que não existam candidatos suficientes para preencher todas as vagas.

Já na LRCd, entram na lista todos os candidatos cujo valor do critério é superior a um valor de corte determinado com base na diferença entre o valor do melhor e pior candidatos. Ou seja:

$$
\begin{gathered}
\text { ValorCorte }=\text { Valor Min }+(\text { Valor Max }- \text { ValorMin }) \times \theta \\
\text { LRCd }=\{i \in \text { Candidados }, \text { Valor }(i) \geq \text { ValorCorte }\}
\end{gathered}
$$

Finalmente, na LRCt, entram na lista todos os candidatos cujo valor do critério é superior a um valor de corte determinado com base em uma porcentagem do valor 
máximo. Desta forma, não se observa os demais valores de candidatos que não o melhor para determinar o valor de corte. Ou seja:

$$
\begin{gathered}
\text { ValorCorte }=\text { Valor Max } \times \lambda \\
\text { LRCt }=\{i \in \text { Candidados }, \text { Valor }(i) \geq \text { ValorCorte }\}
\end{gathered}
$$

A escolha de clientes nas LRC também podem ser feitas de diversas formas. A seguir são listadas as principais, que são estudadas nesse trabalho:

- Escolha Aleatória: Todos os candidatos da LRC têm a mesma chance de serem escolhidos;

- Escolha Enviesada pelo Valor: A probabilidade de um candidato ser escolhido é proporcional ao seu valor;

- Escolha Enviesada pela Posição: A probabilidade de um cliente ser escolhido é proporcional à posição que ocupa na LRC, pressupondo que na primeira posição esteja com candidato com maior valor e na última posição o candidato de menor valor.

A Escolha Aleatória apresenta a vantagem de privilegiar a geração de maior diversidade de soluções, o que é correlacionado com seu ponto fraco, que é a maior probabilidade de geração de soluções de baixa qualidade. Desta forma sua utilização deve ser combinada a uma cuidadosa geração da LRC. Nesse caso a probabilidade de escolha de um candidato da lista ser escolhido é dada por:

$$
P(i)=\frac{1}{N}
$$

onde $P(i)$ é a probabilidade da escolha do candidato $i$ e $N$ é o número de candidatos na LRC.

A Escolha Enviesada pelo Valor tem vantagens e desvantagens opostas à Escolha Aleatória. Privilegiar candidatos com melhores valores tende a gerar soluções de melhor qualidade, porém limita a diversidade. Nesse caso a probabilidade de escolha de um candidato da lista ser escolhido é dada por:

$$
P(i)=\frac{\text { Valor }(i)}{\sum_{j \in L R C} \operatorname{Valor}(j)}
$$

onde $\operatorname{Valor}(i)$ é o valor do candidato $i$.

A Escolha Enviesada pela Posição tenta encontrar um meio termo entre geração de 
soluções com boa diversidade e boa qualidade. Assim, não considerar o valor de cada candidato, mas sim qual a posição na lista de candidatos, valoriza os candidatos de melhor valor - afinal eles estarão entre os primeiros da lista - mas também permite que um valor menor seja escolhido. Nesse caso a probabilidade de escolha de um candidato da lista ser escolhido é dada por:

$$
P(i)=\frac{N-(O(i)-1)}{1+2+\cdots+N}
$$

onde $O(i)$ é a posição do candidato $i$ na LRC e $N$ o total de candidatos na lista.

\subsubsection{GRASP Aplicado ao FSMVRPTWSC}

Para o problema deste trabalho, o FSMVRPTWSC, o GRASP é aplicado o mais próximo possível de forma básica e utiliza uma adaptação da heurística construtiva SCIH.

O Algorítmo 7 apresenta o GRASP utilizado como solução iniciala para o VNS.

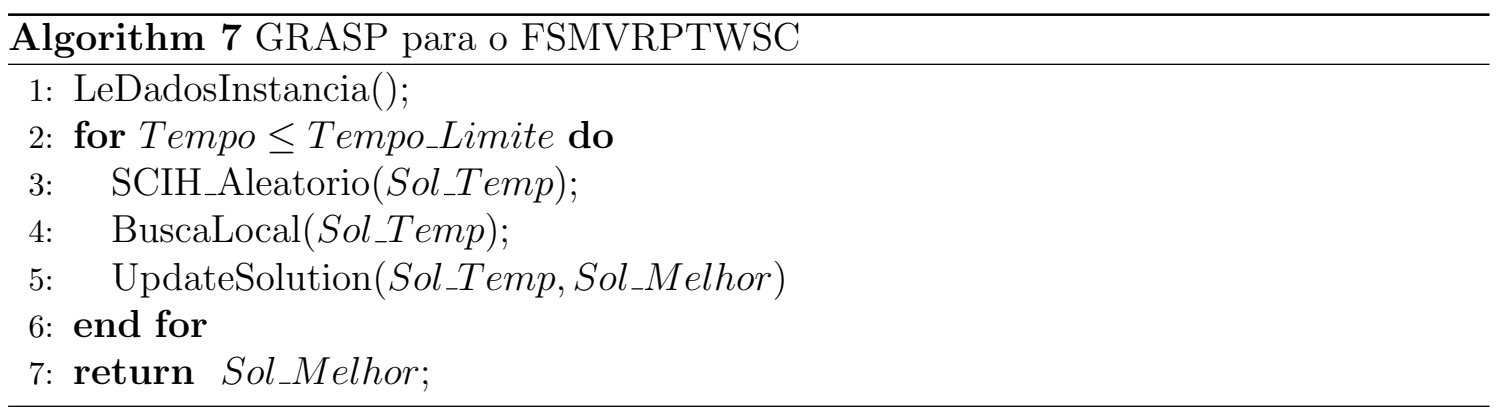

O método utiliza o SCIH_Aleatório para gerar uma solução antes da busca local. Esse procedimento é a heurística construtiva SCIH2 (descrita na seção 6.2.2) com alguns elementos de decisão inseridos com aleatoriedade. Em dois momentos foram adicionados o uso de probabilidades: na escolha do cliente para início da rota, que no método proposto deve ser o cliente mais distante do depósito, e a escolha do cliente para inserção na rota em construção, que no método original se trata da inserção que gera o maior valor de $\mathrm{C} 2$.

Desta forma o pseudo-código da SCIH_Aleatório no Algorítmo 8 detalha o método de geração de instâncias com aleatoriedades baseadas no SCIH porém com as aleatoriedades nas escolhas de com qual cliente se iniciará a nova rota, na linha 5, bem como na escolha de qual cliente será escolhido para ser inserido na rota, a linha 34.

É fácil observar que o Algoritmo 8 tem muitas similaridades com o Algoritmo 1. Da linha 2 até a 5 nas quais se gera uma lista de clientes já marcados como não atendidos e alimenta-se o contador regressivo de quantos clientes faltam rotear, os dois procedimentos são idênticos. 


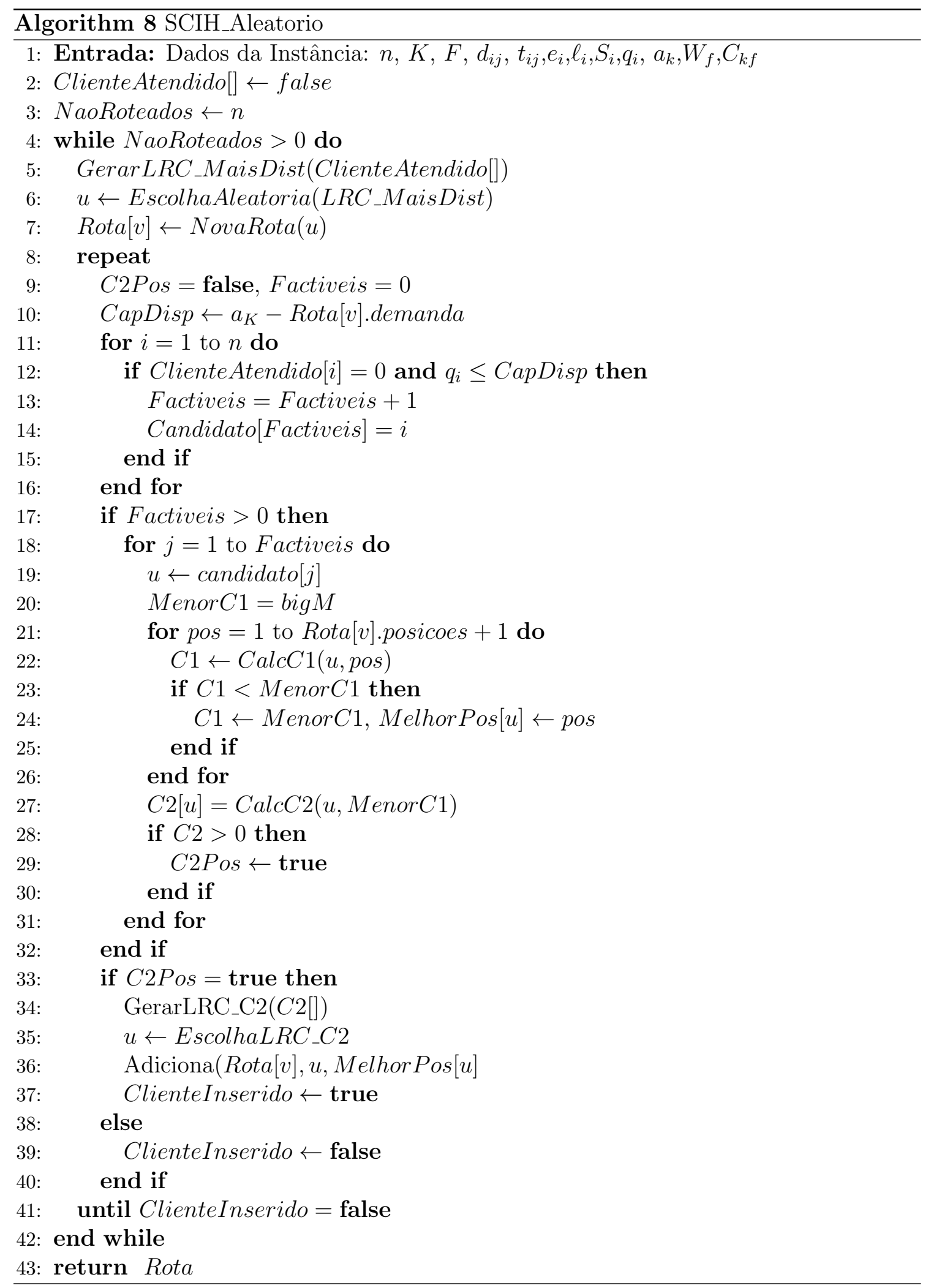


Em seguida, na linha 5 é feita a escolha do cliente para iniciar uma nova rota. No método construtivo SCIH, o cliente mais distante é escolhido, entretanto, no SCIH_Aleatório, uma lista restrita de candidatos mais distantes é gerada na função Gerar LRC_MaisDist(). Essa função que tem como entrada a lista de clientes ainda não roteados e gera a lista LRC_MaisDist, cujo tamanho deve ser fixo e critério de escolha é aleatório. O cliente $u$ dessa lista é escolhido aleatoriamente e com ele se gera a rota $v$ na linha 7

A partir da geração da nova rota com o cliente $u$ escolhido na linha 7 os procedimentos SCIH e SCIH_Aleatorio voltam a ser idênticos, com criação da lista de candidatos factíveis (linha 11) para os quais C1 e C2 são calculados.

Caso exista pelo menos um C2 positivos, significa que podemos avaliar a inserção de um cliente na rota. Essa será feita a partir da geração da lista de candidatos $L R C \_C 2$ (linha 34). A escolha do cliente a ser adicionado a partir da $L R C \_C 2$ é feita de modo aleatório, porém com probabilidades de escolha proporcionais ao valor de $\mathrm{C} 2$ de cada candidato na lista. Desta forma, para todos os clientes na lista, a probabilidade de ele ser escolhido é igual ao seu valor de C2 dividido pela somatória dos valores de C2 de todos os clientes com $\mathrm{C} 2$ positivos.

$$
P(u)=\frac{C 2(u)}{\sum_{i / C 2(i)>0} C 2(i)}
$$

Essa forma de avaliação permite manter as características de decisão do problema, mantendo o processo com soluções iniciais de boa qualidade e, ainda assim, permitir diversidade de soluções para buscar novos mínimos locais.

O tamanho das LRC são definidos a partir de experimentos numéricos. No caso da LRC_MaisDist, está pré-definido que se trata de uma lista de tamanho fixo, porém o tamanho será calibrado. Já no caso da $L R C \_C 2$, o tipo de lista ainda está a ser definido, do tipo fixo, proporcional à distância entre o maior e menor $\mathrm{C} 2$ ou tolerância a partir do maior $\mathrm{C} 2$.

\subsubsection{Instâncias de Dimensões Menores}

Nessa seção, experimentos numéricos serão conduzidos com o GRASP, tanto para calibrar seus parâmetros como, ao ter os parâmetros propriamente definidos, avaliar a qualidade do método proposto frente aos três tipos de instâncias apresentados. 


\subsubsection{Processo de Calibração de Parâmetros do GRASP}

Como detalhado na Seção 8.2.2 é necessário calibrar as duas listas restritas de candidatos e o tempo de execução para o procedimento SCIH_Aleatorio.

A LRC_Dist está pré-definida como do tipo fixo. para determinar qual o tamanho que deve ser usado, avaliamos tamanhos de 2 a 5. Para a LRC_C2 ainda deve se calibrar de qual tipo ela será, portanto são avaliados os três tipos descritos neste trabalho e para cada uma qual o tamanho a ser utilizado. Desta forma, as avaliações são:

- Tamanho LRC_Dist: 2, 3, 4 ou 5 candidatos.

- Tipo $L R C \_C 2$ :

LRCf (tamanho fixo): 2, 3, 4 ou 5 candidatos;

LRCd (proporcional à diferença entre o maior e menor C2): 10\%, 20\% e 30\%;

LRCt (tolerância em relação ao valor do maior C2): 10\%, $20 \%$ e $30 \%$.

Todas essas combinações geram $4 \times(4+3+3)$, ou seja, 40 combinações possíveis. Essas foram avaliadas nas mesmas 36 instâncias que foram utilizadas na calibração dos parâmetros do VNS (ver Seção 8.1.4 por 3 minutos cada. Um total de 3 dias de execução.

A partir desse esforço computacional a combinação que trouxe melhor resultados foi:

- LRC_Dist de 5 candidatos;

- $L R C \_C 2$ do tipo LRCd (proporcional à diferença entre o maior e menor C2) com tolerância de $10 \%$.

A partir destas conclusões, partiu-se para a calibração do critério de parada, o tempo de execução. Assim como na calibração do VNS, fez-se uma rodada longa, de 15 minutos com os 54 problemas de Calibração para se avaliar em que momento o ganho em continuar executando o procedimento deixa de ser benéfico.

O resultado obtido pode ser visto na Figura 28, que apresenta o exemplo a evolução para as instâncias de calibração do tipo R1. É possível notar uma intensa evolução da solução nos primeiros instantes, mas um comportamento mais suave depois de algum tempo.

Para avaliar o limitante de tempo para todas as 54 instâncias, foi elaborada a Figura 29. Nela é possível ver a cada minuto (eixo horizontal) quantas das instâncias (eixo vertical) já havia encontrado seu valor mínimo. 


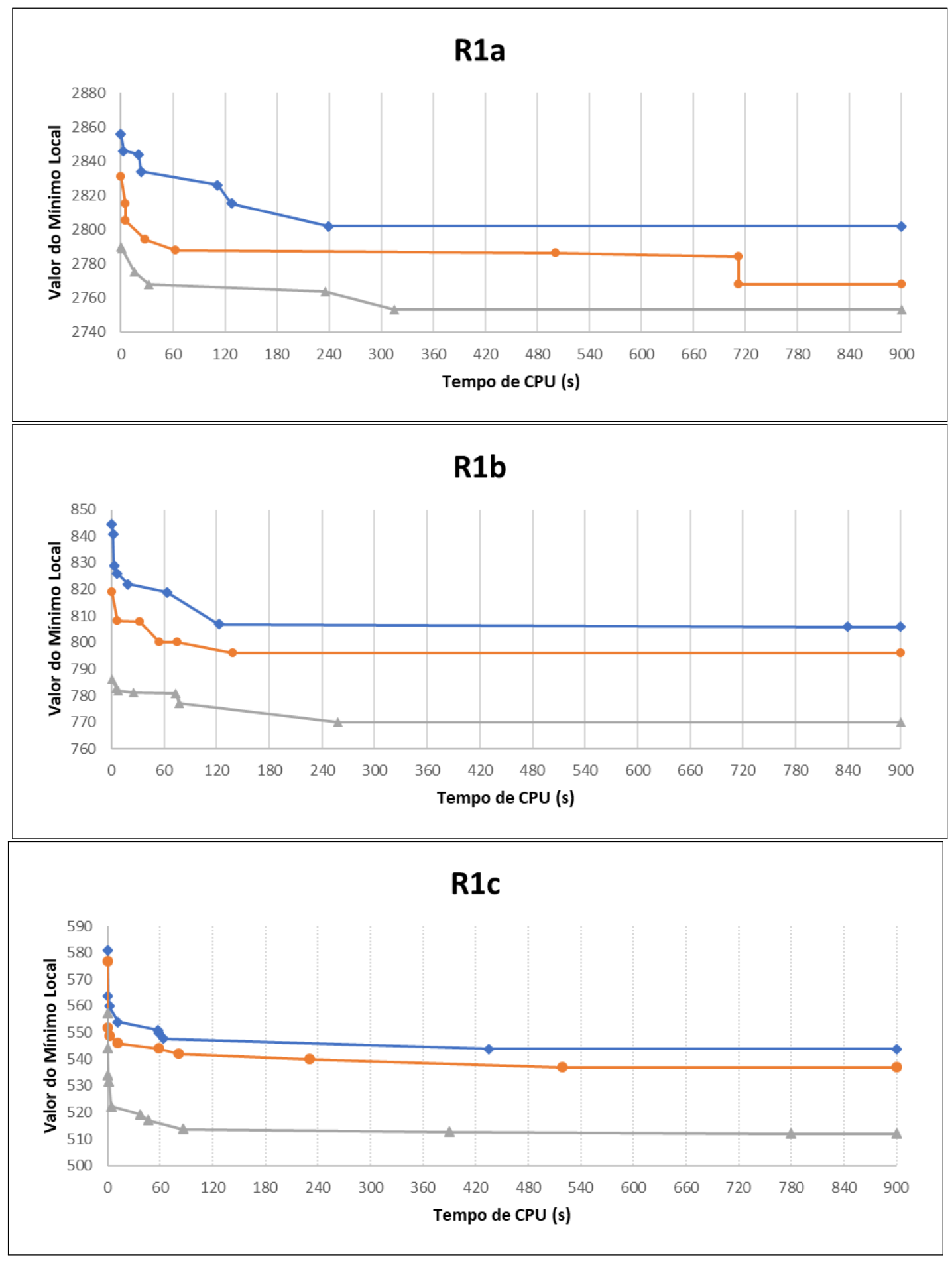

Figura 28: Gráficos da evolução no tempo do mínimo local conhecido para as 3 instâncias de calibração de cada tipo R1a, R1b e R1c pelo GRASP. 


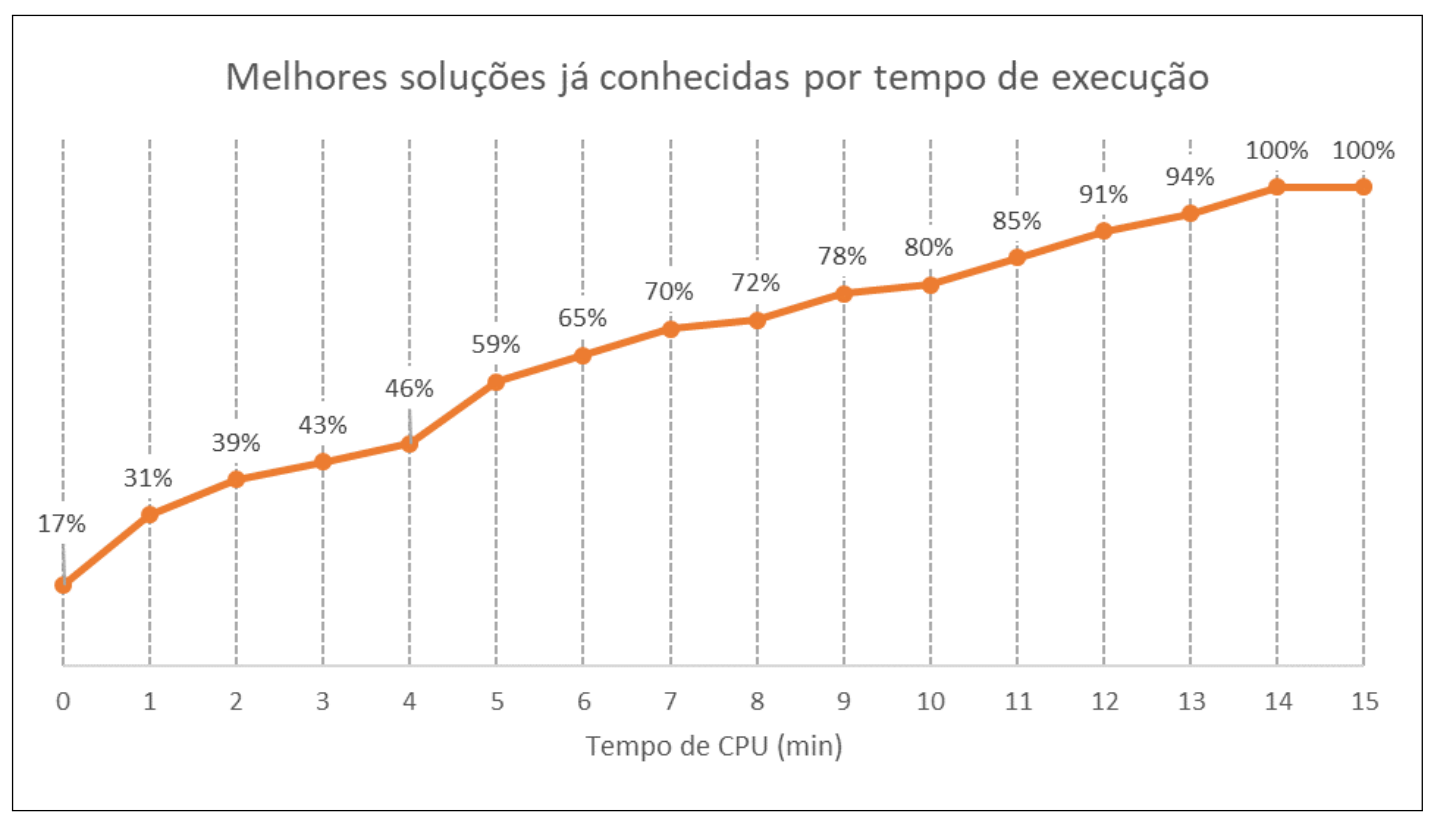

Figura 29: Gráficos da evolução no tempo em que já é conhecido o menor mínimo local conhecido para cada instância pelo GRASP.

É interessante observar que, apesar de ser um gráfico de características semelhantes ao elaborado para o VNS, o tempo para obter o mínimo local tem comportamento diferente, com uma reta de aspecto próximo do linear, com difícil determinação de um ponto em que o ganho em esperar se torna pouco relevante.

A definição, portanto, se deu em 12 minutos, onde $91 \%$ dos mínimos valores conhecidos e nos próximos 3 minutos (20\% do tempo) apenas mais $9 \%$ dos mínimos vai ser conhecido. Esse tempo de execução será usados para todas as avaliações com as diferentes instâncias geradas.

\subsubsection{Instâncias de Referência}

A avaliação do GRASP nas instâncias de referência foi feita usando os o parâmetros determinados na Seção 8.2.2.2. Os resultados são apresentados na Tabela 14. A tabela apresenta como referência a heurística construtiva SCIH2 após a busca local Cross, que foi a que apresentou melhor resultado na Seção 7.3.3 e o VNS. Para cada um desses métodos de referência é apresento o valor da função objetivo, ou seja, o custo do roteamento. Em seguida, os dados do GRASP são apresentados. Na coluna "Custo"é apresentado o valor da sua função objetivo, na coluna "\%Imp 1"é apresentado o quanto de melhoria (ou seja, redução do custo) foi obtido em relação à construtiva com busca local e na coluna "\%Imp 2" a redução de custo em relação ao VNS. Para as colunas de redução de custo, valores 


\begin{tabular}{c|c|r|rr|rrr}
\hline Grupo & Qtd & SCIH2+BL & \multicolumn{2}{|c|}{ VNS } & \multicolumn{3}{|c}{ GRASP } \\
& & Custo & Custo & \%BL & Custo & \%BL & \%VNS \\
\hline C1a & 9 & $6,168.8$ & $\mathbf{6 , 1 4 5 . 4}$ & 0.4 & $6,151.4$ & 0.3 & -0.1 \\
C1b & 9 & $1,597.5$ & $1,584.0$ & 0.8 & $\mathbf{1 , 5 7 1 . 3}$ & 1.6 & 0.8 \\
C1c & 9 & $1,025.7$ & $1,011.8$ & 1.4 & $\mathbf{9 9 5 . 6}$ & 2.9 & 1.6 \\
C1 & 27 & $2,930.7$ & $2,913.7$ & 0.6 & $\mathbf{2 , 9 0 6 . 1}$ & 0.8 & 0.3 \\
\hline C2a & 8 & $5,292.0$ & $\mathbf{5 , 2 4 3 . 3}$ & 0.9 & $5,277.8$ & 0.3 & -0.7 \\
C2b & 8 & $1,292.0$ & $\mathbf{1 , 2 4 0 . 1}$ & 4.0 & $1,287.6$ & 0.3 & -3.8 \\
C2c & 8 & 802.6 & $\mathbf{7 4 3 . 3}$ & 7.4 & 775.9 & 3.3 & -4.4 \\
C2 & 24 & $2,462.2$ & $\mathbf{2 , 4 0 8 . 9}$ & 2.2 & $2,447.1$ & 0.6 & -1.6 \\
\hline R1a & 12 & $2,805.7$ & $\mathbf{2 , 7 4 9 . 0}$ & 2.0 & $2,756.0$ & 1.8 & -0.3 \\
R1b & 12 & 799.8 & 765.5 & 4.3 & $\mathbf{7 6 3 . 6}$ & 4.5 & 0.3 \\
R1c & 12 & 539.8 & $\mathbf{5 0 0 . 8}$ & 7.2 & 503.5 & 6.7 & -0.5 \\
R1 & 36 & $1,381.7$ & $\mathbf{1 , 3 3 8 . 5}$ & 3.1 & $1,341.0$ & 2.9 & -0.2 \\
\hline R2a & 11 & $2,709.8$ & $\mathbf{2 , 6 4 0 . 2}$ & 2.6 & $2,689.4$ & 0.8 & -1.9 \\
R2b & 11 & 887.9 & $\mathbf{8 2 8 . 0}$ & 6.7 & 862.5 & 2.9 & -4.2 \\
R2c & 11 & 648.5 & 624.6 & 3.7 & $\mathbf{5 8 8 . 9}$ & 9.2 & 5.7 \\
R2 & 33 & $1,415.4$ & $\mathbf{1 , 3 6 4 . 3}$ & 3.6 & $1,380.3$ & 2.5 & -1.2 \\
\hline RC1a & 8 & $3,313.8$ & $3,290.9$ & 0.7 & $\mathbf{3 , 2 4 7 . 9}$ & 2.0 & 1.3 \\
RC1b & 8 & $1,036.7$ & $\mathbf{9 9 7 . 4}$ & 3.8 & $1,006.0$ & 3.0 & -0.9 \\
RC1c & 8 & 683.5 & $\mathbf{6 3 5 . 4}$ & 7.0 & 650.7 & 4.8 & -2.4 \\
RC1 & 24 & $1,678.0$ & $1,641.2$ & 2.2 & $\mathbf{1 , 6 3 4 . 9}$ & 2.6 & 0.4 \\
\hline RC2a & 8 & $3,119.9$ & $3,086.5$ & 1.1 & $\mathbf{3 , 0 5 7 . 9}$ & 2.0 & 0.9 \\
RC2b & 8 & 871.5 & 864.5 & 0.8 & $\mathbf{8 2 8 . 5}$ & 4.9 & 4.2 \\
RC2c & 8 & 534.6 & 534.6 & 0.0 & $\mathbf{5 1 4 . 0}$ & 3.9 & 3.9 \\
RC2 & 24 & $1,508.7$ & $1,495.2$ & 0.9 & $\mathbf{1 , 4 6 6 . 8}$ & 2.8 & 1.9 \\
\hline Média & 168 & $1,852.1$ & $\mathbf{1 , 8 1 5 . 3}$ & 2.0 & $1,818.2$ & 1.8 & -0.2 \\
\hline & & & & & & & \\
& & & & & & & \\
& & & & & & &
\end{tabular}

Tabela 14: Resultados da instâncias de referência resolvidas com a meta-heurística GRASP comparados com os resultados da Heurística construtiva SCIH2 após a busca local Cross e com o método VNS.

positivos significa que o custo foi reduzido e negativos que o custo aumentou.

É possível observar, na Tabela 14 que o GRASP tem desempenho similar ao da VNS, alcançando valores muito parecidos na média geral, com diferença média limitada a $0,2 \%$. Dentre as instâncias, entretanto, o desempenho varia entre as meta-heurísticas propostas. GRASP alcança valores melhores para $\mathrm{RC} 2$, com redução de de 1,9\% na média, com destaque para RC2c, onde o VNS não melhora em relação à SCIH2 com a busca local Cross, mas o GRASP reduz o valor em 3,9\%. Ambos os métodos superam a heurística construtiva de melhores resultados seguida da busca local de melhor desempenho. 


\begin{tabular}{c|cc|cc|cc|cc}
\hline \multirow{2}{*}{ Dia } & \multicolumn{2}{|c|}{ Reportado } & \multicolumn{2}{|c|}{ SCIH2 } & \multicolumn{2}{c|}{ VNS } & \multicolumn{2}{c}{ GRASP } \\
& Custo & Rotas & Custo & Rotas & Custo & Rotas & Custo & Rotas \\
\hline 1 & $27,676.6$ & 58 & $27,189.0$ & 66 & $24,433.5$ & 41 & $26,425.2$ & 64 \\
2 & $35,151.3$ & 65 & $28,307.1$ & 62 & $27,500.0$ & 50 & $28,650.0$ & 61 \\
3 & $32,379.9$ & 59 & $28,654.2$ & 67 & $25,604.5$ & 43 & $27,781.2$ & 64 \\
\hline Total & $95,207.8$ & 182 & $84,150.3$ & 195 & $77,538.0$ & 134 & $82,856.4$ & 189 \\
\hline
\end{tabular}

Tabela 15: Custo e quantidade de rotas geradas a partir de cada método de solução para as instâncias inspiradas em dados reais

\subsubsection{Instâncias de Dimensões Menores}

$\mathrm{Na}$ avaliação do desempenho do GRASP em instâncias de dimensões menores, para as quais 72 soluções ótimas são conhecidas, o método encontra 28 resultados ótimos, com valor de função objetivo, em média, $3,3 \%$ maior que os ótimos conhecidos.

É um desempenho superior ao das heurísticas construtivas, a SCIH2 encontrou 14 soluções ótimas e em média fica 6,7\% acima dos ótimos. Por outro lado, é resultado inferior ao obtido pelo VNS que encontra todos os ótimos conhecidos.

\subsubsection{Instâncias Inspiradas em Dados Reais}

$\mathrm{Na}$ avaliação de desempenho frente às instâncias inspiradas em dados reais, foram obtidos os dados da Tabela 15. Para comparação nessa tabela estão presentes os custos e número de rotas geradas com o uso da melhor heurística construtiva, a SCIH2, e o VNS.

É possível observar que o GRASP tem desempenho superior ao da SCIH2 em todos os aspectos. Em relação ao reportado, a redução de custo é relevante, apesar de não haver uma redução no número de rotas. Isso também foi percebido ao avaliar o desempenho da SCIH2, a empresa pode estar gerando rotas longas demais para fazer entregas que poderiam ser quebradas, ou reagrupadas em mais rotas, porém menos custosas.

Já na comparação com o desempenho do VNS, o GRASP apresenta custos maiores e gera mais rotas em todos os cenários, sendo dominado, gerando custo fica $6,4 \%$ acima no total dos três dias.

Portanto, é interessante observar que, apesar de um desempenho similar ao da VNS nas instâncias de referência, o GRASP não faz o mesmo nas instâncias de dimensões menores, nem nas inspiradas em dados reais. 


\subsection{Método Híbrido}

Como visto nas seções anteriores deste capítulo, é possível perceber que os dois métodos propostos (VNS e GRASP) atingem bons resultados e possuem estratégias similares. Ambos iniciam com um método construtivo seguido por busca local, porém com formas de execução dessas etapas diferentes. Desta forma, foi levantada a hipótese de uma combinação das estratégias destes métodos ter potencial para gerar um método híbrido obter resultados melhores nas instâncias deste problema.

Métodos híbridos, que combinam dois ou mais métodos em um, são aplicados na literatura visando obter soluções de melhor resultado. Festa e Resende (2009) exploram diversas formas de utilização do GRASP, tanto como um método único, como em procedimentos híbridos. Dentre os métodos que podem ser combinados e são explorados pelos autores, o VNS é apresentado como um possível método para combinação. O GRASP e o VNS, segundo os autores, podem ser combinados utilizando o GRASP para gerar a fase construtiva antes da busca em vizinhança variável do VNS.

Em Palomo-Martínez et al. (2017), é abordado um problema de Orientação. Este problema se trata em, a partir de um dado conjuntos de nós que possuem pontuação positiva e uma distância máxima pré definida, escolher um caminho que passe por esses nós maximizando a pontuação. O problema é resolvido utilizando uma meta-heurística que combina GRASP com VNS. O método obtém resultados melhores aos conhecidos previamente na literatura e, em comparação com instâncias cujos resultados ótimos são conhecidos, encontra 98\% das soluções ótimas. O método híbrido exposto em PalomoMartínez et al. (2017) gera uma solução inicial a partir do GRASP e, a partir deste ponto, utiliza a busca local usando a fase de busca com vizinhança variável do VNS.

A combinação entre GRASP e VNS para o FSMVRPTWSC, neste trabalho, segue as boas práticas já conhecidas na literatura, como em Festa e Resende (2009) e PalomoMartínez et al. (2017). São usadas a geração multistart de solução construtiva com aleatoriedade como no GRASP e a busca local com variações para a fase de melhorias conforme o VNS. O pseudo-código 9 apresenta o procedimento básico do método híbrido proposto.

No Algorítimo 9 é possível notar que o procedimento é inicializado com a heurística construtiva SCIH2 na linha 3 . Em seguida inicia-se a execução da SCIH_Aleat repetidamente. Essa execução é repetida por um percentual (Per Aleat) do tempo total de execução (Tempo_Limite) pré-determinado, por instância, como visto na linha 4. Em seguida pelo tempo restante disponível para a instância a busca em vizinhança aleatória 


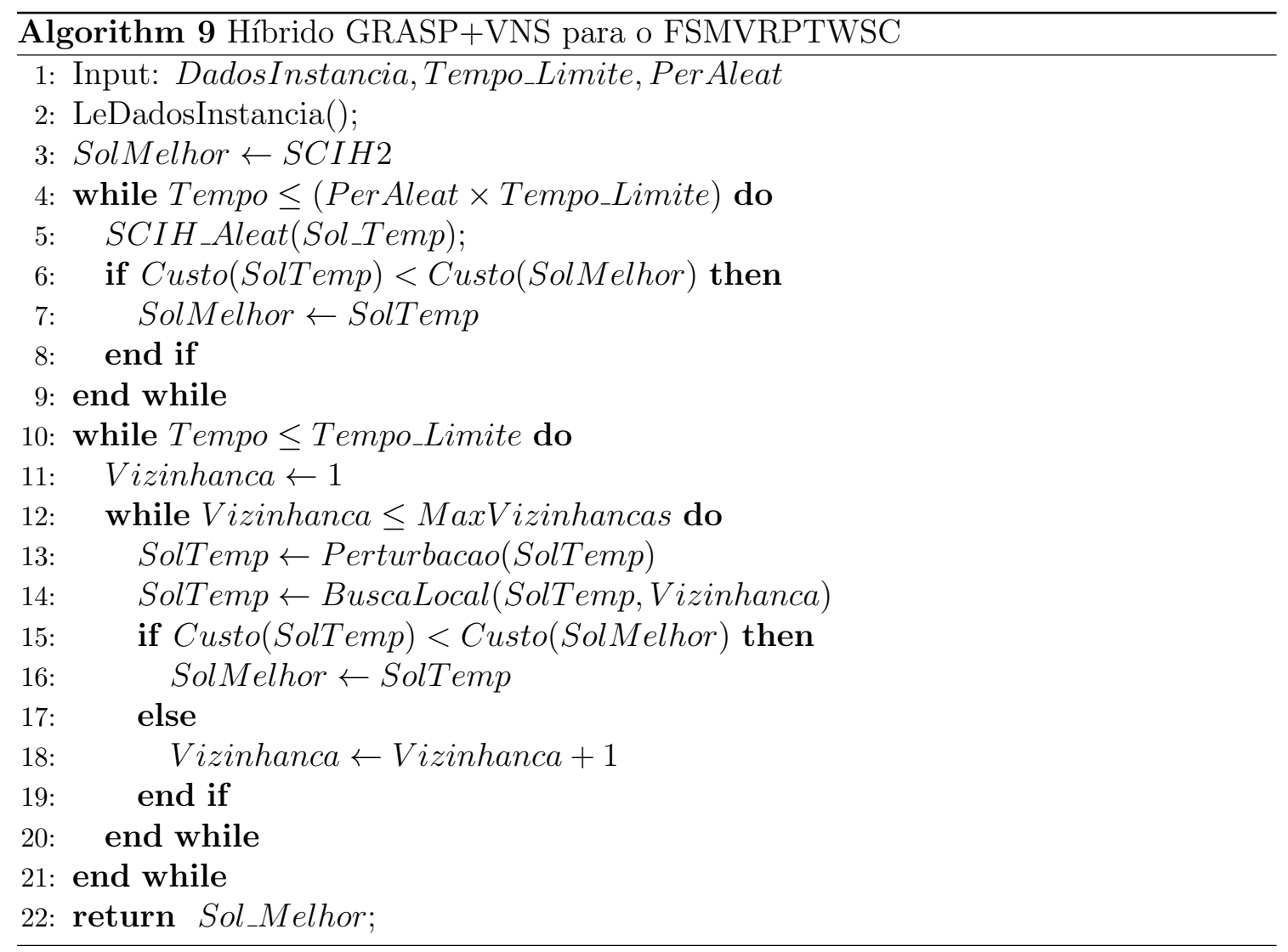

é executada.

\subsubsection{Calibração de Parâmetros}

Os parâmetros de cada método já utilizado anteriormente são replicados para o híbrido. Assim, os critérios para formação das Listas Restritas de Candidatos no procedimento SCIH_Aleat são os mesmos determinados para o GRASP na Seção 8.2.2.2. A sequência e parâmetros de vizinhanças a serem investigados, bem como os critérios de perturbação na busca local, são os mesmos já determinados na Seção 8.1.4. O tempo de solução, para permitir a comparação entre os métodos apresentados neste trabalho, também é mantido em 12 minutos como determinado para o GRASP na Seção 8.2.2.2.

Desta forma é necessário, portanto, calibrar o parâmetro Per Aleat. Essa calibração foi feita usando as instâncias de calibração, descritas na Seção 4.1.1. Cada uma das 54 instâncias foi executada por 12 minutos para diferentes valores de Per Aleat: 0,01, 0,03, $0,05,0,10,0,15,0,20, \ldots, 0,50$.

A Tabela 16 apresenta o resultado da calibração dos diferentes valores de Per Aleat por grupo de instâncias e total. É possível notar que os resultados obtidos são próximos 


\begin{tabular}{c|cccccc|c}
\hline Per Aleat & $\mathrm{R} 1$ & $\mathrm{R} 2$ & $\mathrm{C} 1$ & $\mathrm{C} 2$ & $\mathrm{RC} 1$ & $\mathrm{RC} 2$ & Total \\
\hline 0.01 & $1,353.7$ & $1,423.0$ & $2,905.2$ & $2,406.0$ & $1,639.1$ & $1,495.3$ & $1,870.4$ \\
0.03 & $1,359.6$ & $1,420.9$ & $2,908.4$ & $2,405.8$ & $1,634.3$ & $1,481.3$ & $1,868.4$ \\
0.05 & $\mathbf{1 , 3 4 3 . 5}$ & $1,425.0$ & $2,904.4$ & $2,402.8$ & $1,637.3$ & $\mathbf{1 , 4 7 5 . 3}$ & $\mathbf{1 , 8 6 4 . 7}$ \\
0.10 & $1,350.3$ & $1,437.9$ & $\mathbf{2 , 9 0 2 . 9}$ & $2,399.9$ & $\mathbf{1 , 6 3 5 . 4}$ & $1,477.0$ & $1,867.2$ \\
0.15 & $1,350.9$ & $1,417.4$ & $2,907.8$ & $2,402.8$ & $1,641.1$ & $1,475.6$ & $1,865.9$ \\
0.20 & $1,348.1$ & $\mathbf{1 , 4 1 6 . 8}$ & $2,904.4$ & $2,409.1$ & $1,639.5$ & $1,478.0$ & $1,866.0$ \\
0.25 & $1,348.6$ & $1,428.3$ & $2,907.6$ & $\mathbf{2 , 3 9 9 . 6}$ & $1,639.0$ & $1,478.3$ & $1,866.9$ \\
0.30 & $1,348.7$ & $1,424.6$ & $2,906.3$ & $2,405.6$ & $1,637.2$ & $1,478.0$ & $1,866.7$ \\
0.35 & $1,345.9$ & $1,427.7$ & $2,905.2$ & $2,403.0$ & $1,639.4$ & $1,476.1$ & $1,866.2$ \\
0.40 & $1,349.6$ & $1,438.7$ & $2,908.3$ & $2,400.0$ & $1,635.9$ & $1,480.7$ & $1,868.9$ \\
0.45 & $1,353.7$ & $1,421.2$ & $2,909.1$ & $2,402.8$ & $1,635.9$ & $1,478.4$ & $1,866.9$ \\
0.50 & $1,347.2$ & $1,421.6$ & $2,904.4$ & $2,405.8$ & $1,639.0$ & $1,481.3$ & $1,866.6$ \\
\hline
\end{tabular}

Tabela 16: Custo médio das instâncias de calibração para diferentes valores de Per Aleat. Em negrito estão os melhores valores encontrados para cada grupo de instâncias.

entre os diferentes valores de PerAleat avaliados, com diferença entre o que obtém a melhor $(0,05)$ e a pior $(0,01)$ média limitada a $0,3 \%$. O gráfico apresentado na Figura 30 auxilia na visualização do valor que encontra os melhores resultados na calibração.

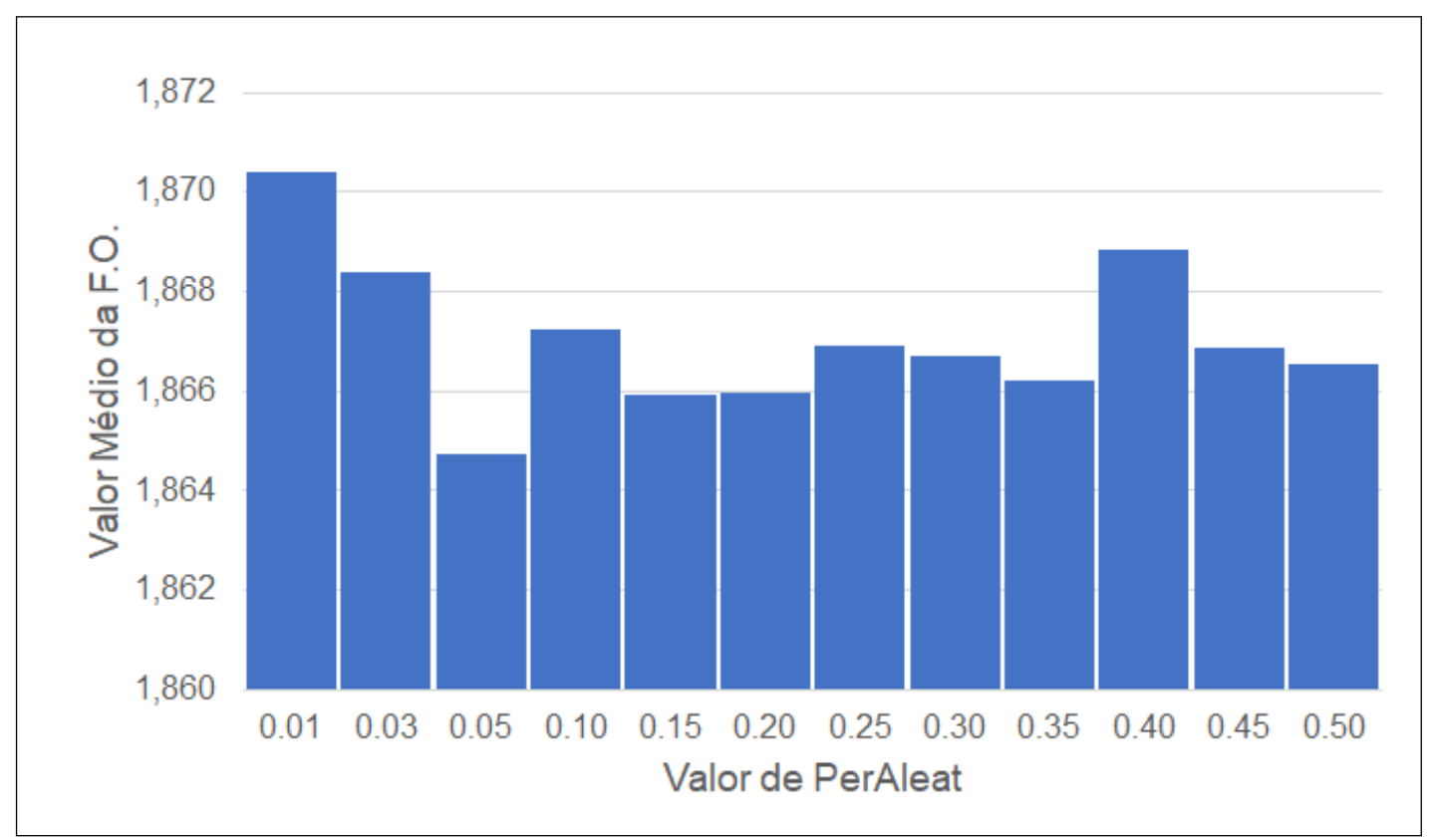

Figura 30: Valor médio da função objetivo obtido no método híbrido para cada valor de PerAleat.

A partir da calibração foi definido, portanto, que o valor a ser utilizado para Per Aleat é 0,05 . 


\begin{tabular}{cc|rrrr}
\hline Set & \#Inst & SCIH2+BL & VNS & GRASP & Híbrido \\
\hline C1a & 9 & $6,168.8$ & $6,145.4$ & $6,151.4$ & $\mathbf{6 , 1 4 0 . 9}$ \\
C1b & 9 & $1,597.5$ & $1,584.0$ & $\mathbf{1 , 5 7 1 . 3}$ & $1,579.1$ \\
C1c & 9 & $1,025.7$ & $1,011.8$ & $\mathbf{9 9 5 . 6}$ & $1,002.1$ \\
C1 & 27 & $2,930.7$ & $2,913.7$ & $\mathbf{2 , 9 0 6 . 1}$ & $2,907.4$ \\
\hline C2a & 8 & $5,292.0$ & $5,243.3$ & $5,277.8$ & $\mathbf{5 , 2 4 0 . 0}$ \\
C2b & 8 & $1,292.0$ & $\mathbf{1 , 2 4 0 . 1}$ & $1,287.6$ & $1,242.9$ \\
C2c & 8 & 802.6 & $\mathbf{7 4 3 . 3}$ & 775.9 & 746.4 \\
C2 & 24 & $2,462.2$ & $\mathbf{2 , 4 0 8 . 9}$ & $2,447.1$ & $2,409.8$ \\
\hline R1a & 12 & $2,805.7$ & $2,749.0$ & $2,756.0$ & $\mathbf{2 , 7 3 8 . 5}$ \\
R1b & 12 & 799.8 & 765.5 & 763.6 & $\mathbf{7 5 5 . 2}$ \\
R1c & 12 & 539.8 & 500.8 & 503.5 & $\mathbf{4 9 5 . 8}$ \\
R1 & 36 & $1,381.7$ & $1,338.5$ & $1,341.0$ & $\mathbf{1 , 3 2 9 . 8}$ \\
\hline R2a & 11 & $2,709.8$ & $\mathbf{2 , 6 4 0 . 2}$ & $2,689.4$ & $2,654.5$ \\
R2b & 11 & 887.9 & $\mathbf{8 2 8 . 0}$ & 862.5 & 834.5 \\
R2c & 11 & 648.5 & 624.6 & $\mathbf{5 8 8 . 9}$ & 591.5 \\
R2 & 33 & $1,415.4$ & $1,364.3$ & $1,380.3$ & $\mathbf{1 , 3 6 0 . 2}$ \\
\hline RC1a & 8 & $3,313.8$ & $3,290.9$ & $\mathbf{3 , 2 4 7 . 9}$ & $3,254.3$ \\
RC1b & 8 & $1,036.7$ & 997.4 & $1,006.0$ & $\mathbf{9 9 4 . 7}$ \\
RC1c & 8 & 683.5 & 635.4 & 650.7 & $\mathbf{6 3 3 . 3}$ \\
RC1 & 24 & $1,678.0$ & $1,641.2$ & $1,634.9$ & $\mathbf{1 , 6 2 7 . 4}$ \\
\hline RC2a & 8 & $3,119.9$ & $3,086.5$ & $3,057.9$ & $\mathbf{3 , 0 5 5 . 3}$ \\
RC2b & 8 & 871.5 & 864.5 & 828.5 & $\mathbf{8 2 8 . 4}$ \\
RC2c & 8 & 534.6 & 534.6 & $\mathbf{5 1 4 . 0}$ & 517.5 \\
RC2 & 24 & $1,508.7$ & $1,495.2$ & $\mathbf{1 , 4 6 6 . 8}$ & $1,467.0$ \\
\hline Média & 168 & $1,852.1$ & $1,815.3$ & $1,818.2$ & $\mathbf{1 , 8 0 5 . 7}$ \\
\hline & & & & & \\
\hline
\end{tabular}

Tabela 17: Custo médio para cada grupo de instâncias de referência em 12 minutos de execução. Em negrito estão os melhores valores encontrados para cada linha da tabela.

\subsubsection{Experimentos Numéricos}

O método híbrido proposto é testado nos 3 grupos de instâncias apresentados no Capítulo 4 para comparar seu desempenho com os demais métodos propostos neste trabalho.

Na Tabela 17 estão apresentados os resultados do método híbrido (coluna "Híbrido") comparado com os demais métodos, SCIH2 com a busca local Cross, VNS e o GRASP. A partir desta tabela é possível observar que o método híbrido apresenta melhores resultados que os demais métodos apresentados nesse trabalho. Ao se avaliar o custo médio obtido nos 168 problemas é encontrado o melhor valor já conhecido, cerca de 0,5\% menor que o segundo melhor, obtido pelo VNS com o mesmo tempo de execução. 
Com o objetivo de obter uma percepção mais clara de melhorias, a Tabela 18 apresenta o número de melhores soluções encontradas por cada método proposto. A coluna "Best" indica o número de melhores resultados encontrados pelo método para cada grupo de instâncias e a "\%" a parcela da quantidade de instâncias do grupo que este número representa. Em caso de mais de um método obter a mesma solução para uma instância que é a melhor, conta-se que ambos os métodos obtiveram o melhor resultado. Por isso, em boa parte das linhas, a soma dos melhores resultados obtidos por cada método é maior que o número de instâncias do grupo apresentado.

Nessa forma de visualização dos resultados obtidos, o desempenho superior do método Híbrido fica mais evidente ao ver que $55 \%$ dos melhores resultados são encontrados no método híbrido, superando de forma consistente os resultados do VNS, GRASP e SCIH2 com busca local. O bom desempenho se evidencia quando se nota que, para 57 instâncias, o resultado obtido pelo Híbrido é melhor do que o encontrado pelos demais métodos, enquanto 36 são empates com o obtido por algum dos outros métodos.

Para avaliar se os três métodos tem diferença de desempenho estatisticamente relevante, o teste de Wilcoxon foi aplicado aos resultados obtidos para as instâncias de referência dois a dois, conforme explicado por Devore (2015). O método deve ser aplicado quando as amostras não seguem uma distribuição normal, como é o caso dos testes nas instâncias de referência, confirmado pelo o teste de Kolmogorov-Smirnov.

O teste de Wilcoxon confirma, com 1\% de significância que se pode rejeitar a hipótese de que os resultados obtidos com o método híbrido e com as meta-heurísticas VNS e GRASP têm distribuições iguais. Com $5 \%$ de significância pode se aceitar a hipótese de que com os métodos VNS e GRASP os resultados tem distribuição similar.

Na Tabela 19 são apresentados os resultados do método híbrido ao resolver as instâncias inspiradas em dados reais. Quando avaliados sob o mesmo tempo de execução, vemos que o desempenho é similar ao do VNS e superior ao do GRASP. A diferença dos resultados obtidos tanto pelo VNS como pelo Híbrido para a soma dos 3 dias de avaliação, fica em 0,5\% para o custo total e $2 \%$ no número de rotas. Avaliando-se cada dia individualmente, os dois melhores métodos são sempre próximos com pequena variação tanto em número de rotas encontradas como em custo total, sendo que nos dias 1 e 2 o VNS tem desempenho melhor e no dia 3 o método híbrido tem desempenho superior.

A Tabela 20 apresenta a avaliação de instâncias de dimensões menores que permitem a comparação com o resultado ótimos obtidos com a formulação numérica em um otimizador. Nessa tabela, a comparação é feita entre os métodos de meta-heurística GRASP, 


\begin{tabular}{|c|c|c|c|c|c|c|c|c|c|}
\hline \multicolumn{2}{|c|}{ Instâncias } & \multicolumn{2}{|c|}{$\mathrm{SCIH} 2+\mathrm{BL}$} & \multicolumn{2}{|c|}{ VNS } & \multicolumn{2}{|c|}{ GRASP } & \multicolumn{2}{|c|}{ Híbrido } \\
\hline Set & \#Inst & Best & $\%$ & Best & $\%$ & Best & $\%$ & Best & $\%$ \\
\hline C1a & 9 & 0 & 0.0 & 5 & 55.6 & 1 & 11.1 & 7 & 77.8 \\
\hline C1b & 9 & 0 & 0.0 & 3 & 33.3 & 9 & 100.0 & 3 & 33.3 \\
\hline $\mathrm{C} 1 \mathrm{c}$ & 9 & 0 & 0.0 & 1 & 11.1 & 7 & 77.8 & 4 & 44.4 \\
\hline $\mathrm{C} 1$ & 27 & 0 & 0.0 & 9 & 33.3 & 17 & 63.0 & 14 & 51.9 \\
\hline $\mathrm{C} 2 \mathrm{a}$ & 8 & 0 & 0.0 & 4 & 50.0 & 0 & 0.0 & 5 & 62.5 \\
\hline $\mathrm{C} 2 \mathrm{~b}$ & 8 & 0 & 0.0 & 5 & 62.5 & 0 & 0.0 & 6 & 75.0 \\
\hline $\mathrm{C} 2 \mathrm{c}$ & 8 & 0 & 0.0 & 5 & 62.5 & 2 & 25.0 & 4 & 50.0 \\
\hline $\mathrm{C} 2$ & 24 & 0 & 0.0 & 14 & 58.3 & 2 & 8.3 & 15 & 62.5 \\
\hline R1a & 12 & 0 & 0.0 & 3 & 25.0 & 1 & 8.3 & 8 & 66.7 \\
\hline R1b & 12 & 0 & 0.0 & 0 & 0.0 & 3 & 25.0 & 9 & 75.0 \\
\hline $\mathrm{R} 1 \mathrm{c}$ & 12 & 0 & 0.0 & 4 & 33.3 & 1 & 8.3 & 7 & 58.3 \\
\hline $\mathrm{R} 1$ & 36 & 0 & 0.0 & 7 & 19.4 & 5 & 13.9 & 24 & 66.7 \\
\hline $\mathrm{R} 2 \mathrm{a}$ & 11 & 1 & 9.1 & 8 & 72.7 & 0 & 0.0 & 4 & 36.4 \\
\hline $\mathrm{R} 2 \mathrm{~b}$ & 11 & 1 & 9.1 & 10 & 90.9 & 2 & 18.2 & 8 & 72.7 \\
\hline $\mathrm{R} 2 \mathrm{c}$ & 11 & 0 & 0.0 & 1 & 9.1 & 8 & 72.7 & 4 & 36.4 \\
\hline $\mathrm{R} 2$ & 33 & 2 & 6.1 & 19 & 57.6 & 10 & 30.3 & 16 & 48.5 \\
\hline $\mathrm{RC} 1 \mathrm{a}$ & 8 & 0 & 0.0 & 0 & 0.0 & 7 & 87.5 & 2 & 25.0 \\
\hline $\mathrm{RC} 1 \mathrm{~b}$ & 8 & 0 & 0.0 & 2 & 25.0 & 1 & 12.5 & 5 & 62.5 \\
\hline $\mathrm{RC} 1 \mathrm{c}$ & 8 & 0 & 0.0 & 4 & 50.0 & 0 & 0.0 & 4 & 50.0 \\
\hline $\mathrm{RC} 1$ & 24 & 0 & 0.0 & 6 & 25.0 & 8 & 33.3 & 11 & 45.8 \\
\hline $\mathrm{RC} 2 \mathrm{a}$ & 8 & 0 & 0.0 & 2 & 25.0 & 5 & 62.5 & 4 & 50.0 \\
\hline $\mathrm{RC} 2 \mathrm{~b}$ & 8 & 0 & 0.0 & 0 & 0.0 & 7 & 87.5 & 4 & 50.0 \\
\hline $\mathrm{RC} 2 \mathrm{c}$ & 8 & 1 & 12.5 & 1 & 12.5 & 8 & 100.0 & 5 & 62.5 \\
\hline $\mathrm{RC} 2$ & 24 & 1 & 4.2 & 3 & 12.5 & 20 & 83.3 & 13 & 54.2 \\
\hline Media & 168 & 3 & 1.8 & 58 & 34.5 & 62 & 36.9 & 93 & 55.4 \\
\hline
\end{tabular}

Tabela 18: Comparação de desempenho entre os métodos propostos com base na quantidade de melhores resultados encontrados por cada um deles para as instâncias de referência.

\begin{tabular}{c|cc|cc|cc|cc}
\hline \multirow{2}{*}{ Dia } & \multicolumn{2}{|c|}{ Reportado } & \multicolumn{2}{|c|}{ VNS } & \multicolumn{2}{c|}{ GRASP } & \multicolumn{2}{c}{ Híbrido } \\
& Custo & Rotas & Custo & Rotas & Custo & Rotas & Custo & Rotas \\
\hline 1 & $27,676.6$ & 58 & $24,433.5$ & 41 & $26,425.2$ & 64 & $24,683.9$ & 44 \\
2 & $35,151.3$ & 65 & $27,500.0$ & 50 & $28,650.0$ & 61 & $27,800.0$ & 53 \\
3 & $32,379.9$ & 59 & $25,604.5$ & 43 & $27,781.2$ & 64 & $25,419.8$ & 40 \\
\hline Total & $95,207.8$ & 182 & $77,538.0$ & 134 & $82,856.4$ & 189 & $77,903.7$ & 137 \\
\hline
\end{tabular}

Tabela 19: Custo e quantidade de rotas geradas a partir de cada método meta-heurístico para as instâncias inspiradas em dados reais. 


\begin{tabular}{l|rrrr}
\hline & CPLEX & GRASP & VNS & Híbrido \\
\hline Sol. Ótimas & 42 & 28 & 42 & 36 \\
Dif. Ótimo (\%) & - & 3.3 & 0.0 & 1.2 \\
Dif. LB (\%) & 17.3 & 19.7 & 16.7 & 17.7 \\
\hline
\end{tabular}

Tabela 20: Avaliações de desempenho das meta-heurísticas propostas neste trabalho comparadas aos resultados ótimos de instâncias de dimensões menores obtidos pelo software de otimização CPLEX.

VNS e Híbrido ao se comparar quantidade de soluções ótimas conhecidas, a diferença média para o valor ótimo conhecido e, para todas as instâncias de dimensões menores, a diferença para o limitando inferior (LB) fornecido pelo otimizador.

Como é possível observar, o método híbrido encontra 36 dos 42 resultados ótimos conhecidos (86\%), apresentando um melhor desempenho que o GRASP, porém pior que o VNS, que foi capaz de encontrar todos as soluções ótimas conhecidas. A diferença média para os ótimos é de 1,2\% e a diferença média para o limitante inferior fornecido pelo otimizador é de 17,7\%. Em todos esses indicadores é notável um domínio do Híbrido sobre o GRASP, mas não sobre VNS, que tem resultados melhores. 


\section{CONCLUSÕES}

Este trabalho abordou o Problema de Roteamento de Veículos com Frota Mista, Janelas de Tempo e Custos Escalonados (Fleet Size and Mix Vehicle Routing Problem with Time Windos and Step Cost function - FSMVPTWSC). Trata-se de um de problema rico de roteamento de veículos que se destaca pela introdução de uma forma diferente de aferição dos custos do roteamento de veículos.

Este trabalho teve como objetivo aprofundar o tema que, como apresentado na Introdução, tem muita aderência à tendencia de evolução dos processos de distribuição visíveis na indústria. Parte do desenvolvimento inicial deste trabalho foi apresentado em Ronconi e Manguino (2016). O aprofundamento se deu tanto com a proposição de novas instâncias para ampliar a diversidade de avaliações possíveis do problema, como com melhorias na formulação matemática, com novas heurísticas construtivas, proposição de buscas locais e de meta-heurísticas.

A nova formulação matemática trouxe novas soluções ótimas, desconhecidas em Man-

guino (2013). Os métodos heurísticos propostos apresentam resultados superiores a métodos construtivos amplamente utilizados como benchmark na literatura. As buscas locais utilizadas foram escolhidas cuidadosamente para se aproveitar das características do problema e resultados mostram o benefício da escolha feita cuidadosamente. As metaheurísticas, VNS e GRASP, são métodos que vêm apresentando resultados de boa qualidade em diversos problemas de roteamento de veículos e foram escolhidos e adaptados para atender as particularidades do FSMVRPTWSC, ambos trazendo resultados que confirmam a boa reputação que a literatura os reserva. A combinação desses dois métodos, VNS e GRASP, em um método híbrido, permitiu obter mais resultados de boa qualidade.

Os próximos passos no desenvolvimento deste tema poderiam se dar em diferentes frentes. Primeiramente é possível desenvolver outras meta-heurísticas para buscar melhores resultados, seja com as características atuais, seja de busca populacional. Uma segunda opção, seria a busca de métodos exatos para a solução deste problema, se aproveitando do ganho tanto de capacidade de processamento de computadores, como dos novos softwares 
de otimização. Isso permitiria obter soluções ótimas para problemas maiores e, quando isso não ocorrer, obter limitantes inferiores que permitam avaliar os métodos heurísticos propostos.

Outra frente seria enfatizar a sua aplicabilidade e convergência com cenários reais. Isso pode ser feito buscando no mercado indústrias e varejistas que fazem distribuição para que tanto se forneçam dados de estudos de caso para ampliar as possibilidades de avaliação dos métodos propostos, como para obter opiniões de quem executa o roteamento na prática sobre os métodos aqui apresentados.

Enfim, é possível, o trabalho cumpriu com suas proposições e objetivos iniciais, apresentando resultados que confirmam esse cumprimento, e ainda abre caminho para futuros desenvolvimentos e aplicações. 


\section{REFERÊNCIAS}

ARNOLD, F.; SÖRENSEN, K. What makes a vrp solution good? the generation of problem-specific knowledge for heuristics. Computers $\& 6$ Operations Research, Elsevier, v. 106, p. 280-288, 2019.

BALDACCI, R.; MINGOZZI, A.; ROBERTI, R. Recent exact algorithms for solving the vehicle routing problem under capacity and time window constraints. European Journal of Operational Research, Elsevier, v. 218, n. 1, p. 1-6, 2012.

BALL, M. O. et al. Planning for truck fleet size in the presence of a common-carrier option. Decision Sciences, Wiley Online Library, v. 14, n. 1, p. 103-120, 1983.

BAŞLIGIL, H. et al. A distribution network optimization problem for third party logistics service providers. Expert Systems with Applications, Elsevier, v. 38, n. 10, p. 12730-12738, 2011.

BASSI, S. Pesquisa operacional aplicada à área de logística de transportes rodoviários em projetos de grande porte. Trabalho de Formatura, 2009.

BELFIORE, P.; YOSHIZAKI, H. T. Y. Scatter search for a real-life heterogeneous fleet vehicle routing problem with time windows and split deliveries in brazil. European Journal of Operational Research, Elsevier, v. 199, n. 3, p. 750-758, 2009.

BRÄYSY, O.; GENDREAU, M. Vehicle routing problem with time windows, part i: Route construction and local search algorithms. Transportation science, INFORMS, v. 39, n. 1, p. 104-118, 2005.

BRÄYSY, O.; GENDREAU, M. Vehicle routing problem with time windows, part ii: Metaheuristics. Transportation science, INFORMS, v. 39, n. 1, p. 119-139, 2005.

BRÄYSY, O. et al. A well-scalable metaheuristic for the fleet size and mix vehicle routing problem with time windows. Expert Systems with Applications, Elsevier, v. 36, n. 4 , p. $8460-8475,2009$.

CLARKE, G.; WRIGHT, J. W. Scheduling of vehicles from a central depot to a number of delivery points. Operations research, INFORMS, v. 12, n. 4, p. 568-581, 1964.

DANTZIG, G. B.; RAMSER, J. H. The truck dispatching problem. Management science, INFORMS, v. 6, n. 1, p. 80-91, 1959.

DELL'AMICO, M. et al. Heuristic approaches for the fleet size and mix vehicle routing problem with time windows. Transportation Science, INFORMS, v. 41, n. 4, p. 516-526, 2007.

DEVORE, J. L. Probability and Statistics for Engineering and the Sciences. [S.l.]:

Cengage Learning, 2015. ISBN 9781305465329. 
DULLAERT, W. et al. New heuristics for the fleet size and mix vehicle routing problem with time windows. Journal of the Operational Research Society, Taylor \& Francis, v. 53, n. 11, p. 1232-1238, 2002.

FEO, T. A.; RESENDE, M. G. A probabilistic heuristic for a computationally difficult set covering problem. Operations research letters, Elsevier, v. 8, n. 2, p. 67-71, 1989.

FEO, T. A.; RESENDE, M. G. Greedy randomized adaptive search procedures. Journal of global optimization, Springer, v. 6, n. 2, p. 109-133, 1995.

FESTA, P.; RESENDE, M. G. Hybrid grasp heuristics. In: Foundations of Computational Intelligence Volume 3. [S.1.]: Springer, 2009. p. 75-100.

GAHM, C.; BRABÄNDER, C.; TUMA, A. Vehicle routing with private fleet, multiple common carriers offering volume discounts, and rental options. Transportation Research Part E: Logistics and Transportation Review, Elsevier, v. 97, p. 192-216, 2017.

GHIANI, G.; LAPORTE, G.; MUSMANNO, R. Introduction to logistics systems planning and control. [S.l.]: John Wiley \& Sons, 2004.

GILLETT, B. E.; MILLER, L. R. A heuristic algorithm for the vehicle-dispatch problem. Operations research, INFORMS, v. 22, n. 2, p. 340-349, 1974.

GOLDEN, B. et al. The fleet size and mix vehicle routing problem. Computers 8 Operations Research, Elsevier, v. 11, n. 1, p. 49-66, 1984.

HANSEN, P.; MLADENOVIC, N. A tutorial on variable neighborhood search. [S.1.]: Groupe d'études et de recherche en analyse des décisions, HEC Montréal, 2003.

HANSEN, P.; MLADENOVIĆ, N.; PÉREZ, J. A. M. Variable neighbourhood search: methods and applications. Annals of Operations Research, Springer, v. 175, n. 1, p. 367-407, 2010.

HEMMELMAYR, V. C.; DOERNER, K. F.; HARTL, R. F. A variable neighborhood search heuristic for periodic routing problems. European Journal of Operational Research, Elsevier, v. 195, n. 3, p. 791-802, 2009.

HOFF, A. et al. Industrial aspects and literature survey: Fleet composition and routing. Computers $\&$ Operations Research, Elsevier, v. 37, n. 12, p. 2041-2061, 2010.

IMRAN, A.; SALHI, S.; WASSAN, N. A. A variable neighborhood-based heuristic for the heterogeneous fleet vehicle routing problem. European Journal of Operational Research, Elsevier, v. 197, n. 2, p. 509-518, 2009.

JR, E. F. S.; TSENG, F. T.; GUPTA, J. N. Comparative evaluation of milp flowshop models. Journal of the Operational Research Society, Taylor \& Francis, v. 56, n. 1, p. 88-101, 2005.

KOÇ, Ç. et al. A hybrid evolutionary algorithm for heterogeneous fleet vehicle routing problems with time windows. Computers $\& 3$ Operations Research, Elsevier, v. 64, p. 11-27, 2015. 
KOÇ, C. et al. The fleet size and mix location-routing problem with time windows: Formulations and a heuristic algorithm. European Journal of Operational Research, Elsevier, v. 248, n. 1, p. 33-51, 2016.

KRITIKOS, M. N.; IOANNOU, G. The heterogeneous fleet vehicle routing problem with overloads and time windows. International Journal of Production Economics, Elsevier, v. 144, n. 1, p. 68-75, 2013.

KYTÖJOKI, J. et al. An efficient variable neighborhood search heuristic for very large scale vehicle routing problems. Computers $\& 5$ Operations Research, Elsevier, v. 34, n. 9, p. 2743-2757, 2007.

LAPORTE, G. Fifty years of vehicle routing. Transportation Science, INFORMS, v. 43, n. 4, p. 408-416, 2009.

LIEB, R.; BENTZ, B. A. The use of third-party logistics services by large american manufacturers: the 2004 survey. Transportation journal, INFORMS, p. 5-15, 2005.

LIEB, R. C.; LIEB, K. J. The north american third-party logistics industry in 2013: The provider ceo perspective. Transportation Journal, INFORMS, v. 54, n. 1, p. 104-121, 2015.

LIN, S. Computer solutions of the traveling salesman problem. Bell System Technical Journal, Wiley Online Library, v. 44, n. 10, p. 2245-2269, 1965.

LIU, F.-H.; SHEN, S.-Y. The fleet size and mix vehicle routing problem with time windows. Journal of the Operational Research Society, Taylor \& Francis, v. 50, n. 7, p. 721-732, 1999.

MAnguino, J. L. V. Problema de roteamento de veículos com frota mista, janelas de tempo e custos escalonados. Dissertação (Mestrado em Engenharia de Produção) Escola Politécnica, Universidade de São Paulo, São Paulo, 2013.

MANGUinO, J. L. V.; RONCONI, D. P. Problema de roteamento de veículos com frota mista, janelas de tempo e custos escalonados. Anais do XLIV SBPO Simpósio Brasileiro de Pesquisa Operacional, SOBRAPO, Rio de Janeiro - RJ, Brazil, p. 1718-1729, 2012.

MARASCO, A. Third-party logistics: A literature review. International Journal of production economics, Elsevier, v. 113, n. 1, p. 127-147, 2008.

MLADENOVIĆ, N.; HANSEN, P. Variable neighborhood search. Computers $\&$ operations research, Elsevier, v. 24, n. 11, p. 1097-1100, 1997.

PALOMO-MARTÍNEZ, P. J. et al. A hybrid variable neighborhood search for the orienteering problem with mandatory visits and exclusionary constraints. Computers $\mathbb{E}$ Operations Research, Elsevier, v. 78, p. 408-419, 2017.

PARASKEVOPOULOS, D. C. et al. A reactive variable neighborhood tabu search for the heterogeneous fleet vehicle routing problem with time windows. Journal of Heuristics, Springer, v. 14, n. 5, p. 425-455, 2008.

PENNA, P. H. V. et al. A hybrid heuristic for a broad class of vehicle routing problems with heterogeneous fleet. Annals of Operations Research, Springer, v. 273, n. 1-2, p. 5-74, 2019. 
PESSOA, A.; SADYKOV, R.; UCHOA, E. Enhanced branch-cut-and-price algorithm for heterogeneous fleet vehicle routing problems. European Journal of Operational Research, Elsevier, v. 270, n. 2, p. 530-543, 2018.

POTVIN, J.-Y.; ROUSSEAU, J.-M. An exchange heuristic for routeing problems with time windows. Journal of the Operational Research Society, Springer, v. 46, n. 12, p. 1433-1446, 1995.

REPOUSSIS, P. P.; TARANTILIS, C. D. Solving the fleet size and mix vehicle routing problem with time windows via adaptive memory programming. Transportation Research Part C: Emerging Technologies, Elsevier, v. 18, n. 5, p. 695-712, 2010.

RESENDE, M. G.; RIBEIRO, C. C. Greedy randomized adaptive search procedures: Advances, hybridizations, and applications. In: Handbook of metaheuristics. [S.l.]: Springer, 2010. p. 283-319.

ROBUSTO, C. C. The cosine-haversine formula. The American Mathematical Monthly, JSTOR, v. 64, n. 1, p. 38-40, 1957.

RONCONI, D. P.; BIRGIN, E. G. Mixed-integer programming models for flowshop scheduling problems minimizing the total earliness and tardiness. In: Just-in-Time systems. [S.l.]: Springer, 2012. p. 91-105.

RONCONI, D. P.; MANGUINO, J. L. V. Heurísticas construtivas para o problema de roteamento de veículos com custos escalonados. Anais do XLVIII SBPO Simpósio Brasileiro de Pesquisa Operacional, SOBRAPO, Vitória - ES, Brazil, p. 1450-1460, 2016.

SIMEONOVA, L. et al. The heterogeneous fleet vehicle routing problem with light loads and overtime: Formulation and population variable neighbourhood search with adaptive memory. Expert Systems with Applications, Elsevier, v. 114, p. 183-195, 2018.

SOLOMON, M. M. Algorithms for the vehicle routing and scheduling problems with time window constraints. Operations Research, INFORMS, v. 35, n. 2, p. 254-265, 1987.

TAILLARD, É. et al. A tabu search heuristic for the vehicle routing problem with soft time windows. Transportation Science, INFORMS, v. 31, n. 2, p. 170-186, 1997.

VIDAL, T. et al. Heuristics for multi-attribute vehicle routing problems: A survey and synthesis. European Journal of Operational Research, Elsevier, v. 231, n. 1, p. 1-21, 2013.

VIDAL, T. et al. A hybrid genetic algorithm with adaptive diversity management for a large class of vehicle routing problems with time-windows. Computers $\& 5$ Operations Research, Elsevier, v. 40, n. 1, p. 475-489, 2013.

VIDAL, T. et al. A unified solution framework for multi-attribute vehicle routing problems. European Journal of Operational Research, Elsevier, v. 234, n. 3, p. 658-673, 2014 .

WANG, Z.; LI, Y.; HU, X. A heuristic approach and a tabu search for the heterogeneous multi-type fleet vehicle routing problem with time windows and an incompatible loading constraint. Computers \& Industrial Engineering, Elsevier, v. 89, p. 162-176, 2015. 


\section{APÊNDICE A - INSTÂNCIAS}

Nesse apêndice estão apresentados todas as instâncias explicadas no Capítulo 4 em detalhes.

\section{A.1 Instâncias de Referência}

Conforme explicado na Seção 4.1 os dados de clientes como sua localização, janelas de tempo e demanda estão disponíveis na página do professor Solomon no endereço 〈http: //w.cba.neu.edu/ msolomon/problems.htm〉. A contribuição deste trabalho se dá nas tabelas de frete 21, 22, 23, 24, 25, e 26 que são apresentadas a seguir.

Nestas tabelas, a linha "Faixa" indica qual a faixa de distância correspondente a cada coluna de custo. A linha "Distância" indica o valor da distância inicial desta faixa. A coluna "Custo Tipo" indica se é do tipo de custo a, b ou c, a coluna "Veículo" indica qual o tipo de veículo, $k=1, \ldots, K$, a coluna "Capacidade" indica a capacidade de cada um dos veículos daquela linha e as colunas seguintes possuem o valor do custo de cada faixa de distância para cada tipo de veículo. 


\begin{tabular}{cc|r|rrrrr}
\hline \multirow{2}{*}{ R1 } & & $\begin{array}{r}\text { Faixa: } \\
\text { Distância: }\end{array}$ & $W_{1}$ & $W_{2}$ & $W_{3}$ & $W_{4}$ & $W_{5}$ \\
& & & 40 & 70 & 100 & 130 \\
\hline Custo Tipo & Veículo $(k)$ & Capacidade & $C_{k 1}$ & $C_{k 2}$ & $C_{k 3}$ & $C_{k 4}$ & $C_{k 5}$ \\
\hline & 1 & 30 & 50 & 57.5 & 64.4 & 70.7 & 1 \\
& 2 & 50 & 80 & 88.1 & 95.6 & 102.5 & 1 \\
$\mathrm{a}$ & 3 & 80 & 140 & 148.7 & 156.8 & 164.3 & 1 \\
& 4 & 120 & 250 & 259.3 & 268 & 276.1 & 1 \\
& 5 & 200 & 500 & 509.9 & 519.2 & 527.9 & 1 \\
\hline & 1 & 30 & 10 & 17.5 & 24.1 & 29.8 & 1 \\
& 2 & 50 & 16 & 24.1 & 31.6 & 38.5 & 1 \\
$\mathrm{~b}$ & 3 & 120 & 28 & 36.7 & 44.8 & 52.3 & 1 \\
& 4 & 200 & 100 & 109.9 & 119.2 & 127.9 & 1 \\
\hline & 5 & 30 & 5 & 12.5 & 19.4 & 25.7 & 1 \\
& 1 & 50 & 8 & 16.1 & 23.6 & 30.5 & 1 \\
& 2 & 80 & 14 & 22.7 & 30.8 & 38.3 & 1 \\
& 3 & 120 & 25 & 34.3 & 43 & 51.1 & 1 \\
& 4 & 200 & 50 & 59.9 & 69.2 & 77.9 & 1 \\
\hline & 5 & & & & & &
\end{tabular}

Tabela 21: Tabela de frete das Instâncias de Referência do Tipo R1.

\begin{tabular}{|c|c|c|c|c|c|c|c|c|}
\hline \multicolumn{2}{|c|}{$\mathrm{R} 2$} & $\begin{array}{r}\text { Faixa: } \\
\text { Distância: }\end{array}$ & $\begin{array}{r}W_{1} \\
0\end{array}$ & $\begin{array}{l}W_{2} \\
80\end{array}$ & $\begin{array}{l}W_{3} \\
140\end{array}$ & $\begin{array}{l}W_{4} \\
200\end{array}$ & $\begin{array}{l}W_{5} \\
260\end{array}$ & $\begin{array}{l}W_{6} \\
320\end{array}$ \\
\hline Custo Tipo & Veículo $(k)$ & Capacidade & $C_{k 1}$ & $C_{k 2}$ & $C_{k 3}$ & $C_{k 4}$ & $C_{k 5}$ & $C_{k 6}$ \\
\hline \multirow{4}{*}{$\mathrm{a}$} & 1 & 300 & 450 & 480 & 508.8 & 536.4 & 562.8 & 1 \\
\hline & 2 & 400 & 700 & 731.2 & 761.2 & 790 & 817.6 & 1 \\
\hline & 3 & 600 & 1200 & 1232.4 & 1263.6 & 1293.6 & 1322.4 & 1 \\
\hline & 4 & 1000 & 2500 & 2533.6 & 2566 & 2597.2 & 2627.2 & 1 \\
\hline \multirow{4}{*}{ b } & 1 & 300 & 90 & 120 & 148.8 & 176.4 & 202.8 & 1 \\
\hline & 2 & 400 & 140 & 171.2 & 201.2 & 230 & 257.6 & 1 \\
\hline & 3 & 600 & 240 & 272.4 & 303.6 & 333.6 & 362.4 & 1 \\
\hline & 4 & 1000 & 500 & 533.6 & 566 & 597.2 & 627.2 & 1 \\
\hline \multirow{4}{*}{$\mathrm{c}$} & 1 & 300 & 45 & 75 & 103.8 & 131.4 & 157.8 & 1 \\
\hline & 2 & 400 & 70 & 101.2 & 131.2 & 160 & 187.6 & 1 \\
\hline & 3 & 600 & 120 & 152.4 & 183.6 & 213.6 & 242.4 & 1 \\
\hline & 4 & 1000 & 250 & 283.6 & 316 & 347.2 & 377.2 & 1 \\
\hline
\end{tabular}

Tabela 22: Tabela de frete das Instâncias de Referência do Tipo R2. 


\begin{tabular}{cc|r|rrrrr}
\hline \multirow{2}{*}{ C1 } & & $\begin{array}{r}\text { Faixa: } \\
\text { Distância: }\end{array}$ & $W_{1}$ & $W_{2}$ & $W_{3}$ & $W_{4}$ & $W_{5}$ \\
& & & 40 & 70 & 100 & 130 \\
\hline Custo Tipo & Veículo $(k)$ & Capacidade & $C_{k 1}$ & $C_{k 2}$ & $C_{k 3}$ & $C_{k 4}$ & $C_{k 5}$ \\
\hline \multirow{2}{*}{$\mathrm{a}$} & 1 & 100 & 300 & 315 & 329.4 & 343.2 & 1 \\
& 2 & 200 & 800 & 815.6 & 830.6 & 845 & 1 \\
& 3 & 300 & 1350 & 1366.2 & 1381.8 & 1396.8 & 1 \\
\hline & 1 & 100 & 60 & 75 & 89.4 & 103.2 & 1 \\
$\mathrm{~b}$ & 2 & 200 & 160 & 175.6 & 190.6 & 205 & 1 \\
& 3 & 300 & 270 & 286.2 & 301.8 & 316.8 & 1 \\
\hline & 1 & 100 & 30 & 45 & 59.4 & 73.2 & 1 \\
$\mathrm{c}$ & 2 & 200 & 80 & 95.6 & 110.6 & 125 & 1 \\
& 3 & 300 & 135 & 151.2 & 166.8 & 181.8 & 1 \\
\hline
\end{tabular}

Tabela 23: Tabela de frete das Instâncias de Referência do Tipo C1.

\begin{tabular}{|c|c|c|c|c|c|c|c|c|}
\hline \multicolumn{2}{|c|}{$\mathrm{C} 2$} & $\begin{array}{r}\text { Faixa: } \\
\text { Distância: }\end{array}$ & $\begin{array}{r}W_{1} \\
0\end{array}$ & $\begin{array}{l}W_{2} \\
\quad 80\end{array}$ & $\begin{array}{l}W_{3} \\
140\end{array}$ & $\begin{array}{c}W_{4} \\
200\end{array}$ & $\begin{array}{c}W_{5} \\
260\end{array}$ & $\begin{array}{l}W_{6} \\
320\end{array}$ \\
\hline Custo Tipo & Veículo $(k)$ & Capacidade & $C_{k 1}$ & $C_{k 2}$ & $C_{k 3}$ & $C_{k 4}$ & $C_{k 5}$ & $C_{k 6}$ \\
\hline \multirow{4}{*}{ a } & 1 & 400 & 1000 & 1030 & 1058.8 & 1086.4 & 1112.8 & 1 \\
\hline & 2 & 500 & 1400 & 1431.2 & 1461.2 & 1490 & 1517.6 & 1 \\
\hline & 3 & 600 & 2000 & 2032.4 & 2063.6 & 2093.6 & 2122.4 & 1 \\
\hline & 4 & 700 & 2700 & 2733.6 & 2766 & 2797.2 & 2827.2 & 1 \\
\hline \multirow{4}{*}{ b } & 1 & 400 & 200 & 230 & 258.8 & 286.4 & 312.8 & 1 \\
\hline & 2 & 500 & 280 & 311.2 & 341.2 & 370 & 397.6 & 1 \\
\hline & 3 & 600 & 400 & 432.4 & 463.6 & 493.6 & 522.4 & 1 \\
\hline & 4 & 700 & 540 & 573.6 & 606 & 637.2 & 667.2 & 1 \\
\hline \multirow{4}{*}{$\mathrm{C}$} & 1 & 400 & 100 & 130 & 158.8 & 186.4 & 212.8 & 1 \\
\hline & 2 & 500 & 140 & 171.2 & 201.2 & 230 & 257.6 & 1 \\
\hline & 3 & 600 & 200 & 232.4 & 263.6 & 293.6 & 322.4 & 1 \\
\hline & 4 & 700 & 270 & 303.6 & 336 & 367.2 & 397.2 & 1 \\
\hline
\end{tabular}

Tabela 24: Tabela de frete das Instâncias de Referência do Tipo C2. 


\begin{tabular}{cc|r|rrrrr}
\hline \multirow{2}{*}{ RC1 } & & $\begin{array}{r}\text { Faixa: } \\
\text { Distância: }\end{array}$ & $W_{1}$ & $W_{2}$ & $W_{3}$ & $W_{4}$ & $W_{5}$ \\
& & & 40 & 70 & 100 & 130 \\
\hline Custo Tipo & Veículo $(k)$ & Capacidade & $C_{k 1}$ & $C_{k 2}$ & $C_{k 3}$ & $C_{k 4}$ & $C_{k 5}$ \\
\hline \multirow{2}{*}{$\mathrm{a}$} & 1 & 40 & 60 & 68.1 & 75.6 & 82.5 & 1 \\
& 2 & 80 & 150 & 158.7 & 166.8 & 174.3 & 1 \\
& 3 & 150 & 300 & 309.3 & 318 & 326.1 & 1 \\
& 4 & 200 & 450 & 459.9 & 469.2 & 477.9 & 1 \\
\hline & 1 & 40 & 12 & 20.1 & 27.6 & 34.5 & 1 \\
$\mathrm{~b}$ & 2 & 80 & 30 & 38.7 & 46.8 & 54.3 & 1 \\
& 3 & 150 & 60 & 69.3 & 78 & 86.1 & 1 \\
& 4 & 200 & 90 & 99.9 & 109.2 & 117.9 & 1 \\
\hline & 1 & 40 & 6 & 14.1 & 21.6 & 28.5 & 1 \\
$\mathrm{c}$ & 2 & 150 & 15 & 23.7 & 31.8 & 39.3 & 1 \\
& 3 & 200 & 45 & 39.3 & 48 & 56.1 & 1 \\
& 4 & & & & & & \\
\hline
\end{tabular}

Tabela 25: Tabela de frete das Instâncias de Referência do Tipo RC1.

\begin{tabular}{|c|c|c|c|c|c|c|c|c|}
\hline \multicolumn{2}{|c|}{$\mathrm{RC} 2$} & Faixa: & $W_{1}$ & $W_{2}$ & $W_{3}$ & $W_{4}$ & $W_{5}$ & $W_{6}$ \\
\hline Custo Tipo & Veículo $(k)$ & Capacidade & $C_{k 1}$ & $C_{k 2}$ & $C_{k 3}$ & $C_{k 4}$ & $C_{k 5}$ & $C_{k 6}$ \\
\hline \multirow{6}{*}{$\mathrm{a}$} & 1 & 100 & 150 & 177.6 & 204 & 229.2 & 253.2 & 1 \\
\hline & 2 & 200 & 350 & 378.8 & 406.4 & 432.8 & 458 & 1 \\
\hline & 3 & 300 & 550 & 580 & 608.8 & 636.4 & 662.8 & 1 \\
\hline & 4 & 400 & 800 & 831.2 & 861.2 & 890 & 917.6 & 1 \\
\hline & 5 & 500 & 1100 & 1132.4 & 1163.6 & 1193.6 & 1222.4 & 1 \\
\hline & 6 & 1000 & 2500 & 2533.6 & 2566 & 2597.2 & 2627.2 & 1 \\
\hline \multirow{6}{*}{$\mathrm{b}$} & 1 & 100 & 30 & 57.6 & 84 & 109.2 & 133.2 & 1 \\
\hline & 2 & 200 & 70 & 98.8 & 126.4 & 152.8 & 178 & 1 \\
\hline & 3 & 300 & 110 & 140 & 168.8 & 196.4 & 222.8 & 1 \\
\hline & 4 & 400 & 160 & 191.2 & 221.2 & 250 & 277.6 & 1 \\
\hline & 5 & 500 & 220 & 252.4 & 283.6 & 313.6 & 342.4 & 1 \\
\hline & 6 & 1000 & 500 & 533.6 & 566 & 597.2 & 627.2 & 1 \\
\hline \multirow{6}{*}{ C } & 1 & 100 & 15 & 42.6 & 69 & 94.2 & 118.2 & 1 \\
\hline & 2 & 200 & 35 & 63.8 & 91.4 & 117.8 & 143 & 1 \\
\hline & 3 & 300 & 55 & 85 & 113.8 & 141.4 & 167.8 & 1 \\
\hline & 4 & 400 & 80 & 111.2 & 141.2 & 170 & 197.6 & 1 \\
\hline & 5 & 500 & 110 & 142.4 & 173.6 & 203.6 & 232.4 & 1 \\
\hline & 6 & 1000 & 250 & 283.6 & 316 & 347.2 & 377.2 & 7 \\
\hline
\end{tabular}

Tabela 26: Tabela de frete das Instâncias de Referência do Tipo RC2. 


\section{A.2 Instância de Dimensões Menores}

As instâncias de dimensões menores usam as mesmas tabelas de frete das instâncias de referência apresentadas na Seção A.1. A seguir são apresentadas os dados dos clientes nas Instâncias de Dimensões Menores nas Tabelas 27, 28, 29, 30, 31, 32,

Nessas tabelas, a coluna "Cenário" indica em qual cenário cada linha está presente. Assim, caso se esteja visualizando o cenário R1a10, somente as 10 primeiras linhas da Tabela 27 são utilizadas. No cenário R1a20, até a linha 20 deve ser observada.

A coluna $i$ indica o número que identifica o cliente, sendo que 0 se trata do armazém. As colunas $x_{i}$ e $y_{i}$ indicam as coordenadas cartesianas dos clientes. A coluna $d_{i}$ indica a demanda de cada cliente. $e_{i}$ e $\ell_{i}$ indicam o início e fim das janelas de tempo de cada cliente e $s_{i}$ o tempo de atendimento. 


\begin{tabular}{|c|c|c|c|c|c|c|c|}
\hline \multicolumn{8}{|c|}{ R1 } \\
\hline Cenário & $i$ & $x_{i}$ & $y_{i}$ & $d_{i}$ & $e_{i}$ & $\ell_{i}$ & $s_{i}$ \\
\hline \multirow{11}{*}{$10 / 15 / 20 / 25$} & 0 & 35 & 35 & 0 & 0 & 230 & 0 \\
\hline & 1 & 41 & 49 & 10 & 161 & 171 & 10 \\
\hline & 2 & 35 & 17 & 7 & 50 & 60 & 10 \\
\hline & 3 & 55 & 45 & 13 & 116 & 126 & 10 \\
\hline & 4 & 55 & 20 & 19 & 149 & 159 & 10 \\
\hline & 5 & 15 & 30 & 26 & 34 & 44 & 10 \\
\hline & 6 & 25 & 30 & 3 & 99 & 109 & 10 \\
\hline & 7 & 20 & 50 & 5 & 81 & 91 & 10 \\
\hline & 8 & 10 & 43 & 9 & 95 & 105 & 10 \\
\hline & 9 & 55 & 60 & 16 & 97 & 107 & 10 \\
\hline & 10 & 30 & 60 & 16 & 124 & 134 & 10 \\
\hline \multirow{5}{*}{$15 / 20 / 25$} & 11 & 20 & 65 & 12 & 67 & 77 & 10 \\
\hline & 12 & 50 & 35 & 19 & 63 & 73 & 10 \\
\hline & 13 & 30 & 25 & 23 & 159 & 169 & 10 \\
\hline & 14 & 15 & 10 & 20 & 32 & 42 & 10 \\
\hline & 15 & 30 & 5 & 8 & 61 & 71 & 10 \\
\hline \multirow{5}{*}{$20 / 25$} & 16 & 10 & 20 & 19 & 75 & 85 & 10 \\
\hline & 17 & 5 & 30 & 2 & 157 & 167 & 10 \\
\hline & 18 & 20 & 40 & 12 & 87 & 97 & 10 \\
\hline & 19 & 15 & 60 & 17 & 76 & 86 & 10 \\
\hline & 20 & 45 & 65 & 9 & 126 & 136 & 10 \\
\hline \multirow{5}{*}{25} & 21 & 45 & 20 & 11 & 62 & 72 & 10 \\
\hline & 22 & 45 & 10 & 18 & 97 & 107 & 10 \\
\hline & 23 & 55 & 5 & 29 & 68 & 78 & 10 \\
\hline & 24 & 65 & 35 & 3 & 153 & 163 & 10 \\
\hline & 25 & 65 & 20 & 6 & 172 & 182 & 10 \\
\hline
\end{tabular}

Tabela 27: Dados de clientes para instâncias de pequenas dimensão do Tipo R1. 


\begin{tabular}{|c|c|c|c|c|c|c|c|}
\hline \multicolumn{8}{|c|}{$\mathrm{R} 2$} \\
\hline Cenário & $i$ & $x_{i}$ & $y_{i}$ & $d_{i}$ & $e_{i}$ & $\ell_{i}$ & $s_{i}$ \\
\hline \multirow{11}{*}{$10 / 15 / 20 / 25$} & 0 & 35 & 35 & 0 & 0 & 1000 & 0 \\
\hline & 1 & 41 & 49 & 10 & 707 & 848 & 10 \\
\hline & 2 & 35 & 17 & 7 & 143 & 282 & 10 \\
\hline & 3 & 55 & 45 & 13 & 527 & 584 & 10 \\
\hline & 4 & 55 & 20 & 19 & 678 & 801 & 10 \\
\hline & 5 & 15 & 30 & 26 & 34 & 209 & 10 \\
\hline & 6 & 25 & 30 & 3 & 415 & 514 & 10 \\
\hline & 7 & 20 & 50 & 5 & 331 & 410 & 10 \\
\hline & 8 & 10 & 43 & 9 & 404 & 481 & 10 \\
\hline & 9 & 55 & 60 & 16 & 400 & 497 & 10 \\
\hline & 10 & 30 & 60 & 16 & 577 & 632 & 10 \\
\hline \multirow{5}{*}{$15 / 20 / 25$} & 11 & 20 & 65 & 12 & 206 & 325 & 10 \\
\hline & 12 & 50 & 35 & 19 & 228 & 345 & 10 \\
\hline & 13 & 30 & 25 & 23 & 690 & 827 & 10 \\
\hline & 14 & 15 & 10 & 20 & 32 & 243 & 10 \\
\hline & 15 & 30 & 5 & 8 & 175 & 300 & 10 \\
\hline \multirow{5}{*}{$20 / 25$} & 16 & 10 & 20 & 19 & 272 & 373 & 10 \\
\hline & 17 & 5 & 30 & 2 & 733 & 870 & 10 \\
\hline & 18 & 20 & 40 & 12 & 377 & 434 & 10 \\
\hline & 19 & 15 & 60 & 17 & 269 & 378 & 10 \\
\hline & 20 & 45 & 65 & 9 & 581 & 666 & 10 \\
\hline \multirow{5}{*}{25} & 21 & 45 & 20 & 11 & 214 & 331 & 10 \\
\hline & 22 & 45 & 10 & 18 & 409 & 494 & 10 \\
\hline & 23 & 55 & 5 & 29 & 206 & 325 & 10 \\
\hline & 24 & 65 & 35 & 3 & 704 & 847 & 10 \\
\hline & 25 & 65 & 20 & 6 & 817 & 956 & 10 \\
\hline
\end{tabular}

Tabela 28: Dados de clientes para instâncias de pequenas dimensão do Tipo R2. 


\begin{tabular}{|c|c|c|c|c|c|c|c|}
\hline \multicolumn{8}{|c|}{$\mathrm{C} 1$} \\
\hline Cenário & $i$ & $x_{i}$ & $y_{i}$ & $d_{i}$ & $e_{i}$ & $\ell_{i}$ & $s_{i}$ \\
\hline \multirow{11}{*}{$10 / 15 / 20 / 25$} & 0 & 40 & 50 & 0 & 0 & 1236 & 0 \\
\hline & 1 & 42 & 65 & 10 & 15 & 67 & 90 \\
\hline & 2 & 40 & 69 & 20 & 621 & 702 & 90 \\
\hline & 3 & 40 & 66 & 20 & 170 & 225 & 90 \\
\hline & 4 & 38 & 68 & 20 & 255 & 324 & 90 \\
\hline & 5 & 38 & 70 & 10 & 534 & 605 & 90 \\
\hline & 6 & 28 & 52 & 20 & 812 & 883 & 90 \\
\hline & 7 & 28 & 55 & 10 & 732 & 777 & 90 \\
\hline & 8 & 25 & 50 & 10 & 65 & 144 & 90 \\
\hline & 9 & 25 & 52 & 40 & 169 & 224 & 90 \\
\hline & 10 & 25 & 55 & 10 & 622 & 701 & 90 \\
\hline \multirow{5}{*}{$15 / 20 / 25$} & 11 & 35 & 32 & 10 & 166 & 235 & 90 \\
\hline & 12 & 33 & 32 & 20 & 68 & 149 & 90 \\
\hline & 13 & 33 & 35 & 10 & 16 & 80 & 90 \\
\hline & 14 & 32 & 30 & 10 & 359 & 412 & 90 \\
\hline & 15 & 30 & 30 & 10 & 541 & 600 & 90 \\
\hline \multirow{5}{*}{$20 / 25$} & 16 & 90 & 35 & 10 & 203 & 260 & 90 \\
\hline & 17 & 88 & 30 & 10 & 574 & 643 & 90 \\
\hline & 18 & 88 & 35 & 20 & 109 & 170 & 90 \\
\hline & 19 & 87 & 30 & 10 & 668 & 731 & 90 \\
\hline & 20 & 85 & 25 & 10 & 769 & 820 & 90 \\
\hline \multirow{5}{*}{25} & 21 & 65 & 55 & 20 & 85 & 144 & 90 \\
\hline & 22 & 65 & 60 & 30 & 645 & 708 & 90 \\
\hline & 23 & 63 & 58 & 10 & 737 & 802 & 90 \\
\hline & 24 & 60 & 55 & 10 & 20 & 84 & 90 \\
\hline & 25 & 60 & 60 & 10 & 836 & 889 & 90 \\
\hline
\end{tabular}

Tabela 29: Dados de clientes para instâncias de pequenas dimensão do Tipo C1. 


\begin{tabular}{|c|c|c|c|c|c|c|c|}
\hline \multicolumn{8}{|c|}{$\mathrm{C} 2$} \\
\hline Cenário & $i$ & $x_{i}$ & $y_{i}$ & $d_{i}$ & $e_{i}$ & $\ell_{i}$ & $s_{i}$ \\
\hline \multirow{11}{*}{$10 / 15 / 20 / 25$} & 0 & 40 & 50 & 0 & 0 & 3390 & 0 \\
\hline & 1 & 45 & 70 & 30 & 213 & 373 & 90 \\
\hline & 2 & 42 & 65 & 10 & 25 & 185 & 90 \\
\hline & 3 & 45 & 65 & 20 & 118 & 278 & 90 \\
\hline & 4 & 42 & 58 & 40 & 8 & 168 & 90 \\
\hline & 5 & 25 & 50 & 10 & 116 & 276 & 90 \\
\hline & 6 & 23 & 52 & 10 & 209 & 369 & 90 \\
\hline & 7 & 20 & 50 & 10 & 398 & 558 & 90 \\
\hline & 8 & 20 & 55 & 10 & 303 & 463 & 90 \\
\hline & 9 & 50 & 35 & 20 & 120 & 280 & 90 \\
\hline & 10 & 50 & 40 & 50 & 25 & 185 & 90 \\
\hline \multirow{5}{*}{$15 / 20 / 25$} & 11 & 47 & 35 & 10 & 588 & 748 & 90 \\
\hline & 12 & 47 & 40 & 10 & 12 & 172 & 90 \\
\hline & 13 & 45 & 35 & 10 & 680 & 840 & 90 \\
\hline & 14 & 53 & 35 & 50 & 213 & 373 & 90 \\
\hline & 15 & 26 & 32 & 10 & 2292 & 2452 & 90 \\
\hline \multirow{5}{*}{$20 / 25$} & 16 & 25 & 30 & 10 & 2200 & 2360 & 90 \\
\hline & 17 & 25 & 35 & 10 & 2385 & 2545 & 90 \\
\hline & 18 & 30 & 30 & 10 & 2105 & 2265 & 90 \\
\hline & 19 & 30 & 35 & 10 & 2480 & 2640 & 90 \\
\hline & 20 & 33 & 32 & 20 & 2666 & 2826 & 90 \\
\hline \multirow{5}{*}{25} & 21 & 62 & 80 & 30 & 881 & 1041 & 90 \\
\hline & 22 & 60 & 85 & 30 & 597 & 757 & 90 \\
\hline & 23 & 58 & 75 & 20 & 978 & 1138 & 90 \\
\hline & 24 & 55 & 80 & 10 & 407 & 567 & 90 \\
\hline & 25 & 55 & 85 & 20 & 502 & 662 & 90 \\
\hline
\end{tabular}

Tabela 30: Dados de clientes para instâncias de pequenas dimensão do Tipo C2. 


\begin{tabular}{|c|c|c|c|c|c|c|c|}
\hline \multicolumn{8}{|c|}{$\mathrm{RC} 1$} \\
\hline Cenário & $i$ & $x_{i}$ & $y_{i}$ & $d_{i}$ & $e_{i}$ & $\ell_{i}$ & $s_{i}$ \\
\hline \multirow{11}{*}{$10 / 15 / 20 / 25$} & 0 & 40 & 50 & 0 & 0 & 240 & 0 \\
\hline & 1 & 25 & 85 & 20 & 145 & 175 & 10 \\
\hline & 2 & 22 & 75 & 30 & 50 & 80 & 10 \\
\hline & 3 & 22 & 85 & 10 & 109 & 139 & 10 \\
\hline & 4 & 20 & 80 & 40 & 141 & 171 & 10 \\
\hline & 5 & 20 & 85 & 20 & 41 & 71 & 10 \\
\hline & 6 & 18 & 75 & 20 & 95 & 125 & 10 \\
\hline & 7 & 15 & 75 & 20 & 79 & 109 & 10 \\
\hline & 8 & 15 & 80 & 10 & 91 & 121 & 10 \\
\hline & 9 & 10 & 35 & 20 & 91 & 121 & 10 \\
\hline & 10 & 10 & 40 & 30 & 119 & 149 & 10 \\
\hline \multirow{5}{*}{$15 / 20 / 25$} & 11 & 8 & 40 & 40 & 59 & 89 & 10 \\
\hline & 12 & 8 & 45 & 20 & 64 & 94 & 10 \\
\hline & 13 & 5 & 35 & 10 & 142 & 172 & 10 \\
\hline & 14 & 5 & 45 & 10 & 35 & 65 & 10 \\
\hline & 15 & 2 & 40 & 20 & 58 & 88 & 10 \\
\hline \multirow{5}{*}{$20 / 25$} & 16 & 0 & 40 & 20 & 72 & 102 & 10 \\
\hline & 17 & 0 & 45 & 20 & 149 & 179 & 10 \\
\hline & 18 & 61 & 52 & 3 & 178 & 208 & 10 \\
\hline & 19 & 57 & 48 & 23 & 95 & 125 & 10 \\
\hline & 20 & 56 & 37 & 6 & 34 & 64 & 10 \\
\hline \multirow{5}{*}{25} & 21 & 55 & 54 & 26 & 132 & 162 & 10 \\
\hline & 22 & 4 & 18 & 35 & 120 & 150 & 10 \\
\hline & 23 & 26 & 52 & 9 & 46 & 76 & 10 \\
\hline & 24 & 26 & 35 & 15 & 77 & 107 & 10 \\
\hline & 25 & 31 & 67 & 3 & 180 & 210 & 10 \\
\hline
\end{tabular}

Tabela 31: Dados de clientes para instâncias de pequenas dimensão do Tipo RC1. 


\begin{tabular}{|c|c|c|c|c|c|c|c|}
\hline \multicolumn{8}{|c|}{$\mathrm{RC2}$} \\
\hline Cenário & $i$ & $x_{i}$ & $y_{i}$ & $d_{i}$ & $e_{i}$ & $\ell_{i}$ & $s_{i}$ \\
\hline \multirow{11}{*}{$10 / 15 / 20 / 25$} & 0 & 40 & 50 & 0 & 0 & 960 & 0 \\
\hline & 1 & 25 & 85 & 20 & 673 & 793 & 10 \\
\hline & 2 & 22 & 75 & 30 & 152 & 272 & 10 \\
\hline & 3 & 22 & 85 & 10 & 471 & 591 & 10 \\
\hline & 4 & 20 & 80 & 40 & 644 & 764 & 10 \\
\hline & 5 & 20 & 85 & 20 & 73 & 193 & 10 \\
\hline & 6 & 18 & 75 & 20 & 388 & 508 & 10 \\
\hline & 7 & 10 & 35 & 20 & 371 & 491 & 10 \\
\hline & 8 & 10 & 40 & 30 & 519 & 639 & 10 \\
\hline & 9 & 8 & 40 & 40 & 195 & 315 & 10 \\
\hline & 10 & 8 & 45 & 20 & 223 & 343 & 10 \\
\hline \multirow{5}{*}{$15 / 20 / 25$} & 11 & 5 & 35 & 10 & 653 & 773 & 10 \\
\hline & 12 & 5 & 45 & 10 & 35 & 155 & 10 \\
\hline & 13 & 2 & 40 & 20 & 174 & 294 & 10 \\
\hline & 14 & 0 & 40 & 20 & 255 & 375 & 10 \\
\hline & 15 & 37 & 47 & 6 & 359 & 479 & 10 \\
\hline \multirow{5}{*}{$20 / 25$} & 16 & 49 & 42 & 13 & 719 & 839 & 10 \\
\hline & 17 & 53 & 43 & 14 & 14 & 134 & 10 \\
\hline & 18 & 61 & 52 & 3 & 808 & 928 & 10 \\
\hline & 19 & 57 & 48 & 23 & 392 & 512 & 10 \\
\hline & 20 & 56 & 37 & 6 & 100 & 220 & 10 \\
\hline \multirow{5}{*}{25} & 21 & 55 & 54 & 26 & 562 & 682 & 10 \\
\hline & 22 & 4 & 18 & 35 & 547 & 667 & 10 \\
\hline & 23 & 26 & 52 & 9 & 172 & 292 & 10 \\
\hline & 24 & 26 & 35 & 15 & 308 & 428 & 10 \\
\hline & 25 & 31 & 67 & 3 & 810 & 930 & 10 \\
\hline
\end{tabular}

Tabela 32: Dados de clientes para instâncias de pequenas dimensão do Tipo RC2. 


\section{A.3 Instâncias Inspiradas em Dados Reais}

A seguir estão apresentadas as tabelas com os dados detalhado das instâncias inspiradas em dados reais. São 131 clientes no Dia 1, por isso as tabelas foram divididas em 4 tabelas, 33, 34, 35 e 36, que possui somente dados do Dia 1. Para cada tabela está apresentado o número que identifica o cliente na coluna "Cliente"e, para cada dia as coordenadas $x_{i}$ e $y_{i}$ dos clientes, bem como sua demanda em $q_{i}$. Não está apresentado nas tabelas, mas como foi informado na Seção 4.3 , todos os clientes tem janelas de tempo de 7 a 17 horas e o tempo de serviço é de 1,5 horas.

Como se trata de um caso real, a empresa solicitou confidencialidade dos dados, portanto os valores das coordenadas foram somados a um fator que permitiu que as distâncias se mantivessem entre os pontos, mas as coordenadas não representam mais sua posição verdadeira. Com isso, as coordenadas que para o Estado de São Paulo são sempre negativas, uma vez que o Estado se encontra no hemisfério sul e a oeste de Greenwich, estão todas positivas.

É importante observar que como se trata de um caso real, as distâncias cartesianas não representam a realidade das distâncias, é necessário usar o cálculo da fórmula de Haversine, conforme Robusto (1957), para o cálculo da distância em quilômetros:

$$
d_{i j}=6371 \times \arccos \left(\sin x_{i} \times \sin x_{j}+\cos x_{i} \times \cos x_{j} \times \cos \left(y_{i}-y_{j}\right)\right)
$$

para obter o tempo de trânsito entre dois pontos, foi considerada uma velocidade média de $50 \mathrm{~km} / \mathrm{h}$. 


\begin{tabular}{|c|c|c|c|c|c|c|c|c|c|}
\hline \multirow{2}{*}{ Cliente } & \multicolumn{3}{|c|}{ Dia 1} & \multicolumn{3}{|c|}{ Dia 2} & \multicolumn{3}{|c|}{ Dia 3} \\
\hline & $x_{i}$ & $y_{i}$ & $q_{i}$ & $x_{i}$ & $y_{i}$ & $q_{i}$ & $x_{i}$ & $y_{i}$ & $q_{i}$ \\
\hline 0 & 0.55 & 1.05 & 0 & 0.55 & 1.05 & 0 & 0.55 & 1.05 & 0 \\
\hline 1 & 0.46 & 1.21 & 13.664 & 0.84 & 1.18 & 1.2 & 0.61 & 1.63 & 0.8 \\
\hline 2 & 0.84 & 1.18 & 1.56 & 0.67 & 0.96 & 14 & 1.19 & 0.78 & 14 \\
\hline 3 & 1.2 & 1 & 3.92 & 0.78 & 0.57 & 1 & 1.35 & 0.77 & 20 \\
\hline 4 & 0.39 & 1.11 & 2 & 0.39 & 1.11 & 11.96 & 0.4 & 1.24 & 7.52 \\
\hline 5 & 0.71 & 0.56 & 2 & 1.06 & 0.95 & 14 & 0.56 & 1.17 & 4 \\
\hline 6 & 1.16 & 0.6 & 4 & 1.17 & 0.79 & 14 & 0.66 & 1.11 & 14 \\
\hline 7 & 0.85 & 1.39 & 13.36 & 0.65 & 0.99 & 6 & 0.38 & 1.28 & 14 \\
\hline 8 & 1.09 & 1.35 & 14 & 0.45 & 1.43 & 13.88 & 0.98 & 1 & 14 \\
\hline 9 & 0.7 & 0.48 & 2 & 1.11 & 1.2 & 14 & 1.16 & 1.21 & 4.1 \\
\hline 10 & 0.66 & 1.11 & 12.184 & 1.11 & 1.19 & 14 & 0.42 & 0.92 & 0.4 \\
\hline 11 & 0.34 & 1.39 & 1.32 & 1.16 & 0.6 & 13.78 & 0.36 & 1.29 & 2 \\
\hline 12 & 1.35 & 0.78 & 0.208 & 0.87 & 0.47 & 4 & 0.61 & 1.14 & 1 \\
\hline 13 & 1.16 & 1.21 & 10 & 0.36 & 1.29 & 1 & 0.38 & 1.59 & 1.6 \\
\hline 14 & 0.62 & 1.11 & 2 & 0.96 & 1.01 & 4 & 1.19 & 0.8 & 14 \\
\hline 15 & 0.85 & 1.17 & 14 & 0.77 & 1.02 & 2.496 & 0.59 & 0.85 & 14 \\
\hline 16 & 0.79 & 0.74 & 1 & 1.09 & 1.35 & 14.04 & 0.45 & 0.94 & 3.2 \\
\hline 17 & 0.34 & 1.36 & 1.6 & 0.92 & 1.11 & 12.4 & 1.18 & 0.8 & 14 \\
\hline 18 & 0.63 & 1.05 & 0.608 & 0.84 & 0.51 & 14 & 1.15 & 0.59 & 14 \\
\hline 19 & 0.33 & 1.32 & 0.66 & 1.55 & 1.36 & 14 & 0.9 & 0.98 & 14 \\
\hline 20 & 0.6 & 0.97 & 14 & 0.41 & 1.12 & 2 & 0.55 & 0.66 & 14 \\
\hline 21 & 0.67 & 1.12 & 0.8 & 1.58 & 1.38 & 13.82 & 0.61 & 0.91 & 14 \\
\hline 22 & 0.67 & 1.11 & 14 & 0.65 & 1.78 & 2 & 0.82 & 0.97 & 14 \\
\hline 23 & 0.36 & 1.2 & 13.94 & 0.42 & 0.92 & 0.1 & 0.84 & 1.35 & 14 \\
\hline 24 & 0.55 & 0.66 & 14 & 0.36 & 1.31 & 14 & 1.2 & 1.23 & 14 \\
\hline 25 & 1.38 & 0.79 & 14 & 1.18 & 0.8 & 20 & 1.35 & 1.41 & 6.4 \\
\hline 26 & 0.63 & 1.12 & 0.4 & 0.71 & 0.55 & 14 & 0.51 & 0.79 & 14 \\
\hline 27 & 1.72 & 1.26 & 14 & 0.86 & 1.18 & 14 & 0.97 & 0.75 & 14 \\
\hline 28 & 0.9 & 0.96 & 4 & 0.6 & 0.98 & 14 & 1.57 & 1.38 & 2 \\
\hline 29 & 0.34 & 1.28 & 14 & 0.9 & 0.98 & 14 & 1.36 & 0.77 & 8 \\
\hline 30 & 1.17 & 1.21 & 14 & 0.58 & 1.6 & 2 & 1.17 & 0.78 & 2 \\
\hline 31 & 1.19 & 0.78 & 3.76 & 0.55 & 0.66 & 14 & 0.63 & 1.15 & 14 \\
\hline 32 & 0.44 & 1.44 & 16 & 1.14 & 1.2 & 13.9 & 1.55 & 1.38 & 10.32 \\
\hline 33 & 0.5 & 1.15 & 1.2 & 0.67 & 1.13 & 0.8 & 0.97 & 0.78 & 14 \\
\hline 34 & 1.16 & 0.61 & 2 & 0.63 & 1.12 & 1 & 0.7 & 1.1 & 8 \\
\hline 35 & 1.1 & 0.62 & 0.416 & 0.64 & 0.94 & 4 & 1.11 & 1.33 & 4 \\
\hline 36 & 0.73 & 0.96 & 6 & 0.66 & 0.99 & 2.8 & 0.99 & 0.74 & 14 \\
\hline 37 & 0.44 & 0.98 & 2 & 0.44 & 0.92 & 1.2 & 1.16 & 0.79 & 0.84 \\
\hline 38 & 0.79 & 0.75 & 1 & 1.19 & 0.78 & 14 & 0.99 & 0.72 & 0.4 \\
\hline 39 & 0.81 & 0.81 & 14 & 0.49 & 0.85 & 4 & 1.35 & 1.4 & 9.936 \\
\hline 40 & 0.95 & 0.74 & 1.2 & 0.66 & 1.74 & 2 & 1.18 & 0.79 & 1 \\
\hline 41 & 0.34 & 1.37 & 2 & 0.97 & 0.99 & 13.9 & 0.61 & 0.92 & 14 \\
\hline 42 & 1.61 & 1.45 & 13.82 & 0.81 & 0.62 & 14 & 0.98 & 0 & 14 \\
\hline
\end{tabular}

Tabela 33: Dados das instâncias inspiradas em dados reais - Clientes 1 a 42. 


\begin{tabular}{|c|c|c|c|c|c|c|c|c|c|}
\hline \multirow{2}{*}{ Cliente } & \multicolumn{3}{|c|}{ Dia 1} & \multicolumn{3}{|c|}{ Dia 2} & \multicolumn{3}{|c|}{ Dia 3} \\
\hline & $x_{i}$ & $y_{i}$ & $q_{i}$ & $x_{i}$ & $y_{i}$ & $q_{i}$ & $x_{i}$ & $y_{i}$ & $q_{i}$ \\
\hline 0 & 0.55 & 1.05 & 0 & 0.55 & 1.05 & 0 & 0.55 & 1.05 & 0 \\
\hline 43 & 1.38 & 0.78 & 2.08 & 0.65 & 1.07 & 1 & 1.14 & 1.19 & 8 \\
\hline 44 & 0.72 & 0.9 & 12.2 & 1.16 & 0.61 & 3.12 & 1.5 & 1.18 & 4.8 \\
\hline 45 & 0.4 & 1.24 & 13.6 & 0.6 & 1.14 & 14 & 0.81 & 0.81 & 14 \\
\hline 46 & 0.43 & 0.93 & 2.4 & 0.83 & 0.84 & 14 & 0.95 & 0.77 & 0.4 \\
\hline 47 & 1.13 & 0.6 & 2 & 0.39 & 1.16 & 6 & 1.38 & 0.78 & 2 \\
\hline 48 & 1.13 & 0.61 & 0.6 & 0.39 & 1.13 & 4.8 & 0.75 & 1.08 & 2 \\
\hline 49 & 0.97 & 0.79 & 4 & 0.6 & 0.98 & 2.26 & 0.81 & 0.88 & 6 \\
\hline 50 & 0.75 & 1.14 & 3 & 0.92 & 1.63 & 2.04 & 0.63 & 1.05 & 2 \\
\hline 51 & 0.8 & 1.1 & 1 & 0.97 & 1.64 & 3.12 & 0.44 & 1.6 & 0.4 \\
\hline 52 & 0.33 & 1.32 & 14 & 0.75 & 1.03 & 20.04 & 1.22 & 1 & 4 \\
\hline 53 & 1.19 & 1.24 & 2 & 1.13 & 0.61 & 14.06 & 0.81 & 0.51 & 14 \\
\hline 54 & 0.44 & 1.22 & 4 & 0.48 & 1.45 & 6 & 0.81 & 0.51 & 1.2 \\
\hline 55 & 0.69 & 0.55 & 2 & 0.42 & 0.92 & 0.608 & 1.22 & 0.98 & 4 \\
\hline 56 & 0.44 & 0.96 & 4 & 0.64 & 1.05 & 12 & 0.39 & 1.2 & 2 \\
\hline 57 & 0.75 & 1.08 & 2 & 1.06 & 1 & 14 & 0.45 & 0.97 & 10 \\
\hline 58 & 0.75 & 0.96 & 1 & 0.36 & 1.29 & 4.104 & 1.17 & 0.77 & 0.8 \\
\hline 59 & 0.98 & 0.72 & 2 & 0.59 & 1.16 & 13.216 & 1.08 & 0.64 & 4 \\
\hline 60 & 0.91 & 0.98 & 2.4 & 0.39 & 1.25 & 14 & 0 & 1.57 & 4 \\
\hline 61 & 0.94 & 0.75 & 14 & 0.35 & 1.24 & 4 & 0.8 & 0.87 & 14 \\
\hline 62 & 0.81 & 0.82 & 8 & 0.67 & 0.95 & 2 & 0.96 & 0.65 & 1.18 \\
\hline 63 & 0.45 & 0.97 & 10 & 0.65 & 1.11 & 15.2 & 0.8 & 0.54 & 6 \\
\hline 64 & 1.75 & 1.59 & 1.4 & 0.68 & 1.37 & 2 & 0.83 & 0.48 & 2 \\
\hline 65 & 0.32 & 1.32 & 4 & 0.44 & 1.64 & 4 & 0.3 & 1.31 & 2 \\
\hline 66 & 0.57 & 1.17 & 2.4 & 0.6 & 0.85 & 2 & 1.14 & 0.59 & 3.2 \\
\hline 67 & 0.8 & 0.54 & 3.2 & 0.44 & 0.93 & 0.8 & 0.47 & 1.24 & 2 \\
\hline 68 & 0.49 & 1.5 & 0.8 & 0.63 & 1.11 & 0.8 & 1.19 & 0.83 & 10 \\
\hline 69 & 0.38 & 1.17 & 14 & 0.6 & 1.51 & 14 & 0.43 & 1.59 & 20 \\
\hline 70 & 0.6 & 1.57 & 2 & 0.85 & 1.39 & 0.8 & 1.19 & 0.77 & 0.44 \\
\hline 71 & 0.45 & 0.96 & 14 & 0.58 & 1.6 & 14 & 0.82 & 0.82 & 8 \\
\hline 72 & 1.01 & 0.27 & 2 & 1.35 & 0.77 & 14 & 0.66 & 1.13 & 4 \\
\hline 73 & 1.12 & 1.2 & 5.12 & 0.96 & 1.01 & 10 & 0.71 & 1.11 & 2 \\
\hline 74 & 1.18 & 1.25 & 2 & 0.76 & 0.96 & 1.2 & 1.18 & 0.79 & 1.2 \\
\hline 75 & 0.38 & 1.23 & 0.8 & 0.54 & 1.34 & 6 & 0.68 & 1.11 & 4 \\
\hline 76 & 1.14 & 1.2 & 4 & 0.37 & 1.29 & 14 & 0.99 & 0.23 & 0.8 \\
\hline 77 & 0.72 & 1.13 & 2 & 0.79 & 0.56 & 2 & 1.2 & 0.78 & 8 \\
\hline 78 & 1.18 & 1.25 & 2 & 0.46 & 1.23 & 2 & 1.75 & 1.6 & 8 \\
\hline 79 & 0.64 & 1.05 & 4 & 0.43 & 0.94 & 2.4 & 0.34 & 1.26 & 2 \\
\hline 80 & 0.42 & 1.58 & 6 & 0.52 & 0.78 & 0.4 & 0.53 & 0.66 & 2 \\
\hline 81 & 1.01 & 0.73 & 0.4 & 0.67 & 0.95 & 2 & 1.08 & 0.73 & 14 \\
\hline 82 & 1.74 & 1.58 & 2 & 0.68 & 0.99 & 4 & 0.61 & 1.14 & 2 \\
\hline 83 & 0.38 & 1.25 & 2 & 0.47 & 0.95 & 4 & 0.42 & 1.6 & 6 \\
\hline 84 & 0.37 & 1.29 & 14 & 0.57 & 1.15 & 14 & 0.78 & 0.77 & 6 \\
\hline
\end{tabular}

Tabela 34: Dados das instâncias inspiradas em dados reais - Clientes 43 a 84 . 


\begin{tabular}{c|rrr|rrr|rrrr}
\hline \multirow{2}{*}{ Cliente } & \multicolumn{3}{|c|}{ Dia 1} & \multicolumn{3}{|c|}{ Dia 2} & \multicolumn{3}{|c}{ Dia 3} \\
& $x_{i}$ & $y_{i}$ & $q_{i}$ & $x_{i}$ & $y_{i}$ & $q_{i}$ & $x_{i}$ & $y_{i}$ & $q_{i}$ \\
\hline 0 & 0.55 & 1.05 & 0 & 0.55 & 1.05 & 0 & 0.55 & 1.05 & 0 \\
85 & 1.26 & 0.61 & 2 & 0.78 & 0.83 & 20 & 0.66 & 1.03 & 6 \\
86 & 1.76 & 1.56 & 1.6 & 0.62 & 0.89 & 4 & 0.82 & 0.86 & 6 \\
87 & 0.96 & 0.64 & 10 & 0.61 & 1 & 14 & 1.14 & 1.21 & 2 \\
88 & 0.96 & 0.74 & 0.4 & 0.48 & 1.26 & 2 & 0.45 & 1.21 & 2 \\
89 & 0.83 & 0.81 & 20 & 0.4 & 1.13 & 2 & 0.42 & 1.57 & 6 \\
90 & 0.98 & 1 & 4 & 0.8 & 0.99 & 4 & 0.76 & 0.86 & 2 \\
91 & 1.5 & 1.18 & 7.56 & 1.16 & 0.85 & 14 & 1.74 & 1.59 & 0.4 \\
92 & 1.56 & 1.38 & 0.8 & 1.14 & 0.59 & 2 & 1.17 & 0.77 & 0.8 \\
93 & 0.77 & 1.09 & 2 & 0.6 & 1.61 & 4 & 0.66 & 1.09 & 6 \\
94 & 0.64 & 1.64 & 4 & 0.7 & 0.96 & 2 & 0.91 & 1.1 & 4 \\
95 & 0.47 & 0.95 & 4.4 & 0.47 & 0.93 & 2 & 0.68 & 1.11 & 0.8 \\
96 & 0.92 & 1.11 & 2 & 0.48 & 1.44 & 20 & 0.52 & 1.14 & 2 \\
97 & 0.8 & 1.6 & 2 & 0.57 & 1.47 & 4 & 0.86 & 0.39 & 2.78 \\
98 & 0.36 & 1.17 & 4 & 0.77 & 1.02 & 14 & 0.47 & 1.2 & 2 \\
99 & 0.96 & 0.72 & 5.6 & 0.66 & 0.98 & 2 & 1.77 & 1.56 & 6 \\
100 & 1.36 & 0.77 & 0.78 & 0.57 & 1.43 & 2 & 0.77 & 0.83 & 2 \\
101 & 0.56 & 1.61 & 6.78 & 0.52 & 1.19 & 10 & 0.62 & 1.62 & 2 \\
102 & 0.42 & 1.6 & 4 & 0.88 & 1.17 & 2 & 0.77 & 1.02 & 14 \\
103 & 0.69 & 1.09 & 1.2 & 1.13 & 0.59 & 2 & 0.83 & 0.49 & 2 \\
104 & 0.68 & 1.11 & 2 & & & & 0.47 & 0.95 & 2 \\
105 & 0.6 & 1.16 & 2 & & & & 0.61 & 1.19 & 14 \\
106 & 1.18 & 0.8 & 14 & & & & 0.98 & 0.23 & 2 \\
107 & 0.71 & 1 & 6 & & & & 0.66 & 1.1 & 14 \\
108 & 0.63 & 1.04 & 2.4 & & & & 0.63 & 1.1 & 4 \\
109 & 1 & 0.28 & 2 & & & & 0.68 & 1.01 & 6 \\
\hline
\end{tabular}

Tabela 35: Dados das instâncias inspiradas em dados reais - Clientes 85 a 131. 


\begin{tabular}{c|rrr}
\hline \multirow{2}{*}{ Cliente } & \multicolumn{3}{|c}{ Dia 1} \\
& $x_{i}$ & $y_{i}$ & $q_{i}$ \\
\hline 0 & 0.55 & 1.05 & 0 \\
110 & 0.46 & 1.18 & 4 \\
111 & 0.45 & 0.91 & 6 \\
112 & 0.53 & 1.15 & 0.4 \\
113 & 0.87 & 0.54 & 2 \\
114 & 1.74 & 1.59 & 2 \\
115 & 0.38 & 1.16 & 4.88 \\
116 & 0.83 & 0.49 & 2 \\
117 & 0.71 & 0.90 & 2 \\
118 & 0.77 & 1.02 & 20 \\
119 & 0.83 & 0.51 & 14 \\
120 & 0.79 & 0.74 & 4 \\
121 & 0.83 & 0.49 & 2 \\
122 & 1.76 & 1.59 & 2 \\
123 & 0.64 & 1.12 & 6 \\
124 & 0.96 & 0.73 & 4 \\
125 & 0.70 & 0.55 & 2 \\
126 & 0.66 & 1.10 & 14 \\
127 & 0.45 & 0.92 & 6 \\
128 & 0.81 & 0.53 & 4 \\
129 & 0.98 & 0.26 & 2 \\
130 & 1.11 & 0.61 & 2 \\
131 & 1.76 & 1.59 & 2 \\
\hline & & &
\end{tabular}

Tabela 36: Dados das instâncias inspiradas em dados reais - Clientes 110 a 131, que somente existem para o Dia 1. 


\section{APÊNDICE B - RESULTADOS}

Nesse apêndice estão apresentados todos os resultados obtidos para as Instâncias geradas neste trabalho com os diferentes métodos apresentados. As instâncias são as explicadas no Capítulo 4.

\section{B.1 Instâncias de Referência}

As instâncias de referência estão apresentadas por grupo de instâncias. A Tabela 37 apresenta os resultados das instâncias do Tipo R1, a Tabela 38 apresenta os resultados das instâncias do Tipo R2, a Tabela 39 apresenta os resultados das instâncias do Tipo C1 e C2 e a Tabela 40 apresenta os resultados das instâncias dos Tipos RC1 e RC2.

Em todas as tabelas estão apresentados, na primeira coluna "Instância" o nome da instância. Em seguida as quatro heurísticas construtivas executadas, sendo duas primeiras, "ACS"e "SH", as de referência para avaliar o desempenho das construtivas propostas "SCIH1"e "SCIH2" no no Capítulo6. Em seguida o resultado das três buscas locais apresentadas no Capítulo 7, todos os valores destas buscas partem do resultado obtido com a construtiva SCIH2. Finalmente o resultado das meta-heurísticas "GRASP" e "VNS"são apresentados, como detalhado no Capítulo 8. 


\begin{tabular}{|c|c|c|c|c|c|c|c|c|c|c|}
\hline \multirow[b]{2}{*}{ Instancia } & \multicolumn{4}{|c|}{ Heurísticas Construtivas } & \multicolumn{3}{|c|}{ Buscas Locais (SCIH2) } & \multicolumn{3}{|c|}{ Meta-Heurísticas } \\
\hline & ACS & $\mathrm{SH}$ & SCIH1 & SCIH2 & Relocate & Cross & 2opt & GRASP & VNS & Híbrido \\
\hline R101a & $3,545.2$ & $2,926.0$ & $3,117.9$ & $2,905.6$ & $2,888.6$ & $2,856.0$ & $2,882.6$ & $2,802.0$ & $2,783.0$ & $2,747.0$ \\
\hline R101b & $1,020.1$ & 885.0 & 889.0 & 855.3 & 838.8 & 830.5 & 848.3 & 806.0 & 799.0 & 778.0 \\
\hline $\mathrm{R} 101 \mathrm{c}$ & 706.7 & 598.0 & 586.8 & 597.0 & 591.0 & 581.0 & 584.0 & 543.8 & 529.0 & 527.0 \\
\hline $\mathrm{R} 102 \mathrm{a}$ & $4,383.1$ & $2,869.0$ & $3,060.1$ & $2,870.9$ & $2,829.9$ & $2,791.9$ & $2,827.4$ & $2,768.0$ & $2,777.9$ & $2,760.0$ \\
\hline $\mathrm{R} 102 \mathrm{~b}$ & $1,172.2$ & 858.0 & 860.0 & 840.8 & 837.8 & 831.0 & 840.8 & 796.0 & 793.0 & 782.0 \\
\hline $\mathrm{R} 102 \mathrm{c}$ & 802.1 & 578.0 & 568.0 & 599.0 & 579.0 & 572.0 & 585.0 & 537.0 & 532.0 & 526.0 \\
\hline R103a & $4,075.9$ & $2,860.0$ & $3,021.8$ & $2,852.9$ & $2,803.0$ & $2,803.0$ & $2,817.9$ & $2,753.1$ & $2,731.0$ & $2,749.3$ \\
\hline R103b & $1,223.9$ & 826.0 & 831.9 & 826.8 & 809.0 & 798.2 & 817.0 & 770.2 & 758.2 & 746.0 \\
\hline $\mathrm{R} 103 \mathrm{c}$ & 825.6 & 545.0 & 557.0 & 560.2 & 541.2 & 543.1 & 558.2 & 512.0 & 509.4 & 502.2 \\
\hline R104a & $4,730.4$ & $2,869.0$ & $2,924.3$ & $2,866.6$ & $2,841.5$ & $2,797.0$ & $2,833.4$ & $2,743.0$ & $2,752.0$ & $2,749.0$ \\
\hline R104b & $1,157.4$ & 788.0 & 821.5 & 786.2 & 786.0 & 785.2 & 786.2 & 744.0 & 751.0 & 752.0 \\
\hline $\mathrm{R} 104 \mathrm{c}$ & 794.1 & 522.0 & 528.0 & 530.3 & 521.3 & 520.3 & 523.3 & 483.9 & 498.7 & 485.0 \\
\hline R105a & $3,947.0$ & $2,859.0$ & $2,972.2$ & $2,894.1$ & $2,854.3$ & $2,842.0$ & $2,860.3$ & $2,778.0$ & $2,762.0$ & $2,747.1$ \\
\hline R105b & $1,034.4$ & 840.0 & 867.4 & 818.4 & 812.4 & 813.4 & 813.4 & 778.4 & 778.4 & 768.0 \\
\hline $\mathrm{R} 105 \mathrm{c}$ & 746.6 & 556.5 & 556.0 & 568.0 & 560.0 & 554.0 & 555.0 & 512.0 & 512.0 & 502.0 \\
\hline R106a & $4,540.4$ & $2,864.0$ & $3,023.2$ & $2,898.5$ & $2,858.0$ & $2,844.0$ & $2,885.4$ & $2,754.0$ & $2,728.0$ & $2,745.0$ \\
\hline R106b & $1,172.7$ & 836.0 & 840.0 & 805.8 & 801.8 & 802.8 & 805.8 & 764.8 & 765.8 & 754.0 \\
\hline $\mathrm{R} 106 \mathrm{c}$ & 740.0 & 557.0 & 552.4 & 557.0 & 548.0 & 542.3 & 545.3 & 507.0 & 500.0 & 498.9 \\
\hline R107a & $5,110.4$ & $2,880.0$ & $2,966.9$ & $2,894.5$ & $2,824.4$ & $2,788.0$ & $2,824.4$ & $2,754.0$ & $2,753.0$ & $2,726.0$ \\
\hline R107b & $1,100.0$ & 798.0 & 813.4 & 807.0 & 804.0 & 799.0 & 807.0 & 753.0 & 766.0 & 749.0 \\
\hline $\mathrm{R} 107 \mathrm{c}$ & 776.2 & 535.0 & 542.0 & & 533.1 & & 540.0 & 489.0 & 499.0 & 479.0 \\
\hline R108a & $4,608.3$ & $2,856.0$ & $2,926.3$ & $2,852.4$ & $2,770.3$ & $2,749.0$ & $2,771.0$ & $2,740.5$ & $2,742.0$ & $2,719.0$ \\
\hline R108b & $1,257.1$ & 790.0 & 818.5 & 800.0 & 797.0 & 778.0 & 790.0 & 746.0 & 756.0 & 749.0 \\
\hline $\mathrm{R} 108 \mathrm{c}$ & 775.9 & 518.0 & 526.0 & 533.3 & 533.3 & 526.3 & 526.3 & 485.9 & 482.0 & 488.0 \\
\hline R109a & $4,091.5$ & $2,870.0$ & $3,020.0$ & $2,924.1$ & $2,857.5$ & $2,799.0$ & $2,864.4$ & $2,763.0$ & $2,771.0$ & $2,741.0$ \\
\hline R109b & $1,160.8$ & 811.0 & 829.0 & 815.0 & 806.0 & 792.0 & 806.0 & 756.0 & 759.0 & 766.8 \\
\hline $\mathrm{R} 109 \mathrm{c}$ & 758.1 & 540.0 & 550.0 & 535.0 & 529.0 & 522.0 & 535.0 & 501.0 & 490.0 & 494.8 \\
\hline R110a & $4,044.5$ & $2,855.0$ & $2,974.6$ & $2,902.4$ & $2,837.0$ & $2,819.0$ & $2,847.0$ & $2,737.0$ & $2,731.0$ & $2,729.2$ \\
\hline R110b & $1,261.3$ & 800.0 & 815.2 & 801.0 & 794.0 & 793.0 & 800.0 & 747.0 & 748.0 & 745.0 \\
\hline $\mathrm{R} 110 \mathrm{c}$ & 790.1 & 539.0 & 548.0 & 536.6 & 524.6 & 533.6 & 534.6 & 495.1 & 478.0 & 482.1 \\
\hline R111a & $4,813.7$ & $2,864.0$ & $3,032.5$ & $2,896.3$ & $2,819.0$ & $2,799.0$ & $2,840.0$ & $2,738.0$ & $2,750.0$ & $2,735.0$ \\
\hline R111b & $1,192.6$ & 807.0 & 832.4 & 807.2 & 803.5 & 796.1 & 801.1 & 759.0 & 767.0 & 744.0 \\
\hline R111c & 801.1 & 536.0 & 537.0 & 559.4 & 542.4 & 533.4 & 547.0 & 489.0 & 483.9 & 487.0 \\
\hline R112a & $4,428.6$ & $2,849.0$ & $2,978.1$ & $2,861.6$ & $2,819.9$ & $2,780.0$ & $2,809.0$ & $2,741.0$ & $2,707.0$ & $2,714.0$ \\
\hline $\mathrm{R} 112 \mathrm{~b}$ & $1,097.7$ & 789.0 & 818.3 & 794.0 & 787.0 & 778.0 & 780.0 & 743.0 & 745.0 & 729.0 \\
\hline $\mathrm{R} 112 \mathrm{c}$ & 697.7 & 524.0 & 516.0 & 542.0 & 529.0 & 519.0 & 537.0 & 485.9 & 496.0 & 478.0 \\
\hline
\end{tabular}

Tabela 37: Resultado de instâncias de referência do Grupo R1. 


\begin{tabular}{|c|c|c|c|c|c|c|c|c|c|c|}
\hline \multirow[b]{2}{*}{ Instancia } & \multicolumn{4}{|c|}{ Heurísticas Construtivas } & \multicolumn{3}{|c|}{ Buscas Locais (SCIH2) } & \multicolumn{3}{|c|}{ Meta-Heurísticas } \\
\hline & ACS & $\mathrm{SH}$ & SCIH1 & SCIH2 & Relocate & Cross & 2opt & GRASP & VNS & Híbrido \\
\hline R201a & 27.9 & 41.1 & 458.7 & 857.6 & $2,767.4$ & $2,832.6$ & $2,830.1$ & $2,801.6$ & $2,767.4$ & $2,734.0$ \\
\hline R201b & 45.2 & $1,464.0$ & $1,066.0$ & 057.6 & 67.4 & $1,032.6$ & 1,0 & 988.7 & 967.4 & 34.0 \\
\hline R201c & 18.2 & 884.0 & 787.0 & 794.0 & 778.0 & & & 745.0 & 749.0 & 49.0 \\
\hline $\mathrm{R} 202 \mathrm{a}$ & 20.7 & $4,084.3$ & $3,243.7$ & $2,929.5$ & $2,756.3$ & $2,772.5$ & 2,80 & $2,773.8$ & $2,707.0$ & $2,680.0$ \\
\hline $\mathrm{R} 202 \mathrm{~b}$ & 46.2 & $1,238.0$ & 1.6 & 97.6 & 005.5 & 934.8 & 0 & 940.0 & 857.6 & 907.0 \\
\hline R202c & 46.4 & 789.0 & 732.0 & 734.0 & 734.0 & 734.0 & 734.0 & 672.7 & 727.0 & 690.0 \\
\hline R203a & 95.0 & $3,385.0$ & $2,739.4$ & $2,734.0$ & $2,653.0$ & $2,680.0$ & $2,680.0$ & $2,734.0$ & $2,653.0$ & $2,680.0$ \\
\hline R203b & 08.0 & $1,025.0$ & & & & & & 880.0 & 826.0 & 826.0 \\
\hline & 4.6 & 674.0 & 58 & 0 & .0 & & & 596.0 & 58.0 & 598.0 \\
\hline R204a & 34.6 & $2,853.0$ & $2,626.0$ & 114.6 & $3,074.0$ & $2,653.0$ & $2,624.0$ & $2,624.0$ & $2,597.0$ & $2,624.0$ \\
\hline R204b & 73.5 & 833.0 & 806.0 & 908.0 & 852.0 & 852.0 & 824.0 & 770.0 & 770.0 & 770.0 \\
\hline R204c & 40.6 & 52.0 & 568.0 & 4.0 & 1.0 & & & 505.0 & 54.0 & 5.0 \\
\hline & 20.8 & $3,644.0$ & 2,78 & $3,491.4$ & & 2,76 & & $2,734.0$ & $2,626.0$ & $2,707.0$ \\
\hline & .8 & 1,0 & & 1, & & & & 880.0 & 0 & 880.0 \\
\hline R205c & 60.9 & 732.0 & 699.0 & .0 & 705.0 & 70 & & 636.0 & 683.0 & 649.0 \\
\hline R206a & 61.8 & $3,197.8$ & $2,766.8$ & ,747.4 & 680.0 & $2,678.5$ & &, 705.0 & $2,651.0$ & $2,678.0$ \\
\hline R206b & 81.8 & $1,007.0$ & & & 26.0 & & & 880.0 & 824.0 & 824.0 \\
\hline & 6.9 & 669.0 & & & 629.0 & & & 582.0 & 614.0 & 606.0 \\
\hline R207a & 04.6 & $3,079.0$ & $2,678.0$ & $3,108.3$ & $2,653.0$ & $2,680.0$ & $2,680.4$ & $2,653.0$ & $2,626.0$ & $2,653.0$ \\
\hline R207k & 01.4 & 919.0 & 860.0 & & 853.0 & & & 824.0 & 797.0 & 797.0 \\
\hline $\mathrm{R} 207 \mathrm{c}$ & 90.8 & 626.0 & 628.0 & & 566.0 & & & 553.0 & 566.0 & 537.0 \\
\hline & $6,093.3$ & $2,572.0$ & $2,597.0$ & $2,793.0$ & ,793.0 & 793.0 & $2,570.0$ &, 599.0 & $2,541.0$ & $2,597.0$ \\
\hline & & & & & & & & 768.0 & 74 & 741.0 \\
\hline $18 \mathrm{c}$ & 27.4 & 537.0 & 539.0 & 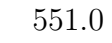 & 1.0 & 5 & & 502.0 & 520.0 & 505.0 \\
\hline R209a & 24.8 & $3,839.3$ & $2,754.9$ & $2,708.3$ & 653.0 & $2,653.0$ & 2,68 & $2,653.0$ & $2,624.0$ & $2,626.0$ \\
\hline R209b & 28.5 & $1,044.0$ & 948.8 & & 880.0 & & & 853.0 & 824.0 & 851.0 \\
\hline & & 644.0 & & & 609.0 & & & 597.0 & 579.0 & 582.0 \\
\hline & 08.0 & 3,58 & $2,761.0$ & 2,71 & 680.0 & 2,70 & & $2,707.0$ & $2,653.0$ & $2,624.0$ \\
\hline & 2.0 & $1,037.0$ & & 934.0 & & & & 880.0 & 824.0 & 853.0 \\
\hline $\mathrm{R} 210 \mathrm{c}$ & 22.0 & 0 & & & & & & 566.0 & 654.0 & 566.0 \\
\hline R211a & 93.7 & $3,503.0$ & $2,678.0$ & $2,599.0$ & $2,597.0$ & $2,597.0$ & $2,597.0$ & $2,599.0$ & $2,597.0$ & $2,597.0$ \\
\hline & 3.5 & 959.0 & & & & & & 824.0 & 797.0 & 797.0 \\
\hline $\mathrm{R} 211 \mathrm{c}$ & $1,376.4$ & 599.0 & 597.0 & 613.0 & 613.0 & 613.0 & 613.0 & 523.0 & 567.0 & 520.0 \\
\hline
\end{tabular}

Tabela 38: Resultado de instâncias de referência do Grupo R2. 


\begin{tabular}{|c|c|c|c|c|c|c|c|c|c|c|}
\hline \multirow[b]{2}{*}{ Instancia } & \multicolumn{4}{|c|}{ Heurísticas Construtivas } & \multicolumn{3}{|c|}{ Buscas Locais (SCIH2) } & \multicolumn{3}{|c|}{ Meta-Heurísticas } \\
\hline & ACS & $\mathrm{SH}$ & SCIH1 & $\mathrm{SCIH} 2$ & Relocate & Cross & 2 opt & GRASP & VNS & Híbrido \\
\hline C101a & $10,088.0$ &, 152.0 &, 165.0 & $6,165.0$ & $6,165.0$ & $6,165.0$ & $6,165.0$ & $6,166.6$ & $6,150.0$ & $6,136.0$ \\
\hline C101b & $2,748.0$ & $1,619.0$ & $1,605.0$ & $1,591.0$ & $1,591.0$ & $1,591.0$ & $1,591.0$ & $1,576.0$ & $1,590.0$ & $1,590.0$ \\
\hline $\mathrm{C} 101 \mathrm{c}$ & $1,713.9$ & $1,025.8$ & $1,035.0$ & $1,021.0$ & $1,021.0$ & $1,021.0$ & $1,021.0$ & $1,006.0$ & $1,013.0$ & 999.0 \\
\hline $\mathrm{C} 102 \mathrm{a}$ & $10,057.1$ & $6,176.0$ & $6,164.0$ & $6,179.0$ & $6,164.0$ & $6,155.3$ & $6,155.3$ & $6,141.3$ & $6,136.0$ & $6,136.0$ \\
\hline $\mathrm{C} 102 \mathrm{~b}$ & $2,770.8$ & $1,616.0$ & $1,604.0$ & $1,619.0$ & $1,604.0$ & $1,595.3$ & $1,595.3$ & $1,576.0$ & $1,576.0$ & $1,576.0$ \\
\hline $\mathrm{C} 102 \mathrm{c}$ & $1,661.1$ & $1,038.0$ & $1,034.0$ & $1,022.0$ & $1,022.0$ & $1,022.0$ & $1,022.0$ & 992.0 & 992.0 & 992.0 \\
\hline C103a & $9,441.5$ & $6,136.0$ & $6,166.0$ & $6,193.0$ & $6,178.0$ & $6,151.0$ & $6,170.7$ & $6,136.0$ & $6,136.0$ & $6,136.0$ \\
\hline C103b & $2,681.5$ & $1,579.1$ & $1,606.0$ & $1,634.0$ & $1,590.0$ & $1,591.0$ & $1,596.7$ & $1,562.0$ & $1,576.0$ & $1,576.0$ \\
\hline $\mathrm{C} 103 \mathrm{c}$ & $1,529.2$ & $1,009.1$ & $1,036.0$ & $1,050.0$ & $1,050.0$ & $1,021.0$ & $1,036.0$ & 992.0 & $1,006.0$ & 999.0 \\
\hline C104a & $11,111.8$ & $6,150.0$ & $6,165.0$ & $6,182.9$ & $6,181.8$ & $6,150.0$ & $6,167.3$ & $6,137.0$ & $6,150.0$ & $6,123.0$ \\
\hline C104b & $2,583.2$ & $1,590.0$ & $1,605.0$ & $1,622.9$ & $1,621.8$ & $1,590.0$ & $1,607.3$ & $1,561.0$ & $1,590.0$ & $1,562.0$ \\
\hline $\mathrm{C} 104 \mathrm{c}$ & $1,627.9$ & $1,027.0$ & $1,035.0$ & $1,053.9$ & & $1,021.0$ & & 978.0 & $1,020.0$ & $1,006.0$ \\
\hline C105a & $9,717.5$ & $6,193.0$ & $6,179.0$ & $6,193.0$ & 3.0 & $6,192.0$ & $6,193.0$ & $6,153.6$ & $6,164.0$ & $6,151.0$ \\
\hline C105b & $2,593.2$ & $1,651.0$ & $1,619.0$ & $1,591.0$ & 1.0 & $1,591.0$ & $1,591.0$ & $1,576.0$ & $1,591.0$ & $1,590.0$ \\
\hline $\mathrm{C} 105 \mathrm{c}$ & $1,752.4$ & $1,045.7$ & $1,049.0$ & $1,021.0$ & 21.0 & $1,021.0$ & 21.0 & 995.3 & $1,014.0$ & $1,006.0$ \\
\hline C106a & $9,897.1$ & $6,153.8$ & $6,179.0$ & $6,179.0$ & $6,179.0$ & $6,155.3$ & $6,165.0$ & $6,150.0$ & $6,136.0$ & $6,150.0$ \\
\hline $\mathrm{C} 106 \mathrm{~b}$ & $2,672.6$ & $1,593.8$ & $1,619.0$ & & & 1,5 & & $1,576.0$ & & \\
\hline $\mathrm{C} 106 \mathrm{c}$ & $1,706.1$ & $1,030.8$ & $1,049.0$ & 1,0 & & & & 993.0 & $1,013.0$ & $1,006.0$ \\
\hline C107a & $10,280.7$ & $6,138.0$ & $6,179.0$ & 6,2 & & 6,17 & & 164.0 & $6,164.0$ & $6,150.0$ \\
\hline $\mathrm{C} 107 \mathrm{~b}$ & $2,617.0$ & $1,632.0$ & $1,619.0$ & $1,591.0$ & 1.0 & $1,591.0$ & 1.0 & $1,576.0$ & $1,591.0$ & $1,576.0$ \\
\hline $\mathrm{C} 107 \mathrm{c}$ & $1,587.9$ & $1,028.0$ & $1,049.0$ & $1,021.0$ & $1,021.0$ & $1,021.0$ & $1,021.0$ & $1,006.0$ & $1,021.0$ & $1,006.0$ \\
\hline C108a & $10,078.8$ & $6,139.9$ & $6,179.0$ & $6,235.0$ & & 6,17 & 6,2 & $6,164.0$ & 6,1 & $6,150.0$ \\
\hline C108b & 737.7 & $1,604.5$ & & & & & & & & $1,576.0$ \\
\hline $\mathrm{C} 108 \mathrm{c}$ & $1,689.0$ & $1,021.5$ & $1,049.0$ & $1,049.0$ & 0.0 & 1,0 & 5.0 & $1,006.0$ & $1,006.0$ & 999.0 \\
\hline C109a & $10,195.0$ & $6,151.5$ & $6,165.0$ & 6,2 & 3.0 & $6,193.0$ & 7.0 & $6,150.0$ & $6,136.0$ & $6,136.0$ \\
\hline C109b & $2,644.3$ & $1,592.6$ & $1,605.0$ & $1,647.0$ & $1,633.0$ & $1,619.0$ & $1,633.0$ & $1,576.0$ & $1,576.0$ & $1,576.0$ \\
\hline $\mathrm{C} 109 \mathrm{c}$ & $1,567.9$ & $1,028.5$ & $1,035.0$ & $1,063.0$ & $1,063.0$ & $1,048.0$ & $1,063.0$ & 992.0 & $1,021.0$ & $1,006.0$ \\
\hline C201a & 038.4 & $7,238.0$ & $5,264.0$ &, 264.0 & $5,264.0$ & $5,264.0$ & $5,264.0$ & $5,264.0$ & $5,235.0$ & $5,208.0$ \\
\hline C201b & $1,878.4$ & $1,638.0$ & $1,264.0$ & $1,264.0$ & $1,264.0$ & $1,264.0$ & $1,264.0$ & $1,264.0$ & $1,237.0$ & $1,208.0$ \\
\hline $\mathrm{C} 201 \mathrm{c}$ & $1,108.4$ & 938.0 & 766.0 & 764.0 & & & 764.0 & 834.0 & 708.0 & 737.0 \\
\hline $\mathrm{C} 202 \mathrm{a}$ & $8,646.0$ & $6,296.0$ & $5,318.0$ & $5,264.0$ & & $5,264.0$ & & $5,264.0$ & & \\
\hline $\mathrm{C} 202 \mathrm{~b}$ & $2,302.8$ & $1,496.0$ & $1,318.0$ & $1,264.0$ & $1,264.0$ & $1,264.0$ & $1,264.0$ & $1,264.0$ & $1,208.0$ & $1,235.0$ \\
\hline $\mathrm{C} 202 \mathrm{c}$ & $1,502.8$ & 896.0 & 764.0 & 764.0 & 764.0 & 764.0 & 764.0 & 764.0 & 708.0 & 764.0 \\
\hline C203a & $9,375.7$ & $6,325.0$ & $5,293.0$ & $5,291.0$ & $5,264.0$ & $5,291.0$ & $5,291.0$ & $5,266.0$ & $5,264.0$ & $5,266.0$ \\
\hline $\mathrm{C} 203 \mathrm{~b}$ & $2,456.8$ & $1,525.0$ & $1,293.0$ & & & & & $1,291.0$ & & $1,264.0$ \\
\hline $\mathrm{C} 203 \mathrm{c}$ & $1,646.8$ & 925.0 & 766.0 & 835.0 & 835.0 & 808.0 & 764.0 & 764.0 & 766.0 & 764.0 \\
\hline $\mathrm{C} 204 \mathrm{a}$ & $8,671.7$ & $5,376.0$ & $5,376.0$ & $5,349.0$ & $5,322.0$ & $5,320.0$ & $5,347.0$ & $5,291.0$ & $5,264.0$ & $5,237.0$ \\
\hline C204b & $2,667.1$ & $1,403.0$ & $1,376.0$ & $1,349.0$ & $1,322.0$ & $1,320.0$ & $1,347.0$ & $1,318.0$ & $1,264.0$ & $1,264.0$ \\
\hline $\mathrm{C} 204 \mathrm{c}$ & $1,788.6$ & 864.0 & 876.0 & 849.0 & 822.0 & 820.0 & 847.0 & 764.0 & 762.0 & 764.0 \\
\hline $\mathrm{C} 205 \mathrm{a}$ & $8,073.6$ & $6,350.0$ & $5,318.0$ & $5,318.0$ & & & & $5,291.0$ & & $5,235.0$ \\
\hline $\mathrm{C} 205 \mathrm{~b}$ & $1,762.9$ & $1,550.0$ & $1,318.0$ & $1,318.0$ & $1,318.0$ & $1,318.0$ & $1,318.0$ & $1,318.0$ & $1,237.0$ & $1,235.0$ \\
\hline $\mathrm{C} 205 \mathrm{c}$ & $1,062.9$ & 950.0 & 818.0 & 818.0 & 818.0 & 818.0 & 818.0 & 764.0 & 764.0 & 735.0 \\
\hline C206a & $7,459.0$ & $5,322.0$ & $5,345.0$ & $5,349.0$ & $5,293.0$ & $5,320.0$ & $5,320.0$ & $5,291.0$ & $5,264.0$ & $5,236.0$ \\
\hline $\mathrm{C} 206 \mathrm{~b}$ & $1,879.9$ & $1,322.0$ & $1,345.0$ & $1,349.0$ & $1,293.0$ & $1,320.0$ & $1,320.0$ & $1,291.0$ & $1,237.0$ & $1,236.0$ \\
\hline $\mathrm{C} 206 \mathrm{c}$ & $1,361.2$ & 822.0 & 793.0 & 849.0 & 793.0 & 820.0 & 820.0 & 762.0 & 737.0 & 679.0 \\
\hline C207a & $8,112.7$ & $6,266.0$ & $5,293.0$ & $5,293.0$ & $5,264.0$ & $5,266.0$ & $5,266.0$ & $5,264.0$ & $5,237.0$ & $5,237.0$ \\
\hline $\mathrm{C} 207 \mathrm{~b}$ & $1,905.6$ & $1,466.0$ & $1,293.0$ & $1,293.0$ & $1,264.0$ & $1,266.0$ & $1,266.0$ & $1,264.0$ & $1,237.0$ & $1,237.0$ \\
\hline $\mathrm{C} 207 \mathrm{c}$ & $1,145.2$ & 866.0 & 793.0 & 793.0 & 764.0 & 766.0 & 766.0 & 791.0 & 737.0 & 764.0 \\
\hline $\mathrm{C} 208 \mathrm{a}$ & $8,777.7$ & $6,294.0$ & $5,318.0$ & $5,293.0$ & $5,293.0$ & $5,293.0$ & $5,293.0$ & $5,291.0$ & $5,237.0$ & $5,264.0$ \\
\hline $\mathrm{C} 208 \mathrm{~b}$ & $1,877.8$ & $1,496.0$ & $1,318.0$ & $1,293.0$ & $1,293.0$ & $1,293.0$ & $1,293.0$ & $1,291.0$ & $1,237.0$ & $1,264.0$ \\
\hline $\mathrm{C} 208 \mathrm{c}$ & $1,207.1$ & 896.0 & 766.0 & 891.0 & 864.0 & 861.0 & 818.0 & 764.0 & 764.0 & 764.0 \\
\hline
\end{tabular}

Tabela 39: Resultado de instâncias de referência dos Grupos C1 e C2. 


\begin{tabular}{|c|c|c|c|c|c|c|c|c|c|c|}
\hline \multirow[b]{2}{*}{ Instancia } & \multicolumn{4}{|c|}{ Heurísticas Construtivas } & \multicolumn{3}{|c|}{ Buscas Locais (SCIH2) } & \multicolumn{3}{|c|}{ Meta-Heurísticas } \\
\hline & ACS & $\mathrm{SH}$ & SCIH1 & $\mathrm{SCIH} 2$ & Relocate & Cross & 2 opt & GRASP & VNS & Híbrido \\
\hline RC101a & $4,751.1$ & 611.0 & 413.0 & $3,383.0$ & $3,361.0$ & $3,317.0$ & $3,353.0$ & $3,263.0$ & $3,301.0$ & $3,257.0$ \\
\hline RC101b & $1,362.0$ & $1,107.5$ & $1,081.1$ & $1,073.7$ & $1,046.7$ & $1,035.8$ & $1,045.5$ & $1,023.6$ & $1,011.8$ & $1,009.3$ \\
\hline RC101c & 940.0 & 756.2 & 750.4 & 754.0 & 729.2 & 735.7 & 744.4 & 690.2 & 672.0 & 678.7 \\
\hline $\mathrm{RC} 102 \mathrm{a}$ & $4,872.1$ & $3,566.0$ & $3,350.5$ & $3,369.0$ & $3,361.0$ & $3,332.0$ & $3,346.0$ & $3,256.0$ & $3,309.0$ & $3,264.0$ \\
\hline $\mathrm{RC} 102 \mathrm{~b}$ & $1,453.2$ & $1,077.4$ & $1,067.5$ & $1,048.0$ & $1,048.0$ & $1,032.0$ & $1,041.0$ & $1,008.0$ & 996.0 & $1,004.0$ \\
\hline $\mathrm{RC} 102 \mathrm{c}$ & 967.1 & 711.0 & 711.2 & 704.5 & 688.7 & 698.0 & 698.0 & 666.9 & 655.0 & 654.0 \\
\hline RC103a & $4,647.9$ & $3,505.0$ & $3,330.0$ & $3,337.0$ & $3,337.0$ & $3,307.0$ & $3,337.0$ & $3,240.0$ & $3,292.0$ & $3,249.0$ \\
\hline RC103b & $1,345.6$ & $1,059.0$ & $1,086.5$ & $1,065.5$ & $1,065.5$ & $1,041.5$ & $1,057.5$ & $1,001.0$ & $1,001.2$ & $1,003.0$ \\
\hline $\mathrm{RC} 103 \mathrm{c}$ & 949.3 & 695.0 & 728.7 & 699.9 & 675.3 & 686.1 & 693.1 & 651.4 & 625.5 & 627.0 \\
\hline RC104a & $4,747.7$ & $3,543.0$ & $3,330.0$ & $3,337.0$ & $3,337.0$ & $3,307.0$ & $3,337.0$ & $3,240.0$ & $3,292.0$ & $3,240.0$ \\
\hline RC104b & $1,268.4$ & $1,039.7$ & $1,062.0$ & $1,064.0$ & $1,064.0$ & $1,048.0$ & $1,056.0$ & $1,001.0$ & 999.0 & 990.1 \\
\hline $\mathrm{RC} 104 \mathrm{c}$ & 879.5 & 673.5 & 675.6 & 671.8 & 661.2 & 665.8 & 671.8 & 608.0 & 603.0 & 604.0 \\
\hline RC105a & 4,937.1 & $3,572.0$ & $3,330.0$ & $3,361.0$ & $3,353.0$ & $3,323.0$ & $3,353.0$ & $3,249.0$ & $3,270.0$ & $3,265.0$ \\
\hline RC105b & $1,510.3$ & $1,095.0$ & $1,068.0$ & $1,089.0$ & $1,066.0$ & $1,058.0$ & $1,073.0$ & $1,014.2$ & $1,011.0$ & $1,005.3$ \\
\hline $\mathrm{RC} 105 \mathrm{c}$ & $1,025.8$ & 752.0 & 735.9 & 711.1 & 688.4 & 691.6 & 694.3 & 681.5 & 654.0 & 657.0 \\
\hline RC106a & $4,818.8$ & $3,536.0$ & $3,391.0$ & $3,343.8$ & $3,330.0$ & $3,308.0$ & $3,336.8$ & $3,248.0$ & 3,292.0 & $3,263.0$ \\
\hline RC106b & $1,410.5$ & $1,079.9$ & $1,071.4$ & $1,043.4$ & $1,042.8$ & $1,024.0$ & $1,042.8$ & $1,002.0$ & $1,006.0$ & 986.0 \\
\hline $\mathrm{RC} 106 \mathrm{c}$ & 899.3 & 720.2 & 745.8 & 707.4 & 681.6 & 697.6 & 705.4 & 667.1 & 641.0 & 632.9 \\
\hline RC107a & $4,664.6$ & $3,535.0$ & $3,391.0$ & $3,343.8$ & $3,330.0$ & $3,308.0$ & $3,336.8$ & $3,247.0$ & $3,293.0$ & $3,248.0$ \\
\hline RC107b & $1,388.9$ & $1,044.8$ & $1,070.0$ & $1,050.3$ & $1,046.0$ & $1,030.0$ & & 999.3 & 994.0 & 991.0 \\
\hline RC107c & 919.8 & 677.2 & 708.7 & 679.2 & 673.9 & 654.3 & 669.3 & 634.3 & 639.0 & 622.9 \\
\hline RC108a & $4,790.7$ & $3,491.6$ & $3,391.0$ & $3,343.8$ & $3,330.0$ & $3,308.0$ & $3,336.8$ & $3,240.0$ & $3,278.0$ & $3,248.0$ \\
\hline RC108b & $1,332.3$ & $1,041.0$ & $1,068.0$ & $1,061.0$ & $1,047.0$ & $1,024.0$ & $1,054.0$ & 999.0 & 960.0 & 969.2 \\
\hline $\mathrm{RC} 108 \mathrm{c}$ & 879.8 & 681.2 & 636.3 & 657.3 & 633.3 & 639.1 & 655.3 & 606.5 & 594.0 & 590.1 \\
\hline $\mathrm{RC} 2$ & 61.7 & 1.0 & $3,200.0$ & 0 & 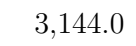 & 3,17 & ${ }^{\circ}$ & $3,118.0$ & $3,142.0$ & 2.0 \\
\hline RC201b & $1,868.5$ & 40.0 & 914.0 & 880.0 & 880.0 & 880.0 & 880.0 & 850.0 & 880.0 & 860.0 \\
\hline RC201c & $1,428.8$ & 589.0 & 571.0 & 589.0 & 589.0 & 589.0 & 589.0 & 551.0 & 589.0 & 551.0 \\
\hline RC202a & $6,095.1$ & $3,209.0$ & $3,092.0$ & $3,142.0$ & $3,116.0$ & $3,116.0$ & $3,142.0$ & $3,062.0$ & $3,116.0$ & $3,088.0$ \\
\hline RC202b & $2,213.7$ & 899.0 & 882.0 & 906.0 & 904.0 & 904.0 & 904.0 & 824.0 & 878.0 & 824.0 \\
\hline RC202c & $1,764.0$ & 578.0 & 554.0 & 520.0 & 520.0 & 520.0 & 520.0 & 520.0 & 520.0 & 527.0 \\
\hline RC203a & $6,639.8$ & $3,260.0$ & $3,064.0$ & $3,148.0$ & $3,092.0$ & $3,092.0$ & $3,120.0$ & $3,034.0$ & $3,092.0$ & $3,034.0$ \\
\hline RC203b & $2,071.3$ & 896.0 & 884.0 & 854.0 & 852.0 & 852.0 & 852.0 & 822.0 & 850.0 & 822.0 \\
\hline $\mathrm{RC} 203 \mathrm{c}$ & $1,418.3$ & 534.0 & 520.0 & 514.0 & 514.0 & 514.0 & 514.0 & 493.0 & 514.0 & 508.0 \\
\hline RC204a & $4,838.2$ & $3,186.0$ & $3,214.0$ & $3,118.0$ & $3,092.0$ & $3,118.0$ & $3,092.0$ & $3,034.0$ & $3,064.0$ & $3,036.0$ \\
\hline RC204b & $1,754.0$ & 911.0 & 824.0 & 850.0 & 850.0 & 850.0 & 850.0 & 820.0 & 850.0 & 803.0 \\
\hline $\mathrm{RC} 204 \mathrm{c}$ & $1,194.0$ & 555.0 & 505.0 & 531.0 & 531.0 & 531.0 & 531.0 & 477.0 & 531.0 & 477.0 \\
\hline RC205a & $6,372.5$ & $3,322.0$ & $3,294.0$ & $3,174.0$ & $3,146.0$ & $3,115.0$ & $3,120.0$ & $3,087.0$ & $3,062.0$ & $3,062.0$ \\
\hline RC205b & $2,391.4$ & 936.0 & 914.0 & 910.0 & 906.0 & 906.0 & 906.0 & 848.0 & 878.0 & 850.0 \\
\hline $\mathrm{RC} 205 \mathrm{c}$ & $1,619.7$ & 590.0 & 563.0 & 569.0 & 569.0 & 569.0 & 569.0 & 552.0 & 569.0 & 552.0 \\
\hline RC206a & $7,658.1$ & $3,242.0$ & $3,146.0$ & $3,198.0$ & $3,118.0$ & $3,144.0$ & $3,172.0$ & $3,062.0$ & $3,090.0$ & $3,064.0$ \\
\hline RC206b & $2,437.3$ & 912.0 & 884.0 & & 880.0 & 880.0 & & 848.0 & 880.0 & 850.0 \\
\hline RC206c & $1,658.3$ & 583.0 & 535.0 & 529.0 & 529.0 & 529.0 & 529.0 & 523.0 & 529.0 & 529.0 \\
\hline RC207a & $7,185.3$ & $3,240.0$ & $3,158.0$ & $3,114.0$ & $3,036.0$ & $3,060.0$ & $3,062.0$ & $3,060.0$ & $3,036.0$ & $3,036.0$ \\
\hline RC207b & $2,173.7$ & 942.0 & 852.0 & 850.0 & 850.0 & 850.0 & 850.0 & 822.0 & 850.0 & 824.0 \\
\hline $\mathrm{RC} 207 \mathrm{c}$ & $1,597.3$ & 590.0 & 567.0 & 533.0 & 533.0 & 533.0 & 533.0 & 523.0 & 533.0 & 523.0 \\
\hline RC208a & $6,675.2$ & $3,306.0$ & $3,186.0$ & $3,144.0$ & $3,118.0$ & $3,144.0$ & $3,118.0$ & $3,006.0$ & $3,090.0$ & $2,980.0$ \\
\hline RC208b & $2,243.4$ & 895.0 & 824.0 & 850.0 & 850.0 & 850.0 & 850.0 & 794.0 & 850.0 & 794.0 \\
\hline RC208c & $1,528.3$ & 525.0 & 492.0 & 492.0 & 492.0 & 492.0 & 492.0 & 473.0 & 492.0 & 473.0 \\
\hline
\end{tabular}

Tabela 40: Resultado de instâncias de referência dos Grupos RC1 e RC2. 


\section{B.2 Instâncias de Dimensões Menores}

O resultado das instâncias de dimensões menores é apresentado a seguir. Na coluna "Instância" o nome da instância é exposto. Esse indica primeiro o tempo de instância (R1, R2, C1, C2, RC1 ou RC2), o tipo de custo de veículo (a, b ou c) e a quantidade de clientes presentes na instância (10, 15, 20 ou 25). Assim, o instância R1a10, é a instância do Tipo R1, veículo tipo a com 10 clientes.

As tabelas 41 e 42 apresentam os resultados obtidos com a resolução por otimizador CPLEX comparando a formulação proposta neste trabalho e a apresentada em Manguino (2013). Para os resultados obtidos com ambas as formulações são apresentados a melhor solução encontrada (coluna "Sol. Inteira"), o limitante inferior (coluna "Lim.Inferior"e a diferença entre a solução encontrada e o limitante inferior (coluna "GAP (\%)"). Para a formulação proposta também é apresentado o tempo de execução de cada instância em segundos (coluna "Tempo (s)"). Os resultados ótimos estão indicados em negrito.

Já as tabelas 43 e 44 comparam os resultados obtidos com a formulação proposta e os métodos heurísticos e meta-heurísticos propostos. Os valores apresentados são os obtidos pelo CPLEX, tanto a melhor solução inteira obtida na coluna "Sol.Inteira", como o Limitante Inferior (Lower Bound) encontrado na coluna "Lim.Inferior". Em seguida o resultado obtido pelas heurísticas construtivas SCIH1 e SCIH2, seguido pelos obtidos ao se aprimorar os resultados da SCIH2 com as três buscas locais propostas, Relocate, Cross e 2-opt, e, finalmentem as três meta-heurísticas propostas, GRASP, VNS e o método híbrido. As soluções ótimas estão destacadas em negrito. 


\begin{tabular}{|c|c|c|c|c|c|c|c|}
\hline \multirow[t]{2}{*}{ Instância } & \multicolumn{3}{|c|}{ Modelo de Manguino (2013) } & \multicolumn{4}{|c|}{ Modelo Proposto } \\
\hline & Sol.Inteira & Lim.Inferior & GAP $(\%)$ & Sol.Inteira & Lim.Inferior & $\operatorname{GAP}(\%)$ & Tempo (s) \\
\hline R1a10 & 332.0 & 332.0 & 0.0 & 332.0 & 332.0 & 0.0 & 0.71 \\
\hline R1b10 & 104.0 & 104.0 & 0.0 & 104.0 & 104.0 & 0.0 & 0.92 \\
\hline $\mathrm{R} 1 \mathrm{c} 10$ & 74.0 & 74.0 & 0.0 & 74.0 & 74.0 & 0.0 & 1.03 \\
\hline R1a15 & 423.0 & 407.5 & 3.8 & 423.0 & 423.0 & 0.0 & 70.19 \\
\hline R1b15 & 147.0 & 133.9 & 9.8 & 147.0 & 130.9 & 12.3 & $1,003.20$ \\
\hline $\mathrm{R} 1 \mathrm{c} 15$ & 105.0 & 89.4 & 17.4 & 105.0 & 90.1 & 16.5 & $1,090.98$ \\
\hline R1a20 & 555.0 & 494.1 & 12.3 & 557.0 & 497.4 & 12.0 & $1,023.18$ \\
\hline R1b20 & 181.0 & 159.4 & 13.6 & 181.0 & 148.2 & 22.1 & $1,061.53$ \\
\hline $\mathrm{R} 1 \mathrm{c} 20$ & 128.0 & 102.2 & 25.2 & 128.0 & 107.5 & 19.1 & $1,098.85$ \\
\hline R1a25 & 698.0 & 610.6 & 14.3 & 707.0 & 615.3 & 14.9 & 987.15 \\
\hline R1b25 & 229.0 & 164.2 & 39.5 & 230.0 & 175.7 & 30.9 & $1,009.76$ \\
\hline $\mathrm{R} 1 \mathrm{c} 25$ & 174.0 & 118.0 & 47.5 & 164.0 & 120.5 & 36.1 & $1,059.41$ \\
\hline R2a10 & 536.0 & 536.0 & 0.0 & 536.0 & 536.0 & 0.0 & 0.82 \\
\hline $\mathrm{R} 2 \mathrm{~b} 10$ & 176.0 & 176.0 & 0.0 & 176.0 & 176.0 & 0.0 & 1.11 \\
\hline $\mathrm{R} 2 \mathrm{c} 10$ & 131.0 & 131.0 & 0.0 & 131.0 & 131.0 & 0.0 & 1.26 \\
\hline R2a15 & $2,310.0$ & $2,309.9$ & 0.0 & $2,310.0$ & $2,309.9$ & 0.0 & 27.46 \\
\hline $\mathrm{R} 2 \mathrm{~b} 15$ & 510.0 & 510.0 & 0.0 & 510.0 & 510.0 & 0.0 & 2.83 \\
\hline $\mathrm{R} 2 \mathrm{c} 15$ & 270.0 & 270.0 & 0.0 & 270.0 & 270.0 & 0.0 & 2.69 \\
\hline $\mathrm{R} 2 \mathrm{a} 20$ & 176.0 & 176.0 & 0.0 & $1,043.0$ & $1,042.9$ & 0.0 & 566.48 \\
\hline $\mathrm{R} 2 \mathrm{~b} 20$ & 323.0 & 323.0 & 0.0 & 323.0 & 323.0 & 0.0 & 409.61 \\
\hline $\mathrm{R} 2 \mathrm{c} 20$ & 221.0 & 221.0 & 0.0 & 221.0 & 221.0 & 0.0 & 110.72 \\
\hline $\mathrm{R} 2 \mathrm{a} 25$ & $1,096.2$ & 827.5 & 32.5 & $1,099.0$ & 667.1 & 64.7 & 994.07 \\
\hline $\mathrm{R} 2 \mathrm{~b} 25$ & 376.2 & 306.1 & 22.9 & 376.2 & 333.7 & 12.7 & 979.03 \\
\hline $\mathrm{R} 2 \mathrm{c} 25$ & 278.0 & 229.3 & 21.2 & 278.0 & 243.5 & 14.2 & $1,030.37$ \\
\hline C1a10 & 900.0 & 900.0 & 0.0 & 900.0 & 900.0 & 0.0 & 0.72 \\
\hline C1b10 & 180.0 & 180.0 & 0.0 & 180.0 & 180.0 & 0.0 & 0.99 \\
\hline $\mathrm{C} 1 \mathrm{c} 10$ & 90.0 & 90.0 & 0.0 & 90.0 & 90.0 & 0.0 & 0.57 \\
\hline C1a15 & 959.0 & 959.0 & 0.0 & 959.0 & 959.0 & 0.0 & 9.61 \\
\hline C1b15 & 239.0 & 239.0 & 0.0 & 239.0 & 239.0 & 0.0 & 5.08 \\
\hline C1c15 & 149.0 & 149.0 & 0.0 & 149.0 & 149.0 & 0.0 & 2.94 \\
\hline $\mathrm{C} 1 \mathrm{a} 20$ & $1,259.0$ & $1,259.0$ & 0.0 & $1,259.0$ & $1,257.9$ & 0.1 & 970.12 \\
\hline C1b20 & 299.0 & 299.0 & 0.0 & 299.0 & 299.0 & 0.0 & 94.02 \\
\hline $\mathrm{C} 1 \mathrm{c} 20$ & 179.0 & 179.0 & 0.0 & 179.0 & 179.0 & 0.0 & 38.87 \\
\hline $\mathrm{C} 1 \mathrm{a} 25$ & $1,341.1$ & $1,316.3$ & 1.9 & $1,341.1$ & $1,341.0$ & 0.0 & 680.09 \\
\hline C1b25 & 381.1 & 346.0 & 10.1 & 381.1 & 339.5 & 12.3 & $1,063.08$ \\
\hline $\mathrm{C} 1 \mathrm{c} 25$ & 238.0 & 211.9 & 12.3 & 238.0 & 209.1 & 13.8 & $1,047.98$ \\
\hline
\end{tabular}

Tabela 41: Resultado de instâncias do tipo R1 e R2 de dimensões menores resolvidas no CPLEX pelo modelo apresentado em Manguino (2013), comparado com o modelo proposto. 


\begin{tabular}{|c|c|c|c|c|c|c|c|}
\hline \multirow[t]{2}{*}{ Instância } & \multicolumn{3}{|c|}{ Modelo de Manguino (2013) } & \multicolumn{4}{|c|}{ Modelo Proposto } \\
\hline & Sol.Inteira & Lim.Inferior & GAP $(\%)$ & Sol.Inteira & Lim.Inferior & GAP $(\%)$ & Tempo (s) \\
\hline $\mathrm{C} 2 \mathrm{a} 10$ & $2,030.0$ & $2,030.0$ & 0.0 & $2,030.0$ & $2,030.0$ & 0.0 & 3.90 \\
\hline $\mathrm{C} 2 \mathrm{~b} 10$ & 430.0 & 430.0 & 0.0 & 430.0 & 430.0 & 0.0 & 4.09 \\
\hline $\mathrm{C} 2 \mathrm{c} 10$ & 230.0 & 230.0 & 0.0 & 230.0 & 230.0 & 0.0 & 2.83 \\
\hline $\mathrm{C} 2 \mathrm{a} 15$ & $2,030.0$ & $2,030.0$ & 0.0 & $2,030.0$ & $2,030.0$ & 0.0 & 15.80 \\
\hline $\mathrm{C} 2 \mathrm{~b} 15$ & 430.0 & 430.0 & 0.0 & 430.0 & 430.0 & 0.0 & 24.23 \\
\hline $\mathrm{C} 2 \mathrm{c} 15$ & 230.0 & 230.0 & 0.0 & 230.0 & 230.0 & 0.0 & 5.93 \\
\hline $\mathrm{C} 2 \mathrm{a} 20$ & $3,000.0$ & $2,999.7$ & 0.0 & $3,000.0$ & $3,000.0$ & 0.0 & 165.03 \\
\hline $\mathrm{C} 2 \mathrm{~b} 20$ & 600.0 & 513.0 & 17.0 & 600.0 & 600.0 & 0.0 & 243.84 \\
\hline $\mathrm{C} 2 \mathrm{c} 20$ & 300.0 & 300.0 & 0.0 & 300.0 & 300.0 & 0.0 & 172.24 \\
\hline $\mathrm{C} 2 \mathrm{a} 25$ & $3,059.0$ & $1,233.8$ & 147.9 & $3,030.0$ & $2,097.8$ & 44.4 & $1,023.81$ \\
\hline $\mathrm{C} 2 \mathrm{~b} 25$ & 630.0 & 348.5 & 80.8 & 659.0 & 457.5 & 44.0 & $1,006.02$ \\
\hline $\mathrm{C} 2 \mathrm{c} 25$ & 330.0 & 245.8 & 34.3 & 330.0 & 330.0 & 0.0 & 819.98 \\
\hline RC1a10 & 439.0 & 439.0 & 0.0 & 439.0 & 439.0 & 0.0 & 6.91 \\
\hline RC1b10 & 138.0 & 138.0 & 0.0 & 138.0 & 138.0 & 0.0 & 21.88 \\
\hline RC1c10 & 90.0 & 90.0 & 0.0 & 90.0 & 90.0 & 0.0 & 13.48 \\
\hline RC1a15 & 652.0 & 558.9 & 16.7 & 652.0 & 600.0 & 8.7 & $1,006.93$ \\
\hline RC1b15 & 204.9 & 164.1 & 24.9 & 204.9 & 174.1 & 17.7 & $1,022.38$ \\
\hline $\mathrm{RC} 1 \mathrm{c} 15$ & 141.9 & 101.9 & 39.3 & 141.9 & 116.4 & 21.9 & 988.34 \\
\hline $\mathrm{RC} 1 \mathrm{a} 20$ & 804.0 & 697.2 & 15.3 & 804.0 & 710.2 & 13.2 & 987.34 \\
\hline RC1b20 & 251.0 & 184.8 & 35.8 & 251.0 & 189.9 & 32.2 & 972.01 \\
\hline $\mathrm{RC} 1 \mathrm{c} 20$ & 169.9 & 108.7 & 56.3 & 167.0 & 122.1 & 36.8 & 994.15 \\
\hline $\mathrm{RC} 1 \mathrm{a} 25$ & 932.0 & 305.7 & 204.9 & 947.0 & 338.6 & 179.7 & $1,006.91$ \\
\hline RC1b25 & 287.0 & 114.8 & 150.0 & 300.7 & 120.4 & 149.8 & $1,021.75$ \\
\hline $\mathrm{RC} 1 \mathrm{c} 25$ & 199.0 & 74.6 & 166.8 & 196.0 & 92.5 & 111.9 & $1,036.18$ \\
\hline $\mathrm{RC} 2 \mathrm{a} 10$ & 506.0 & 506.0 & 0.0 & 506.0 & 506.0 & 0.0 & 22.83 \\
\hline $\mathrm{RC} 2 \mathrm{~b} 10$ & 146.0 & 146.0 & 0.0 & 146.0 & 146.0 & 0.0 & 9.62 \\
\hline RC2c10 & 101.0 & 101.0 & 0.0 & 101.0 & 101.0 & 0.0 & 22.76 \\
\hline $\mathrm{RC} 2 \mathrm{a} 15$ & 682.0 & 682.0 & 0.0 & 682.0 & 682.0 & 0.0 & 467.95 \\
\hline $\mathrm{RC} 2 \mathrm{~b} 15$ & 202.0 & 202.0 & 0.0 & 202.0 & 202.0 & 0.0 & 959.77 \\
\hline $\mathrm{RC} 2 \mathrm{c} 15$ & 131.0 & 131.0 & 0.0 & 131.0 & 131.0 & 0.0 & 534.32 \\
\hline RC2a20 & 806.0 & 649.0 & 24.2 & 806.0 & 673.6 & 19.7 & 993.95 \\
\hline $\mathrm{RC} 2 \mathrm{~b} 20$ & 206.0 & 148.7 & 38.5 & 206.0 & 158.6 & 29.9 & 985.45 \\
\hline $\mathrm{RC} 2 \mathrm{c} 20$ & 131.0 & 105.8 & 23.8 & 131.0 & 90.0 & 45.6 & 981.69 \\
\hline $\mathrm{RC} 2 \mathrm{a} 25$ & 834.0 & 347.1 & 140.3 & 886.0 & 592.8 & 49.5 & $1,038.17$ \\
\hline $\mathrm{RC} 2 \mathrm{~b} 25$ & 234.0 & 140.4 & 66.7 & 236.0 & 145.1 & 62.6 & $1,034.95$ \\
\hline $\mathrm{RC} 2 \mathrm{c} 25$ & 146.0 & 70.6 & 106.8 & 146.0 & 73.4 & 98.9 & $1,012.78$ \\
\hline
\end{tabular}

Tabela 42: Resultado de instâncias do tipo R1 e R2 de dimensões menores resolvidas no CPLEX pelo modelo apresentado em Manguino (2013), comparado com o modelo proposto. 


\begin{tabular}{|c|c|c|c|c|c|c|c|c|c|c|}
\hline \multirow[t]{2}{*}{ Instância } & \multicolumn{2}{|c|}{ Modelo Proposto } & \multicolumn{2}{|c|}{ Construtivas } & \multicolumn{3}{|c|}{ SCIH2+Busca Local } & \multicolumn{3}{|c|}{ Meta-Heurísticas } \\
\hline & Sol.Inteira & Lim.Inferior & SCIH1 & $\mathrm{SCIH} 2$ & Relocate & Cross & 2-opt* & GRASP & VNS & Híbrido \\
\hline R1a10 & 332.0 & 332.0 & 352.0 & 332.0 & 340.0 & 352.0 & 352.0 & 344.0 & 332.0 & 332.0 \\
\hline R1b10 & 104.0 & 104.0 & 104.0 & 104.0 & 104.0 & 104.0 & 104.0 & 104.0 & 104.0 & 104.0 \\
\hline R1c10 & 74.0 & 74.0 & 74.0 & 74.0 & 79.0 & 87.0 & 87.0 & 74.0 & 74.0 & 74.0 \\
\hline R1a15 & 423.0 & 423.0 & 480.0 & 461.0 & 440.0 & 474.0 & 480.0 & 468.0 & 423.0 & 423.0 \\
\hline R1b15 & 147.0 & 130.9 & 154.0 & 166.0 & 161.0 & 151.0 & 151.0 & 147.0 & 147.0 & 147.0 \\
\hline R1c15 & 105.0 & 90.1 & 111.0 & 122.0 & 107.0 & 117.0 & 117.0 & 111.0 & 105.0 & 105.0 \\
\hline R1a20 & 557.0 & 497.4 & 617.0 & 607.0 & 600.0 & 638.0 & 651.0 & 588.0 & 555.0 & 555.0 \\
\hline R1b20 & 181.0 & 148.2 & 196.0 & 201.0 & 188.0 & 193.0 & 194.0 & 181.0 & 181.0 & 181.0 \\
\hline $\mathrm{R} 1 \mathrm{c} 20$ & 128.0 & 107.5 & 134.0 & 140.0 & 139.0 & 136.0 & 143.0 & 129.0 & 128.0 & 128.0 \\
\hline $\mathrm{R} 1 \mathrm{a} 25$ & 707.0 & 615.3 & 800.0 & 747.0 & 754.0 & 824.0 & 831.0 & 724.0 & 697.0 & 698.0 \\
\hline R1b25 & 230.0 & 175.7 & 245.0 & 257.0 & 246.0 & 245.0 & 249.0 & 231.0 & 229.0 & 229.0 \\
\hline $\mathrm{R} 1 \mathrm{c} 25$ & 164.0 & 120.5 & 174.0 & 183.0 & 180.0 & 177.0 & 184.0 & 167.0 & 164.0 & 164.0 \\
\hline R2a10 & 536.0 & 536.0 & 536.0 & 536.0 & 536.0 & 536.0 & 536.0 & 536.0 & 536.0 & 536.0 \\
\hline $\mathrm{R} 2 \mathrm{~b} 10$ & 176.0 & 176.0 & 176.0 & 176.0 & 176.0 & 176.0 & 176.0 & 176.0 & 176.0 & 176.0 \\
\hline $\mathrm{R} 2 \mathrm{c} 10$ & 131.0 & 131.0 & 131.0 & 165.0 & 180.0 & 180.0 & 180.0 & 131.0 & 131.0 & 131.0 \\
\hline R2a15 & $2,310.0$ & $2,309.9$ & $2,340.0$ & $2,340.0$ & $2,340.0$ & $2,310.0$ & $2,340.0$ & $2,310.0$ & $2,310.0$ & $2,310.0$ \\
\hline $\mathrm{R} 2 \mathrm{~b} 15$ & 510.0 & 510.0 & 540.0 & 540.0 & 540.0 & 510.0 & 540.0 & 510.0 & 510.0 & 510.0 \\
\hline $\mathrm{R} 2 \mathrm{c} 15$ & 270.0 & 270.0 & 315.0 & 300.0 & 315.0 & 315.0 & 315.0 & 270.0 & 270.0 & 270.0 \\
\hline R2a20 & $1,043.0$ & $1,042.9$ & $1,151.6$ & $1,129.7$ & $1,088.6$ & $1,072.0$ & $1,099.5$ & $1,043.0$ & $1,043.0$ & $1,043.0$ \\
\hline R2b20 & 323.0 & 323.0 & 402.5 & 409.7 & 352.0 & 352.0 & 352.0 & 352.0 & 323.0 & 343.0 \\
\hline $\mathrm{R} 2 \mathrm{c} 20$ & 221.0 & 221.0 & 262.0 & 272.7 & 266.0 & 284.0 & 284.0 & 255.0 & 221.0 & 221.0 \\
\hline $\mathrm{R} 2 \mathrm{a} 25$ & $1,099.0$ & 667.1 & $1,299.0$ & $1,286.9$ & $1,114.7$ & $1,126.0$ & $1,130.3$ & $1,102.4$ & $1,085.1$ & $1,099.0$ \\
\hline $\mathrm{R} 2 \mathrm{~b} 25$ & 376.2 & 333.7 & 464.0 & 559.0 & 379.0 & 379.0 & 379.0 & 379.0 & 365.1 & 379.0 \\
\hline $\mathrm{R} 2 \mathrm{c} 25$ & 278.0 & 243.5 & 364.0 & 334.0 & 356.0 & 374.0 & 374.0 & 314.0 & 275.1 & 280.4 \\
\hline Cla10 & 900.0 & 900.0 & 943.0 & 943.0 & 915.0 & 943.0 & 943.0 & 929.0 & 900.0 & 900.0 \\
\hline C1b10 & 180.0 & 180.0 & 223.0 & 195.0 & 195.0 & 223.0 & 223.0 & 209.0 & 180.0 & 180.0 \\
\hline $\mathrm{C} 1 \mathrm{c} 10$ & 90.0 & 90.0 & 105.0 & 90.0 & 105.0 & 133.0 & 133.0 & 119.0 & 90.0 & 90.0 \\
\hline C1a15 & 959.0 & 959.0 & 973.0 & 973.0 & 973.0 & 959.0 & 973.0 & 959.0 & 959.0 & 959.0 \\
\hline C1b15 & 239.0 & 239.0 & 253.0 & 253.0 & 253.0 & 239.0 & 253.0 & 239.0 & 239.0 & 239.0 \\
\hline $\mathrm{C} 1 \mathrm{c} 15$ & 149.0 & 149.0 & 163.0 & 149.0 & 163.0 & 149.0 & 163.0 & 149.0 & 149.0 & 149.0 \\
\hline $\mathrm{C} 1 \mathrm{a} 20$ & $1,259.0$ & $1,257.9$ & $1,273.0$ & $1,273.0$ & $1,273.0$ & $1,273.0$ & $1,273.0$ & $1,259.0$ & $1,259.0$ & $1,259.0$ \\
\hline C1b20 & 299.0 & 299.0 & 313.0 & 313.0 & 313.0 & 313.0 & 313.0 & 299.0 & 299.0 & 299.0 \\
\hline $\mathrm{C} 1 \mathrm{c} 20$ & 179.0 & 179.0 & 193.0 & 193.0 & 193.0 & 193.0 & 193.0 & 179.0 & 179.0 & 179.0 \\
\hline $\mathrm{C} 1 \mathrm{a} 25$ & $1,341.1$ & $1,341.0$ & $1,729.1$ & $1,679.6$ & $1,616.0$ & $1,616.0$ & $1,630.0$ & $1,588.0$ & $1,341.1$ & $1,588.0$ \\
\hline C1b25 & 381.1 & 339.5 & 430.0 & 430.0 & 416.0 & 416.0 & 430.0 & 388.0 & 381.1 & 388.0 \\
\hline $\mathrm{C} 1 \mathrm{c} 25$ & 238.0 & 209.1 & 280.0 & 266.0 & 266.0 & 266.0 & 280.0 & 238.0 & 238.0 & 238.0 \\
\hline
\end{tabular}

Tabela 43: Resultado de instâncias de dimensões menores do Tipo R1, R2 e C1. 


\begin{tabular}{|c|c|c|c|c|c|c|c|c|c|c|}
\hline \multirow[t]{2}{*}{ Instância } & \multicolumn{2}{|c|}{ Modelo Proposto } & \multicolumn{2}{|c|}{ Construtivas } & \multicolumn{3}{|c|}{ SCIH2+Busca Local } & \multicolumn{3}{|c|}{ Meta-Heurísticas } \\
\hline & Sol.Inteira & Lim.Inferior & SCIH1 & SCIH2 & Relocate & Cross & 2-opt* & GRASP & VNS & Híbrido \\
\hline C2a10 & $2,030.0$ & $2,030.0$ & $2,030.0$ & $2,030.0$ & $2,030.0$ & $2,030.0$ & $2,030.0$ & $2,030.0$ & $2,030.0$ & $2,030.0$ \\
\hline $\mathrm{C} 2 \mathrm{~b} 10$ & 430.0 & 430.0 & 430.0 & 430.0 & 430.0 & 430.0 & 430.0 & 430.0 & 430.0 & 430.0 \\
\hline $\mathrm{C} 2 \mathrm{c} 10$ & 230.0 & 230.0 & 230.0 & 230.0 & 230.0 & 230.0 & 230.0 & 230.0 & 230.0 & 230.0 \\
\hline $\mathrm{C} 2 \mathrm{a} 15$ & $2,030.0$ & $2,030.0$ & $2,059.0$ & $2,059.0$ & $2,059.0$ & $2,030.0$ & $2,030.0$ & $2,030.0$ & $2,030.0$ & $2,030.0$ \\
\hline C2b15 & 430.0 & 430.0 & 459.0 & 459.0 & 459.0 & 430.0 & 430.0 & 430.0 & 430.0 & 430.0 \\
\hline $\mathrm{C} 2 \mathrm{c} 15$ & 230.0 & 230.0 & 259.0 & 230.0 & 259.0 & 230.0 & 230.0 & 230.0 & 230.0 & 230.0 \\
\hline $\mathrm{C} 2 \mathrm{a} 20$ & $3,000.0$ & $3,000.0$ & $3,059.0$ & $3,059.0$ & $3,059.0$ & $3,030.0$ & $3,059.0$ & $3,030.0$ & $3,000.0$ & $3,030.0$ \\
\hline $\mathrm{C} 2 \mathrm{~b} 20$ & 600.0 & 600.0 & 659.0 & 659.0 & 659.0 & 630.0 & 659.0 & 630.0 & 600.0 & 630.0 \\
\hline $\mathrm{C} 2 \mathrm{c} 20$ & 300.0 & 300.0 & 359.0 & 359.0 & 359.0 & 330.0 & 359.0 & 330.0 & 300.0 & 330.0 \\
\hline $\mathrm{C} 2 \mathrm{a} 25$ & $3,030.0$ & $2,097.8$ & $3,116.0$ & $3,116.0$ & $3,089.0$ & $3,059.0$ & $3,086.0$ & $3,059.0$ & $3,030.0$ & $3,059.0$ \\
\hline $\mathrm{C} 2 \mathrm{~b} 25$ & 659.0 & 457.5 & 716.0 & 716.0 & 689.0 & 659.0 & 686.0 & 659.0 & 630.0 & 659.0 \\
\hline $\mathrm{C} 2 \mathrm{c} 25$ & 330.0 & 330.0 & 416.0 & 386.0 & 389.0 & 359.0 & 386.0 & 359.0 & 330.0 & 359.0 \\
\hline RC1a10 & 439.0 & 439.0 & 507.0 & 439.0 & 439.0 & 439.0 & 439.0 & 439.0 & 439.0 & 439.0 \\
\hline RC1b10 & 138.0 & 138.0 & 142.0 & 142.0 & 142.0 & 142.0 & 142.0 & 142.0 & 138.0 & 138.0 \\
\hline RC1c10 & 90.0 & 90.0 & 97.0 & 90.0 & 90.0 & 90.0 & 90.0 & 90.0 & 90.0 & 90.0 \\
\hline RC1a15 & 652.0 & 600.0 & 662.2 & 652.0 & 652.0 & 652.0 & 652.0 & 652.0 & 652.0 & 652.0 \\
\hline RC1b15 & & & 221.2 & 210.0 & 210.0 & 206.9 & 210.0 & 205.9 & & 204.9 \\
\hline $\mathrm{RC} 1 \mathrm{c} 15$ & 141.9 & 116.4 & 159.0 & 162.0 & 144.9 & 162.0 & 162.0 & 141.9 & 141.9 & 141.9 \\
\hline RC1a20 & 804.0 & 710.2 & 856.0 & 804.0 & 804.0 & 804.0 & 804.0 & 804.0 & 804.0 & 804.0 \\
\hline RC1b20 & 251.0 & 189.9 & 271.0 & 272.0 & 265.0 & 266.0 & 266.0 & 254.0 & 253.0 & 253.0 \\
\hline $\mathrm{RC} 1 \mathrm{c} 20$ & 167.0 & 122.1 & 189.0 & 179.0 & 174.0 & 179.0 & 179.0 & 177.0 & 169.0 & 169.0 \\
\hline RC1a25 & 947.0 & 338.6 & 970.0 & 970.0 & 970.0 & 963.0 & 960.7 & 940.0 & 940.0 & 940.0 \\
\hline RC1b25 & 300.7 & 120.4 & 327.0 & 325.0 & 326.0 & 312.0 & 326.0 & 294.0 & 285.0 & 286.0 \\
\hline RC1c25 & 196.0 & 92.5 & 208.1 & 218.0 & 202.0 & 218.0 & 218.0 & 195.0 & 191.0 & 191.0 \\
\hline RC2a10 & & & & & & & & & & 506.0 \\
\hline $\mathrm{RC} 2 \mathrm{~b} 10$ & 6.0 & 5.0 & 176.0 & 176.0 & 172.0 & 176.0 & 176.0 & 146.0 & 146.0 & 146.0 \\
\hline $\mathrm{RC} 2 \mathrm{c} 10$ & 101.0 & 101.0 & 122.0 & 116.0 & 116.0 & 116.0 & 116.0 & 101.0 & 101.0 & 101.0 \\
\hline RC2a15 & 682.0 & 682.0 & 684.0 & 684.0 & 684.0 & 682.0 & 684.0 & 682.0 & 682.0 & 682.0 \\
\hline $\mathrm{RC} 2 \mathrm{~b} 15$ & 202.0 & 202.0 & 206.0 & 206.0 & 206.0 & 206.0 & 206.0 & 206.0 & 202.0 & 202.0 \\
\hline $\mathrm{RC} 2 \mathrm{c} 15$ & 131.0 & 131.0 & 131.0 & 131.0 & 131.0 & 131.0 & 131.0 & 131.0 & 131.0 & 131.0 \\
\hline $\mathrm{RC} 2 \mathrm{a} 20$ & 806.0 & 673.6 & 956.0 & 888.0 & 862.0 & 860.0 & 888.0 & 806.0 & 806.0 & 806.0 \\
\hline RC2b20 & 206.0 & 158.6 & 236.0 & 236.0 & 234.0 & 236.0 & 236.0 & 206.0 & 206.0 & 206.0 \\
\hline $\mathrm{RC} 2 \mathrm{c} 20$ & 131.0 & 90.0 & 152.0 & 146.0 & 146.0 & 146.0 & 146.0 & 131.0 & 131.0 & 131.0 \\
\hline $\mathrm{RC} 2 \mathrm{a} 25$ & 886.0 & 592.8 & $1,010.0$ & 886.0 & 834.0 & 834.0 & 860.0 & 834.0 & 834.0 & 832.0 \\
\hline $\mathrm{RC} 2 \mathrm{~b} 25$ & 236.0 & 145.1 & 236.0 & 236.0 & 236.0 & 236.0 & 236.0 & 236.0 & 232.0 & 234.0 \\
\hline $\mathrm{RC} 2 \mathrm{c} 25$ & 146.0 & 73.4 & 146.0 & 146.0 & 146.0 & 146.0 & 146.0 & 146.0 & 146.0 & 146.0 \\
\hline
\end{tabular}

Tabela 44: Resultado de instâncias de dimensões menores do Tipo C2, RC1 e RC2. 


\begin{tabular}{|c|c|c|c|c|c|c|c|c|c|c|}
\hline \multirow[t]{2}{*}{ Instância } & \multicolumn{2}{|c|}{ Modelo Proposto } & \multicolumn{2}{|c|}{ Construtivas } & \multicolumn{3}{|c|}{ SCIH2+Busca Local } & \multicolumn{3}{|c|}{ Meta-Heurísticas } \\
\hline & Sol.Inteira & Lim.Inferior & SCIH1 & SCIH2 & Relocate & Cross & 2-opt* & GRASP & VNS & Híbrido \\
\hline R1a10 & 332.0 & 0.00 & 6.02 & 0.00 & 2.41 & 6.02 & 6.02 & 3.61 & 0.00 & 0.00 \\
\hline R1b10 & 104.0 & 0.00 & 0.00 & 0.00 & 0.00 & 0.00 & 0.00 & 0.00 & 0.00 & 0.00 \\
\hline R1c10 & 74.0 & 0.00 & 0.00 & 0.00 & 6.76 & 17.57 & 17.57 & 0.00 & 0.00 & 0.00 \\
\hline R1a15 & 423.0 & 0.01 & 13.48 & 8.99 & 4.02 & 12.06 & 13.48 & 10.64 & 0.01 & 0.01 \\
\hline R1b15 & 130.9 & 12.28 & 17.63 & 26.79 & 22.98 & 15.34 & 15.34 & 12.28 & 12.28 & 12.28 \\
\hline $\mathrm{R} 1 \mathrm{c} 15$ & 90.1 & 16.50 & 23.16 & 35.36 & 18.72 & 29.81 & 29.81 & 23.16 & 16.50 & 16.50 \\
\hline $\mathrm{R} 1 \mathrm{a} 20$ & 497.4 & 11.99 & 24.05 & 22.04 & 20.63 & 28.27 & 30.88 & 18.22 & 11.58 & 11.58 \\
\hline R1b20 & 148.2 & 22.16 & 32.29 & 35.66 & 26.89 & 30.26 & 30.94 & 22.16 & 22.16 & 22.16 \\
\hline $\mathrm{R} 1 \mathrm{c} 20$ & 107.5 & 19.03 & 24.61 & 30.19 & 29.26 & 26.47 & 32.98 & 19.96 & 19.03 & 19.03 \\
\hline $\mathrm{R} 1 \mathrm{a} 25$ & 615.3 & 14.90 & 30.01 & 21.40 & 22.54 & 33.91 & 35.05 & 17.66 & 13.27 & 13.44 \\
\hline R1b25 & 175.7 & 30.88 & 39.42 & 46.25 & 39.99 & 39.42 & 41.70 & 31.45 & 30.32 & 30.32 \\
\hline $\mathrm{R} 1 \mathrm{c} 25$ & 120.5 & 36.13 & 44.43 & 51.90 & 49.41 & 46.92 & 52.73 & 38.62 & 36.13 & 36.13 \\
\hline R2a10 & 536.0 & 0.00 & 0.00 & 0.00 & 0.00 & 0.00 & 0.00 & 0.00 & 0.00 & 0.00 \\
\hline R2b10 & 176.0 & 0.00 & 0.00 & 0.00 & 0.00 & 0.00 & 0.00 & 0.00 & 0.00 & 0.00 \\
\hline $\mathrm{R} 2 \mathrm{c} 10$ & 131.0 & 0.00 & 0.00 & 25.95 & 37.40 & 37.40 & 37.40 & 0.00 & 0.00 & 0.00 \\
\hline R2a15 & $2,309.9$ & 0.01 & 1.31 & 1.31 & 1.31 & 0.01 & 1.31 & 0.01 & 0.01 & 0.01 \\
\hline R2b15 & 510.0 & 0.00 & 5.88 & 5.88 & 5.88 & 0.00 & 5.88 & 0.00 & 0.00 & 0.00 \\
\hline $\mathrm{R} 2 \mathrm{c} 15$ & 270.0 & 0.00 & 16.67 & 11.11 & 16.67 & 16.67 & 16.67 & 0.00 & 0.00 & 0.00 \\
\hline $\mathrm{R} 2 \mathrm{a} 20$ & $1,042.9$ & 0.01 & 10.42 & 8.32 & 4.38 & 2.79 & 5.43 & 0.01 & 0.01 & 0.01 \\
\hline $\mathrm{R} 2 \mathrm{~b} 20$ & 323.0 & 0.00 & 24.61 & 26.84 & 8.98 & 8.98 & 8.98 & 8.98 & 0.00 & 6.19 \\
\hline $\mathrm{R} 2 \mathrm{c} 20$ & 221.0 & 0.01 & 18.56 & 23.41 & 20.37 & 28.52 & 28.52 & 15.40 & 0.01 & 0.01 \\
\hline $\mathrm{R} 2 \mathrm{a} 25$ & 667.1 & 64.74 & 94.72 & 92.90 & 67.09 & 68.79 & 69.43 & 65.25 & 62.66 & 64.74 \\
\hline $\mathrm{R} 2 \mathrm{~b} 25$ & 333.7 & 12.74 & 39.06 & 67.53 & 13.58 & 13.58 & 13.58 & 13.58 & 9.42 & 13.58 \\
\hline $\mathrm{R} 2 \mathrm{c} 25$ & 243.5 & 14.17 & 49.50 & 37.17 & 46.21 & 53.60 & 53.60 & 28.96 & 12.98 & 15.16 \\
\hline C1a10 & 900.0 & 0.00 & 4.78 & 4.78 & 1.67 & 4.78 & 4.78 & 3.22 & 0.00 & 0.00 \\
\hline C1b10 & 180.0 & 0.00 & 23.89 & 8.33 & 8.33 & 23.89 & 23.89 & 16.11 & 0.00 & 0.00 \\
\hline C1c10 & 90.0 & 0.00 & 16.67 & 0.00 & 16.67 & 47.78 & 47.78 & 32.22 & 0.00 & 0.00 \\
\hline C1a15 & 959.0 & 0.00 & 1.46 & 1.46 & 1.46 & 0.00 & 1.46 & 0.00 & 0.00 & 0.00 \\
\hline C1b15 & 239.0 & 0.00 & 5.86 & 5.86 & 5.86 & 0.00 & 5.86 & 0.00 & 0.00 & 0.00 \\
\hline $\mathrm{C} 1 \mathrm{c} 15$ & 149.0 & 0.00 & 9.40 & 0.00 & 9.40 & 0.00 & 9.40 & 0.00 & 0.00 & 0.00 \\
\hline $\mathrm{C} 1 \mathrm{a} 20$ & $1,257.9$ & 0.09 & 1.20 & 1.20 & 1.20 & 1.20 & 1.20 & 0.09 & 0.09 & 0.09 \\
\hline C1b20 & 299.0 & 0.00 & 4.68 & 4.68 & 4.68 & 4.68 & 4.68 & 0.00 & 0.00 & 0.00 \\
\hline $\mathrm{C} 1 \mathrm{c} 20$ & 179.0 & 0.00 & 7.82 & 7.82 & 7.82 & 7.82 & 7.82 & 0.00 & 0.00 & 0.00 \\
\hline $\mathrm{C} 1 \mathrm{a} 25$ & $1,341.0$ & 0.01 & 28.94 & 25.25 & 20.51 & 20.51 & 21.55 & 18.42 & 0.01 & 18.42 \\
\hline C1b25 & 339.5 & 12.27 & 26.67 & 26.67 & 22.55 & 22.55 & 26.67 & 14.30 & 12.27 & 14.30 \\
\hline $\mathrm{C} 1 \mathrm{c} 25$ & 209.1 & 13.84 & 33.92 & 27.23 & 27.23 & 27.23 & 33.92 & 13.84 & 13.84 & 13.84 \\
\hline
\end{tabular}

Tabela 45: Diferença percentual (\%) entre a solução obtida por cada método de solução e o limitante inferior obtido com a formulação matemática para os grupos de instâncias $\mathrm{R} 1, \mathrm{R} 2$ e $\mathrm{C} 1$. 


\begin{tabular}{|c|c|c|c|c|c|c|c|c|c|c|}
\hline \multirow[t]{2}{*}{ Instância } & \multicolumn{2}{|c|}{ Modelo Proposto } & \multicolumn{2}{|c|}{ Construtivas } & \multicolumn{3}{|c|}{ SCIH2+Busca Local } & \multicolumn{3}{|c|}{ Meta-Heurísticas } \\
\hline & Sol.Inteira & Lim.Inferior & SCIH1 & SCIH2 & Relocate & Cross & 2 -opt ${ }^{*}$ & GRASP & VNS & Híbrido \\
\hline $\mathrm{C} 2 \mathrm{a} 10$ & $2,030.0$ & 0.00 & 0.00 & 0.00 & 0.00 & 0.00 & 0.00 & 0.00 & 0.00 & 0.00 \\
\hline $\mathrm{C} 2 \mathrm{~b} 10$ & 430.0 & 0.01 & 0.01 & 0.01 & 0.01 & 0.01 & 0.01 & 0.01 & 0.01 & 0.01 \\
\hline $\mathrm{C} 2 \mathrm{c} 10$ & 230.0 & 0.00 & 0.00 & 0.00 & 0.00 & 0.00 & 0.00 & 0.00 & 0.00 & 0.00 \\
\hline $\mathrm{C} 2 \mathrm{a} 15$ & $2,030.0$ & 0.00 & 1.43 & 1.43 & 1.43 & 0.00 & 0.00 & 0.00 & 0.00 & 0.00 \\
\hline $\mathrm{C} 2 \mathrm{~b} 15$ & 430.0 & 0.00 & 6.74 & 6.74 & 6.74 & 0.00 & 0.00 & 0.00 & 0.00 & 0.00 \\
\hline $\mathrm{C} 2 \mathrm{c} 15$ & 230.0 & 0.00 & 12.61 & 0.00 & 12.61 & 0.00 & 0.00 & 0.00 & 0.00 & 0.00 \\
\hline $\mathrm{C} 2 \mathrm{a} 20$ & $3,000.0$ & 0.00 & 1.97 & 1.97 & 1.97 & 1.00 & 1.97 & 1.00 & 0.00 & 1.00 \\
\hline $\mathrm{C} 2 \mathrm{~b} 20$ & 600.0 & 0.00 & 9.83 & 9.83 & 9.83 & 5.00 & 9.83 & 5.00 & 0.00 & 5.00 \\
\hline $\mathrm{C} 2 \mathrm{c} 20$ & 300.0 & 0.00 & 19.67 & 19.67 & 19.67 & 10.00 & 19.67 & 10.00 & 0.00 & 10.00 \\
\hline $\mathrm{C} 2 \mathrm{a} 25$ & $2,097.8$ & 44.44 & 48.54 & 48.54 & 47.25 & 45.82 & 47.11 & 45.82 & 44.44 & 45.82 \\
\hline $\mathrm{C} 2 \mathrm{~b} 25$ & 457.5 & 44.03 & 56.49 & 56.49 & 50.59 & 44.03 & 49.93 & 44.03 & 37.69 & 44.03 \\
\hline $\mathrm{C} 2 \mathrm{c} 25$ & 330.0 & 0.01 & 26.07 & 16.98 & 17.89 & 8.80 & 16.98 & 8.80 & 0.01 & 8.80 \\
\hline RC1a10 & 439.0 & 0.00 & 15.49 & 0.00 & 0.00 & 0.00 & 0.00 & 0.00 & 0.00 & 0.00 \\
\hline $\mathrm{RC} 1 \mathrm{~b} 10$ & 138.0 & 0.00 & 2.90 & 2.90 & 2.90 & 2.90 & 2.90 & 2.90 & 0.00 & 0.00 \\
\hline RC1c10 & 90.0 & 0.00 & 7.78 & 0.00 & 0.00 & 0.00 & 0.00 & 0.00 & 0.00 & 0.00 \\
\hline RC1a15 & 600.0 & 8.67 & 10.37 & 8.67 & 8.67 & 8.67 & 8.67 & 8.67 & 8.67 & 8.67 \\
\hline RC1b15 & 174.1 & 17.67 & 27.03 & 20.60 & 20.60 & 18.82 & 20.60 & 18.24 & 17.67 & 17.67 \\
\hline $\mathrm{RC} 1 \mathrm{c} 15$ & 116.4 & 21.86 & 36.54 & 39.12 & 24.43 & 39.12 & 39.12 & 21.86 & 21.86 & 21.86 \\
\hline $\mathrm{RC} 1 \mathrm{a} 20$ & 710.2 & 13.20 & 20.53 & 13.20 & 13.20 & 13.20 & 13.20 & 13.20 & 13.20 & 13.20 \\
\hline RC1b20 & 189.9 & 32.18 & 42.71 & 43.23 & 39.55 & 40.08 & 40.08 & 33.76 & 33.23 & 33.23 \\
\hline $\mathrm{RC} 1 \mathrm{c} 20$ & 122.1 & 36.73 & 54.74 & 46.56 & 42.46 & 46.56 & 46.56 & 44.92 & 38.37 & 38.37 \\
\hline $\mathrm{RC} 1 \mathrm{a} 25$ & 338.6 & 179.66 & 186.46 & 186.46 & 186.46 & 184.39 & 183.71 & 177.60 & 177.60 & 177.60 \\
\hline RC1b25 & 120.4 & 149.81 & 171.66 & 170.00 & 170.83 & 159.20 & 170.83 & 144.24 & 136.77 & 137.60 \\
\hline $\mathrm{RC} 1 \mathrm{c} 25$ & 92.5 & 111.81 & 124.88 & 135.58 & 118.29 & 135.58 & 135.58 & 110.73 & 106.40 & 106.40 \\
\hline $\mathrm{RC} 2 \mathrm{a} 10$ & 506.0 & 0.01 & 5.15 & 14.83 & 5.15 & 5.15 & 14.83 & 0.01 & 0.01 & 0.01 \\
\hline $\mathrm{RC} 2 \mathrm{~b} 10$ & 146.0 & 0.00 & 20.55 & 20.55 & 17.81 & 20.55 & 20.55 & 0.00 & 0.00 & 0.00 \\
\hline $\mathrm{RC} 2 \mathrm{c} 10$ & 101.0 & 0.00 & 20.79 & 14.85 & 14.85 & 14.85 & 14.85 & 0.00 & 0.00 & 0.00 \\
\hline $\mathrm{RC} 2 \mathrm{a} 15$ & 682.0 & 0.00 & 0.29 & 0.29 & 0.29 & 0.00 & 0.29 & 0.00 & 0.00 & 0.00 \\
\hline $\mathrm{RC} 2 \mathrm{~b} 15$ & 202.0 & 0.01 & 1.99 & 1.99 & 1.99 & 1.99 & 1.99 & 1.99 & 0.01 & 0.01 \\
\hline $\mathrm{RC} 2 \mathrm{c} 15$ & 131.0 & 0.00 & 0.00 & 0.00 & 0.00 & 0.00 & 0.00 & 0.00 & 0.00 & 0.00 \\
\hline $\mathrm{RC} 2 \mathrm{a} 20$ & 673.6 & 19.65 & 41.92 & 31.82 & 27.96 & 27.66 & 31.82 & 19.65 & 19.65 & 19.65 \\
\hline $\mathrm{RC} 2 \mathrm{~b} 20$ & 158.6 & 29.85 & 48.76 & 48.76 & 47.50 & 48.76 & 48.76 & 29.85 & 29.85 & 29.85 \\
\hline $\mathrm{RC} 2 \mathrm{c} 20$ & 90.0 & 45.56 & 68.89 & 62.22 & 62.22 & 62.22 & 62.22 & 45.56 & 45.56 & 45.56 \\
\hline $\mathrm{RC} 2 \mathrm{a} 25$ & 592.8 & 49.47 & 70.39 & 49.47 & 40.70 & 40.70 & 45.09 & 40.70 & 40.70 & 40.36 \\
\hline $\mathrm{RC} 2 \mathrm{~b} 25$ & 145.1 & 62.66 & 62.66 & 62.66 & 62.66 & 62.66 & 62.66 & 62.66 & 59.90 & 61.28 \\
\hline $\mathrm{RC} 2 \mathrm{c} 25$ & 73.4 & 98.91 & 98.91 & 98.91 & 98.91 & 98.91 & 98.91 & 98.91 & 98.91 & 98.91 \\
\hline
\end{tabular}

Tabela 46: Diferença percentual (\%) entre a solução obtida por cada método de solução e o limitante inferior obtido com a formulação matemática para os grupos de instâncias $\mathrm{C} 2, \mathrm{RC} 1$ e RC2. 